\title{
Dynamic Characteristics of Light-Frame Wood Buildings
}

by

\section{Ghazanfarah Hafeez}

Ph.D. thesis submitted to the

Faculty of Graduate and Postdoctoral Studies

in partial fulfillment of the requirements for the degree of

\section{Doctor of Philosophy}

in Civil Engineering

Under the auspices of the Ottawa-Carleton Institute for Civil Engineering

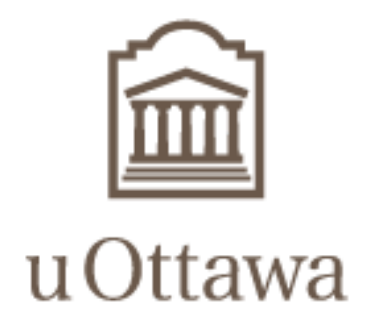

L'Université canadienne Canada's university

Graduate Program in Engineering Science

Department of Civil and Environmental Engineering

May 2017

(C) Ghazanfarah Hafeez, Ottawa, Canada, 2017 


\begin{abstract}
This research project deals with dynamic field testing of light-frame wood buildings with wood based shear walls. The primary objective of the investigation is to evaluate the code formula for estimating light wood frame building's fundamental period, through intensive field testing and numerical modelling. The project also aims to propose an alternative simplified rational approach where applicable. The thesis provides insight to the ambient vibration testing procedures of light-frame wood buildings and explains the protocol adopted for the current research program.

Ambient vibration (AV) field tests were conducted on several multi-storey wood and beam-and-post buildings in Canada. Modal parameters of measured buildings, such as natural frequency, mode shapes and equivalent structural damping were obtained from Frequency Domain (FD) analysis of ambient motion records.

Experimental and numerical investigations were performed to evaluate the effect of non-structural components, and the connectivity between firewall-separated buildings, on dynamic properties of light-frame wood buildings. The study provides a reliable expression for building period estimate based on field testing and numerical modeling.
\end{abstract}




\section{Acknowledgments}

I sincerely express my appreciation to Prof. Ghasan Doudak who provided me this opportunity to carry out my research at university of Ottawa under his supervision. I am grateful to my research supervisors, Prof. Ghasan Doudak and Prof. Ghyslaine McClure for their valuable guidance and encouragement throughout my Ph.D. work. Their expertise in field of timber engineering and dynamics helped me to complete this demanding work.

I would like to thank Natural Sciences Engineering Research Council of Canada, NSERC-NEWBuildS, for funding this research project.

To my friends, thank you for offering me advice, and supporting me through this entire process, especially, I would like to thank, Aiman Mustafa, for his discussions on the topic, and his encouragement in my ups and downs. I would also like to thank Mr. Benoit Pelletier for his consistent assistance in the field testing. It is my great pleasure to acknowledge my colleagues, Ms. Marina Bazolli, Ms. Madelyn Pos, Mr. Mohammad Mehdi Ebadi, Mr. Mohammad Mehdi Bagheri Chizeh, Mr. Mohammed Mestar, Mr. Christian Viau, and Mr. Qiuwu Xiao for their help in the experimental work. I would also like to acknowledge many building managers and owners who allowed me to measure their buildings. 
Finally, thanks go to my parents for giving me vision to follow this path and to my siblings for their encouragement. I would like to say special thanks to my dear husband, Nawaz Alam, for his care, love and unfailing support during this challenging journey.

Above all I want to thank my Lord to Whom I shall return. 


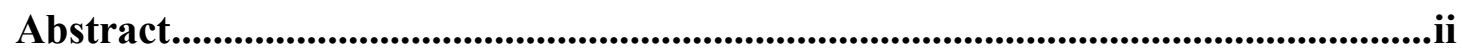

Acknowledgments ..............................................................................................................iii

List of Figures......................................................................................................................viii

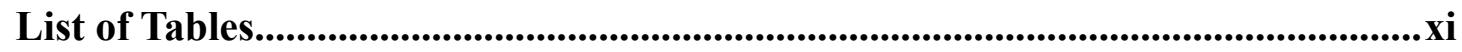

List of Symbols ................................................................................................

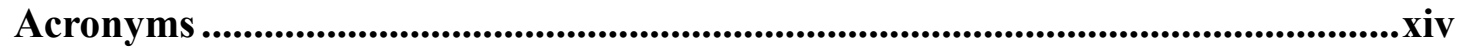

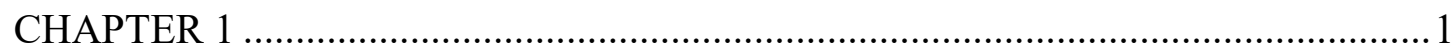

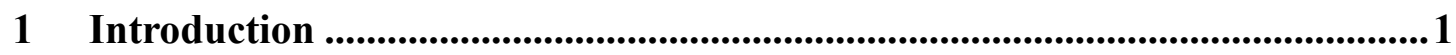

1.1 An Overview of Light Wood Frame Buildings .......................................... 1

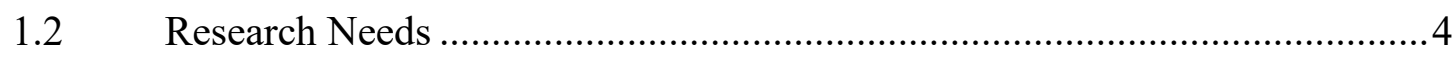

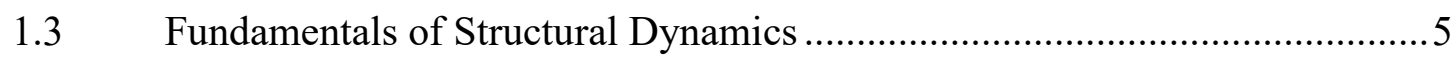

1.3.1 Dynamic Response of Linear SDOF System........................................ 5

1.3.2 Dynamic Response of Linear Multi-degree-of-freedom (MDOF) System

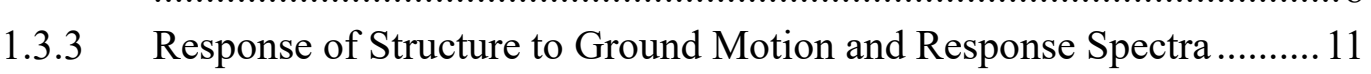

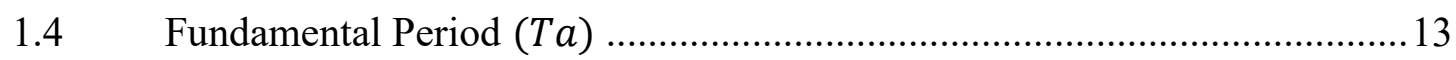

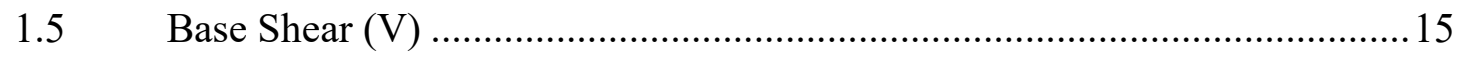

1.6 Effect of Non-Structural Elements on Natural Period of Structure ............... 16

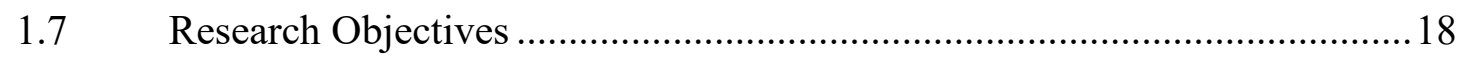

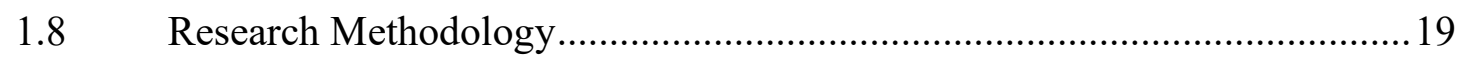

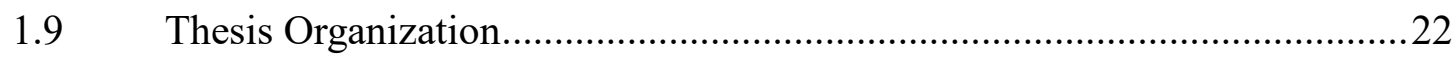

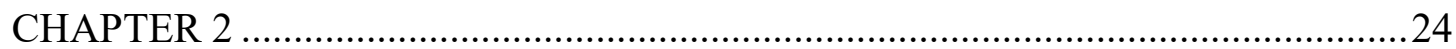

2 Literature Review ...................................................................................24

2.1 A Survey of Experimental Work on Light Wood Frame Buildings ..............24

2.1.1 Goel and Chopra (1998) ....................................................................24

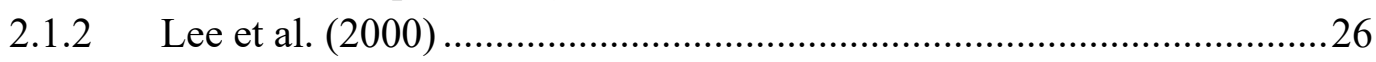

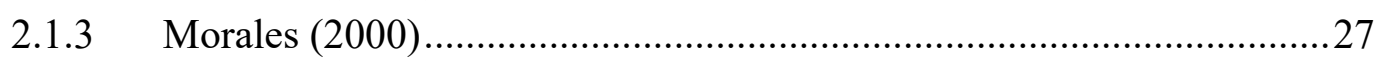

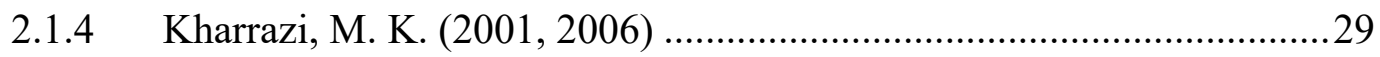

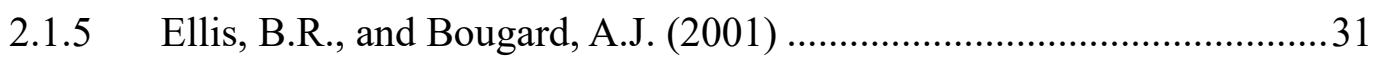

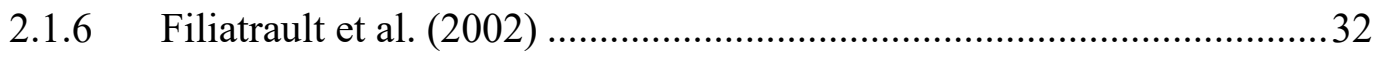

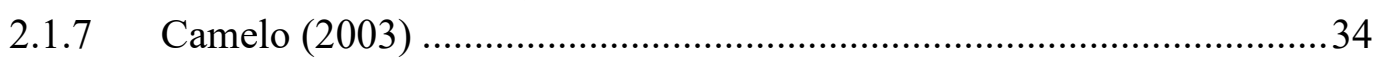

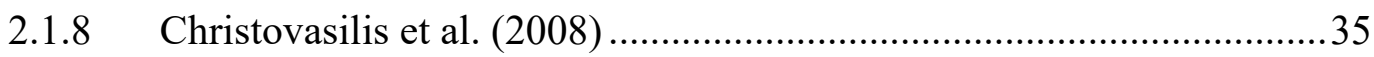

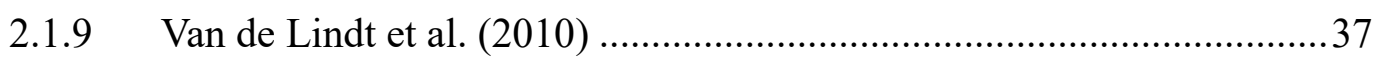

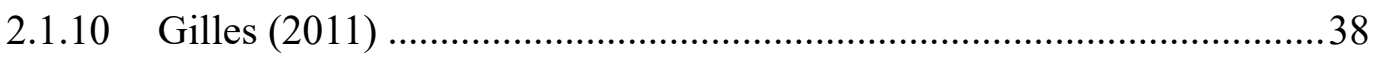

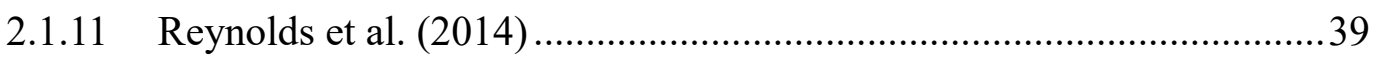




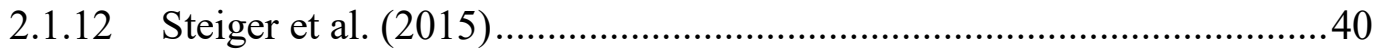

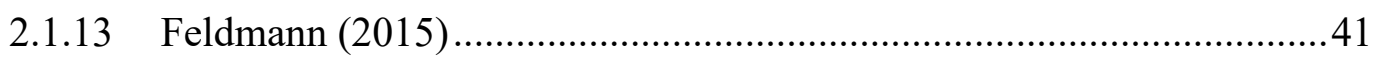

2.2 Numerical Research on Light Wood Frame Buildings ...............................42

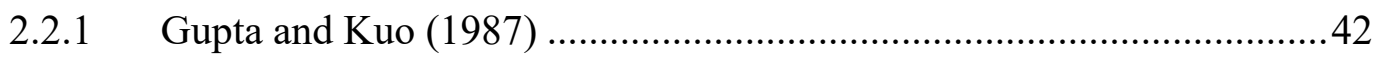

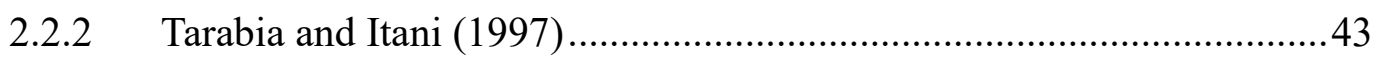

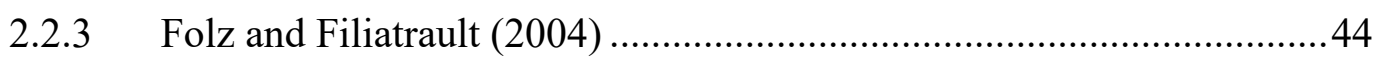

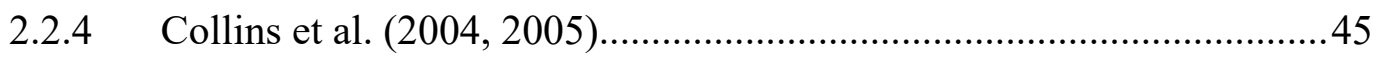

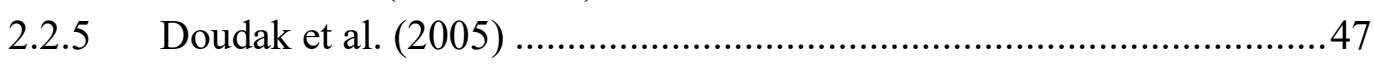

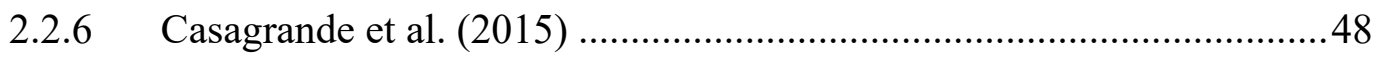

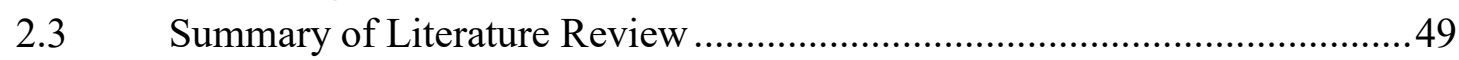

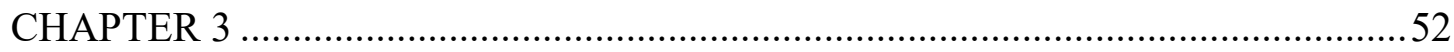

3 Experimental Investigation..................................................................5

3.1 Ambient Vibration Field Testing (AVT) ................................................52

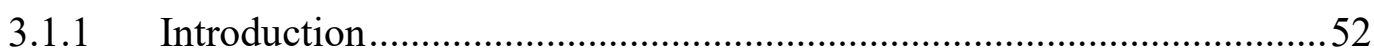

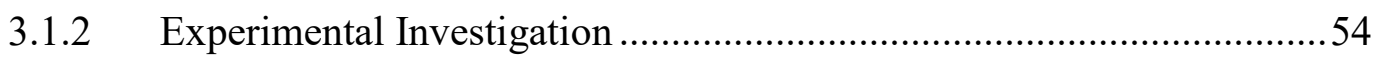

3.2 Geometric Description of Tested Buildings ...................................................55

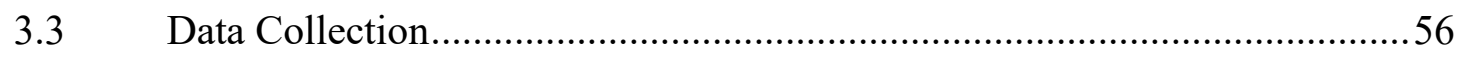

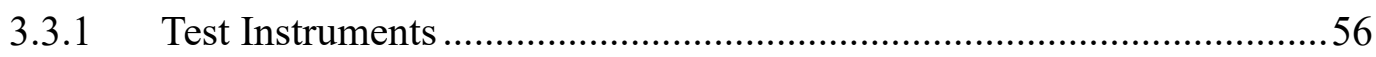

3.3.2 Field Test Procedure........................................................................... 57

3.3.3 Recorded Signals and Excitation ..........................................................59

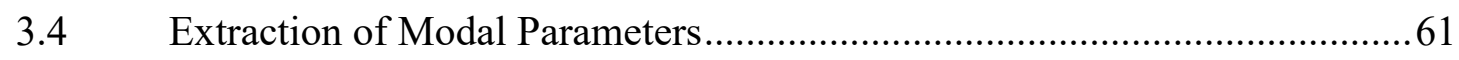

3.4.1 Frequency Domain Decomposition (FDD) ..........................................62

Where $i=1,2,3, \mathrm{~m}$ is measurement configuration (sensor setup)........................6

3.4.2 Enhanced Frequency Domain Decomposition (EFDD) .......................6 63

3.5 Investigating the Effect of Firewall-Separation ...........................................67

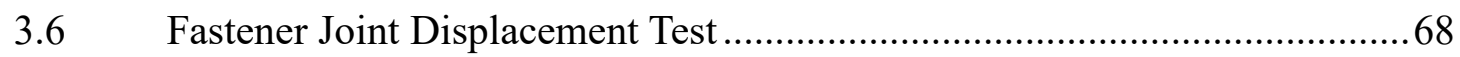

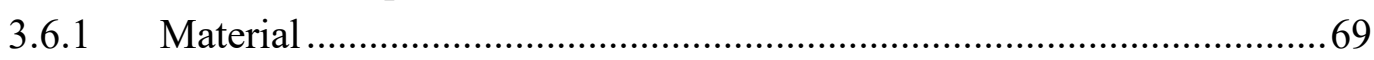

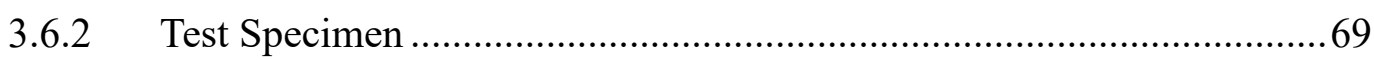

3.6.3 Test Procedure ............................................................................ 71

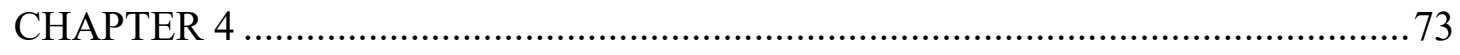

4 Global Results Extracted from AVM Records ...............................................73

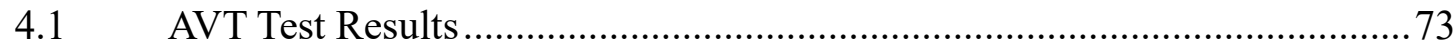

4.2 Effect of Firewall-Separation on the Dynamic Properties of Wood Buildings .

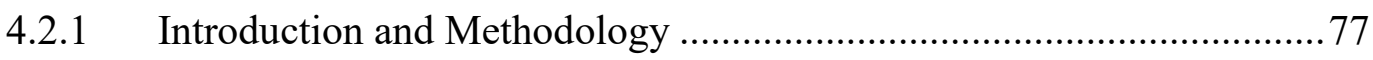

4.2.2 Results for Finished Construction Stage of Firewall-separated Buildings

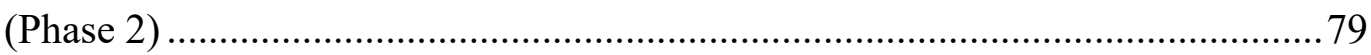

4.2.3 Results for Buildings at Various Construction Stages ......................... 80

4.3 Results of Post-and-Beam Construction Buildings......................................82

4.4 Output of Typical Load-Slip Behavior Tests ............................................... 83 
CHAPTER 5

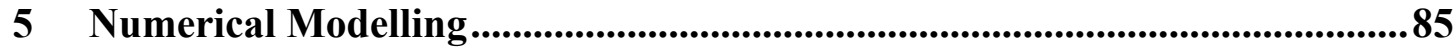

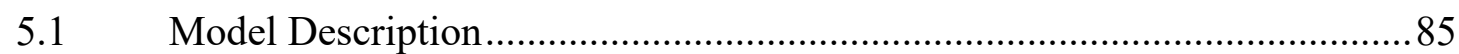

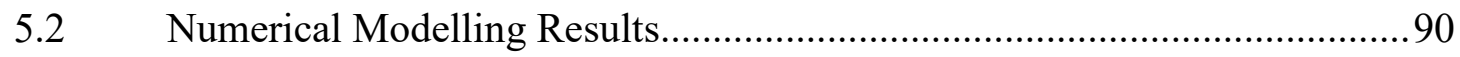

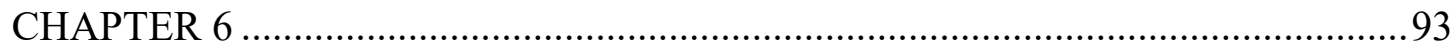

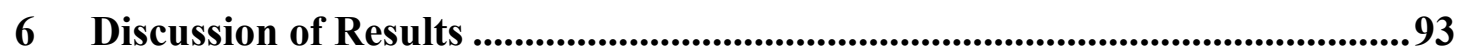

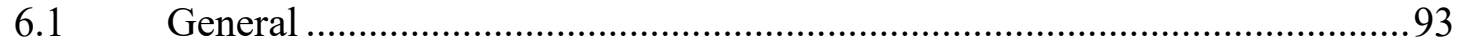

6.2 Experimental Results and Discussion ........................................................93

6.2.1 Observation on Measured Periods and Comparison to Literature and

Established Code Equations ......................................................................... 93

6.2.2 Differences between Construction Phase 1 and 2 ............................. 102

6.3 Effect of Fire-Separation Walls on Dynamic Properties of Wood Buildings....

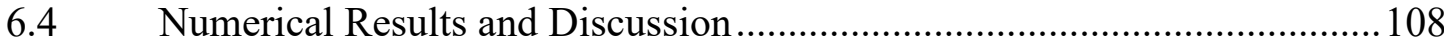

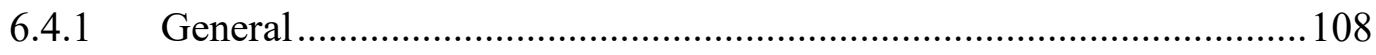

6.4.2 Validation of Finite Element Models ................................................. 109

6.4.2.1 Comparison with Measured Buildings in Phase 1 and Phase 2.............. 109

6.4.2.2 Model Verifications using Building at Different Stages of Construction 111

6.4.3 Variation of Computed Period during Idealized Construction Stages of

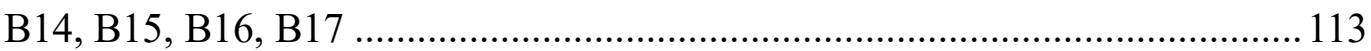

6.5 Effect of Different Stiffness Models ......................................................... 116

6.6 Estimating the Period Formula for Light-Frame Wood Buildings ............... 118

6.6.1 Proposed Period Formula for Light-Frame Wood Buildings ................ 121

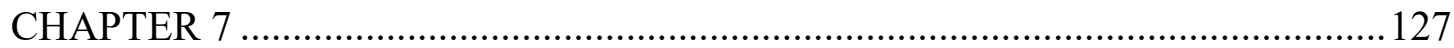

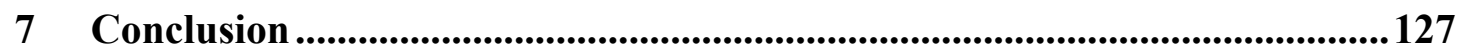

7.1 Original Research Contributions ........................................................... 130

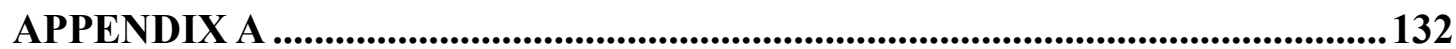

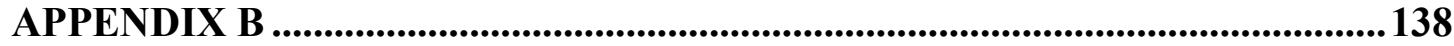

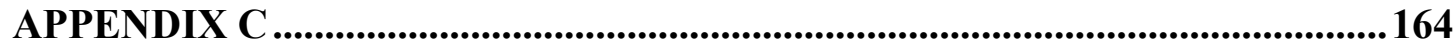

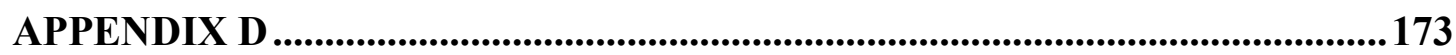

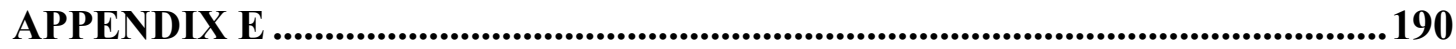

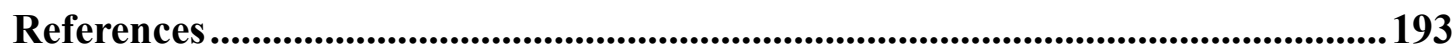




\section{List of Figures}

Figure 1-1 Interior of a shear wall

Figure 1-2 Schematic representation of the proposed research methodology

Figure 2-1 Measured period vs $\left(\mathrm{h} / \mathrm{A}_{\mathrm{e}}{ }^{0.5}\right)$ from nine concrete instrumented buildings

(Source Goel and Chopra, 1998)

Figure 2-2 Measured period vs $\left(\mathrm{h}^{0.2} / \mathrm{Lw}^{0.5}\right)$ from fifty concrete instrumented buildings used to obtain Equation 2-3 (Source Lee et al., 2000).

Figure 2-3 Measured period vs $\left(\mathrm{h} / \mathrm{I}^{0.25}\right)$ from concrete instrumented buildings used to develop Equation 2-5 (Source Morales, 2000) 29

Figure 2-4 Correlation between ambient and force vibration test results 30

Figure 2-5 Global degrees of freedom for house model (Source Gupta and Kuo (1987))

Figure 2-6 Finite element model of the tested house (Source Collins et al. (2004-2005))

Figure 3-1 Tromino® (sensor) with radio antenna .57

Figure 3-2 Typical sensor configurations for L-shaped buildings. .58

Figure 3-3 Typical sensor configurations for rectangular buildings.... 59

Figure 3-4 Raw signals in three orthogonal directions for different channels. 61

Figure 3-5 Singular value plot showing SDOF bell-shaped function, building B6. .65

Figure 3-6 Time domain .66

Figure 3-7 An example of masonry firewall-separations provided between buildings ........68

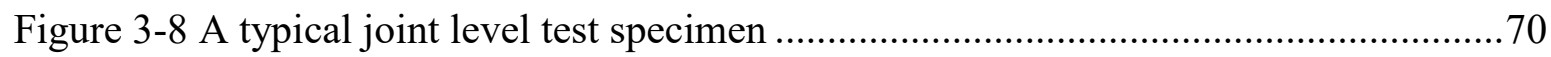

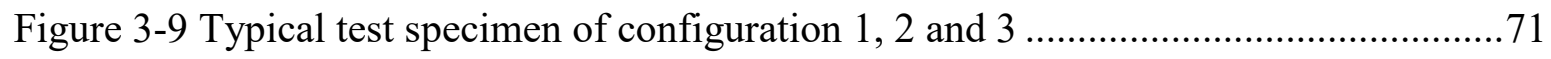

Figure 3-10 Test setup, universal testing machine (UTM) ..........................................72

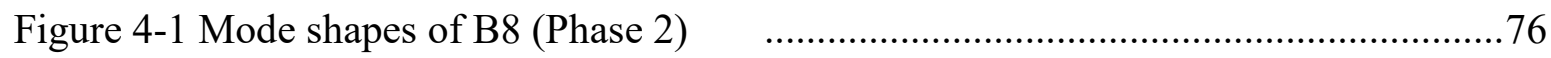

Figure 4-2 Firewall-separated buildings (Phase 2) …...................................................... 78 
Figure 4-3 Construction stages of building complex (B14-B15-B16-B17)........................80

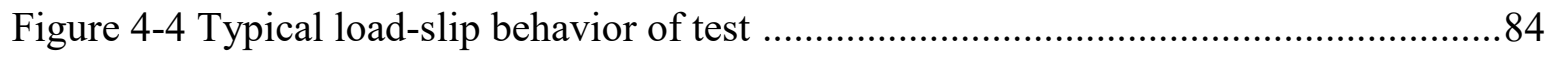

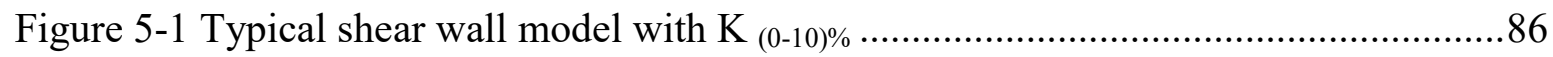

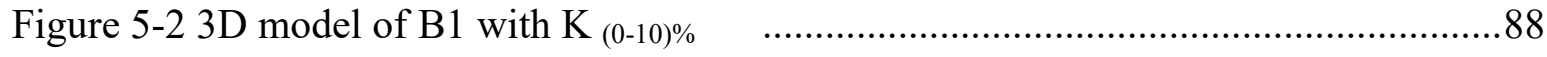

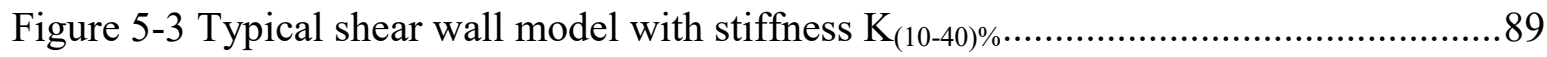

Figure 6-1 Measured fundamental periods vs. building height in Phase 1 construction stage

Figure 6-2 Measured fundamental period vs. building height in Phase 2 construction stage

Figure 6-3 Fundamental periods available in the literature and from current study vs. building height (Phase 1)

Figure 6-4 Fundamental periods available in the literature and from current study vs. building height (Phase 2)

Figure 6-5 Comparison of fundamental periods obtained from NBCC equation,

Equation 2-6, Equation 2-7, Equation 2-8 and current study (Phase 2) AVM test data.......99

Figure 6-6 Frequency over height relationship representation of ambient vibration

data points available in literature and from current study

Figure 6-7 Difference between measured fundamental periods of Phase $1 \&$ Phase 2

(with all finishing), (Transverse direction)

Figure 6-8 Difference between measured fundamental periods of Phase 1 \& Phase 2

(with all finishing), (Longitudinal direction)

Figure 6-9 Plan view and mode shapes of building B31-B32 .....

Figure 6-10 Comparison between Test 2 and Test 3 (Transverse mode shapes of B31 and $\mathrm{B} 32)$

Figure 6-11 Measured periods vs. model periods (Phase 1) ..........................................110

Figure 6-12 Measured periods vs. model periods (Phase 2) ...........................................110

Figure 6-13 Measured periods vs. model periods (B31-B32) ........................................112 
Figure 6-14 Computed period of different construction stages of the complex against measured period (validation of numerical model)

Figure 6-15 Model stages

Figure 6-16 Comparison of longer of the two computed periods by different stiffness models with $\mathrm{T}_{\max }$ and $\mathrm{T}_{\text {code }}$

Figure 6-17 Comparison of smaller of the two computed periods by different stiffness models with $\mathrm{T}_{\max }$ and $\mathrm{T}_{\text {code }}$

Figure 6-18 Correlation between measured and Raleigh periods 120

Figure 6-19 Correlation between model and Raleigh periods 121

Figure 6-20 $\mathrm{T}_{\text {measured }}$ of selected buildings versus building height.

Figure 6-21 $\mathrm{T}_{\text {measured }}$ of selected buildings versus building height $h l * A$

Figure 6-22 Comparison of measured periods, code periods and periods by Equation

6-4 (Transverse direction of the buildings)

Figure 6-23 Comparison of measured periods, code periods and periods by Equation 6-4 (Longitudinal direction of the buildings) 125 


\section{List of Tables}

Table 4-1 Measured natural periods and damping ratios of wood-frame buildings (Phase 1)

Table 4-2 Measured natural periods and damping ratios of wood-frame buildings

(Phase 2) .75

Table 4-3 Measured natural periods and damping ratios of B10, B11 and B10-B11 ..........79

Table 4-4 Measured natural periods and damping ratios of B18, B19 and B18-B19..........79

Table 4-5 Measured natural periods and damping ratios of B20, B21 and B20-B21 .........79

Table 4-6 Measured natural periods and damping ratios of B26, B27 and B26-B27..........79

Table 4-7 Measured natural periods and damping ratios of B31, B32 and B31-B32 2.........81

Table 4-8 Measured natural periods of B14, B15, B16, B17 and B14-B15-B16-B17 ........81

Table 4-9 Measured estimated damping ratios of B14, B15, B16, B17 and B14-B15-

B16-B17

Table 4-10 Fundamental periods and modal damping ratios extracted from AVM tests

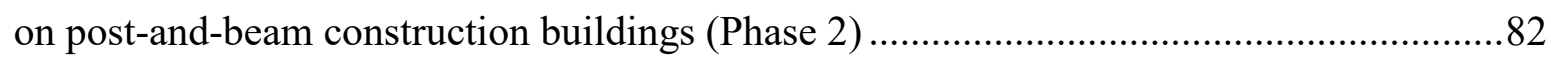

Table 5-1 FE model results of Phase 1 buildings ........................................................... 91

Table 5-2 FE model results of Phase 2 buildings ......................................................... 91

Table 5-3 Computed periods of B31, B32, and B31-B32 ............................................92

Table 5-4 Measured natural periods of B14, B15, B16, B17 and B14-B15-B16-B17 .........92

Table 6-1 Computed period of different modeled construction stages .............................114

Table 6-2 Periods from AV measurements, finite element modeling and Raleigh approximation 


\section{List of Symbols}

\section{Dynamic Response of SDOF}

$h(t) \quad$ Impulse response function of SDOF

$\mathrm{H}(\omega) \quad$ Frequency response function of an SDOF

$\mathrm{F}(\omega) \quad$ Fourier transform of forcing function

$f(\tau) \quad$ Series of impulses occurring at time $(\tau)$

K Stiffness of SDOF system

m Mass of SDOF system

$\mathrm{p}(\mathrm{t}) \quad$ Generalized time varying external force

$\mathrm{p}_{\mathrm{o}} \quad$ Unit impulse force

$\omega_{\mathrm{n}} \quad$ Natural circular frequency of oscillating system in $(\mathrm{rad} / \mathrm{s})$

$\omega_{\mathrm{d}} \quad$ Damped natural frequency oscillating system in $(\mathrm{rad} / \mathrm{s})$

$\dot{\mathrm{x}}(\mathrm{t}) \quad$ Velocity

$\ddot{\mathrm{x}}(\mathrm{t}) \quad$ Acceleration

$\mathrm{x}(\mathrm{t}) \quad$ Displacement

$\xi \quad$ Viscous damping ratio of an SDOF (expressed as a fraction of critical)

$\delta(\mathrm{t}) \quad$ Dirac delta function

\section{Dynamic Response of MDOF}

$[C] \quad$ Damping matrix of viscously damped linear MDOF system

$\left[C^{*}\right] \quad$ Modal (or generalized) damping matrix

$[K] \quad$ Stiffness matrix of linear MDOF system

$\left[K^{*}\right] \quad$ Modal (or generalized) stiffness matrix

$K_{r} \quad$ Modal stiffness corresponding to mode $\mathrm{r}$

$[M] \quad$ Mass matrix of linear MDOF system

$M_{\mathrm{r}} \quad$ Modal mass corresponding to mode $\mathrm{r}$

$\left[\mathrm{M}^{*}\right] \quad$ Modal (or generalized) mass matrix

$N \quad$ Number of DOF

$\{q(t)\} \quad$ Vector of modal coordinates

$\{\dot{q}(t)\} \quad$ First derivative of modal coordinate vector with respect to time

$\{\ddot{q}(t)\} \quad$ Second derivative of modal coordinate vector with respect to time

$[\varphi] \quad$ Mode shape matrix

$[\varphi]^{T} \quad$ Transpose of mode shape matrix

$\left\{\varphi_{r}\right\} \quad$ Eigen vectors (mode shapes r)

$Q_{r}(t) \quad$ Force of $r^{\text {th }}$ mode

$\omega_{r} \quad$ Natural frequency of mode $r$ in radians

$X i(\omega) \quad$ Fourier spectrum of response at DOF $i$

$\zeta_{r} \quad$ Viscous damping ratio of mode $\mathrm{r}$ (expressed as a fraction of critical)

\section{Response of Structure to Ground Motion and Response Spectra}

$S_{a} \quad$ Pseudo-acceleration spectrum

$S_{d} \quad$ Relative displacement spectrum

$S_{v} \quad$ Pseudo-velocity spectrum 
$T_{n} \quad$ Natural period of structure

$u(t) \quad$ Displacement of mass relative to ground

$\dot{u}(t) \quad$ Velocity of mass relative to ground

$\ddot{u}(t) \quad$ Acceleration of mass relative to ground

$\ddot{u}_{g} \quad$ Ground acceleration

\section{Fundamental Period $\left(\mathbf{T}_{\mathbf{a}}\right)$}

$h_{n} \quad$ Building height above ground (m)

$N \quad$ Number of storeys

$n_{1} \quad$ Fundamental natural frequency of structure in $\mathrm{Hz}$

$T_{a} \quad$ Fundamental building period

\section{Base Shear (V)}

$I_{E} \quad$ Earthquake importance factor of a building

$M_{v} \quad$ Higher mode factor

$R_{d} \quad$ Ductility related force modification factor

$R_{o} \quad$ Over-strength force modification factor

$S\left(T_{a}\right) \quad$ Design spectral acceleration

$V \quad$ Base shear

$W \quad$ Total building weight

\section{Research Methodology}

$\mathrm{K}_{(0-10) \%}$, Stiffness obtained as $0-10 \%$ slope on the capacity deflection curve

$\mathrm{K}_{(10-40) \%}$, Stiffness obtained as $10-40 \%$ slope on the capacity deflection curve

\section{Spectral Density Function}

$\begin{array}{cl}G_{x y}(\omega) & \text { Spectral density between two time-history records } x(t) \text { and } y(t) \\ {[G]} & \text { PSD matrix to be decomposed } \\ H & \text { Hermitian transform } \\ n & \text { Different measured configurations } \\ {[\mathrm{S}]} & \text { Singular value matrix } \\ S_{i} & \text { Singular values corresponding to singular vector } \\ {[U]} & \text { Left unitary matrices } \\ U_{i} & \text { Singular vector at frequencies } \omega \\ {[V]} & \text { Right unitary matrices } \\ x(t) & \text { Arbitrary time history record or signal } \\ y(t) & \text { Arbitrary time history record or signal } \\ X(\omega) & \text { Fourier transform of records } x(t) \\ Y(\omega) & \text { Fourier transform of records } y(t) \\ \{\varphi(\omega)\} & \text { Averaged mode shape at resonant frequency } \omega\end{array}$

\section{Model Description}

$A \quad$ Cross-sectional area of end studs $\left(\mathrm{mm}^{2}\right)$

$\alpha_{i} \quad$ Small angles

$B_{v} \quad$ The through-thickness shear rigidity of sheathing panel $(\mathrm{N} / \mathrm{mm})$

$d_{a} \quad$ Horizontal deflection due to anchorage details such as rotation and slip at hold-down connections ( $\mathrm{mm}$ )

$d_{f} \quad$ Fastener's diameter $(\mathrm{mm})$ 


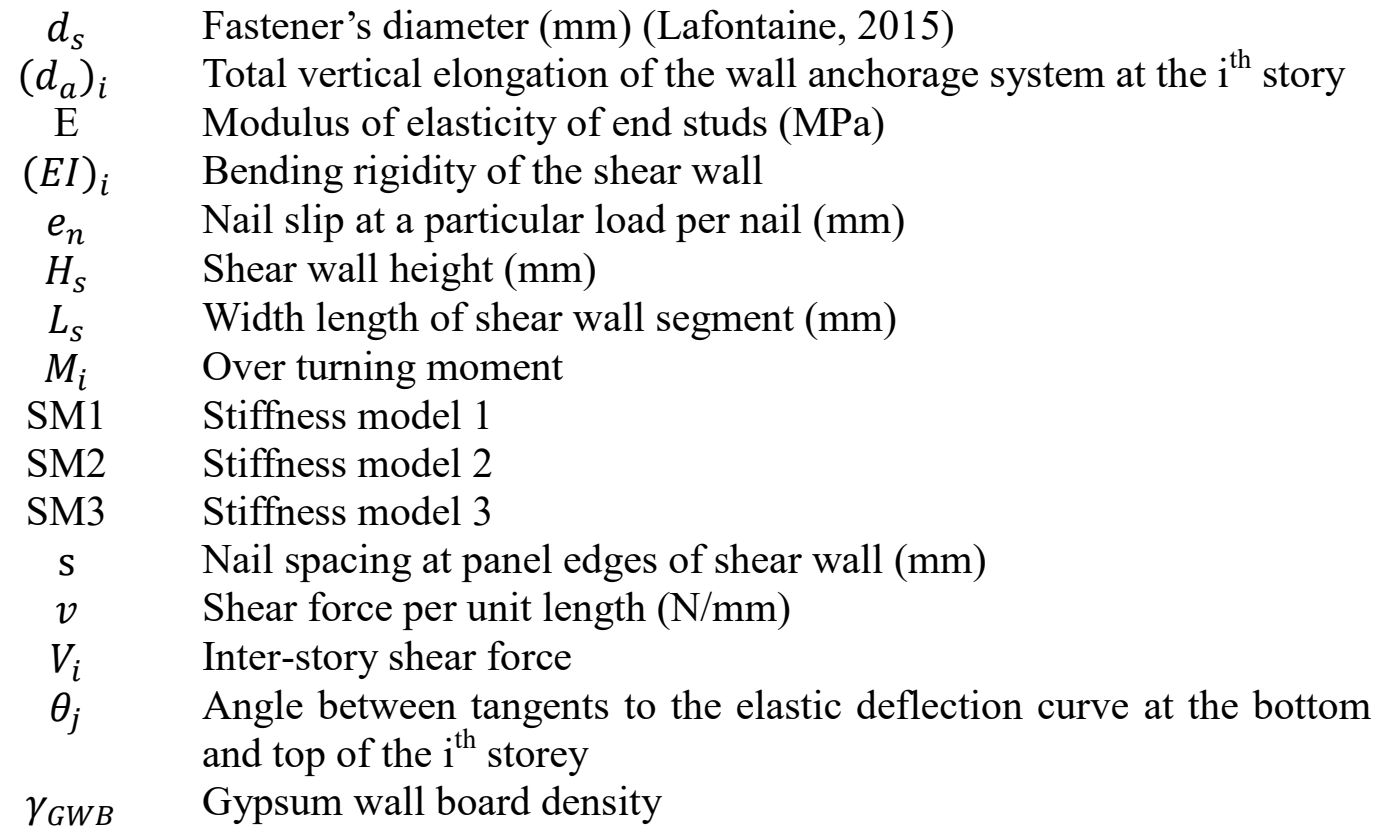

\section{Estimating the Period Formula for Light-Frame Wood Buildings}

$\begin{array}{cl}k & \text { Stiffness of shearwall } \\ h & \text { Building height above base } \\ l & \text { Total length of shearwalls in the direction of consideration } \\ A & \text { Building plan area } \\ \mathrm{F}_{x} & \text { Force at level x } \\ \mathrm{g} & \text { Acceleration due to gravity } \\ \mathrm{T}_{\text {Code }} & \text { Period estimated by Equation } 1-20 \\ \mathrm{~T}_{\text {maesured }} & \text { Period obtained by ambient vibration measurements } \\ \mathrm{T}_{\text {Code }} & \text { Period provided by NBCC as limit } \\ \mathrm{T}_{\text {Raleigh }} & \text { Period obtained by taking } \delta_{x}=1 / k \text { in Raleigh approximation } \\ \mathrm{T}_{\text {model }} & \text { Period obtained by finite element analysis } \\ \mathrm{W}_{x} & \text { Seismic weight of building } \\ \delta_{x} & \text { Elastic lateral displacement due to force } \mathrm{F}_{x}\end{array}$

\section{Acronyms}

$\begin{array}{cl}\text { AVT } & \text { Ambient vibration testing } \\ \text { AVM } & \text { Ambient vibration measurement } \\ \text { DOF } & \text { Degrees of freedom } \\ \text { EC } & \text { Euro code } \\ \text { EFDD } & \text { Enhanced frequency domain decomposition } \\ \text { FDD } & \text { Frequency domain decomposition } \\ \text { FFT } & \text { Fast Fourier transform } \\ \text { FRF } & \text { Frequency response function } \\ \text { FV } & \text { Force vibration } \\ \text { GWB } & \text { Gypsum wall board } \\ \text { IRF } & \text { Impulse response function } \\ \text { LVDT } & \text { Linear variable differential transducers } \\ \text { MAC } & \text { Modal assurance criterion } \\ \text { MDOF } & \text { Multiple-degree-of-freedom } \\ \text { NBCC } & \text { National Building Code of Canada }\end{array}$


OSB Oriented Strand Board

PSD Power spectral density

SDOF Single-degree-of-freedom

SFRS Seismic force resisting system

UTM Universal test machine 


\section{CHAPTER 1}

\section{Introduction}

\subsection{An Overview of Light Wood Frame Buildings}

Light wood frame structures represent a large share of the construction industry in North America, where the majority of this construction type consists of low-rise residential and commercial occupancies. The expected performance of such buildings of normal importance is that the safety of occupants is preserved under any conditions including extreme event of natural catastrophes such as strong wind storms and earthquakes. In a typical light frame wood structure, the main types of structural components that resist lateral loads are horizontal floor and roof diaphragms and vertical shear walls. The floor diaphragm is typically a system of equally spaced joists covered with structural sheathing and fastened mechanically to the storey below or the concrete foundation wall by anchor bolts. A shear wall (Figure 1-1) is an assembly of bottom and top plates and vertical studs and sheathing, designed to resist the horizontal effects of high wind and seismic forces. Floor or roof elements are typically attached to the top plates of the walls using mechanical fasteners. The vertical elements (studs) of shear walls are connected with structural sheathing, such as oriented strand board (OSB) or plywood, through nails. The floors are connected 
together using anchorages and the end studs of the shear wall are attached with discrete or continuous hold-down connections. Roofing consists of prefabricated truss elements, covered with sheathing attached to the top chord of the trusses. For more construction details of light frame wood buildings the reader is referred to documents such as CMHC (2014).

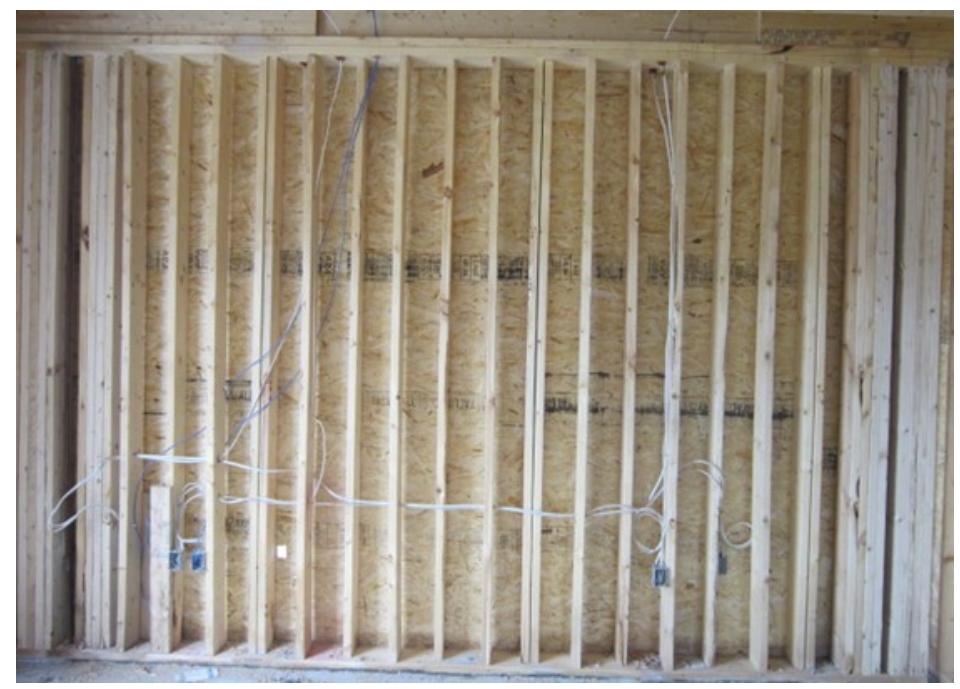

Figure 1-1 Interior of a shear wall

While light-frame buildings have performed well during moderate earthquakes, failures and extensive damage have been observed in stronger earthquakes triggering financial losses and social disturbance. In particular, the January $17^{\text {th }}, 1994$ Northridge earthquake (magnitude Mw6.7) in California highlighted the seismic vulnerability of residential wood frame constructions. The property loss documented in wood frame constructions as a result of this single event was estimated at \$20 billion US (Kircher et al., 1997). Also, after the February $9^{\text {th }}, 1971$ San Fernando 
earthquake (magnitude, Mw6.5), the reported damages of single-family homes were between $\$ 58$ and $\$ 114$ million (Soltis 1984). The sources of seismic damage in these earthquakes have been extensively investigated, and one chief cause was identified as insufficient lateral bracing. Therefore, more precise predictions of the seismic behavior of wood shear walls is required to mitigate damage and ensure the safety of existing wood buildings (Salenikovich, 2000).

The maximum structural response values of velocity, displacement, and acceleration resulting from earthquake motion can be determined from earthquake response spectra using the fundamental natural frequency (or period) and modal damping ratio as input values. Therefore, it is critical that the natural period of a building, and its damping ratio (to a lesser extent) can be estimated with reasonable accuracy so that realistic values of base shear can be estimated for design purposes. A review of the seismic behaviour of wood-frame constructions in a number of recent earthquakes has shown that the life-safety objective of building codes has largely been satisfied when proper design guidelines for engineered buildings are enforced (Rainer \& Karacabeyli, 2000).

The following sections summarize current knowledge and identify research needs that the current study tries in part to address. The fundamental equations governing the dynamic behaviour of structures are presented next, followed by research objectives and methodology. 


\subsection{Research Needs}

A detailed understanding of the dynamic behavior of light-frame wood buildings is lacking mainly due to limited data records of their response under strong wind events and earthquakes. Taller light-frame wood structures (5-6 storeys in height) have become more common practice following recent building code revisions in some Canadian provinces, which allow the construction of timber buildings up to six storeys (APEGBC 2009, Ontario Reg. 191/14). It is anticipated that future demands and expectations of building designers and owners will further push the existing allowable limit. Designing taller wood buildings is certainly challenging from an engineering perspective, as more accurate and reliable guidelines are needed to assess the dynamic behavior of mid-rise wood-frame buildings whose investigation is sparse in the literature, compared to other traditional construction materials such as reinforced concrete and steel.

The behavior of a building during an earthquake is determined by the characteristics of the ground shaking (intensity and frequency content) and the dynamic properties of the building's lateral load resisting system, namely its natural frequencies, mode shapes, and damping ratios. These dynamic parameters are difficult to determine accurately before the structure is built, and it is, therefore, common in design to make certain simplifying assumptions to estimate them. The National Building Code of Canada NBCC (2015) specifies design seismic ground motions as five percent- 
damped uniform hazard acceleration spectra (UHS) and provides a simple empirical formula to estimate the fundamental period of a building for preliminary design. The general accuracy of this formula is uncertain considering that it has not been calibrated to light-frame wood buildings. The current research is motivated to support a more rational design approach by establishing reliable guidelines to assess the fundamental period and lateral stiffness of wood buildings based on a suitable database of field tests.

The following paragraphs explain basic concepts used in dealing with dynamics of structures. The information provided in the subsequent sections $(1.3 .1,1.3 .2$, and 1.3.3) is mainly based on published literature such as Ewins (2000), Chopra (2012) and (Wirsching, Paez, and Ortiz, 2006).

\subsection{Fundamentals of Structural Dynamics}

\subsubsection{Dynamic Response of Linear SDOF System}

A single-degree-of-freedom model of a single-story building consists of lumped mass $(m)$ of the building at roof level and a spring that represents the equivalent lateral stiffness $(k)$ of the structural components such as columns and walls. The energy dissipation of the system is represented by an equivalent viscous damper. The mass of the building is allowed to oscillate only along the spring direction.

In general, the evaluation of damping is difficult. In theory, damping in structural 
systems can be categorized into three ideal classes: undamped system (impossible in practice), viscously damped system and structurally (hysterically) damped system. The most commonly used SDOF system for analysis in the time domain consists of viscous damping where the damping forces are considered proportional to the velocity of the mass.

The equation of motion of a linear single-degree-of-freedom (SDOF) system is given as Equation 1-1;

$$
m \ddot{x}(t)+c \dot{x}(t)+k x(t)=p(t)
$$

Where $x(t)$ is the displacement, $\dot{x}(t)$ is the velocity, $\ddot{x}(t)$ is the acceleration of the mass $m$ with stiffness $k$ and viscous damping constant $c$, and $p(t)$ is generalized timevarying external force.

Using the Dirac delta function $\delta(t)$ and unit impulse force $\left(p_{o}=1\right)$ acting on the linear SDOF system, the equation of motion for impulsive loading is given as Equation 1-2:

$$
m \ddot{h}(t)+c \dot{h}(t)+k h(t)=\delta(t)
$$

Where, $h(t)$ is the unit impulse response function (IRF) of single-degree-of-freedom system that involves its natural frequency and damping ratio, as provided in Equation 1-3: 


$$
h(t)=\frac{1}{m \omega_{d}} e^{\left(-\xi \omega_{n} t\right)} \operatorname{Sin} \omega_{d} t
$$

$\omega_{n}$ is the natural circular frequency of the oscillating system in $(\mathrm{rad} / \mathrm{s})$ and is defined as:

$$
\omega_{n}=\sqrt{\frac{k}{m}}
$$

and the damped natural frequency $\omega_{d}$ is defined as;

$$
\omega_{d}=\omega_{n} \sqrt{1-\xi^{2}}
$$

$\xi$ is the viscous damping ratio, defined as the ratio of damping coefficient $c$ to the critical damping coefficient $c_{c r i t}=\frac{c}{2 \omega_{n}}, c_{c r i t}$ is the critical damping value.

$$
\xi=\frac{c}{c_{c r i t}}
$$

For a linear SDOF system, the force-displacement response of an oscillator that is excited by an applied force during time $\tau$ can be defined as the sum of series of impulse responses. In Equation 1-7 the convolution integral represents the displacement response, $x(t)$, where the unit impulse response $h(t-\tau)$ is scaled by the magnitude of the input function, $f(\tau)$, represented as a series of impulses occurring at time $(\tau)$.

$$
x(t)=\int_{0}^{t} f(\tau) h(t-\tau) d \tau
$$

The SDOF response can also be evaluated in the frequency domain using Fourier 
transformation. By using complex algebra on the equation of motion of a force excited system with applied unit harmonic loading, the complex frequency response function (FRF) or transfer function is provided below as Equation 1-8;

$$
H(\omega)=\frac{1}{\left(k-m \omega^{2}\right)+i c \omega}
$$

$H(\omega)$ is determined by the dynamic properties of the system and forms a Fourier pair with the impulse response function (IRF), $h(t)$. The SDOF response is obtained when $H(\omega)$, obtained for the unit harmonic load, is multiplied by the Fourier transform of the forcing function, $F(\omega)$, shown below as Equation 1-9. The convolution integral in the time domain (Equation 1-7) becomes a simple product in the frequency domain.

$$
X(\omega)=H(\omega) F(\omega)
$$

\subsubsection{Dynamic Response of Linear Multi-degree-of-freedom (MDOF) System}

For a multiple storey building, the mass, stiffness, and damping are distributed throughout the building height but for simplification they can be assumed to be concentrated at each floor level if overall horizontal vibration is examined. The horizontal response of multi-storey buildings under lateral loads or horizontal base motion is defined as three DOFs per floor level: in-plane floor translation in two horizontal orthogonal directions and in-plane floor rotation about the vertical direction, assuming in-plane rigid body motion of the floors and vertical elements. For 
such a model (classical shear building model), the linear equation of motion is given as:

$$
[M]\{\ddot{x}(t)\}+[C]\{\dot{x}(t)\}+[K]\{x(t)\}=\{P(t)\}
$$

Where $[M],[C]$ and $[K]$ are the non-zero mass, damping and stiffness matrices of the building corresponding to the $\mathrm{N}$ dynamic degrees of freedom defining the system motion. A set of $N$ differential equations can be solved simultaneously for $N$ unknowns and can be uncoupled if transformed in the modal coordinate domain. The normal mode superposition method provides an approximate solution to the problem of large linear structures where the degrees of freedom are numerous. At first, the system is presumed to be undamped and the eigenvalue problem is solved for the modal matrix $[\varphi]$ which will provide the new coordinate system. For an $N$-DOF system, the modal matrix contains $N$ eigenvectors (mode shapes) $\left\{\varphi_{r}\right\}, r=$ $1,2,3 \ldots . N$, that correspond to specific eigenvalues (natural frequencies) of the system. In the modal coordinate system, the equations of motion are uncoupled and easily solved. Later, the displacements vectors $\{x(t)\}$ are obtained by multiplying mode shapes matrix with time dependent variables, also known as modal coordinates $\{q(t)\}$, which modifies Equation 1-10 as follows:

$$
\left[M^{*}\right]\{\ddot{q}(t)\}+\left[C^{*}\right]\{\dot{q}(t)\}+\left[K^{*}\right]\{q(t)\}=[\varphi]^{T}\{P(t)\}
$$

$\left[M^{*}\right]=[\varphi]^{T}[M][\varphi]$ and $\left[K^{*}\right]=[\varphi]^{T}[K][\varphi]$ represent modal mass/inertia and 
stiffness matrices, which are diagonal due to the orthogonality properties of the eigenvectors. $[C]$ is a non-diagonal modal damping matrix in the viscous damping model and it is assumed that the modal matrix diagonalized the damping matrix as $\left[C^{*}\right]=[\varphi]^{T}[C][\varphi]$ to completely uncouple the equations of motion as follows:

$$
\ddot{q}_{r}(t)+2 \zeta_{r} \omega_{r} \dot{q}_{r}(t)+\omega_{r}^{2} q_{r}(t)=\frac{Q_{r}(t)}{M_{r}}
$$

Where, $M_{\mathrm{r}}$ is a component of the diagonal mass matrix and corresponds to the $r^{\text {th }}$ mode, $Q_{r}(t)=\left\{\varphi_{r}\right\}^{T}\{P(t)\}$ is the modal force of the $r^{t h}$ mode, and $\left\{\varphi_{r}\right\}^{T}$ is the transpose of the eigenvector corresponding to mode r. $q_{r}(t)$, for a particular mode $r$ shows the participation of that vibration mode in the total motion of the structure. The individual contribution of the vibration modes can be superimposed to obtain the total motion of the structure as follows;

$$
\{x(t)\}=[\varphi]\{q(t)\}=\sum_{r=1}^{N}\left\{\varphi_{r}\right\} q_{r}(t)
$$

Similarly, in the frequency domain, the response of a linear MDOF system is obtained from the response of each modal coordinate associated with each applied harmonic force of the system described by $F_{k}(\omega)$ and its corresponding frequency response function $H_{k}(\omega)$. Following is the expression for $N$-DOF system, where $X i(\omega)$ is the response at DOF $i$ due to applied force at DOF $k, F_{k}(\omega)$,

$$
X_{i}(\omega)=H_{i k}(\omega) F_{k}(\omega)
$$


Where,

$$
H_{i k}(\omega)=\sum_{r=1}^{N} \frac{\varphi_{i r} \varphi_{k r}}{K_{r}} \frac{1}{\left[1-\left(\frac{\omega}{\omega_{r}}\right)^{2}\right]+i\left[2 \zeta_{r}\left(\frac{\omega}{\omega_{r}}\right)\right]}
$$

And $K_{r}$ is modal stiffness for mode $r . \varphi_{i r}$, and $\varphi_{k r}$ are the elements of $r^{\text {th }}$ mode corresponding to DOF $i$ and DOF $k$ respectively.

\subsubsection{Response of Structure to Ground Motion and Response Spectra}

The maximum structural response values of velocity, displacement, and acceleration resulting from earthquake motion can be determined from earthquake response spectra using the linear structure's natural period $T_{n}$ or natural circular frequency $\omega_{n}$, for a particular damping ratio $\zeta_{n}$ as input values. It is therefore critical that the natural period and damping ratio (to a lesser extent) of a building be estimated with reasonable accuracy so that realistic values of base shear exerted on the building are used in design.

The equation of motion for a linear SDOF structure subjected to an earthquake motion (ground acceleration) is given as (Chopra 2012):

$$
m \ddot{u}(t)+c \dot{u}(t)+k u(t)=-m \ddot{u_{g}}(t)
$$

The damping and elastic forces depend on relative displacement and velocity, while the inertia force is a function of the absolute mass acceleration. $\ddot{u}_{g}(t)$ is the ground acceleration and $u(t)$ represents the displacement of the mass relative to ground. 
The relative spectral displacement $\left(S_{d}\right)$, pseudo-velocity $\left(S_{v}\right)$, and pseudo-acceleration $\left(S_{a}\right)$ are commonly used response spectra for characterizing the effect of ground motions on structure. Knowing one of the variables, the other two can be obtained by simple algebra. The displacement spectrum provides peak relative displacements of a SDOF structure as a function of natural period (or frequency) and damping; the pseudo-velocity spectrum provides an approximation of the maximum velocity of the structure and is also representative of the peak strain energy stored in the structure during an earthquake; and the pseudo-acceleration spectrum is an approximation of the maximum acceleration of the structure and is directly related to the peak value of equivalent static base shear. Usually, the displacement spectrum is obtained, by numerically identifying the maximum relative displacement for numerous natural frequencies, and then $S_{v}$ and $S_{a}$ can be calculated as follows,

$$
\begin{array}{lr}
S_{v}\left(\omega_{n}, \zeta\right)=\omega_{n} S_{d}\left(\omega_{n}, \zeta\right) & 1-17 \\
S_{a}\left(\omega_{n}, \zeta\right)=\omega_{n}{ }^{2} S_{d}\left(\omega_{n}, \zeta\right) & 1-18
\end{array}
$$

The maximum response of linear MDOF systems to the ground motion is commonly estimated using response spectrum analysis. The maximum response is calculated by applying a statistical combination method (for example, the Square Root of Sum of Square (SRSS)) on each vibration mode response contribution. Using the SRSS method, the maximum relative displacement, $u_{i, r}$ of DOF $i$ in a linear MDOF system for widely-spaced modes can be approximated as follow, 


$$
\left|u_{i}\right|_{\max }=\sqrt{\sum_{r=1}^{N}\left(\left|u_{i, r}\right|_{\max }\right)^{2}}
$$

In this approach the assumption is that all modal peaks occur at the same time (which is an overly conservative assumption), and ignoring the algebraic sign (i.e. combining absolute values of modal responses) overestimate the response. To overcome this limitation, other combination methods exist, and the Complete Quadratic Combination (CQC) method is preferred particularly when modes are closely spaced.

\subsection{Fundamental Period $\left(T_{a}\right)$}

The dynamic characteristics of a structure determine its behavior under time-varying loading such as wind or seismic action. Despite the time-varying nature of earthquakes and their dynamic effects on buildings, many building codes around the world, including the National Building Code of Canada (NBCC, 2015), allow designers to analyze regular buildings (that are without significant stiffness or mass irregularities) using equivalent static load method due to its simplicity in application. Also, the current building code provides procedures to determine wind loads on structures of different types, but no specific guidance if provided to estimate the fundamental frequency of a structure subjected to wind loading.

For structures having light-frame wood shear walls as their seismic force resisting system, the NBCC empirical formula for approximating the fundamental building 
period, $T_{a}$ for seismic load calculation, is a function of only the building height, $h_{n}$ :

$$
T_{a}=0.05 h_{n}^{3 / 4}
$$

The code also provides formulas to estimate the fundamental period of other structural systems such as steel moment-resisting frames (Equation 1-21), reinforced concrete moment-resisting frames (Equation 1-22), other moment-resisting frames (Equation $1-23$, where $N$ is the number of storeys), and steel braced frames (Equation 1-24).

$$
\begin{aligned}
T_{a} & =0.085 h_{n}^{3 / 4} \\
T_{a} & =0.075 h_{n}^{3 / 4} \\
T_{a} & =0.1 \mathrm{~N} \\
T_{a} & =0.025 h_{n}
\end{aligned}
$$

The coefficients (and exponents) in these formulas were derived based on regression analysis using the fundamental periods measured for several buildings in California during the 1971 San Fernando earthquake (ATC, 1978). The measured data used for the derivation of Equation 1-20 were based on reinforced concrete shear wall buildings. Large scatter was observed in the collected data when the measured period was related to only the height of the structures (Saatcioglu and Humar, 2003). Further, since the coefficient of 0.05 and the exponent of $3 / 4$ in Equation 1-20 were calibrated using period data from mostly concrete buildings located in California, it is questionable whether this equation reflects the fundamental periods of buildings of other materials (such as in light-frame sheathed wood structures) and at a different 
location where construction practices may also significantly differ.

According to the NBCC, Equation 1-20 has general applicability to shear walls of various materials, such as concrete, steel, and wood. Over the past few decades, the inadequacy of this equation for concrete buildings has been recognized by some researchers who have suggested improvements. Research has been conducted by various researchers (e.g. Gilles (2011), Lee et al. (2000), Morales (2000), and Goel and Chopra (1998)) to evaluate the applicability of various code period equations for concrete buildings. A summary of these studies is provided in section 2.1.

Contrarily, no simplified equation can be found in the NBCC (2015) for estimating the natural period or frequency of multi-storey buildings for the purpose of wind design. Such formula can however be found in the Eurocode (2010), as seen in Equation 1-25.

$$
n_{1}=\frac{46}{h}
$$

Where, $n_{1}$ is the fundamental natural frequency of the building in $\mathrm{Hz}, h$ is the height of the structure in meters $(\mathrm{m})$.

\subsection{Base Shear (V)}

Unlike static gravity and live loads, the determination of seismic loads on buildings is complex because the dynamic forces are a function of the building properties and behavior during earthquake ground motion. The simplest method used for design is 
the equivalent static load procedure that distributes the base shear forces in a linear fashion over the height of the structure with equivalent static forces applied at each floor level. Higher magnitude forces are applied at the roof level due to the amplified acceleration resulting from higher mode effects, and provide storey shear forces similar to those calculated for the first mode of vibration. Equation 1-26 shows the relationship between fundamental period and equivalent force $V$, where the period $T_{a}$ is required for determining the design spectral acceleration $S\left(T_{a}\right)$ from uniform hazard design spectra UHS provided by the NBCC.

$$
\mathrm{V}=\frac{I_{E} W M_{V} S\left(T_{a}\right)}{R_{d} R_{o}}
$$

Where $I_{E}$ is the earthquake importance factor, $W$ is the total building weight, $M_{v}$ is the higher mode factor, $R_{d}$ is the ductility related force modification factor used to account for the reduction in response due to inelastic deformation of the structure and $R_{O}$ is the over-strength force modification factor.

The base shear obtained by the equivalent static force procedure is considered a minimum value for design, with implication that those values obtained by dynamic analysis should be scaled up to the static value when found lower.

\subsection{Effect of Non-Structural Elements on Natural Period of Structure}

A building is comprised of structural elements that resist loads and non-structural elements and sub-systems that make the building functional, such as architectural, 
mechanical, and electrical components to name a few. It has been recognized in the past that finishing materials (architectural components) greatly influence the mass, damping, strength, and stiffness of wood buildings and therefore their seismic performance (e.g. Uang and Gatto, 2003; Asiz et al., 2011). The current research also aims to evaluate the effect of non-structural components, such as interior dry walls and exterior finishes, on the fundamental period of wood-frame buildings, by means of ambient vibration measurements in real buildings.

The lateral strength and stiffness of wood structures are mainly dependent on the characteristics of the structural components and their connections, such as shear walls, nail-slip between the sheathing panels and framing elements, vertical anchorage deformation, bending deformation of the studs and in-plane deformation of the sheathing panels. The stiffening effect of the architectural components is relatively much higher in light-frame wood structures than in other structures made of other materials (masonry, concrete, steel). Sentence 4.1.8.3 (7) of the NBCC states that "the stiffness imparted to the structure from elements not part of the SFRS [...] shall not be used to resist the earthquake deflections but shall be accounted for in calculating the period of the structure for determining forces if the added stiffness decreases the fundamental lateral period by more than 15\%" (NBCC, 2015). This is of particular importance for low- to medium-rise buildings because the reduction in the period would result in a significant increase in inertial forces. Such considerations need to be 
kept in mind when a structural model is being analyzed so that the modeling incorporates a realistic representation of the magnitude and distribution of building mass and stiffness. Sentence 4.1.8.11 (3) (d) of the NBCC allows for "other established methods of mechanics" to calculate the building period. Although the use of rational mechanics methods is allowed by the code, it is specified that the period value obtained by such methods is limited to twice the value determined by the empirical period formula for shear walls (Equation 1-20). This limit is based on consideration of the uncertainties in the engineering assumptions and inputs to the calculation model, the contribution of non-structural elements, and differences between what is specified at the design stage and what is actually built. The goal is to achieve reasonable conservatism and avoid using a period too large that would correspond to unrealistically low spectral acceleration values (NRC, 2015).

In the current study, some buildings with different geometries have been tested with and without installation of dry walls and other architectural components to observe their effects on the building fundamental periods and damping ratios.

\subsection{Research Objectives}

The overarching goal of this research project is to develop a reliable method of estimating the building period of light-frame wood buildings. More specifically the study aims to: 
- Evaluate the adequacy of contemporary code formula for estimating the fundamental period of timber buildings, specifically those consisting of lightframe wood shear walls.

- Develop reliable and accurate expression for building period estimate based on field testing and numerical modelling.

- Evaluate the effect of non-structural components on the dynamic characteristics of the buildings.

\subsection{Research Methodology}

A schematic representation of the proposed methodology is shown in Figure 1-2.The essential elements that define the research methodology are ambient vibration field testing, analysis of recorded measurements, and stiffness estimation of lateral load resisting system. 


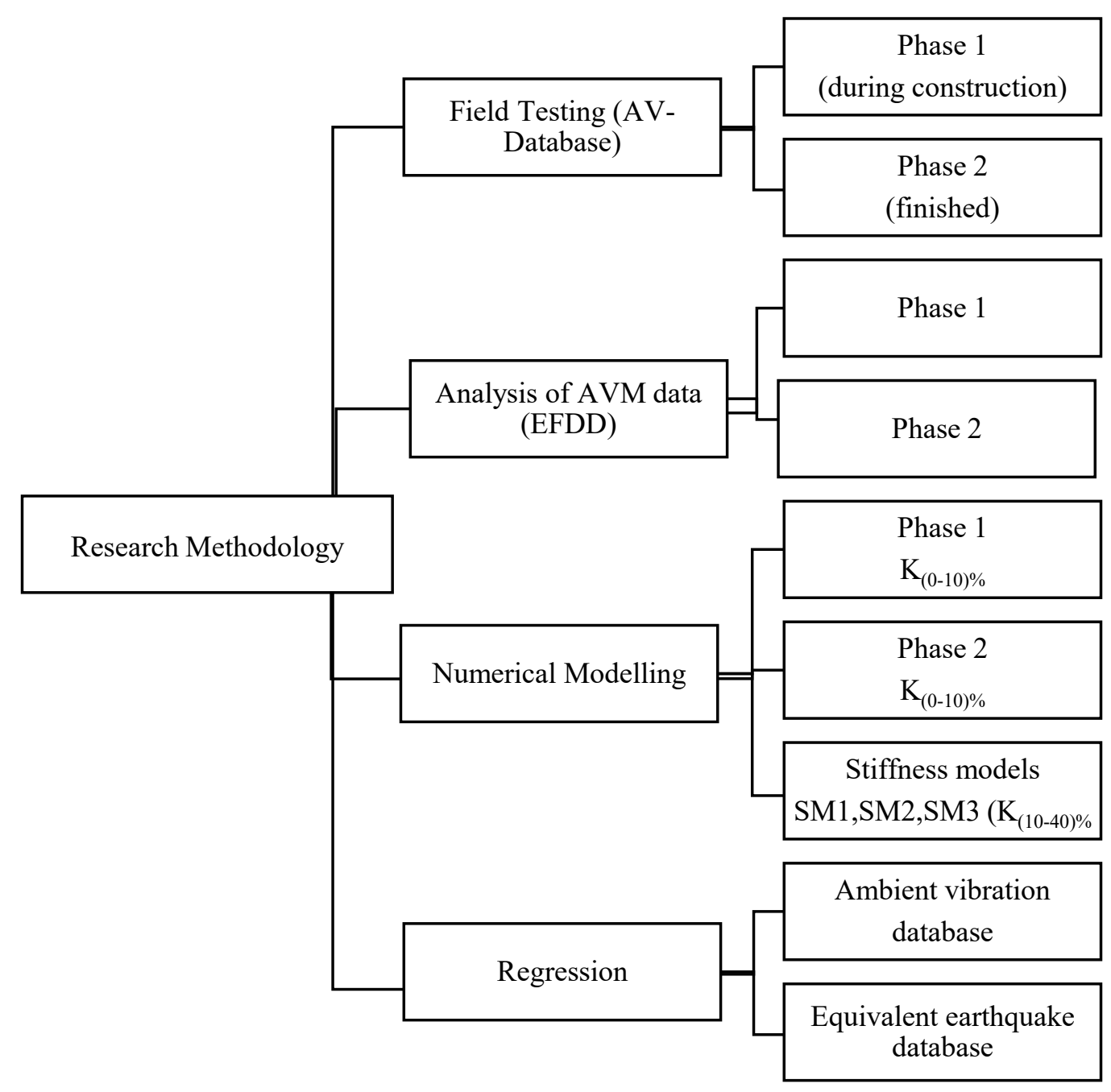

Figure 1-2 Schematic representation of the proposed research methodology

Numerical models are developed for each construction stage and validated with the data obtained from field testing. The validated models are then used to evaluate different stiffness models used to estimate the fundamental periods of light frame wood buildings.

Ideally, building period measurements would occur during a moderate to strong earthquake event to be more representative than ambient motion results for seismic 
design. Although these measurements would still be uniquely associated with the seismic load characteristics, the amplitude of motions would be more representative of that experienced in an actual design-level earthquake. Since measurements of dynamic characteristics of light-frame wood buildings during real earthquakes are rarely available, the following approach has been employed:

- Conduct field ambient vibration tests on a large number of representative light-frame wood buildings with different heights, horizontal dimensions, shear wall layouts, and stages of construction. When possible, emphasis is put on testing the structures when all structural elements have been constructed but no finishing materials installed (denoted as Phase 1) and when the building is completely finished (denoted as Phase 2).

- Identify the dynamic properties from the recorded measurements (Phase 1 and Phase 2) of the buildings for fundamental mode as provided by the Enhanced Frequency Domain Decomposition (EFDD) method.

- Develop numerical models of the tested buildings with the initial stiffness obtained as $0-10 \%$ slope on the capacity deflection curve, taking into account the low level of deflection at ambient vibration. These models will be validated using field test data.

- Re-analyze the validated models with higher stiffness values (proposed 10- 
40\% slope on capacity-deflection curve, (ASTM E2126)), which are assumed to be representative of those experienced during earthquake events. These data will be compared with expressions proposed in the literature.

- Conduct regression analysis of periods measured at AV level and modify the period estimates to levels representative of earthquake forces using expressions in the literature to produce a more reliable period expression than that found in the NBCC.

- Finally, evaluate the effects of non-structural components on the dynamic behavior of the buildings and the adequacy of current code provisions in estimating the building period.

\subsection{Thesis Organization}

Chapter 1 describes the basic concepts of structural dynamics and addresses some relevant material on seismic properties of wood-frame buildings with an overview of design provisions.

Chapter 2 presents a survey of the literature on light-frame wood buildings related research topics such as dynamic field and laboratory testing, finite element modeling, and analytical models.

Chapter 3 provides a comprehensive description of the experimental methods. 
Ambient vibration testing equipment and testing procedure are described, and the analysis of the recorded measurements is discussed.

Chapter 4 reports on the laboratory and ambient vibration field testing results.

Chapter 5 describes the various shearwall models utilized based on the construction stages of the measured buildings. Results of finite element model are discussed for each modeled building.

Chapter 6 summarizes the discussion of the results from the experimental field measurements and numerical models of the buildings. Discusison on ways to evaluate the building period is also presented.

Chapter 7 presents concluding remarks on the research project. 


\section{CHAPTER 2}

\section{Literature Review}

This chapter surveys the literature and presents established knowledge on laboratory and field experimental work on the dynamic characteristics of buildings (section 1.1). Key studies, especially those that present alternative solutions to the building code period formula are presented. Section 1.2 deals with selected studies found in the literature that offer various numerical approaches to modeling light-frame wood structures.

\subsection{A Survey of Experimental Work on Light Wood Frame Buildings}

\subsubsection{Goel and Chopra (1998)}

Goel and Chopra evaluated the code period equation specified in US building codes (NEHRP-94, SEAOC-96 and UBC-1997) for concrete shear wall buildings based on field measurements, where the fundamental period was measured during strong ground motions. The study found large scatter in the measured data when compared with that obtained by code equations. An improved method was suggested by the authors, based on regression analyses of experimental results from nine shear wall buildings that was not limited to the wall height as a variable but also incorporated a parameter related to shear wall dimensions (see Equation 2-1). This equation has been 
included in some international codes such as ASCE (2005) and BSSC (2003).

$$
T=\frac{0.0062 h}{\sqrt{A_{e}}}
$$

Where, $h$ represents the total building height in $\mathrm{m}$ and $A_{e}$ represents equivalent shear area and is given as;

$$
A_{e}=\frac{100}{A_{B}} \sum_{i=1}^{N W}\left(\frac{h}{h_{i}}\right)^{2} \frac{A_{i}}{\left[1+0.83\left(\frac{h_{i}}{D_{i}}\right)^{2}\right]}
$$

In Equation 2-2, $A_{i}, D_{i}$ and $h_{i}$ are the plan area, height and width of each shear wall in the direction considered for calculating the fundamental period. $A_{B}$ represents the building plan area at the base of the building.

As part of their investigation, Goel and Chopra (1998) enhanced the database, comprised of 106 buildings whose motions were recorded during several California earthquakes, including 21 buildings that experienced peak ground acceleration during the 1994 Northridge earthquake. They recommended that the assumptions based on this data set should be followed with caution in other regions, due to different soil conditions, seismicity and design and construction practices. Figure 2-1 shows the correlation between the measured fundamental period of concrete shear wall buildings from the author's database as a function of building height and the parameter $\left(\frac{h}{A_{e} e^{0.5}}\right)$. 


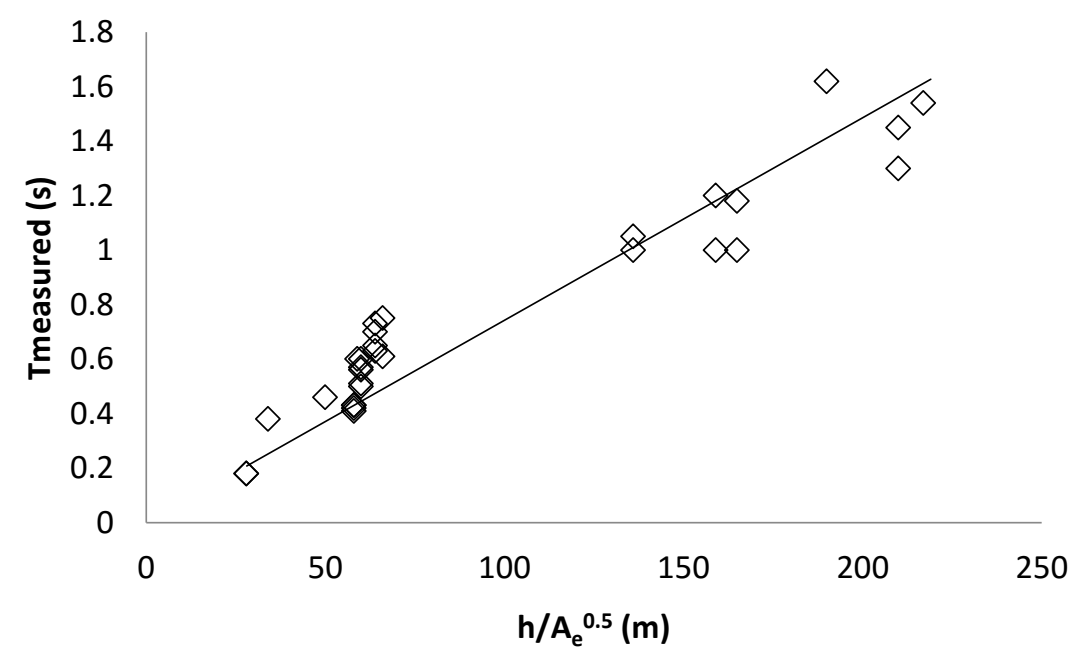

Figure 2-1 Measured period vs $\left(\mathbf{h} / \mathbf{A}_{\mathrm{e}}{ }^{0.5}\right)$ from nine concrete instrumented buildings (Source Goel and Chopra, 1998)

\subsubsection{Lee et al. (2000)}

This study focused on the evaluation of the period formula in the Korean building code using a data base of fifty reinforced concrete shear wall buildings located in Korea, whose periods were measured using ambient vibration testing. The measured buildings have 10-25 storeys with variable plan dimensions and the identified fundamental frequencies of these buildings ranging from $0.43 \mathrm{~Hz}$ to $0.62 \mathrm{~Hz}$ for motion in the longitudinal direction and $0.56 \mathrm{~Hz}$ to $1.16 \mathrm{~Hz}$ in the transverse direction. Figure 2-2 shows the scatter of the measured periods. The alternative equation that was derived for a uniform cantilever shear beam is shown below (Equation 2-3).

$$
T=0.4\left[\frac{h^{0.2}}{\sqrt{L_{w}}}\right]-0.5
$$

Where $h$ and $L_{w}$ represent height of building (m) and the total wall width per unit 
plan area in $m^{-1}$, calculated as follows:

$$
L_{w}=\frac{\sum_{i=1}^{N W} D_{i}}{A_{B}}
$$

$A_{B}$, and $D_{i}$ are the building plan area, and width of each shear wall in the direction considered for calculating the fundamental period respectively.

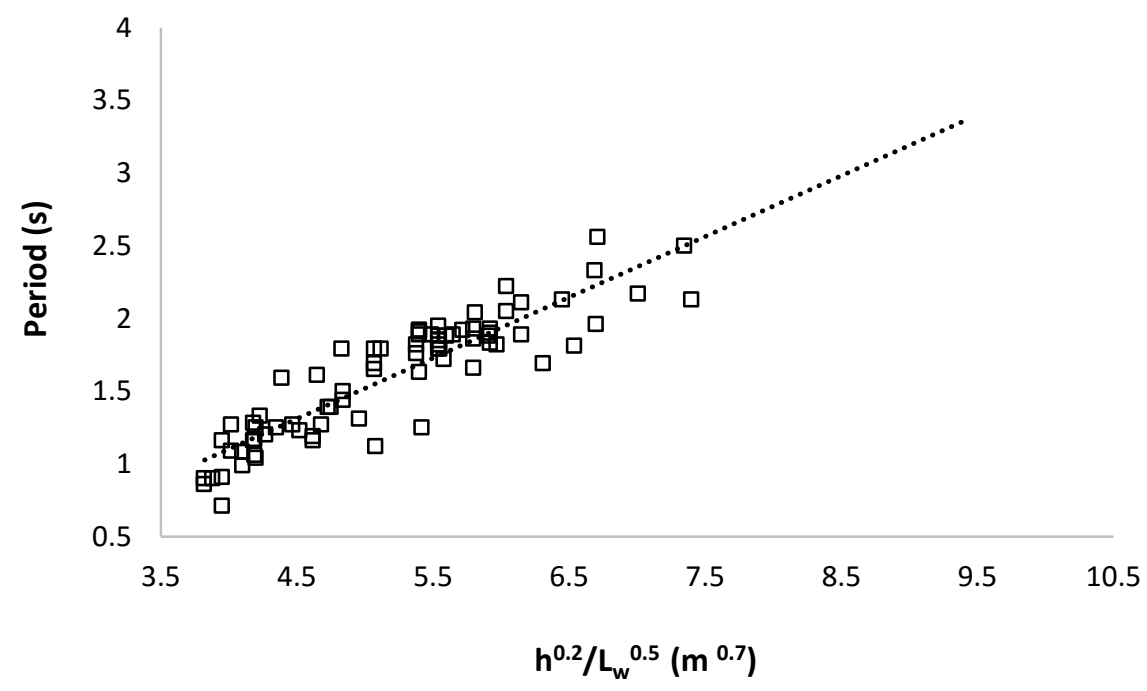

Figure 2-2 Measured period vs $\left(\mathrm{h}^{0.2} / \mathrm{Lw}^{0.5}\right)$ from fifty concrete instrumented buildings used to obtain Equation 2-3 (Source Lee et al., 2000)

\subsubsection{Morales (2000)}

Morales evaluated the code period formula for concrete shear walls and frame buildings and proposed an equation that accounted for the moment of inertia (equivalent second moment of area) and height of the building. The proposed equation (Equation 2-5 was derived from the data base of the buildings whose fundamental periods were measured during strong earthquake motions by California 
Strong Motion Instrumentation Program (CSMIP), and by National Oceanic and Atmospheric Administration (NOAA) (this data is mostly similar to the data used by Goel and Chopra in developing Equation 2-1). The subset of database comprised of 26 reinforced concrete shear wall buildings, four masonry shear wall buildings and three buildings with shear walls in one direction and concrete moment resisting frame in the other direction. The equation was linear with height but non-linear with the moment of inertia and showed good correlation with the measured periods. Figure 2-3 shows the fit of the measured period plotted against the dimensionless parameter $\left(\frac{h}{I^{0.25}}\right)$.

$$
T=0.13 \frac{h}{I^{0.25}}-0.4
$$

Where, $h(m)$ is total building height, and $I\left(\mathrm{~m}^{4}\right)$ is calculated as the sum of the second moment of each wall in the direction of consideration. 


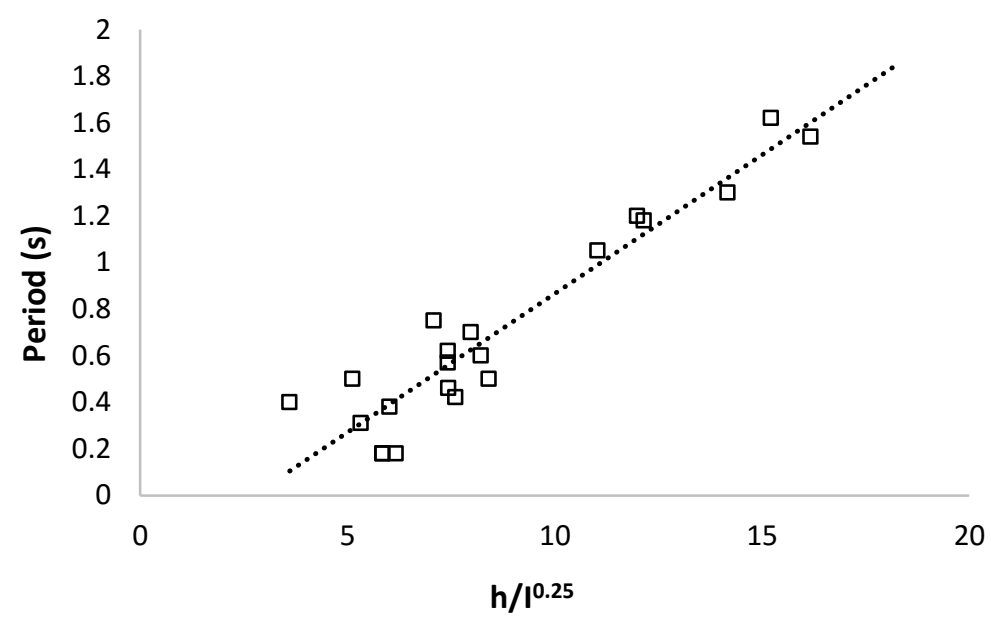

Figure 2-3 Measured period vs $\left(\mathrm{h}^{-\mathbf{I}^{0.25}}\right)$ from concrete instrumented buildings used to develop Equation 2-5 (Source Morales, 2000)

\subsubsection{Kharrazi, M. K. (2001, 2006)}

Kharrazi (2001) performed a research study on low-rise timber buildings in Canada with emphasis on vibration behavior using ambient vibration, forced vibration, and full-scale shake-table testing. The performance of existing wood houses was investigated in the lower mainland of British Columbia to develop procedures for seismic retrofitting of such structures. The research was also focused on determining the dynamic characteristics of single- and two-storey houses with different sheathing configurations using laboratory shake table testing at the University of British Columbia. Ambient vibration and sinusoidal tests were carried out on the house specimens before and after the earthquake motion simulations to observe the decrease in natural frequency resulting from the stiffness degradation (damage incurred) during testing. 
The findings concluded that the natural frequency by ambient vibration and sinusoidal tests, before and after the earthquake motion record simulations, for the one-storey building, were in the range of $(1.93-3.91) \mathrm{Hz}$ and $(0.76-3.08) \mathrm{Hz}$, respectively. The damping ratios were in range of (1.93-2.90)\% for ambient vibration test and (4.20$8.92) \%$ for sinusoidal tests. Natural frequencies by ambient vibration and sinusoidal tests, for the two-storey house of different structural configurations were in the range of $(1.83-6.38) \mathrm{Hz}$ and $(0.85-5.58) \mathrm{Hz}$, respectively. Natural frequency by ambient vibration and force vibration field tests on four-storey wooden houses were in range of $(2.22-2.48)$ and $(2-2.02) \mathrm{Hz}$, respectively. The study established a correlation between ambient and forced vibration test results as shown in Figure 2-4, for correcting the period measured by ambient vibration testing, which is generally shorter than the building period during strong shaking.

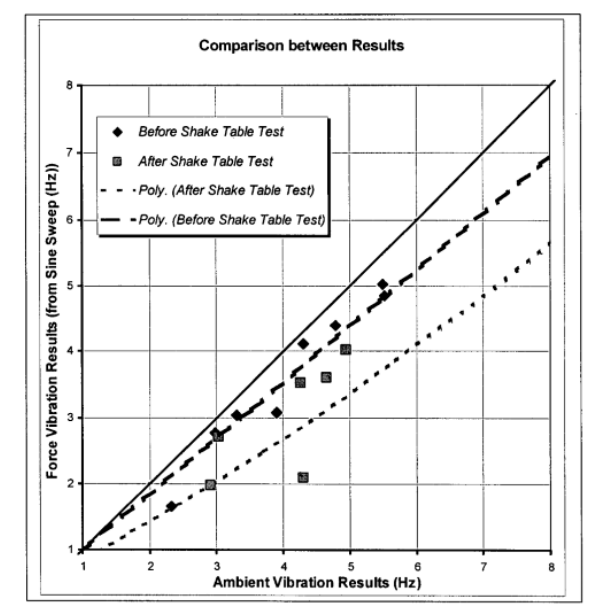

Figure 2-4 Correlation between ambient and force vibration test results (Source Kharrazi, M. K., 2001)

The study also suggested two relationships for the wood frame houses, exposed to low 
(Equation 2-6) and high (Equation 2-7) levels of excitation. $F_{V}$ and $F_{A V}$ are force vibration and ambient vibration frequencies, and the factor, $\propto$, in Equation 2-6, takes on the values of $0.76,1.03$, and 1.42 for non-engineered, engineered and stucco houses, respectively.

$$
\begin{aligned}
& F_{V}=\propto 0.65\left(F_{A V}\right)^{1.1} \\
& F_{V}=0.32\left(F_{A V}\right)^{1.4}
\end{aligned}
$$$$
2-6
$$

\subsubsection{Ellis, B.R., and Bougard, A.J. (2001)}

Ellis and Bougard performed dynamic testing of a six-storey timber building in three different construction stages: 1) timber frame alone, 2) timber frame plus staircase, plaster board walls and 3) ceiling linings and the completed building with masonry cladding. The six-storey timber framed building was constructed at Building Research Establishment (BRE) laboratory in the United Kingdom. The building had a base of $25 \mathrm{~m} \times 13 \mathrm{~m}$ with a total height of $19.5 \mathrm{~m}$. Details about the building construction is provided in the literature (Enjily V. and Palmer S., 1998). The objective of the study was to determine the racking stiffness from measured fundamental modes of vibration with known masses of the bare frame and the completed building.

During construction, laser measurements were performed using a long-range laser interferometer to identify the fundamental frequencies and mode shapes at seven different stages of construction, whenever a new storey was added to the structure. 
The fundamental frequency observed for the full six-storey for various construction stages ranged from $2.36 \mathrm{~Hz}$ to $4.99 \mathrm{~Hz}$ in the $\mathrm{N}-\mathrm{S}$ direction, $3.15 \mathrm{~Hz}$ to $3.73 \mathrm{~Hz}$ in the $\mathrm{E}$ W direction and measured torsion frequency ranged from $3.64 \mathrm{~Hz}$ to $6.20 \mathrm{~Hz}$. The ambient response of the structure was also measured at four intermediate finishing stages, where the frequency fluctuations were observed with the change of building mass and stiffness, as expected. Later, forced vibration testing was also performed at three finishing stages to determine natural frequencies, mode shapes, and damping ratios. The fundamental frequencies from the forced vibration tests ranged between $2.00 \mathrm{~Hz}$ to $4.71 \mathrm{~Hz}$ in the N-S direction, $2.49 \mathrm{~Hz}$ to $3.57 \mathrm{~Hz}$ in the E-W direction and the fundamental torsional mode frequency from $3.23 \mathrm{~Hz}$ to $5.88 \mathrm{~Hz}$. The damping ratios ranged between 2.44 to 3.86 . In the finished structure, measurements performed using the two different methods (ambient vibration and forced vibration) confirmed that measurements taken during forced vibration tests produced smaller frequencies than those from ambient vibrations, however the difference between the two test methods was deemed small. The study also concluded that brick cladding, staircase, and plasterboard had a great effect on the stiffness of the building.

\subsubsection{Filiatrault et al. (2002)}

The seismic performance of a two-storey, single-family wood frame house was evaluated on a reduced scale uni-axial shake table at the University of California, San Diego (Filiatrault et al. 2000). The primary objective of this experimental study was 
to investigate the dynamic characteristics with and without wall finishes material attached to the test structure. The footprint of the test structure was $4.9 \mathrm{~m} \times 6.1 \mathrm{~m}$, smaller than a typical residence due to limitations of shake table size. The test structure was attached to the steel base frame, which incorporated extension cantilevers in east and west directions to accommodate the plan dimensions of the test structure. For the seismic tests, the 1994 Northridge Earthquake ground motion record at Canoga Park, and the near-field ground motion that represented a seismic hazard level with the probability of exceedance of $2 \%$ in 50 years were chosen. To determine the fundamental period and damping ratio of the wood building, ambient, and free vibration tests were also performed.

Ambient vibration testing was performed using low-level white noise having a (0-20) $\mathrm{Hz}$ frequency band before and after each seismic test, to determine the effect on fundamental period and mode shapes of the test structure. The frequency changed from $4 \mathrm{~Hz}$ to $6.6 \mathrm{~Hz}$ after installation of finishing materials, which indicated an increase of lateral stiffness of the structure. The free vibration testing was performed using low-intensity harmonic base excitation. It was concluded that the roof displacement was decreased by more than a factor of three due to increasing in lateral stiffness of the structure incorporating the wall finishing materials. The wall interior and exterior finishing materials also had great influence on the seismic response of the structure and it was recommended that the effect of finishes be considered while 
computing the initial fundamental period a wood frame building. The mean damping ratio observed by free vibration test for bare frame structure was $5.2 \%$ of critical, and the value increased to $7.1 \%$ when wall finishes were added.

\subsubsection{Camelo (2003)}

The vibration behavior of wood based buildings was studied by developing a database of dynamic properties through analyses of available earthquake records on five shear wall wood framed buildings instrumented by California Strong Motion Instrumentation Program and by performing forced vibration testing on five other buildings located in California. Eight sets of earthquake records were analyzed using system identification procedure to obtain the fundamental frequency and damping ratios of one-, two- and three-storey wood frame buildings. A computer program, MODE-ID method, based on non-linear least squares output error method, was used to extract the modal parameters from the recorded measurements. The extracted fundamental frequencies varied between $4.4 \mathrm{~Hz}$ (three-storey building) to $8.7 \mathrm{~Hz}$ (single-storey building). Forced vibration testing was performed on existing twostorey, and three-storey wood buildings, where the force was induced using a shaker and the response was measured by force balance accelerometers. The maximum observed fundamental frequency was $6.7 \mathrm{~Hz}$ (two-storey building), and the minimum value was $1.2 \mathrm{~Hz}$. Ambient vibration field testing were also performed on eight other buildings located in California and Los Angeles, and the frequency range was found 
to be between $13 \mathrm{~Hz}$ (single-storey building) and $4.5 \mathrm{~Hz}$ (three-storey building). Two full scale shake-table test on wood frame buildings were also performed under the same project (CUREE Caltech Woodframe Project) and data obtained from these tests were used to validate the proposed formula for estimating the fundamental period of wood based buildings. A two-storey house at UC San Diego and a three-storey building with tuck-under parking at UC Berkley were tested at different phases of construction, and the frequency range was found to be $4.16 \mathrm{~Hz}$ to $1.88 \mathrm{~Hz}$ (un-finished construction stage) and $7.21 \mathrm{~Hz}$ to $3.50 \mathrm{~Hz}$ (finished construction stage). The compiled database, excluding the results of ambient vibration field testing, was analyzed to obtain the best fit curve for the median fundamental period, $T$ as a function of building height, $h_{n}$ (in feets). The median period formula shown in Equation 2-8, was proposed to represent the behavior of wood buildings more accurately than the period formula provided in Uniform Building Code (UBC-97).

$$
T=0.032 h_{n}^{0.55}
$$

\subsubsection{Christovasilis et al. (2008)}

Christovasilis et al. performed full-scale testing on a tri-axial shake table in the

Structural Engineering and Earthquake Simulation Laboratory (SEESL) at the University at Buffalo (UB), to study the parameters that influence the seismic behavior of light-frame wood buildings. The footprint of the tested structure was $7 \mathrm{~m} \mathrm{x}$ $18 \mathrm{~m}$, and the total height from the floor to the roof eaves was $5.3 \mathrm{~m}$. Two tables were 
required to accommodate the size and weight of full-scale structure test. Multiple configurations of the structure and two different types of tri-axial ground motions were used for the shake table testing and the effect of interior and exterior wall finishes on the seismic response of the building was evaluated.

Dynamic properties, such as fundamental frequency, mode shapes and damping ratios of the tested buildings were also determined using ambient vibration testing. The structure was excited by low-level white noise base acceleration input with a uniform spectrum of $0.5-50 \mathrm{~Hz}$. The natural frequencies obtained ranged between $3 \mathrm{~Hz}$ and $5 \mathrm{~Hz}$ and first modal damping ratios ranged between $10 \%$ and $20 \%$ with a mean damping ratio of $15 \%$ of critical. The research concluded that finishing material increased the lateral stiffness and consequently reduced the displacement response of the building. After application of stucco, the increase in the lateral stiffness was found to be $29 \%$ and $32 \%$ along the transverse and longitudinal directions of the building, respectively, and a reduction of $66 \%$ in peak drift was observed in the garage wall line when compared to the bare frame building. The fundamental frequency of the building increased from $3.0 \mathrm{~Hz}$ to $3.33 \mathrm{~Hz}$ (transverse direction) and $4.34 \mathrm{~Hz}$ to $4.54 \mathrm{~Hz}$ (longitudinal direction) with the application of gypsum wall board and further increased to $3.44 \mathrm{~Hz}$ and $5.0 \mathrm{~Hz}$ respectively in the two directions when stucco was applied on the exterior of the building. The overall (global) hysteretic response of the building showed a $44 \%$ reduction in roof transverse displacement by attaching 
gypsum wall board only on the structural walls, and was further reduced by $29 \%$ when gypsum wall boards were added to the interior partition walls and ceiling of the building. The results provided clear evidence of the significant influence of the wall finish materials on the behavior of the lateral load resisting system, and the researchers emphasized the need for a performance-based seismic design methodology for wood buildings that takes into account the effect of wall finishes material.

\subsubsection{Van de Lindt et al. (2010)}

Full-scale shake table testing was performed on a six-storey light wood frame apartment building in Miki, Japan. The structure was designed according to performance-based seismic design procedure and the goal of the test was to determine parameters such as building fundamental period, base shear, inter-storey drifts, acceleration and hold-down forces. The plan dimension of test structure was $18 \mathrm{~m} \mathrm{x}$ $12 \mathrm{~m}$ and total height was approximately $17 \mathrm{~m}$. Multiple seismic tests were performed using the Northridge ground motion recorded at Canoga Park. The natural period of the building was identified before and after every seismic test using white noise excitation. The fundamental frequency in three orthogonal directions was estimated to be $2.43 \mathrm{~Hz}$ (X-direction), $2.38 \mathrm{~Hz}$ (Y-direction) and $7.69 \mathrm{~Hz}$ (Z-direction; vertical). For design earthquake level shaking, the peak displacement $(140 \mathrm{~mm})$ at roof level was found to be less than $1 \%$ of the building height. Although the floorplan of the building 
was approximately symmetric and the seismic masses were evenly distributed, torsional response was observed during the seismic test, which pushed the inter-storey drift of some shear walls (near the building corner) slightly beyond 3\%. The damage was not significant for seismic test even for 2500-year earthquake; however, some visible damage, limited to only non-structural components were noticed, in the gypsum wall board. This study suggested that the design of light frame wood building using performance-based seismic design enabled better performance and that torsion needs to be considered in seismic design.

\subsubsection{Gilles (2011)}

Gilles established a database of modal properties of 39 concrete buildings located in Montreal (Québec), using ambient vibration testing. Regression analysis on the results obtained for twenty-seven concrete shear wall buildings in addition to 130 similar buildings available in the literature was performed. The study compared the measured fundamental period with that of Equation 1-20 and suggested an alternative expression to calculate the mean fundamental period (Equation 2-9) as a function of building height $(h)$, which was found to have a better fit with the database than the NBCC period formula. In addition to providing a measure of uncertainty associated with the period estimation, two period equations were proposed and it was suggested that the equation corresponding to mean minus one standard deviation (Equation 2-10 could be used to estimate the fundamental period for the purpose of calculating 
seismic forces using the equivalent static force procedure while the equation corresponding to mean plus one standard deviation (Equation 2-11) could be used to to calculate seismic displacements.

$$
\begin{aligned}
& T_{1}=0.020 h \\
& T_{1}=0.015 h \\
& T_{1}=0.025 h
\end{aligned}
$$

\subsubsection{Reynolds et al. (2014)}

Reynolds et al. studied the dynamic behavior of cross-laminated timber (CLT) buildings located in Sweden (eight-storey buildings) and UK (seven- and eight- storey buildings). Ambient vibration testing was performed using three piezoelectric accelerometers. The response of the structures was processed by random decrement technique. This technique is useful for output-only analysis of structural vibration, where the autocorrelation function is extracted from a time-history of vibration measurement by averaging many samples. Frequencies and damping ratios observed in the eight-storey buildings ranged from $2.24 \mathrm{~Hz}$ to $3.63 \mathrm{~Hz}$ and $2.3 \%$ to $3.1 \%$, respectively. The seven-storey building was tested in two stages; first, when only the CLT structure was completed and the observed frequency was $2.70 \mathrm{~Hz}$ and damping ratio was $3.6 \%$. The second test was done when cement screed was applied to the floors and finishes were provided to the building, which increased the mass and stiffness of the building. The frequency was reduced to $2.45 \mathrm{~Hz}$ due to the addition of 
mass was dominant over the increase in stiffness, but damping ratio was increased to $5.4 \%$.

\subsubsection{Steiger et al. (2015)}

Experimental modal analysis of a three-storey light-frame wood building was performed in two construction stages; stage 1 where only structural components were present and stage 2 where both structural and non-structural components were included. The tested structure had a footprint of $24 \mathrm{~m} \times 14.6 \mathrm{~m}$ with the total height of $11.5 \mathrm{~m}$ above an underground garage. The structure is located near Zurich, Switzerland. First, the ambient vibration tests were carried out to identify the modal parameters at low amplitude excitation level followed by forced vibration tests. Forced vibration tests were performed for three levels of excitation; broad band random excitation to assess the frequencies for a higher level of excitation, narrow band excitation to identify the natural frequency with precision, and harmonic excitation of different levels to determine the modal damping ratios. The recorded measurement for AVT and FVT in two orthogonal horizontal directions were analysed by identifying the system matrices of linear time invariant system, after which natural frequencies and modal damping ratios were computed from eigen values of the system matrix.

The investigation found that all natural frequencies decreased and damping ratios increased considerably with increased amplitude. The decrease in frequencies ranged 
from 5 to $10 \%$, which was attributed to a reduction in overall stiffness of building of about 10 to $20 \%$. The study showed little difference in the mode shapes between stage 1 and stage 2 testing, despite the noticeable changes in modal damping and frequency for all identified modes.

\subsubsection{Feldmann (2015)}

Feldmann (2015) evaluated the dynamic properties of twelve existing tall timber structures of different construction types and heights using ambient vibration testing. The tested structures include three multi-storey timber buildings, eight towers and one wind power station, with heights range from $20 \mathrm{~m}$ to $100 \mathrm{~m}$, located in Germany and Austria. The measurements were recorded for either 20 minutes or 40 minutes using three piezoelectric accelerometers. The output from the ambient vibration testing records was analyzed by time and frequency domain methods to obtain fundamental frequencies, associated damping ratios, and mode shapes of the tested structures.

The fundamental natural frequencies and damping ratios of the tested buildings and towers had a range of $1 \mathrm{~Hz}-0.3 \mathrm{~Hz}$, and $0.5 \%-3 \%$ respectively. The results obtained by time and frequency domain matched well for frequencies and damping ratios. The investigation found that damping ratios of existing tall timber structures cover a broader range compared to the suggestions given in codes, and suggested that the recommended damping values in design guidelines underestimate the actual damping of the building. Finally, the influence of construction type on the dynamic properties 
of the measured structures was analyzed, and a trend of increasing damping ratio with increasing ratio of steel for connections and cladding in timber buildings was observed. The natural frequencies of the structure decreased with increasing height of the structure, but increased by adding more secondary structures.

\subsection{Numerical Research on Light Wood Frame Buildings}

\subsubsection{Gupta and Kuo (1987)}

A linear elastic simplified analytical model was developed, to analyze a wood frame house subjected to earthquake and wind forces, and the model was validated with test results provided in the literature (Tumoi and McCutcheon 1974). The house was analyzed in five stages of construction: in the first stage the shear wall system was modeled without any door or window opening, while in later stages openings were added to the shear walls, and then gypsum dry walls, exterior cladding, orthogonal partition walls, and finally the roof.

The shear wall model builds on previous work by the authors (Gupta and Kuo, 1985), where the nail deformation of joints and the shear deformation in sheathings were considered while the bending and axial deformations of the wall studs were disregarded. Globally, the house behaviour was defined in terms of nine degrees of freedom that included horizontal ( $\mathrm{u} 1, \mathrm{u} 2, \mathrm{u} 3, \mathrm{u} 4, \mathrm{u} 5)$ and the total vertical displacements $(v 1, v 2)$ at the defined locations (see Figure 2-5). The displacements 
$\Delta v 1, \Delta v 2$ were the uplift in the studs at the base. The analytically evaluated uplift forces between stud and sole-plate, at five different construction stages, were found in good agreement with the experimental results.

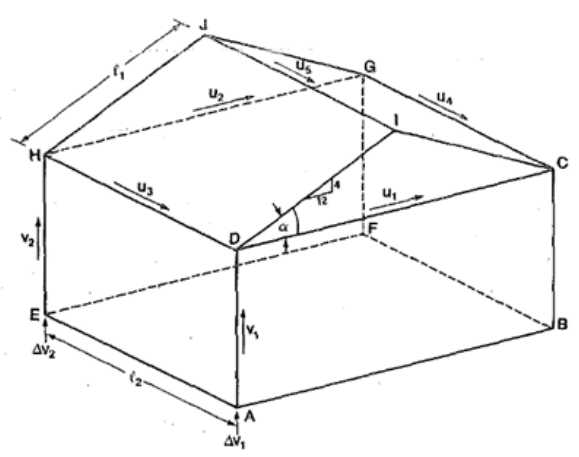

Figure 2-5 Global degrees of freedom for house model (Source Gupta and Kuo (1987))

\subsubsection{Tarabia and Itani (1997)}

The authors developed a general three-dimensional (3D) model of light-frame wood buildings with different geometric configurations to evaluate their seismic response. In the study, the effects of the asymmetric in-plane stiffness, dimensions of the horizontal diaphragm, the presence of partition walls, and the ground motion intensity on the structural response were investigated. Diaphragm elements were used to represent walls, floors, and roof subsystems and inter-component connection elements were used to model the interfaces between diaphragms and between diaphragms and foundations.

Master degrees of freedom were assigned to connecting nodes among the diaphragms 
and between the diaphragms and inter-component elements, with three translational degrees of freedom assigned to each master node. Framing elements, sheathing elements, sheathing interface elements, framing connector elements, and fastener elements were accounted for to obtain the in-plane stiffness of diaphragms. All masses of the different diaphragms were computed and lumped directly at the master nodes of the diaphragms, while the mass of the inter-component connection elements was neglected. Two different experimental cases were used to verify the dynamic model. The first case was the test of shear walls under seismic loads as reported by Dolan (1989), where the dimensions of the walls were $2.4 \mathrm{~m} \mathrm{X} 2.4 \mathrm{~m}$. The second case was a pseudo-dynamic test (Kamiya, 1988) where six shear walls with dimensions of $1.82 \mathrm{~m}$ X $2.42 \mathrm{~m}$ were evaluated.

It was reported that the proposed model showed excellent correlation with the experimental data. The differences of the predicted and experimental maximum displacements were in the range of $2-15 \%$ whereas those of the reactions were within $4 \%$. The study indicated that rigidity of the horizontal diaphragm is influenced by its overall dimensions (aspect ratio) and that partition walls resist a substantial amount of seismic forces depending on their stiffness and the aspect ratio of the horizontal diaphragm.

\subsubsection{Folz and Filiatrault (2004)}

The authors presented a simple numerical model that can be used to assess the 
performance of light frame wood buildings. In the model, the building structure was composed of a rigid horizontal diaphragms and nonlinear lateral load resisting shear walls, to predict the dynamic and quasi-static pushover and seismic behavior of wood buildings. The three-dimensional building was degenerated into two-dimensional planar models with the assumption of zero height shear wall spring elements that represent strength and stiffness degradation. Each shear wall in the model was represented by a single in-plane horizontal degree of freedom. All diaphragms in the model were considered to have infinite in-plane stiffness. This simple numerical model was able to predict the dynamic characteristics, quasi-static pushover and seismic response of wood-frame buildings. Incorporated into the computer program SAWS "Seismic Analysis of Wood-frame Structures", the model was validated using the test results of full scale two storeys single-family home and provided reasonably accurate estimates of dynamic characteristics, quasi-state pushover and seismic response of the test structure (Folz and Filiatrault (2004b)). Further, the model needed minimum input parameters to perform the computational work. The model does not capture the overturning and flexural response of a structure, which was argued to be acceptable for low-rise wood frame.

\subsubsection{Collins et al. (2004, 2005)}

Collins et al. developed a 3D finite element model with nonlinear hysteretic springs to predict the static and dynamic behavior of light-frame wood building (see Figure 2-6) 
in the inelastic range. The model's predictive ability was verified experimentally for global and local response comparisons of the energy dissipation, forces, and displacements. The 3D model was comprised of linear elastic shell elements, beam elements, and nonlinear spring elements. The mesh was developed considering nail and stud spacing and associated discontinuities such as windows and doors. Shear walls and diaphragms were modeled using shell elements. Framing members were modelled as beam elements and two diagonal hysteresis springs were used to capture the non-linearity.

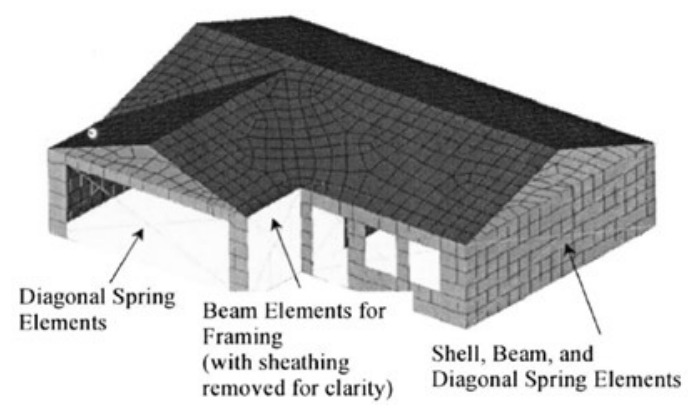

Figure 2-6 Finite element model of the tested house (Source Collins et al. (2004-2005))

For validation of the FE model with test results, an L-shaped house with non-uniform shear walls was investigated. The testing was performed on the unfinished structure to facilitate the validation of FE model with only structural elements of the building. Similar displacement-control (in lieu of applied loads) was incorporated in FE model as that used in the destructive testing of the house. The authors concluded that reliable results could be obtained from the model and there was agreement between testing 
and numerical force-displacement curves of the load resisting walls.

\subsubsection{Doudak et al. (2005)}

Numerical modelling using finite element approximation was used to compare with full scale testing and monitoring of a single-storey wood frame building. Linear Hermitian "Frame" elements with six degrees-of-freedom per node were used to model all the framing elements, including the effects of biaxial bending, torsion, axial deformation and biaxial shear deformation. Individual sheathing panels were modeled as linear "Thin Shell" elements which had four nodes, with six degrees of freedom at each node. All nailed sheathing-to-framing and framing-to-framing connections were modelled using nonlinear link elements (NL-Link in SAP2000) composed of springs with axial, transverse (shear) and rotational degrees of freedom. Assigning realistic load-deformation properties to the NL-Links was deemed very important. The modelling of links involved multi-linear load-deformation function fitted directly to connection test data and included the softening regime that occurs when nails have begun to yield. The model was verified using full scale test of a rectangular shaped bungalow structure with an $8.5 \times 17 \mathrm{~m}$ footprint and a duo-pitch roof with 4/12 slopes. The complete superstructure rested on a set of fifteen three-axis load cells sandwiched between the bottom of the floor platform and a perimeter reinforced concrete frost-wall foundation. This allowed instantaneous and accurate determinations of total and point horizontal and vertical force exchanges/flows. The 
overall finding of the study was that the adopted modelling techniques were able to accurately predict the response of the test bungalow.

\subsubsection{Casagrande et al. (2015)}

The paper presents simplified analytical and numerical modelling techniques for elastic analysis of one-storey timber shear wall buildings. The study was intended to provide designers and researchers with a tool to evaluate the elastic response of light timber frame shear-walls and cross laminated timber (CLT) shear-walls. Full-scale test was carried out on two wall specimens at the Materials and Structural Testing Laboratory of the University of Trento, in order to demonstrate the suitability of proposed numerical model.

The analysis of the timber wall stiffness presented two possible deformation modes, the first is where the hold-downs were not activated (due to greater stabilizing moment than overturning moment), and the second where the hold-down is in tension. A simplified numerical model was developed for single-storey wall, comprising of only three elastic springs in series, representative of the total wall stiffness. This is the main feature of the model as it reduces the analysis time without compromising on the results. The frame bending was not considered as suggested by (Källsner and Girhammer, 2009)

The laboratory test and numerical model results agree well with differences in the 
range of $1-8 \%$ for two walls. However, an exception of $20 \%$ difference between test and numerical model results was observed for one of the wall specimen, which was attributed to the friction in the foundation and sill beam of the wall assembly.

\subsection{Summary of Literature Review}

The literature survey shows that several studies have been conducted to investigate the dynamic characterictics of buildings, especially those constructed of reinforced concrete. Valuable informations have been collected from key studies on wood however there is still a need to perform methodical investigations of light-frame wood buildings, especially those taller than three storeys, since in past decades most of the research has been conducted on low-rise wood houses (one to three storeys). Understanding the dynamic response of timber buildings with light frame shearwalls as lateral load resisting systems is crucial in establishing safe and efficient seismic design guidelines. The proposed research program aims to enrich the literature with a comprehensive field testing program to establish a better understand of the dynamic response of wood buildings (including three to six storeys).

The following specific observations can be drawn from the reviewed literature:

1. As expected, the natural frequencies obtained using ambient vibration testing are higher than those obtained from forced vibration tests. A relationship has been established (Kharrazi, 2001) to obtain equivalent forced vibration 
frequencies from ambient vibration testing results. This relationship will be considered in the current study as one means of transforming the ambient vibration frequencies measured to equivalent force vibration level frequencies.

2. Brick finishing contributes significantly to the overall lateral stiffness of wood buildings (Ellis and Bougard, 2001). Finishing materials such as gypsum wall board and exterior stucco also contribute and, in turn, causes a reduction in displacement response and fundamental period of the structure (Filiatrault et al., 2002). Furthermore, there is a need to incorporate the effect of wall finishing material (Christovasilis et al., 2008) and torsional effect (Van de Lindt et al. (2010)) in performance-based approach.

3. Several studies have developed numerical analysis models to mimic the performance of light frame wood buildings at a system and component levels (e.g. Gupta and Kuo (1987), Folz and Filiatrault (2004), Collins et al. (2004, 2005), Doudak et al. (2005), Casagrande et al. (2015)) with varying levels of complexity. These approaches will be evaluated and suitable modeling techniques will be selected to analyze the tested buildings.

4. The code period formula used to calculate the building's fundamental period has been evaluated by several researchers (Goel and Chopra 1998; Lee et al., 2000; Morales, 2000; Gilles, 2011) for its applicability to concrete shear wall 
buildings. Only one study proposed an alternative period equation for wood based buildings (Camelo, 2003), which presents a clear need to evaluate the code period equation, using a comprehensive data base of natural periods from real buildings. 


\section{CHAPTER 3}

\section{Experimental Investigation}

This chapter addresses the experimental, field and laboratory, work conducted on light wood framed buildings in the current research project. The chapter starts by describing the field testing and then summarizes the methods of measurements adopted for multi-storey wood frame buildings. The analyses performed on the recorded measurements are explained, followed by a description of the experimental work performed at university of Ottawa laboratory on connection joints.

\subsection{Ambient Vibration Field Testing (AVT)}

\subsubsection{Introduction}

The dynamic properties of a structure, such as its natural frequencies, corresponding mode shapes and damping ratios, can be obtained by a number of experimental methods including forced vibration, free vibration, and ambient vibration testing (AVT). AVT has become a popular and practical experimental method for assessing the dynamic behavior of full-scale structures mainly because of its non-destructive nature and its simplicity, where the building is excited by operational loads (e,g, wind and traffic), whether under construction or in use. In AVT, the excitation forces on the 
structure are undefined, and the modal properties are obtained from the measured response only; this is also known as output-only modal identification. Additional practical advantages of AVT are that the preliminary results are available shortly after each test run and testing can be performed on different sizes and types of structures. Following section describes the development and some uses of AVT since its inception.

The ambient vibration testing for the period measurements of structures began in the early 1930's by U.S. Coast and Geological Survey (Carder, 1936; Hudson, 1970). Crawford and Ward (1964) and Ward and Crawford (1966) showed that modal properties of the structure such as natural frequencies and respective mode shapes can be extracted using ambient vibration measurement methods. Trifunac (1970a, 1970b) measured twenty two- and thirty nine-storey steel frame buildings using wind and micro-tremor induced vibration, and established a relationship between ambient and force vibration test results (Trifunac, 1972). Later, the ambient vibration tests results were further used to compare with higher amplitude response and to study the effect of pre-and post-earthquake response (Mulhern and Maley, 1973; Udwadia and Trifunac, 1974). Low amplitude ambient vibration method was also used to study the changeability in the structure during construction (Schuster et al., 1994; Skrinar and Strukelj, 1996; Ventura and Schuster, 1996) and to monitor the structure properties between low (ambient) and high (earthquake shaking) amplitude (Gates, 1993; Hart et 
al., 1972, 1975; Ivanovic et al., 2001; Oliveria et al., 1982; Beck et al., 1994a).

Progression in ambient vibration testing has evolved the development of algorithm to treat the recorded measurements, and the most commonly used algorithm for identification of modal properties is frequency domain decomposition (FDD) method (Brinker et al., 2001b). Current study utilized this method, which is implanted in the commercial Software ARTeMIS Extractor (Structural Vibration Solutions A/S, 2010) to determine the dynamic parameters of measured building.

\subsubsection{Experimental Investigation}

As a part of current research an experimental program was established to perform AVT on wood buildings located in different regions in Canada. The tested buildings are classified into two major groups, depending on the construction of their lateral load resisting system, namely light-frame wood buildings and post-and-beam buildings.

For light-frame wood buildings under construction, the testing was organized, when possible, in two phases; Phase 1: where the buildings were measured during construction, having all structural components installed (ideally) without the presence of any finishing material, and Phase 2: where the measurements were taken once all non-structural elements (architectural finishes) were attached externally and internally to the building. Despite the complexity in analyzing light frame wood structures, they 
have become the focus of the current study because of their abundance in North America and due to available research effort to describe their behaviour.

For the post-and-beam buildings, only Phase 2 testing was possible since these were all finished buildings. Although the results from field testing are reported herein and comparisons are made to established design codes, no attempts were made to model the buildings. Reason for this relates to the difficulty in defining the lateral load resisting systems since all tested buildings had been seismically retrofitted using primarily steel bracing. This combined with the fact that due to the age of the buildings (most are around century old) no structural drawings are available, have made it difficult to obtain reliable model inputs other than crude geometries. By providing the test data, however, the author is hoping that future studies conducted on these buildings can benefit from the work undertaken in the current research study.

\subsection{Geometric Description of Tested Buildings}

Light-frame wood buildings of both regular and irregular layouts, located in moderate to high seismic zones in Canada, have been tested and analyzed. Ten of the buildings in the data base were tested at both construction stages (Phase 1 and Phase 2), while six buildings were investigated at various construction stages. Also, the connectivity between firewall-separated buildings and the effect of non-structural components on building's behavior were investigated. 
Nine post-and-beam buildings were tested as part of the current project. These buildings are located in Toronto Ontario (a zone of low seismicity) and have variable geometry in their plan and elevations. Eight buildings were of regular shape, and one building was of an L-shape.

The locations, heights and plan geometries of all tested buildings are provided in Appendix A. The test structures are also identified with a building ID, which will be referred to throughout the thesis.

\subsection{Data Collection}

In this study, the devices used for field testing are Tromino ${ }^{\circledR}$ (http://www.tromino.eu), which will be referred to as "sensors" in the following sections.

\subsubsection{Test Instruments}

Instrumentation used throughout this study comprises of wireless sensors equipped with radio antennas. The sensors have a compact portable size of $100 \mathrm{~mm} \times 140 \mathrm{~mm} \times$ $8 \mathrm{~mm})$ and weight $(1.1 \mathrm{~kg})$. Four soft-touch keys are available to enable the user to input required sensing parameters such as record duration, sampling rate, and partition number (to store data). The acquisition frequency range is $(0.1-256) \mathrm{Hz}$, which suffices to include all significant natural frequencies of the building in relation to its overall wind and seismic response. Each sensor is equipped with three orthogonal electrodynamics velocimeters and three orthogonal digital accelerometers. The sensor 
stores data in an internal memory card and data can be transferred to a personal computer using USB cable through the Grilla interface software (S.P.A., 2008). As shown in Figure 3-1, a sensor is connected to a radio antenna that enables synchronization among the sensors through radio communication. Radio synchronization of sensors with the amplifiers depends on indoor and outdoor locations and physical obstacles. In principle, synchronization among each couple of sensors is possible at a distance up to $400 \mathrm{~m}$.

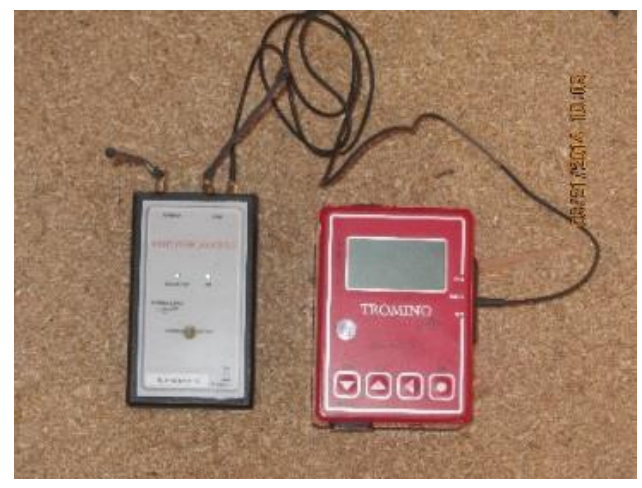

Figure 3-1 Tromino ${ }^{\circledR}$ (sensor) with radio antenna

\subsubsection{Field Test Procedure}

The ambient vibration data were gathered by similar sensor configurations on the buildings for both Phase 1 and Phase 2 testing. Various setups were configured according to the building geometry to obtain the fundamental mode shape of each building in two orthogonal directions. Typically, one reference sensor (at fixed location) and multiple roving sensors were used for each measurement setup. Data were recorded based on roving sensor scheme where, preferably, the reference sensor 
was positioned at the roof level for stronger signal communication, while the roving sensors were moved to the various predetermined floor points of the structure for each measurement. The ambient response vibrations were recorded for eight minutes per configuration at a sampling frequency of $128 \mathrm{~Hz}$, which allows sufficient downscaling of the data and record length for accurate modal extraction. Figure 3-2 and Figure 3-3 show typical sensor configurations. In the case of L-shape buildings, the floor measurements were recorded on both wings of the buildings to capture fundamental mode shapes corresponding to both extensions.

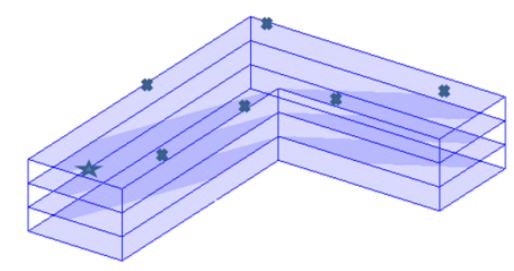

a) AVT setup 1

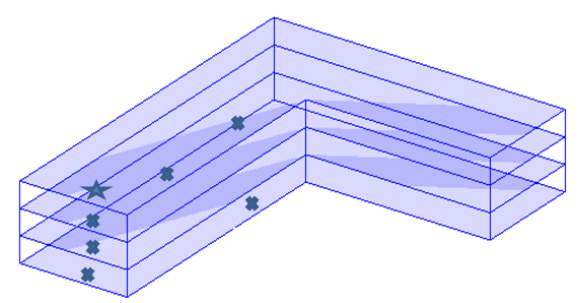

c) AVT setup 3

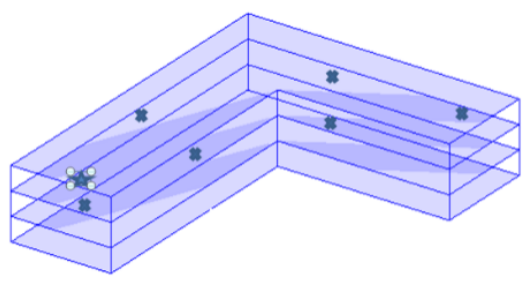

b) AVT setup 2

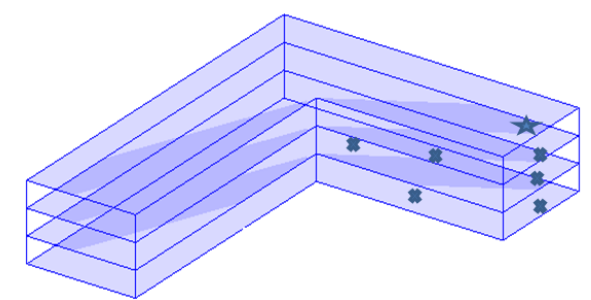

d) AVT setup 4

Roving sensor

$\star$ Reference sensor

Figure 3-2 Typical sensor configurations for L-shaped buildings 


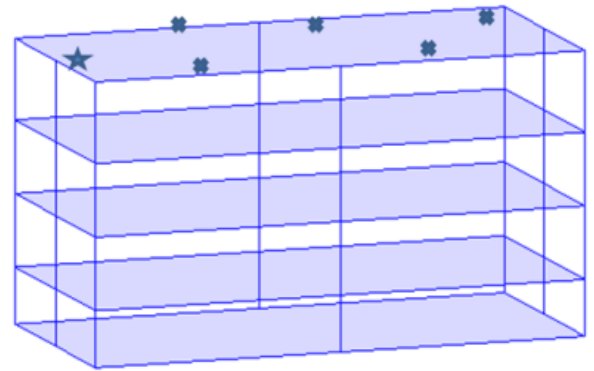

a) AVT setup 1

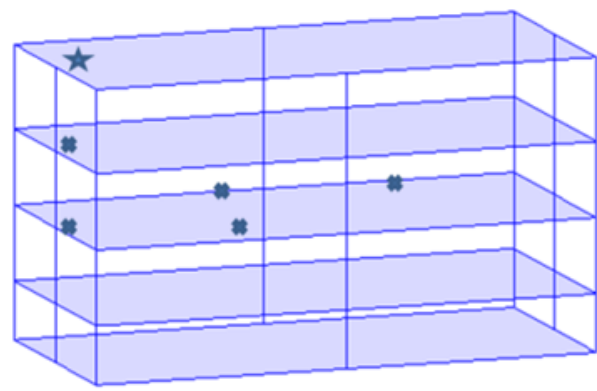

c) AVT setup 3

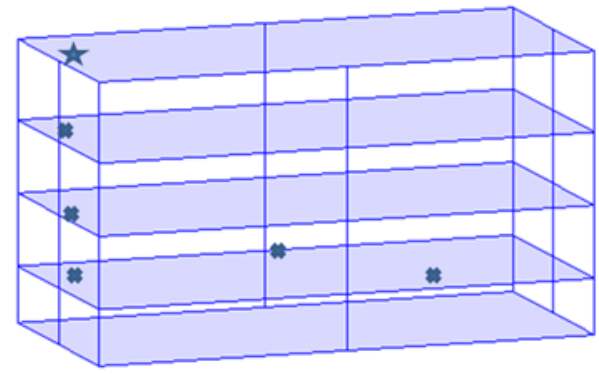

e) AVT setup 5

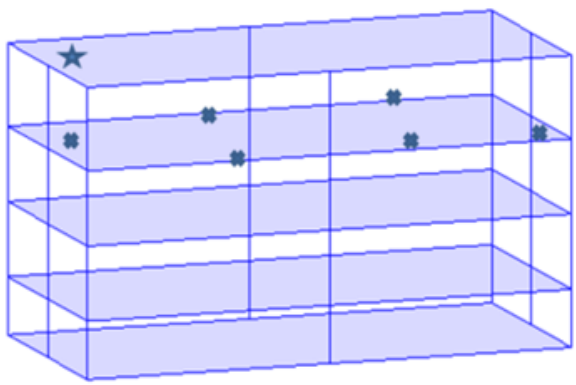

b) AVT setup 2

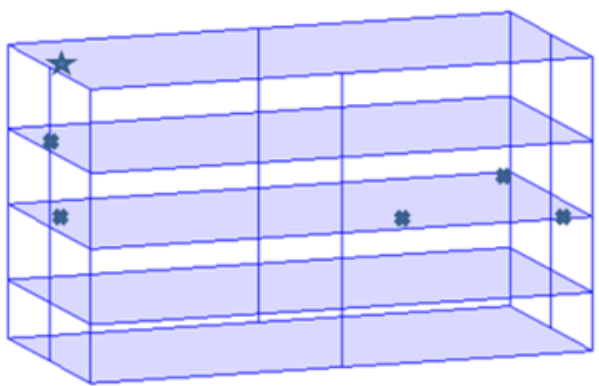

d) AVT setup 4

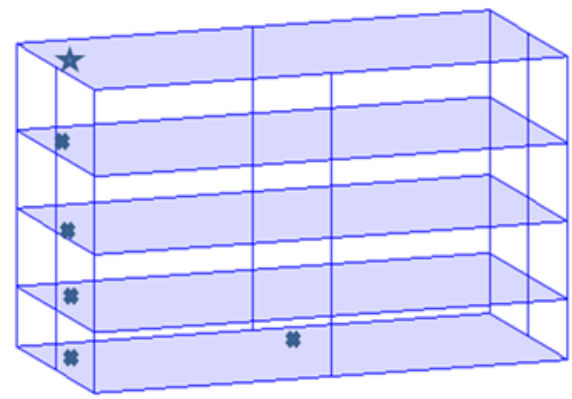

f) AVT setup 6

Roving sensor

$\star$ Reference sensor

Figure 3-3 Typical sensor configurations for rectangular buildings

\subsubsection{Recorded Signals and Excitation}

To obtain an accurate modal response, synchronization of the recorded signals was 
essential. As noted earlier, the sensors operate using radio communication, where the devices follow one another through a radio chain, and the reference sensor sends messages to the roving sensors. The excitation forces are undefined in AVT, therefore, to obtain the modal parameters, the excitation is assumed to be a broadband, stationary Gaussian white noise, with approximately equal energy content throughout the frequency range of interest (Bendat and Piersol, 2000).

An example of the recorded signals in seven different channels of the reference sensor is shown in Figure 3-4. The figure shows the motion components recorded by the sensor in North-South, East-West and Up-Down directions for length of two minutes (data is recorded for eight minutes length, but to avoid the data cluster the records are shown only for two minutes). Measurements such as acceleration components in all three orthogonal directions and velocity component in "Up-Down" directions were removed from the raw measurements as they are not used in modal extraction in this project. The data files (.txt) carrying East-West and North-South velocity-time histories of the reference and roving sensors were imported to ARTeMIS Extractor software (Structural Vibration Solutions, 2010a) for extraction of modal frequencies, mode shapes, and estimated damping ratios using frequency domain decomposition techniques. 


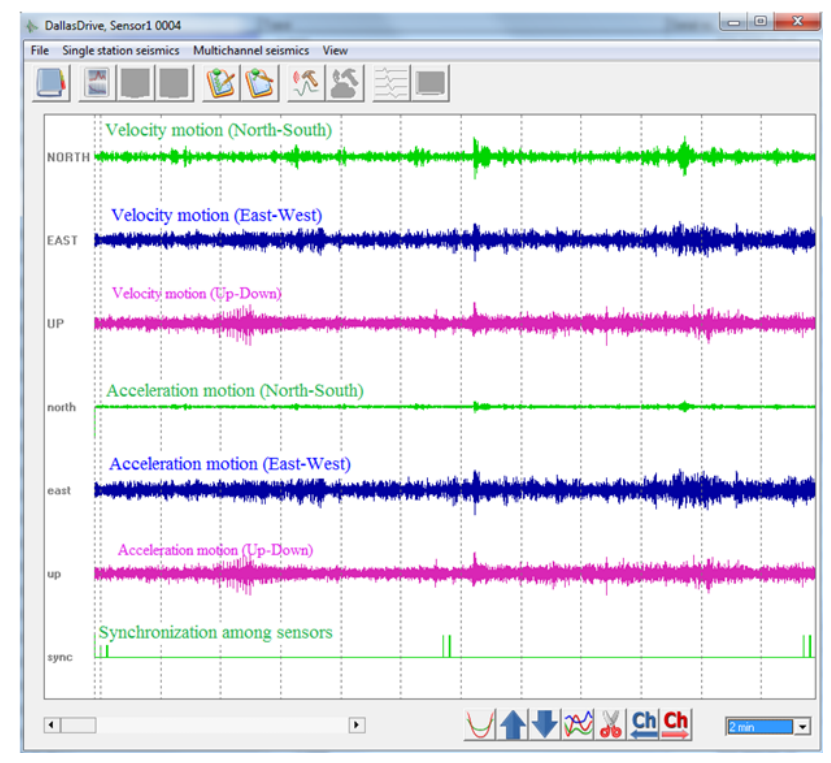

Figure 3-4 Raw signals in three orthogonal directions for different channels

\subsection{Extraction of Modal Parameters}

Fundamental natural frequencies and mode shapes of the tested buildings were extracted by importing the data (.txt) file with required records to the software together with user input on geometric properties of the buildings. The data was then analyzed by the enhanced frequency domain decomposition (EFDD) technique as employed in the ARTeMIS Extractor software (Structural Vibration Solutions A/S, 2011).

The details about the procedures described next is based on information from Brincker et al., (2001), user's manual of the ARTeMIS Extractor software (Structural Vibration Solutions A/S, 2011) and Gilles, (2011). 


\subsubsection{Frequency Domain Decomposition (FDD)}

Frequency Domain Decomposition is a linear technique where the system response is decomposed into independent degrees of freedom system sets, representing the modal behavior. In FDD, the modal frequencies are extracted by peak-picking on singular value plots. For AV recorded measurements, the first step is estimating the spectral density (SD) between all individual records. The SD of a time signal describes the distribution of energy with respect to frequency and is used to identify the modal frequencies that correspond to high energy peaks (although not all high energy peaks correspond to a modal frequency of the system). Recorded velocity-time histories were treated with autocorrelation functions, which were then transformed into frequency domain using Fast Fourier Transform (FFT) algorithm to generate power spectral density (PSD) matrices. The SDs between each pair of measured record are computed and stored in $(N x N)$ spectral density matrices, where each PSD matrix is a Hermitian matrix. The row and column elements of the matrix, at any frequency, represent the SD between row and column degrees of freedom at that particular frequency. The SD between two time-history records $x(t)$ and $y(t)$ having corresponding Fourier transform $X(\omega)$ and $Y(\omega)$ is given as;

$$
G_{x y}(\omega)=E[X(\omega) Y(\omega) *]
$$

where * indicates the complex conjugate. Singular value decomposition (SVD) is performed on each PSD matrix and transforms it into three matrices as follows 
(Schott, 2005);

$$
[G]=[U][S][V]^{H}
$$

Where $[G]$ is PSD matrix (to be decomposed) at each frequency, $[S]$ is the singular value matrix, $[U]$ and $[V]$ represent unitary matrices containing orthonormal, left and right singular vectors respectively. $\mathrm{H}$ denotes Hermitian transform.

Since the peaks in FDD are picked at singular values plot, for each PSD matrix the singular value decomposition is performed at each discrete frequency, resulting from the FFT operation, giving $\mathrm{n}$ sets of singular vectors (representing an approximation to mode shapes) and singular values. The SVD of the output PSD matrix is therefore an approximation to its modal decomposition (Brinker et al., 2001b). The singular values from each measured configuration are averaged across $n$ different measured configurations by normalizing the area under preceding singular value curve. The averaging operation is performed individually for each singular value, as given in Equation 3-3 (Structural Vibration Solutions, 2011)

$$
\left\{S_{i}(\omega)\right\}=\frac{1}{n} \sum_{m=1}^{n} S_{i}(\omega, m)
$$

Where $i=1,2,3, \mathrm{~m}$ is measurement configuration (sensor setup).

\subsubsection{Enhanced Frequency Domain Decomposition (EFDD)}

As explained in the previous section, in FDD a modal frequency and its corresponding mode shape are estimated based on the peak-point on the singular value plot and the 
accuracy of modal parameters entirely depends on the selection of the peak-point. Also, modal damping can not be obtained in the FDD technique. The EFDD technique is an enhancement of the more classical frequency domain decomposition (FDD) technique which uses reliability analysis to reduce the uncertainty on frequency peak signal identification. It provides improved estimates of modal frequencies, mode shapes and an opportunity to yield rough estimates of the modal viscous damping ratios ((Structural Vibration Solutions A/S, 2011); Gilles, (2011)). In EFDD, a single degree of freedom (SDOF) bell-shaped function is formed for each measured configuration and the modal parameters are then estimated using a range of frequencies (for this study: 0-20) in the neighborhood of the peak-point selected (SDOF spectral bell).

Once the average normalized singular value plots are developed, similar to FDD technique, the peaks are identified as potential modal frequencies. As shown in Figure $3-5$, these averaged singular values are plotted against frequency to offer potential peaks for identification of the building's natural frequencies excited by ambient sources. A single-degree-of-freedom (SDOF) bell-shaped function is produced for each measured configuration, by considering all frequencies in the vicinity of a potential peak (resonance frequency) with a singular vector with a high Modal Assurance Criterion (MAC). MAC defines a measure of consistency (correlation) between two vectors $\left\{\varphi_{1}\right\}$ and $\left\{\varphi_{2}\right\}$ and is given by; 


$$
\operatorname{MAC}\left(\left\{\varphi_{1}\right\},\left\{\varphi_{2}\right\}\right)=\frac{\left|\left\{\varphi_{1}\right\}^{H},\left\{\varphi_{2}\right\}\right|^{2}}{\left|\left\{\varphi_{1}\right\}^{H},\left\{\varphi_{2}\right\}\right| \cdot\left|\left\{\varphi_{1}\right\}^{H},\left\{\varphi_{2}\right\}\right|}
$$

MAC values can vary from 0 to 1 , representing inconsistency and complete orthogonality between two mode shapes, respectively.

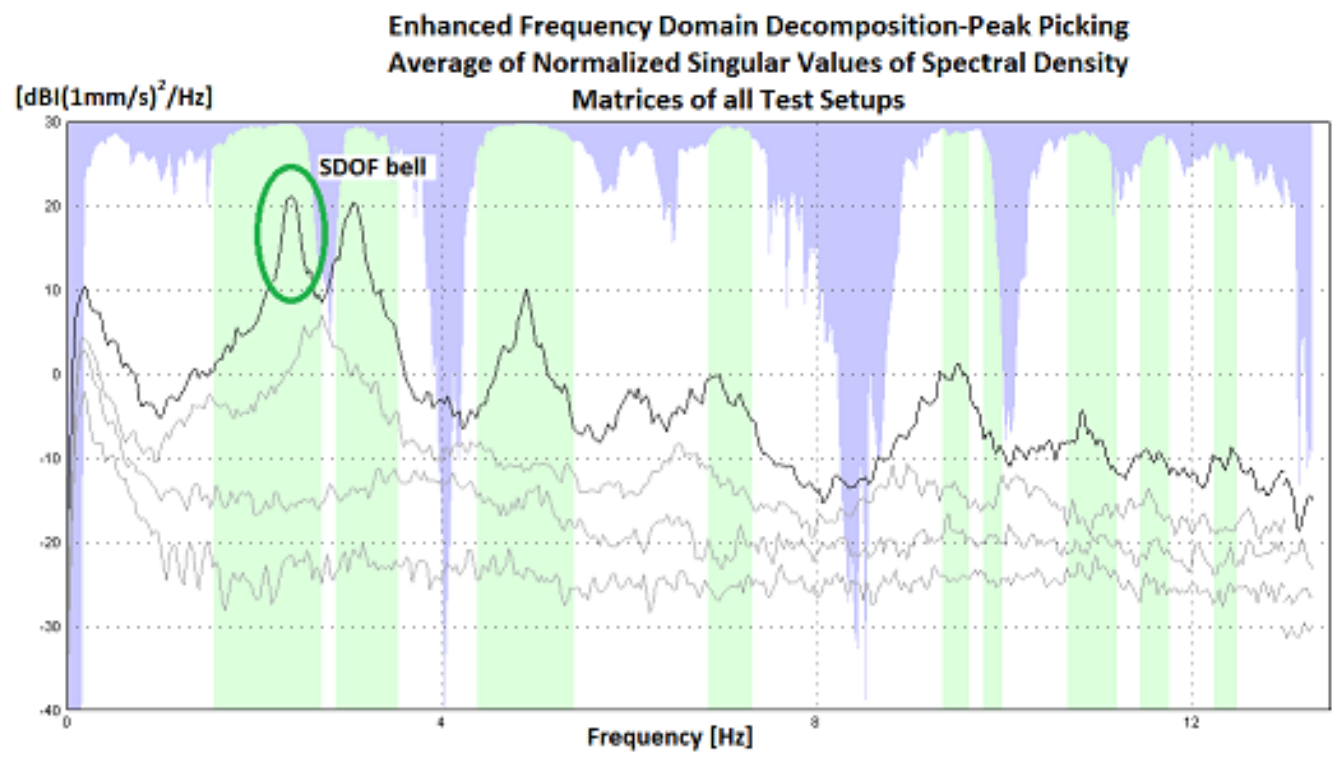

Figure 3-5 Singular value plot showing SDOF bell-shaped function, building B6

After identification of SDOF spectral bell, an improved estimate of mode shape is obtained by weighting the singular vectors $U_{i}$ at frequencies $\omega$, by their corresponding singular values $S_{i}$ (Structural Vibration Solutions, 2010a); $\{\varphi(\omega)\}$ is averaged mode shape at resonant frequency $\omega$.

$$
\{\varphi(\omega)\}=\frac{\sum \operatorname{Si}(\omega)\{U i(\omega)\}}{\sum \operatorname{Si}(\omega)}
$$

The identified SDOF bell-shaped function of each measured configuration (sensor setup) is brought back to the time domain using inverse Fast Fourier transformation 
(IFFT). This time, the function is an approximation of the SDOF autocorrelation function (see Figure 3-6a)) of the corresponding mode (Bendot and Persol, 2000). Linear regression is performed on zero crossings plotted against time, and the obtained slope represents the number of zero crossings per second or twice the number of cycles per second since the function crosses zero twice per cycle; so half of the regression slope of zero crossings provides the frequency value (see Figure 3-6b)). The SDOF autocorrelation function decays exponentially like the free response of a linear SDOF oscillator with viscous damping (see Figure 3-6c)). For this reason, the logarithmic decrement technique, which is commonly applied to estimate the viscous damping ratio of an SDOF oscillator from its free vibration response, can be extended to the SDOF autocorrelation function (Clough and Penzien, 2003)

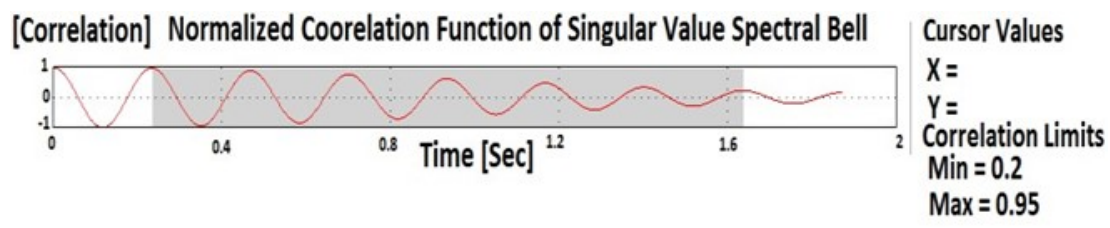

a) Autocorrelation function (Time-Domain), B6

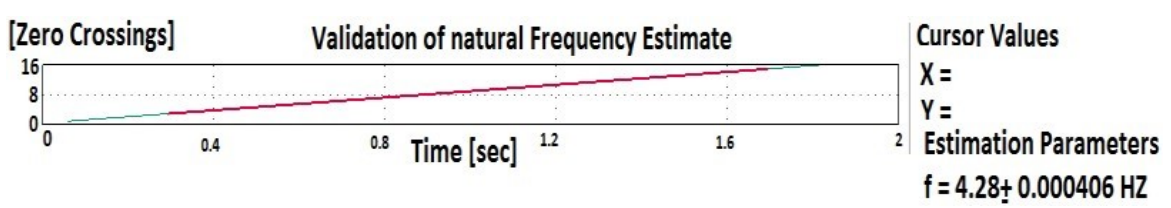

b) Improved estimate of frequency, B6

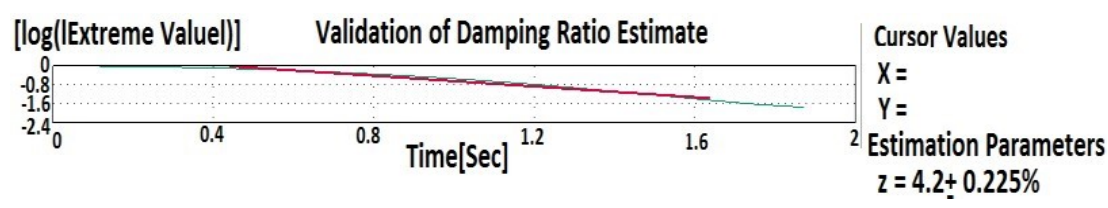

c) Estimate of viscous damping, B6

Figure 3-6 Time domain 


\subsection{Investigating the Effect of Firewall-Separation}

In this part of the study, modal analysis was applied in order to study the effect of firewall-separation on the dynamic behavior of wood buildings. The buildings were measured as individual structures and as combined buildings in order to evaluate whether the introduction of the firewall would cause the two buildings to act in unison. This has great implication on design since it is always debated whether firewall-separated buildings should be considered as individual buildings or whether the entire structure should be taken as one. An example of the firewall construction can be seen in Figure 3-7.

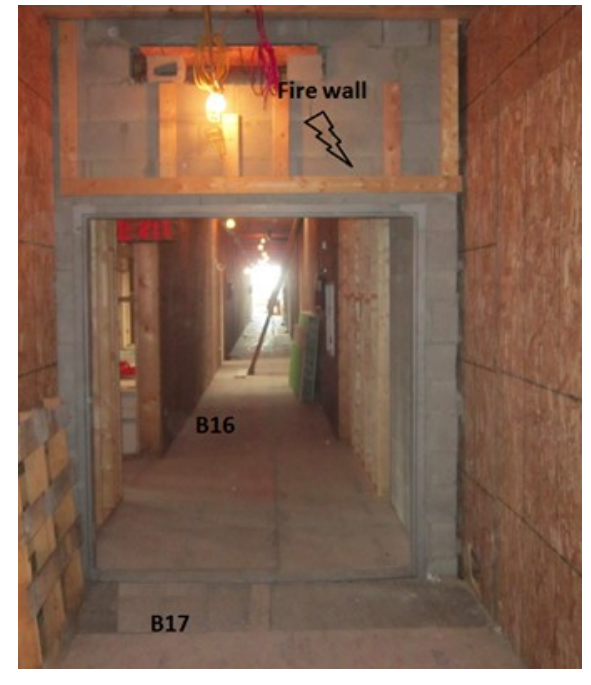

a) Fire wall between $\mathrm{B} 16$ and $\mathrm{B} 17$

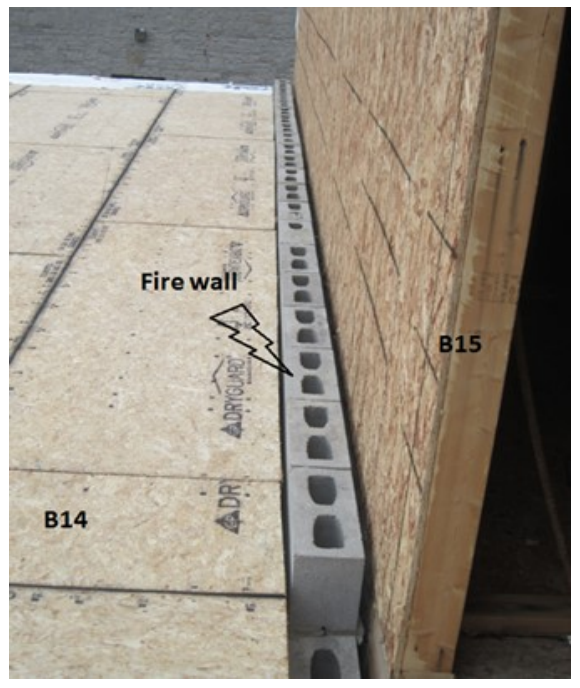

b) Fire wall between B14 and B15 


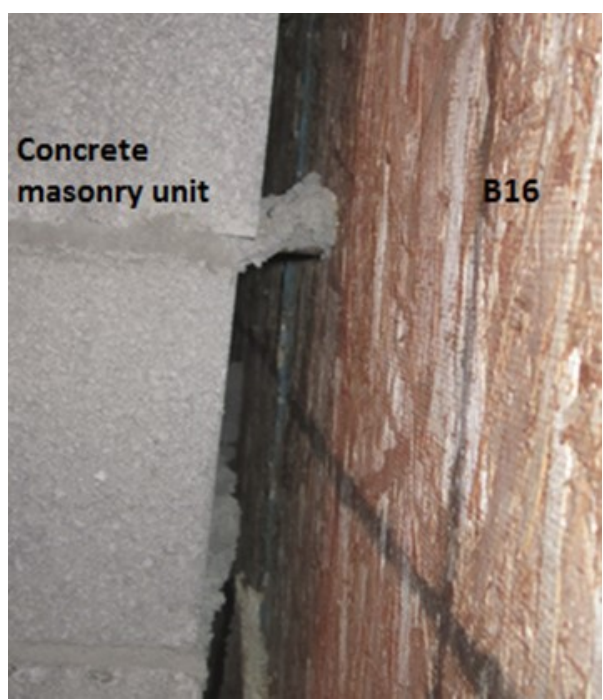

c) Connection between B16 and concrete masonry wall

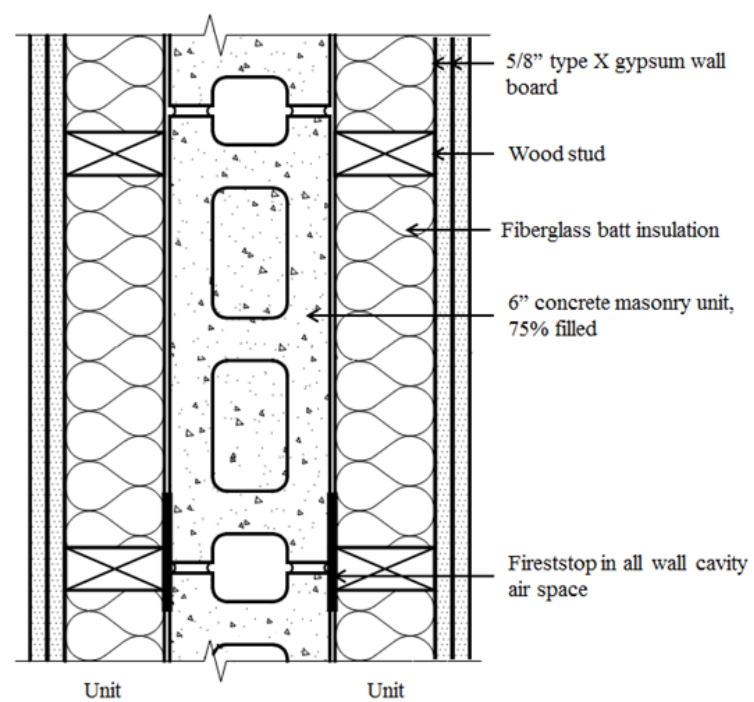

d) Two hours rated firewall assembly (between units of two buildings)

Figure 3-7 An example of masonry firewall-separations provided between buildings

The combined effect of the firewall and presence of non-structural components on their dynamic behavior of the buildings was also investigated.

\subsection{Fastener Joint Displacement Test}

The Canadian wood design standard (CSA-086 (2014)) provides an expression for fastener slip as a function of nail diameter when fasteners are used to attach wood sheathing to the studs. Additionally, a constant value of $0.76 \mathrm{~mm}$ is prescribed when Gypsum Wallboard (GWB) sheathing is used together with nail fasteners. Currently there is no fastner slip model available for the shearwalls in which GWB is fastened with the screws, which is the most common fastener type. The sheathing to stud fasteners are the main contributors to the deflection of a shearwall and determining their performance is key to having accurate models. 
In order to enhance the prediction of wall stiffness, selected fastener slip tests were conducted in the lab for Oriented Strand Board (OSB), plywood, and GWB sheathings. The results are used as input in some of the numerical models described in Chapter 5.

Three different test specimen configurations were used to evaluate load-slip behavior in joint displacement level tests, namely nail joints connecting plywood and OSB panels and screw joints connecting GWB to stud wall elements. These specimen configurations were selected to mimic the details found in the actual construction.

\subsubsection{Material}

The materials tested were obtained from the construction sites to represent, as much as possible, the actual condition and material properties of the joints. The Gypsum wallboard was type-x with a thickness of 5/8" $(15.9 \mathrm{~mm})$ attached to framing members with $1-5 / 8 "(41.28 \mathrm{~mm})$ screws. The sheathing materials consisted of $3 / 4 "$ (19.05 mm) plywood or 7/16" (12.7 mm) OSB nailed to the framing with 31/4" long common wire nails. The framing lumber used was 2x6" (38x140 mm), No. 2, SprucePine-Fir.

\subsubsection{Test Specimen}

Three specimens of each configuration were tested. The sheathing was cut into 4" (101.6 mm) wide and 10.5” (266.7 mm) long sections. A typical specimen (see Figure 
3-8) consisted of two 8 inch long $2 \times 6$ lumber pieces fastened to a sheathing section on both sides. One end of the lumber pieces contained the tested joint and the other end was considered to be the dummy end. Two holes were drilled into the lumber pieces using a 3/4" (19.1 mm) drill to attach the specimen to the steel side plate. The tested fasteners were placed 2" from the top end of the stud to prevent end distance failure.

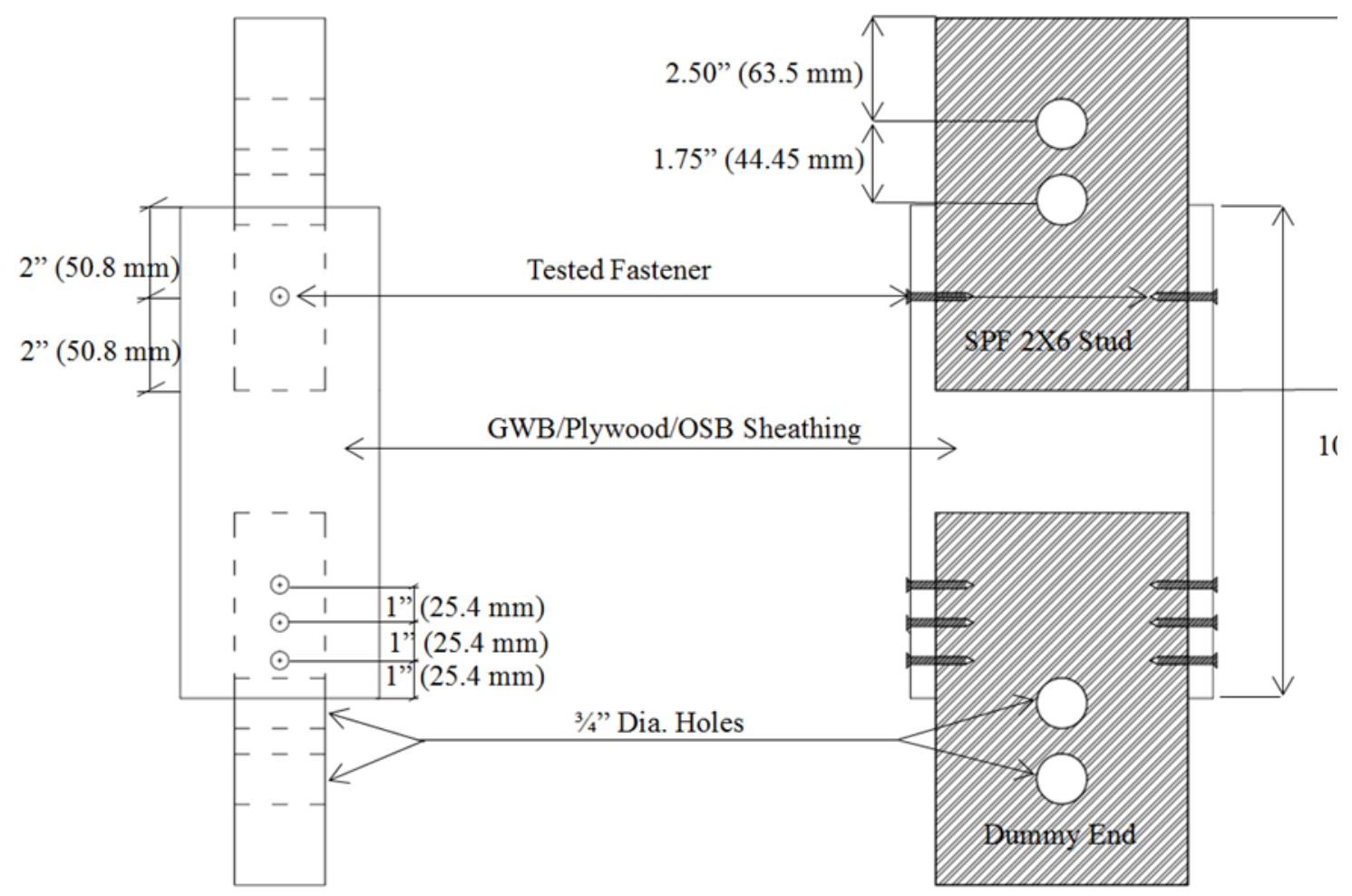

Figure 3-8 A typical joint level test specimen 


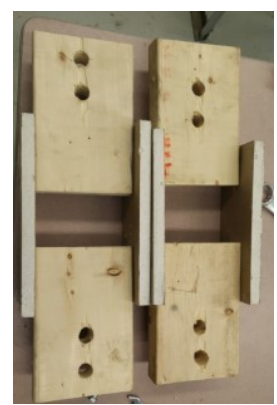

a) gypsum sheathing with screws and lumber pieces

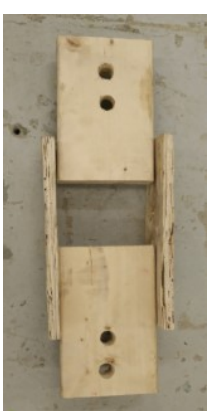

b) plywood sheathing with nails and lumber pieces

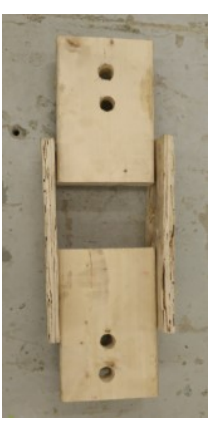

c) OSB sheathing with nails and lumber pieces

Figure 3-9 Typical test specimen of configuration 1, 2 and 3

\subsubsection{Test Procedure}

The joint level tests were carried out on a universal test machine (UTM), Figure 3-10, using a displacement-controlled monotonic protocol to obtain maximum displacement. The UTM is capable of applying displacements at a pre-programmed rate of $2.5 \mathrm{~mm} / \mathrm{minute}$ for the monotonic test (ASTM D1761-12). The test setup is equiped with a load-cell measuring the applied loads. The fastener slips between the sheathing and the lumber were recorded using linear variable differential transducers (LVDT). Two LVDTs were placed at each side of the test end of the specimen. 


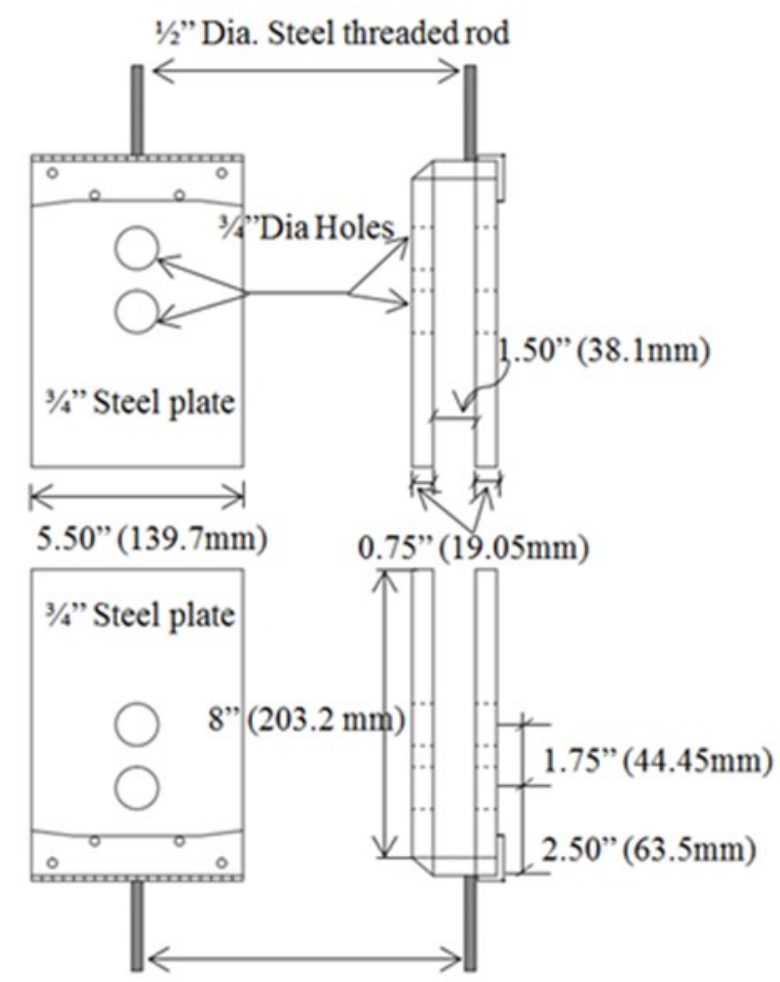

$1 / 2$ " Dia. Steel threaded rod

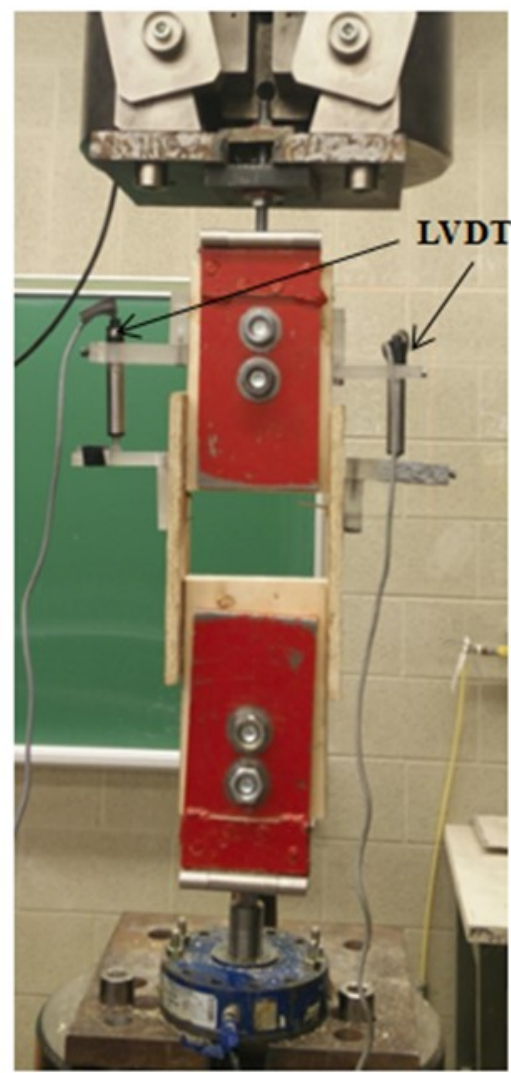

Figure 3-10 Test setup, universal testing machine (UTM) 


\section{CHAPTER 4}

\section{Global Results Extracted from AVM Records}

This chapter summarizes the ambient vibration test results obtained in this research project. This includes the fundamental periods and damping ratios database of lightframe and post-and-beam construction buildings. Subsequently, the results of buildings tested at multiple stages of construction and buildings separated by firewall are also presented.

\subsection{AVT Test Results}

Table 4-1 and Table 4-2 summarize the fundamental periods and damping ratios obtained for individual light-frame wood buildings tested in Phase 1 and Phase 2, respectively. Unidentified properties following the processing of AVM records are shown as hyphen "-" in the following tables. Although two significant digits are provided for damping ratios in the tables, such values are deemed very approximate due to simplifying assumptions in the record analysis (see Chapter 3).

Since several tested buildings were existing and completed prior to the commencement of the current project, they could not be tested in their Phase 1. Also, some buildings (B3, B28 and B29) were tested only in their Phase 1 because once a building is occupied, permission from a different source is required and access could 
not be ensured for those buildings.

Table 4-1 Measured natural periods and damping ratios of wood-frame buildings (Phase 1)

\begin{tabular}{|c|c|c|c|c|}
\hline \multirow{2}{*}{$\begin{array}{c}\text { Building } \\
\text { ID }\end{array}$} & \multicolumn{2}{|c|}{ Natural Period (s) } & \multicolumn{2}{c|}{$\begin{array}{c}\text { Estimated Modal Damping Ratio } \\
\text { (\%) }\end{array}$} \\
\cline { 2 - 5 } & Transverse & Longitudinal & Transverse & Longitudinal \\
\hline B1 & 0.31 & - & 1.5 & - \\
\hline B3 & 0.46 & 0.35 & 3.8 & 2.7 \\
\hline B4 & 0.37 & 0.29 & 2.4 & 1.7 \\
\hline B5 & 0.37 & 0.25 & 2.6 & - \\
\hline B6 & 0.44 & 0.31 & 3.9 & 4.1 \\
\hline B7 & 0.34 & 0.37 & 2.2 & 5 \\
\hline B22 & 0.26 & 0.32 & 2.0 & 2.8 \\
\hline B23 & 0.42 & 0.33 & 3.8 & 3.1 \\
\hline B24 & 0.53 & 0.31 & 4.0 & 3.0 \\
\hline B25 & 0.37 & 0.24 & 3.7 & 1.1 \\
\hline B28 & 0.26 & 0.29 & - & 2.2 \\
\hline B29 & 0.26 & 0.32 & 3.3 & 1.6 \\
\hline B30 & 0.24 & 0.13 & 3.6 & \\
\hline
\end{tabular}


Table 4-2 Measured natural periods and damping ratios of wood-frame buildings (Phase 2)

\begin{tabular}{|c|c|c|c|c|}
\hline \multirow{2}{*}{ Building ID } & \multicolumn{2}{|c|}{ Natural Period (s) } & \multicolumn{2}{|c|}{ Estimated Modal Damping Ratio (\%) } \\
\hline & Transverse & Longitudinal & Transverse & Longitudinal \\
\hline B1 & 0.20 & 0.29 & - & 6.0 \\
\hline B2 & 0.29 & 0.31 & 2.3 & 2.9 \\
\hline B4 & 0.37 & 0.29 & 2.5 & 1.8 \\
\hline B5 & 0.28 & 0.35 & 4.5 & 5.5 \\
\hline B6 & 0.20 & 0.19 & 4.3 & 2.4 \\
\hline B7 & 0.25 & 0.23 & 4.6 & 3.1 \\
\hline B8 & 0.40 & 0.25 & 2.3 & 2.2 \\
\hline B9 & 0.20 & 0.19 & 3.7 & - \\
\hline B12 & 0.29 & 0.32 & 2.1 & 2.3 \\
\hline B13 & 0.32 & 0.19 & 4.7 & 4.1 \\
\hline B22 & 0.18 & 0.14 & 3.1 & 4.6 \\
\hline B23 & 0.21 & 0.23 & 1.1 & 3.7 \\
\hline B24 & 0.35 & 0.29 & 1.9 & 1.1 \\
\hline B25 & 0.20 & 0.17 & 1.8 & 1.5 \\
\hline B30 & 0.20 & 0.12 & 1.9 & 1.3 \\
\hline B33 & 0.22 & 0.28 & 5.7 & - \\
\hline B34 & 0.24 & 0.28 & 3.6 & - \\
\hline B35 & 0.13 & - & - & - \\
\hline B36 & 0.15 & - & 7.3 & - \\
\hline B37 & 0.14 & - & - & - \\
\hline B38 & 0.12 & - & 4 & - \\
\hline B39 & 0.17 & - & 3.4 & - \\
\hline B40 & 0.11 & - & - & - \\
\hline B41 & - & 0.26 & - & 2.3 \\
\hline
\end{tabular}

From Table 4-1 and Table 4-2, it can be observed that the frequency ranges for all tested buildings were 1.9 to $7.7 \mathrm{~Hz}(0.53-0.13 \mathrm{~s})$ and 2.5 to $9.1 \mathrm{~Hz}(0.4-0.11 \mathrm{~s})$ for buildings tested in Phase 1 and Phase 2, respectively. Similarly, ranges found for damping ratio were (1.1-5.0) \% and (1.1-7.3) \% for Phase 1 and Phase 2 testing, respectively. 
An example of the mode shape analyzed in ARTeMIS Extractor (Structural Vibration Solutions, 2010a) can be seen in Figure 4-1. All mode shapes of the measured buildings are presented in Appendix B.

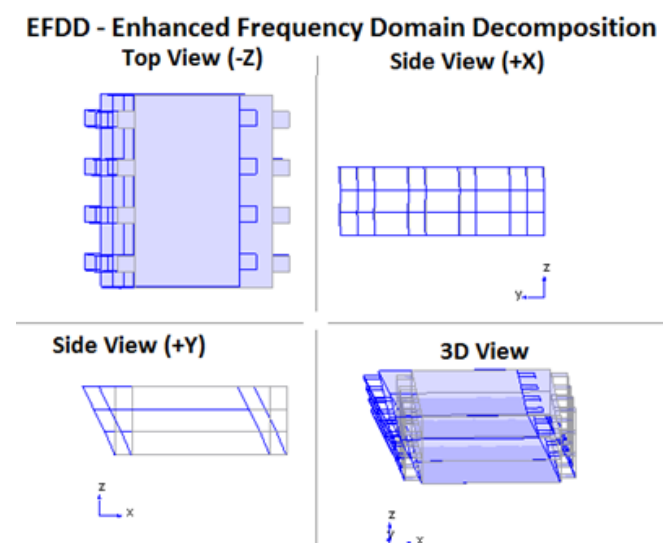

Transversal mode

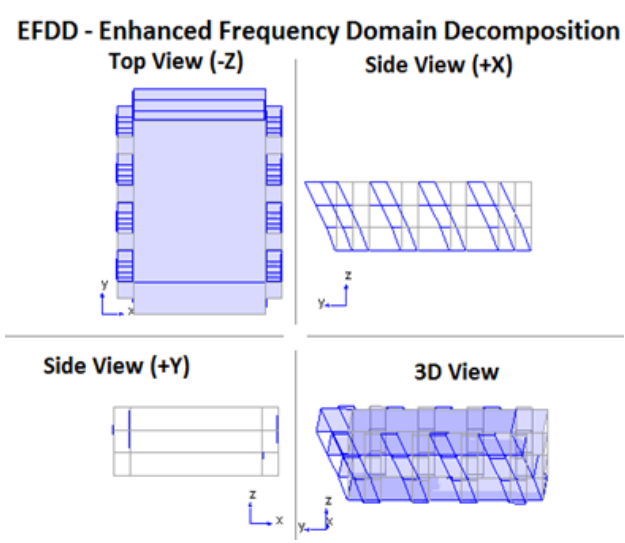

Longitudinal mode

Figure 4-1 Mode shapes of B8 (Phase 2)

In general it can be observed from Table 4-1 and Table 4-2 that the period in transverse direction is typically higher than that obtained for the same building in the longitudinal direction, however, some exceptions can also be seen. A more detailed discussion of these results is provided in Chapter 6. In general, higher damping values are observed for buildings tested in Phase 2, suggesting that wall finish materials such as drywalls, stucco, and plaster contribute to damping in light wood frame buildings. This seems reasonable since in wood building structures the energy dissipation mechanism is mainly contributed by friction and slippage in connections (Polensek and Schimel, 1991). 


\subsection{Effect of Firewall-Separation on the Dynamic Properties of Wood Buildings}

\subsubsection{Introduction and Methodology}

The dynamic properties of light-frame wood buildings have been assessed in the presence of firewall separation by employing ambient vibration measurements. Variations in the measured fundamental periods and corresponding sway mode shapes of each building were identified to investigate the influence of the connectivity between buildings in the presence of masonry firewalls. The approximate modal damping ratios of the buildings have been reported in every construction stage. The investigated buildings and their corresponding building components are shown in Figure 4-2.

All firewall-separated buildings were measured in their complete finished stage (Phase 2), two building complexes (B31-B32 and B14-B15-B16-B17) were further investigated at different construction stages.

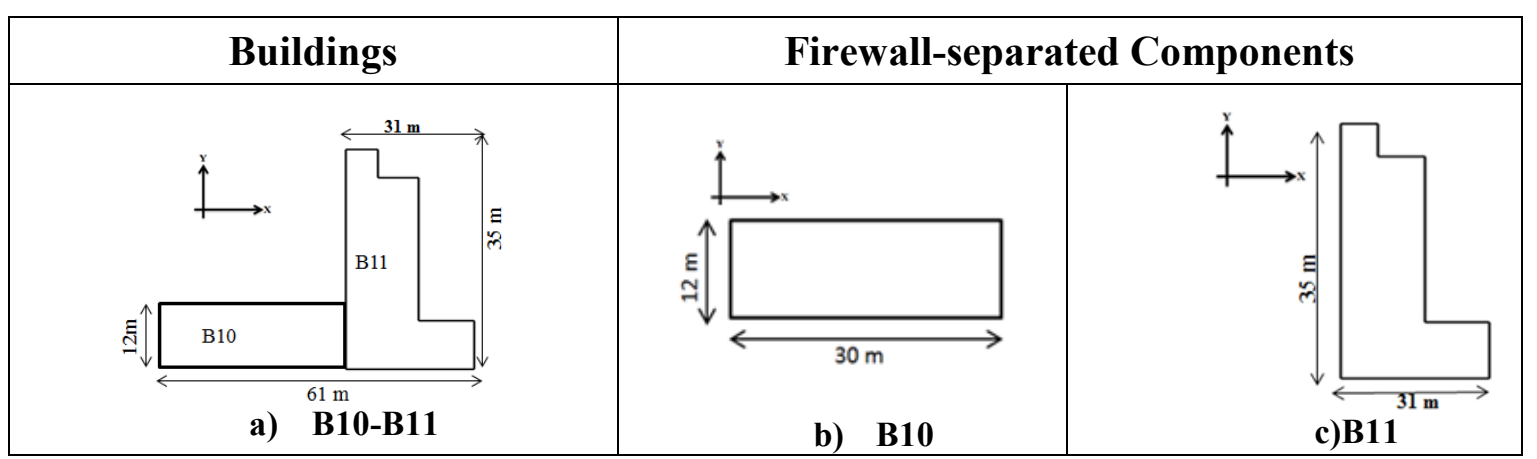




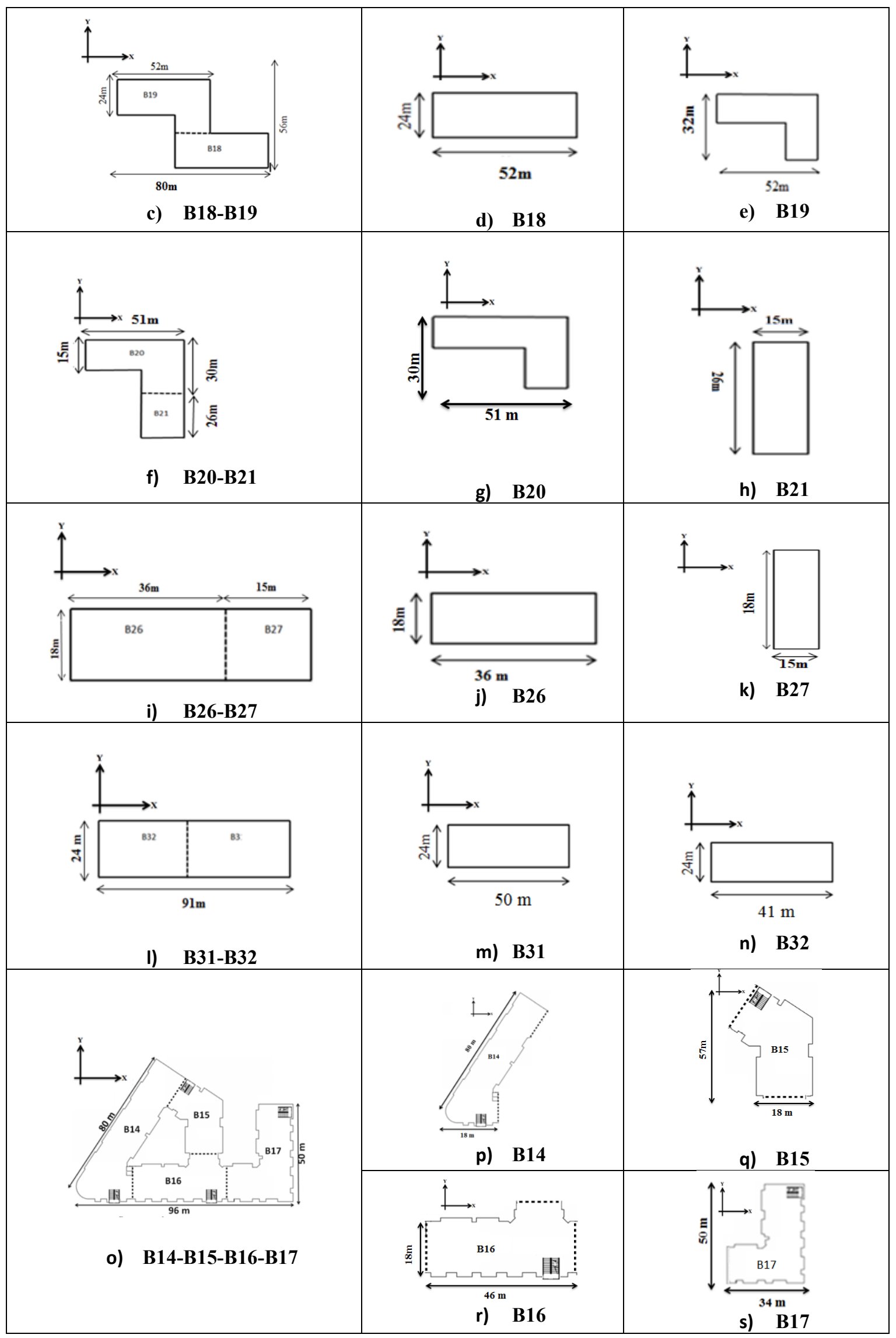

Figure 4-2 Firewall-separated buildings (Phase 2) 


\subsubsection{Results for Finished Construction Stage of Firewall-separated Buildings}

(Phase 2)

Measured fundamental periods and estimated damping ratios of the fire-separated buildings tested only in Phase 2 construction stage are provided in Table 4-3 to Table 4-6. Due to the irregular shape of the combined building in some cases, the period values are provided for a global coordinate system $(\mathrm{X}, \mathrm{Y})$ as defined in Figure 4-2. As mentioned before, unidentified properties are shown as hyphen "-" in the following tables. Mode shapes for all buildings are provided in Appendix B.

Table 4-3 Measured natural periods and damping ratios of B10, B11 and B10-B11

\begin{tabular}{|c|c|c|c|c|c|c|c|c|c|c|c|c|}
\hline \multirow{2}{*}{$\begin{array}{c}\text { Test } \\
\text { Stage }\end{array}$} & \multicolumn{6}{|c|}{ Natural Period (s) } & \multicolumn{6}{|c|}{ Estimated Damping Ratios (\%) } \\
\hline & \multicolumn{2}{|c|}{ B10 } & \multicolumn{2}{|c|}{ B11 } & \multicolumn{2}{|c|}{ B10-B11 } & \multicolumn{2}{|c|}{ B10 } & \multicolumn{2}{|c|}{ B11 } & \multicolumn{2}{|c|}{ B10-B11 } \\
\hline Phase & $\mathbf{X}$ & $\mathbf{Y}$ & $\mathbf{X}$ & $\mathbf{Y}$ & $\mathbf{X}$ & $\mathbf{Y}$ & $\mathbf{X}$ & $\mathbf{Y}$ & $\mathbf{X}$ & $\mathbf{Y}$ & $\mathbf{X}$ & $\mathbf{Y}$ \\
\hline 2 & 0.23 & 0.26 & 0.22 & 0.27 & 0.21 & 0.26 & - & 1.46 & 2.4 & 2.2 & - & 1.46 \\
\hline
\end{tabular}

Table 4-4 Measured natural periods and damping ratios of B18, B19 and B18-B19

\begin{tabular}{|c|c|c|c|c|c|c|c|c|c|c|c|c|}
\hline \multirow{2}{*}{$\begin{array}{c}\text { Test } \\
\text { Stage }\end{array}$} & \multicolumn{6}{|c|}{ Natural Period (s) } & \multicolumn{6}{|c|}{ Estimated Damping Ratios (\%) } \\
\hline & \multicolumn{2}{|c|}{ B18 } & \multicolumn{2}{|c|}{ B19 } & \multicolumn{2}{|c|}{ B18-B19 } & \multicolumn{2}{|c|}{ B18 } & \multicolumn{2}{|c|}{ B19 } & \multicolumn{2}{|c|}{ B18-B19 } \\
\hline & $\mathbf{X}$ & $Y$ & $\mathbf{X}$ & $Y$ & $\mathbf{X}$ & $\mathbf{Y}$ & $\mathbf{X}$ & $\mathbf{Y}$ & $\mathbf{X}$ & $\mathbf{Y}$ & $\mathbf{X}$ & $\mathbf{Y}$ \\
\hline $\begin{array}{c}\text { Phase } \\
2\end{array}$ & 0.19 & 0.24 & 0.18 & 0.23 & 0.19 & 0.21 & - & 3.4 & 1.4 & 1.2 & 1.2 & 1.1 \\
\hline
\end{tabular}

Table 4-5 Measured natural periods and damping ratios of B20, B21 and B20-B21

\begin{tabular}{|c|c|c|c|c|c|c|c|c|c|c|c|c|}
\hline \multirow{2}{*}{$\begin{array}{c}\text { Test } \\
\text { Stage }\end{array}$} & \multicolumn{6}{|c|}{ Natural Period (s) } & \multicolumn{6}{|c|}{ Estimated Damping Ratios (\%) } \\
\hline & \multicolumn{2}{|c|}{ B20 } & \multicolumn{2}{|c|}{ B21 } & \multicolumn{2}{|c|}{ B20-B21 } & \multicolumn{2}{|c|}{ B20 } & \multicolumn{2}{|c|}{ B21 } & \multicolumn{2}{|c|}{ B20-B21 } \\
\hline Phase & $\mathbf{X}$ & $\mathbf{Y}$ & $\mathbf{X}$ & $\mathbf{Y}$ & $\mathbf{X}$ & $\mathbf{Y}$ & $X$ & $Y$ & $\mathbf{X}$ & $Y$ & $\mathbf{X}$ & $\mathbf{Y}$ \\
\hline 2 & 0.26 & 0.23 & 0.27 & - & 0.26 & 0.24 & - & 0.8 & 1.4 & - & 1.9 & 2.8 \\
\hline
\end{tabular}

Table 4-6 Measured natural periods and damping ratios of B26, B27 and B26-B27

\begin{tabular}{|c|c|c|c|c|c|c|c|c|c|c|c|c|}
\hline \multirow{2}{*}{$\begin{array}{c}\text { Test } \\
\text { Stage }\end{array}$} & \multicolumn{6}{|c|}{ Natural Period (s) } & \multicolumn{6}{|c|}{ Estimated Damping Ratios (\%) } \\
\hline & \multicolumn{2}{|c|}{ B26 } & \multicolumn{2}{|c|}{ B27 } & \multicolumn{2}{|c|}{ B26-B27 } & \multicolumn{2}{|c|}{ B26 } & \multicolumn{2}{|c|}{ B27 } & \multicolumn{2}{|c|}{ B26-B27 } \\
\hline Phase & $\mathbf{X}$ & $\mathbf{Y}$ & $\mathbf{X}$ & $\mathbf{Y}$ & $\mathbf{X}$ & $\mathbf{Y}$ & $\mathbf{X}$ & $\mathbf{Y}$ & $\mathbf{X}$ & $\mathbf{Y}$ & $\mathbf{X}$ & $\mathbf{Y}$ \\
\hline 2 & - & 0.24 & 0.29 & 0.23 & 0.28 & 0.23 & - & 2.6 & 1.4 & 3.2 & 1.3 & 1.4 \\
\hline
\end{tabular}




\subsubsection{Results for Buildings at Various Construction Stages}

In this buildings test series, AVM was performed on two building complexes, one with a regular (B31-B32) and the other with irregular (B14-B15-B16-B17) building layout at different stages of their construction. The building complex geometry at the different construction stages and observations during each test are provided in Appendix C.

Table 4-7 to Table 4-9 show the measured fundamental periods and damping ratios for the two building complexes, and provide measured periods when the sensors were placed in either one of the individual buildings (e.g. B31) or spread out across the whole complex (e.g. B31-B32). The main goal was to investigate whether the two buildings should be considered as individual buildings or whether nominal connections to the firewall mean that the whole complex would behave as one building. The plan layout for the B31-B32 complex was always the same since buildings B31 and B32 were built simultaneously. Figure 4-3 shows the plan layout of complex B14-B15-B16-B17 at various stages of tests.

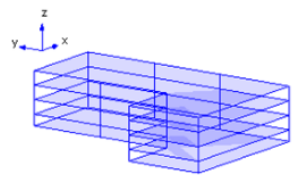

a) Test 1

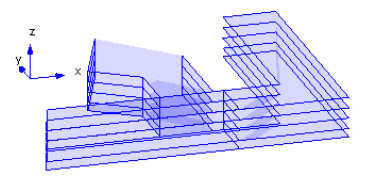

b) Test 2

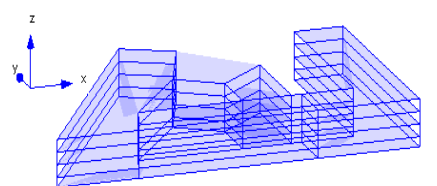

c) Test 3, Test 4, Test 5

Figure 4-3 Construction stages of building complex (B14-B15-B16-B17)

The construction details at each stage of construction are documented carefully and a 
numerical model was created to match the exact condition of each construction stage.

The modeling techniques and the results are presented and discussed in Chapter 5.

The results from all construction stages are used to validate the FE model developed in chapter 5 .

Table 4-9 summarizes the measured periods and damping ratios of the building complex in different stages of construction. For Test 1 the results of individual building B17 are the same as B14-B15-B16-B17.

Table 4-7 Measured natural periods and damping ratios of B31, B32 and B31-B32

\begin{tabular}{|c|c|c|c|c|c|c|c|c|c|c|c|c|}
\hline \multirow{3}{*}{$\begin{array}{c}\text { Test } \\
\text { Stage }\end{array}$} & \multicolumn{6}{|c|}{ Natural Period (s) } & \multicolumn{6}{|c|}{ Estimated Damping Ratios (\%) } \\
\hline & \multicolumn{2}{|c|}{ B31 } & \multicolumn{2}{|c|}{ B32 } & \multicolumn{2}{|c|}{ B31-B32 } & \multicolumn{2}{|c|}{ B31 } & \multicolumn{2}{|c|}{ B32 } & \multicolumn{2}{|c|}{ B31-B32 } \\
\hline & $\mathbf{X}$ & $\mathbf{Y}$ & $\mathbf{X}$ & $\mathbf{Y}$ & $\mathbf{X}$ & $\mathbf{Y}$ & $\mathbf{X}$ & $\mathbf{Y}$ & $\mathbf{X}$ & $\mathbf{Y}$ & $\mathbf{X}$ & $\mathbf{Y}$ \\
\hline 1 & 0.17 & 0.30 & 0.18 & 0.33 & 0.17 & 0.29 & 4.2 & 2.6 & 4.0 & 1.7 & 2.8 & 1.6 \\
\hline 2 & 0.18 & 0.33 & 0.19 & 0.35 & 0.18 & 0.29 & 1.1 & 1.4 & 5.8 & 3.2 & 3.1 & 3.6 \\
\hline 3 & 0.16 & 0.27 & 0.14 & 0.31 & \multicolumn{2}{|c|}{$\begin{array}{c}\text { Not } \\
\text { measured }\end{array}$} & 1.8 & 5.1 & 5.3 & 2.6 & \multicolumn{2}{|c|}{$\begin{array}{c}\text { Not } \\
\text { measured }\end{array}$} \\
\hline 4 & 0.16 & 0.30 & 0.15 & 0.30 & - & 0.31 & 2.8 & - & 1.4 & 3.6 & - & 3.6 \\
\hline 5 & 0.15 & 0.23 & 0.14 & 0.29 & 0.16 & 0.23 & 4.4 & 5.0 & - & 3.8 & 1.5 & 2.4 \\
\hline 6 & 0.16 & 0.26 & 0.17 & 0.27 & 0.16 & 0.24 & 1.3 & 4.3 & 1.3 & 5.1 & - & 4.2 \\
\hline 7 & 0.16 & 0.20 & 0.16 & 0.21 & 0.16 & 0.19 & 1 & 2.2 & 3.8 & 1.7 & 1 & - \\
\hline
\end{tabular}

Table 4-8 Measured natural periods of B14, B15, B16, B17 and B14-B15-B16-B17

\begin{tabular}{|c|c|c|c|c|c|c|c|c|c|c|}
\hline \multirow{3}{*}{$\begin{array}{c}\text { Test } \\
\text { Stage }\end{array}$} & \multicolumn{10}{|c|}{ Natural Period (s) } \\
\hline & \multicolumn{2}{|c|}{ B14 } & \multicolumn{2}{|c|}{ B15 } & \multicolumn{2}{|c|}{ B16 } & \multicolumn{2}{|c|}{ B17 } & \multicolumn{2}{|c|}{$\begin{array}{l}\text { B14-B15- } \\
\text { B16-B17 }\end{array}$} \\
\hline & $\mathbf{X}$ & $\mathbf{Y}$ & $\mathbf{X}$ & $\mathbf{Y}$ & $\mathbf{X}$ & $\mathbf{Y}$ & $\mathbf{X}$ & $\mathbf{Y}$ & $\mathbf{X}$ & $\mathbf{Y}$ \\
\hline 1 & \multicolumn{2}{|c|}{ Not built } & \multicolumn{2}{|c|}{ Not built } & \multicolumn{2}{|c|}{ Not built } & 0.41 & 0.33 & 0.41 & 0.33 \\
\hline 2 & \multicolumn{2}{|c|}{ Not built } & 0.35 & 0.28 & 0.35 & 0.41 & 0.35 & 0.31 & 0.35 & 0.41 \\
\hline 3 & 0.37 & 0.23 & 0.37 & - & 0.27 & 0.34 & 0.29 & 0.26 & 0.28 & 0.26 \\
\hline 4 & 0.32 & 0.22 & - & 0.29 & 0.25 & 0.28 & 0.26 & 0.22 & 0.21 & 0.23 \\
\hline 5 & 0.33 & 0.23 & 0.31 & 0.29 & 0.27 & 0.29 & 0.27 & 0.22 & 0.23 & 0.21 \\
\hline
\end{tabular}


Table 4-9 Measured estimated damping ratios of B14, B15, B16, B17 and B14-B15-B16-B17

\begin{tabular}{|c|c|c|c|c|c|c|c|c|c|c|}
\hline \multirow{2}{*}{$\begin{array}{c}\text { Test } \\
\text { Stage }\end{array}$} & \multicolumn{2}{|c|}{ B14 } & \multicolumn{2}{|c|}{ B15 } & \multicolumn{2}{c|}{ B16 } & \multicolumn{2}{c|}{ B17 } & \multicolumn{2}{|c|}{$\begin{array}{c}\text { B14-B15- } \\
\text { B16-B17 }\end{array}$} \\
\cline { 2 - 11 } & $\mathbf{X}$ & Y & X & Y & X & Y & X & Y & X & Y \\
\hline & \multicolumn{2}{|c|}{ Not built } & \multicolumn{2}{|c|}{ Not built } & \multicolumn{2}{|c|}{ Not built } & 2.6 & 2.0 & 2.6 & 2.0 \\
\hline 2 & \multicolumn{2}{|c|}{ Not built } & 3.5 & 1.6 & 3.9 & 2.6 & 3.8 & 3.5 & 3.8 & 3.5 \\
\hline 3 & 3.2 & 1.0 & 2.9 & - & 2.4 & 2.9 & 3.7 & 2.1 & 2.9 & 3.7 \\
\hline 4 & 2.5 & 2.6 & - & 2.1 & 1.7 & 4.1 & 3.2 & - & 4.1 & 3.2 \\
\hline 5 & 3.2 & 1.4 & 4.6 & 2.2 & 2.3 & 3.3 & 4.0 & 2.1 & 3.3 & 4.0 \\
\hline
\end{tabular}

\subsection{Results of Post-and-Beam Construction Buildings}

Table 4-10 summarized the dynamic properties extracted from the AVM records for post-and-beam construction buildings (M1 to M9) in their Phase 2 construction stage.

The corresponding mode shapes of the measured buildings are presented in Appendix

B.

Table 4-10 Fundamental periods and modal damping ratios extracted from AVM tests on postand-beam construction buildings (Phase 2)

\begin{tabular}{|c|c|c|c|c|}
\hline \multirow{2}{*}{ Building ID } & \multicolumn{2}{|c|}{ Natural Period (s) } & \multicolumn{2}{c|}{$\begin{array}{c}\text { Estimated Modal Damping } \\
\text { Ratio (\%)* }\end{array}$} \\
\cline { 2 - 5 } & Transverse & Longitudinal & Transverse & Longitudinal \\
\hline M1 & 0.28 & 0.31 & - & 1.8 \\
\hline M2 & 0.50 & 0.56 & 4 & 4.2 \\
\hline M3 & 0.50 & 0.73 & 3.5 & 4.6 \\
\hline M4 & 0.39 & 0.46 & 2.4 & 3.0 \\
\hline M5 & 0.62 & - & 1.7 & - \\
\hline M6 & 0.22 & 0.33 & 2.1 & 1.1 \\
\hline M7 & 0.25 & 0.40 & 2.8 & 4.6 \\
\hline M8 & 0.50 & 0.23 & 6.7 & - \\
\hline M9 & 0.43 & 0.26 & 6.1 & 1.4 \\
\hline
\end{tabular}




\subsection{Output of Typical Load-Slip Behavior Tests}

For the three sets of test specimen configurations considered, failure consisted of crushing in the wood member, crushing of gypsum wall board member and yielding of steel fasteners.

Figure 4-4a) shows a typical load-slip behaviour (average of the three test results), of the screw size of $1-5 / 8 "(41.28 \mathrm{~mm})$ used to fastened gypsum sheathing pieces of type x 5/8”(15.9mm) with lumber pieces.

Figure 4-4b) and Figure 4-4c) show typical load-slip behavior of test specimens (average of three test results), where common wire nail (31/4" long) used to fastened plywood sheathing and OSB sheathing with lumber. The average displacement from the two LVDTs was determined and the measured load was divided by a factor of 2 to obtain the force per fastener.
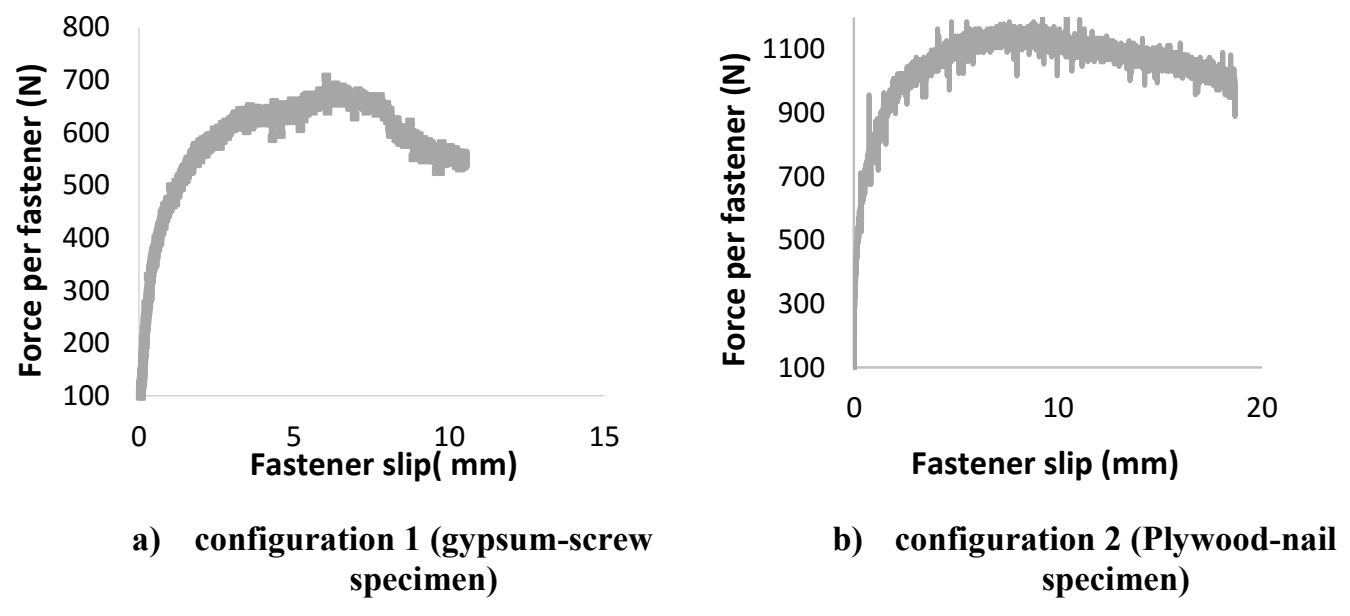


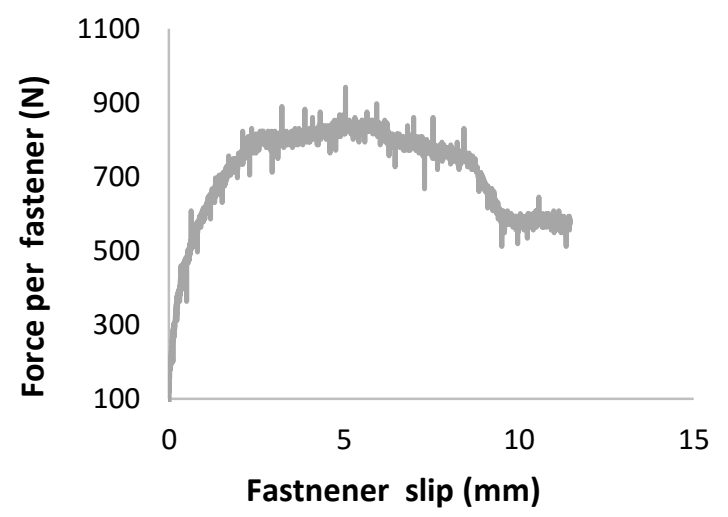

c) configuration 3 (OSB-nail specimen)

Figure 4-4 Typical load-slip behavior of test 


\section{CHAPTER 5}

\section{Numerical Modelling}

\subsection{Model Description}

Selected buildings from the database were modeled in detail using the commercially available software SAP2000® (Computers and Structures, 2014, 2016). The choice of these buildings was made based on the availability of detailed information obtained from the structural drawings. The goal of this part of the study is to develop a simplified analytical model that would mimic the performance of light frame buildings at a level of loading consistent with that experienced by the structure when AVT is conducted (i.e. very low levels of vibration). Appropriate modelling techniques have been suggested in the literature, where it is assumed that bending deflection of stud framing members and rigid body rotation can be ignored when predicting the lateral response (e.g. Casagrande et al. 2015, Källsner and Girhammer, 2009). Next, modeling considerations are discussed using building B1 model as an illustrative example.

Simplified 3D linear elastic models were created for the multi-storey buildings tested in order to determine the fundamental sway period in each orthogonal geometric direction. The structural model is assumed to be pinned at its support, and the floor 
diaphragms are assumed to be rigid. The building masses were lumped at each floor level. Shearwalls were modeled using horizontal linear elastic links, as shown in Figure 5-1.

The masonry firewalls and diaphragms were modeled using shell elements. Material property of masonry wall based on unit strength and mortar type was obtained from the material design standard (CSA-A179-04).

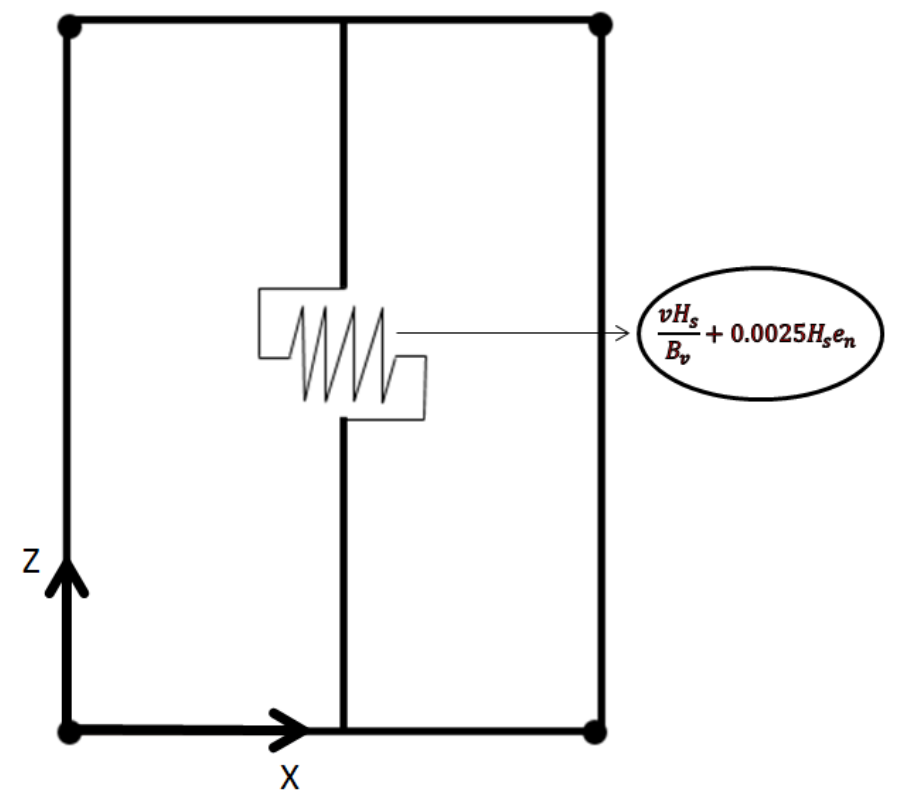

Figure 5-1 Typical shear wall model with $K_{(0-10) \%}$

The in-plane lateral stiffness of the wood shearwalls was estimated using the deflection attributed to the second and third terms of the deflection equation provided in the Canadian timber design standard, CSA O86 Engineering Design in Wood (CSA, 2014), reproduced in Equation 5-1. 


$$
\Delta_{s w}=\frac{2 v H_{s}{ }^{3}}{3 E A L_{s}}+\frac{v H_{s}}{B_{v}}+0.0025 H_{s} e_{n}+\frac{H_{s}}{L_{s}} d_{a}
$$

Where $\Delta_{s w}$ is the total lateral in-plane deflection, $v$ is applied shear force per unit width length $(\mathrm{N} / \mathrm{mm}), H_{s}$ is wall height $(\mathrm{mm}), E$ is the modulus of elasticity of end studs (MPa), $A$ is the cross-sectional area of end studs $\left(\mathrm{mm}^{2}\right), L_{S}$ is the width length of shear wall segment $(\mathrm{mm}), B_{v}$ is the through-thickness shear rigidity of sheathing panel $(\mathrm{N} / \mathrm{mm})$, and $d_{a}$ is the horizontal deflection due to anchorage details such as rotation and slip at hold-down connections (mm).

$e_{n}$ is the nail slip at a particular load per nail $(\mathrm{mm})$ and calculated as shown in Equation 5-2.

$$
e_{n}=\left[\frac{0.013 v s}{d_{f}^{2}}\right]^{2}
$$

In Equation 5-2, $v$ represents shear force per unit length $(\mathrm{N} / \mathrm{mm}), \mathrm{s}$ is the nail spacing at panel edges of shear wall $(\mathrm{mm})$, and $d_{f}$ is fastener's diameter $(\mathrm{mm})$.

CSA-2014 defines $e_{n}$ value as $0.76 \mathrm{~mm}$ for dry lumber with gypsum wall board. In current research values for $e_{n}$ for gypsum wall board were obtained from test results where the shear wall configuration matches with the test specimen configuration, however for the buildings with different shear wall configuration, $e_{n}$ was obtained using exponential empirical model equation for joints fastened with screws developed by (Lafontaine, 2015). The model accounts for gypsum wall board density $\left(\gamma_{G W B}\right)$ and fasteners' diameters $\left(d_{s}\right) \cdot v_{f}$ is the load per fastener $(\mathrm{N})$. 


$$
e_{n}=\left(4.92-0.42 \gamma_{G W B}\right)\left[\frac{0.016 v_{f}}{d_{s}^{1.33}}\right]^{5.5}
$$

The developed building models were validated using ambient vibration field results. For this purpose, the initial stiffness of a shear walls, $\mathrm{K}_{(0-10) \% \text {, was determined and }}$ used to represent the level of loading at ambient conditions. Stiffness and masses were calculated, for bare frame conditions to allow comparison with Phase 1 results, and the contribution of gypsum sheathing and other finishes (for mass and stiffness) was considered for Phase 2 modelling. A Simplified 3D linear elastic model of building B1 is shown in Figure 5-2.

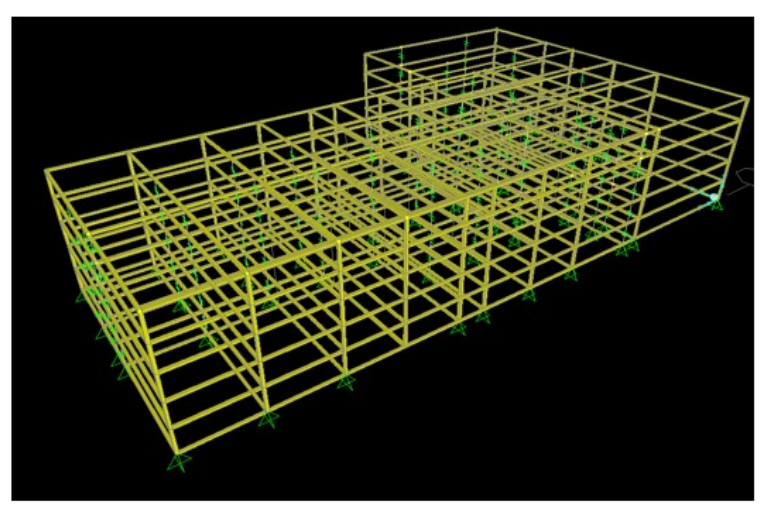

Figure 5-2 3D model of B1 with $K_{(0-10) \%}$

Once the FE models of measured buildings were calibrated with field results at

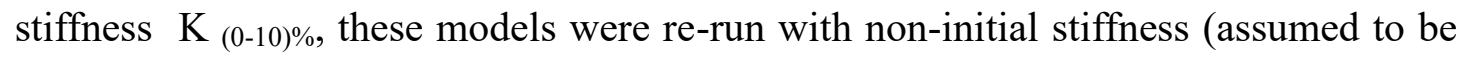
$\left.\mathrm{K}_{(10-40) \%}\right)$, in order to predict the fundamental period of wood buildings exposed to seismic action. The validity of this assumption will be discussed in Chapter 6 by comparing the results obtained from the model runs with those found in the literature. 
The models are modified to capture the vertical effect of holdowns (activated during an earthquake) by providing a vertical spring representative of the hold-downs stiffness. A typical shear wall model with non-initial stiffness $\left(\mathrm{K}_{(10-40) \%}\right)$ is shown in Figure 5-3.

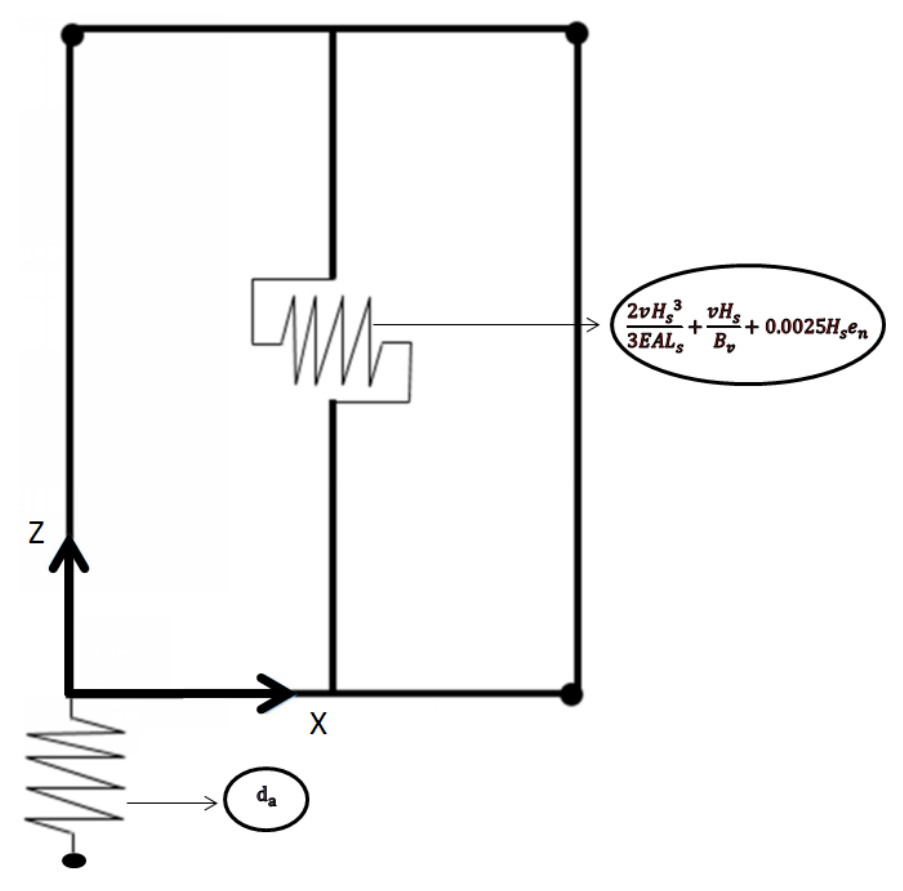

Figure 5-3 Typical shear wall model with stiffness $\mathbf{K}_{(10-40) \%}$

Three different stiffness models SM1, SM2, and SM3, were created to investigate their suitability to capture the seismic level period.

Stiffness model SM1 is created using all four terms of Equation 5-1 while models SM2 and SM3 additionally include cumulative terms (APEGBC 2009). In stiffness model SM2, the effect of cumulative frame bending without the rotational effects of the lower stories was considered, the first term of Equation 5-1 was modified as 
shown below,

$$
\Delta_{b, i}=\left[\frac{M_{i+1} H^{2}}{2(E I)_{i}}+\frac{V_{i} H^{3}}{3(E I)_{i}}\right]
$$

Where, $M_{i}$ is over turning moment, $V_{i}$ is an inter-story shear force $(E I)_{i}$ is total bending rigidity of the shear wall under consideration.

In model SM3, the stiffness of wood shear wall is calculated by incorporating the effect of both cumulative frame bending, and the rotational effects of the lower stories. The first and last terms of Equation 5-1 were modified as shown in Equation 5-5 and Equation 5-6 respectively,

$$
\Delta_{b, i}=\left[\frac{M_{i+1} H^{2}}{2(E I)_{i}}+\frac{V_{i} H^{3}}{3(E I)_{i}}\right]+H_{i}\left(\sum_{1}^{i-1} \theta_{j}\right)
$$

Where, $\theta_{j}$ is the angle between tangents to the elastic deflection curve at the bottom and top of the $\mathrm{i}^{\text {th }}$ storey.

$$
\Delta_{h d, i}=H_{i} \alpha_{i}+H_{i}\left(\sum_{1}^{i-1} \alpha_{j}\right)
$$

Where, $\alpha_{i}=\left(d_{a}\right)_{i} / L_{s}$ for small angles and $\left(d_{a}\right)_{i}$ is total vertical elongation of the wall anchorage system at the $\mathrm{i}^{\text {th }}$ story.

\subsection{Numerical Modelling Results}

Fundamental periods computed with SAP 2000 are shown in Table 5-1 and Table 5-2 Mode shapes illustration in two orthogonal directions is provided in Appendix D. 
Table 5-1 FE model results of Phase 1 buildings

\begin{tabular}{|c|c|c|c|}
\hline \multirow{2}{*}{ Buildings } & Building Height & \multicolumn{2}{|c|}{ T (sec) } \\
\cline { 3 - 4 } & $(\mathbf{m})$ & Trans & Long \\
\hline B1 & 15.0 & 0.34 & 0.32 \\
\hline B5 & 18.1 & 0.42 & 0.37 \\
\hline B6 & 14.2 & 0.46 & 0.33 \\
\hline B7 & 14.9 & 0.37 & 0.38 \\
\hline B25 & 10.11 & 0.39 & 0.25 \\
\hline B31-B32 & 12.4 & 0.32 & 0.19 \\
\hline
\end{tabular}

Table 5-2 FE model results of Phase 2 buildings

\begin{tabular}{|c|c|c|c|}
\hline \multirow{2}{*}{ Buildings } & Building Height & \multicolumn{2}{|c|}{ T (sec) } \\
\cline { 3 - 4 } & $(\mathbf{m})$ & Trans & Long \\
\hline B1 & 15.0 & 0.26 & 0.34 \\
\hline B5 & 18.1 & 0.30 & 0.40 \\
\hline B6 & 14.2 & 0.22 & 0.23 \\
\hline B7 & 14.9 & 0.32 & 0.28 \\
\hline B9 & 12.4 & 0.22 & 0.28 \\
\hline B22 & 12.3 & 0.19 & 0.17 \\
\hline B25 & 10.11 & 0.22 & 0.2 \\
\hline B18-B19 & 16.7 & 0.25 & 0.26 \\
\hline B20-B21 & 15.8 & 0.27 & 0.28 \\
\hline B26-B27 & 12.4 & 0.27 & 0.38 \\
\hline B31-B32 & 12.4 & 0.21 & 0.19 \\
\hline B14-B15-B16-B17 & 14.3 & 0.25 & 0.23 \\
\hline
\end{tabular}

Buildings that were tested at different stages of construction had to be modelled at the exact point of time they were tested. The results are provided below in Table 5-3. Mode shapes are provided in Appendix D. Discussion about the field and computed periods is provided in Chapter 6 . 
Table 5-3 Computed periods of B31, B32, and B31-B32

\begin{tabular}{|c|c|c|c|c|c|c|}
\hline \multirow{3}{*}{$\begin{array}{c}\text { Tests } \\
\#\end{array}$} & \multicolumn{6}{|c|}{ Period (s) } \\
\hline & \multicolumn{2}{|c|}{ B31 } & \multicolumn{2}{|c|}{ B32 } & \multicolumn{2}{|c|}{ B31-B32 } \\
\hline & $\mathbf{X}$ & $\mathbf{Y}$ & $\mathbf{X}$ & $\mathbf{Y}$ & $\mathbf{X}$ & $\mathbf{Y}$ \\
\hline 1 & 0.19 & 0.33 & 0.20 & 0.36 & 0.19 & 0.31 \\
\hline 2 & 0.19 & 0.36 & 0.20 & 0.38 & 0.19 & 0.32 \\
\hline 3 & 0.18 & 0.30 & 0.20 & 0.38 & 0.18 & 0.29 \\
\hline 4 & 0.18 & 0.29 & 0.17 & 0.33 & 0.16 & 0.35 \\
\hline 5 & 0.17 & 0.26 & 0.17 & 0.33 & 0.16 & 0.23 \\
\hline 6 & 0.19 & 0.31 & 0.19 & 0.31 & 0.18 & 0.28 \\
\hline 7 & 0.19 & 0.31 & 0.18 & 0.29 & 0.20 & 0.30 \\
\hline 8 & 0.19 & 0.24 & 0.20 & 0.25 & 0.19 & 0.22 \\
\hline
\end{tabular}

Table 5-4 provides computed periods of individual buildings (B14, B15, B16, and

B17) and four individual buildings measured as one complex (B14-B15-B16-B17).

Table 5-4 Measured natural periods of B14, B15, B16, B17 and B14-B15-B16-B17

\begin{tabular}{|c|c|c|c|c|c|c|c|c|c|c|}
\hline \multirow{3}{*}{$\begin{array}{c}\text { Test } \\
\#\end{array}$} & \multicolumn{10}{|c|}{ Natural Period (s) } \\
\hline & \multicolumn{2}{|c|}{ B14 } & \multicolumn{2}{|c|}{ B15 } & \multicolumn{2}{|c|}{ B16 } & \multicolumn{2}{|c|}{ B17 } & \multicolumn{2}{|c|}{$\begin{array}{l}\text { B14-B15- } \\
\text { B16-B17 }\end{array}$} \\
\hline & $\mathbf{X}$ & $\mathbf{Y}$ & $\mathbf{X}$ & $\mathbf{Y}$ & $\mathbf{X}$ & $\mathbf{Y}$ & $\mathbf{X}$ & $\mathbf{Y}$ & $\mathbf{X}$ & $\mathbf{Y}$ \\
\hline 1 & \multicolumn{2}{|c|}{ Not built } & \multicolumn{2}{|c|}{ Not built } & \multicolumn{2}{|c|}{ Not built } & 0.43 & 0.34 & 0.43 & 0.34 \\
\hline 2 & \multicolumn{2}{|c|}{ Not built } & 0.37 & 0.30 & 0.39 & 0.45 & 0.44 & 0.34 & 0.37 & 0.44 \\
\hline 3 & 0.42 & 0.29 & 0.43 & 0.31 & 0.30 & 0.36 & 0.35 & 0.27 & 0.30 & 0.28 \\
\hline 4 & 0.41 & 0.28 & 0.39 & 0.38 & 0.30 & 0.36 & 0.33 & 0.28 & 0.25 & 0.24 \\
\hline 5 & 0.41 & 0.28 & 0.39 & 0.38 & 0.30 & 0.36 & 0.33 & 0.28 & 0.25 & 0.23 \\
\hline
\end{tabular}




\section{CHAPTER 6}

\section{Discussion of Results}

\subsection{General}

In this chapter the experimental results are discussed and compared to those obtained from the literature and existing expressions from building codes. The effect of nonstructural components, especially the effect of firewall separation between buildings, is also discussed. Detailed building-level numerical models are validated using buildings with known construction details and the models are then used to conduct a parametric study to establish stiffness levels that are suitable for calculating periods for wind and seismic design.

\subsection{Experimental Results and Discussion}

\subsubsection{Observation on Measured Periods and Comparison to Literature and Established Code Equations}

The periods of all measured buildings were documented in both the longitudinal and transverse directions. In seismic design it is typical to provide the same capacity and stiffness of shear walls in the two orthogonal directions since the base shear is a function of the building mass, and the period is therefore assumed to be similar in the 
two main directions. However due to differences in geometry, it is anticipated that the building would have different horizontal stiffness values and therefore different natural periods in the two main directions.

The measured period results from the experimental program using AVT technique can be seen in Figure 6-1 and Figure 6-2, as a function of building height $(\mathrm{m})$ in the transverse and longitudinal directions of Phase 1 and Phase 2, respectively. Height is chosen here because it is typically the only variable used to describe building periods in building codes (e.g. NBCC 2015; ASCE 2005; BSSC 2003; SEAOC 1999). Significant scatter is observed in both phases, which clearly indicates that relying on the building height alone to describe the building period is not sufficient to provide accurate estimates. From Figure 6-1 it can be seen that, in general, the period in the transverse direction is greater than that obtained for the same building in the longitudinal direction for Phase 1, where only the structural components of the buildings are present. This trend is less clear when all non-structural components are installed in Phase 2, as seen in Figure 6-2. In other words, although for the finished buildings the period in the two main orthogonal directions is observed to be similar, once the building undergoes significant shaking and once the non-structural components experience some damage, the building period elongation in the two directions may be different. 


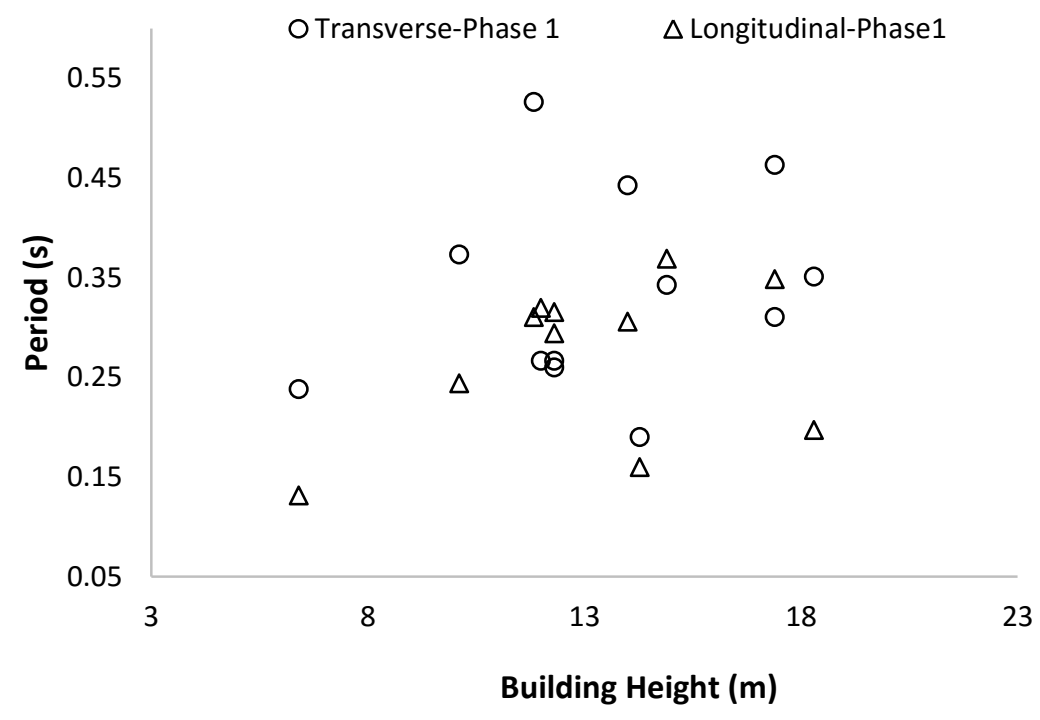

Figure 6-1 Measured fundamental periods vs. building height in Phase 1 construction stage

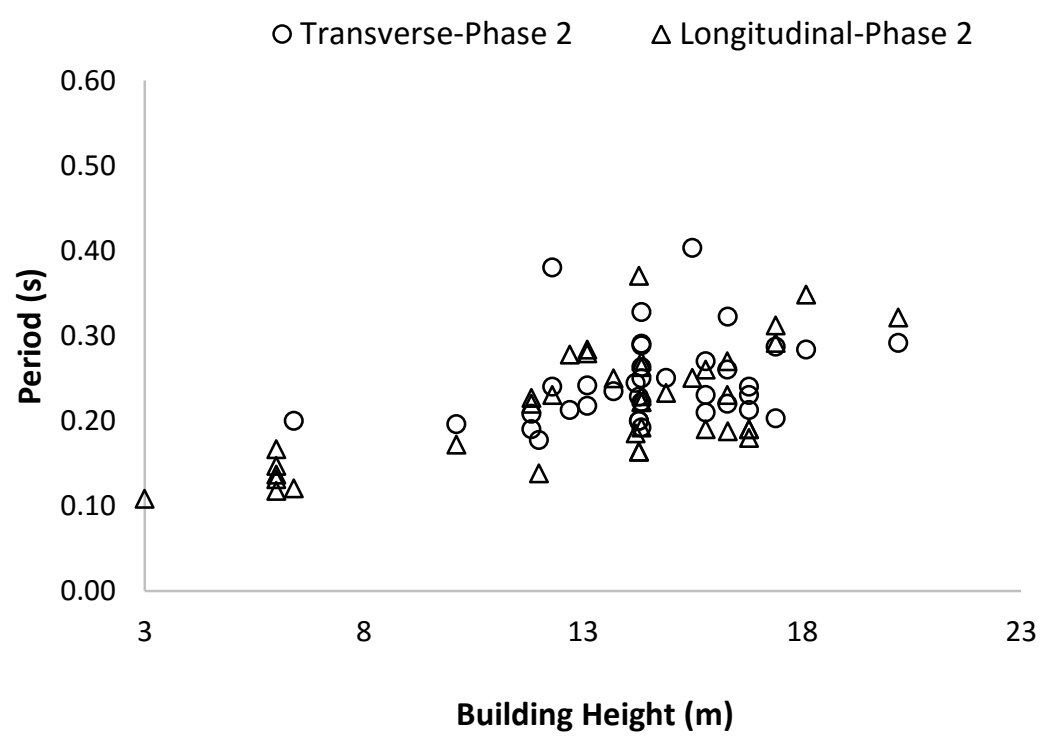

Figure 6-2 Measured fundamental period vs. building height in Phase 2 construction stage

The fundamental periods measured in the current study (AV) together with test results collected from the literature for ambient vibration (AV), forced vibration (FV), and 
shake table (ST) tests are plotted against building height, as shown in Figure 6-3 and Figure 6-4 Fundamental periods available in the literature and from current study vs. building height (Phase 2). As expected, the wide scatter in the data persists.

For Phase 1 buildings, the data points collected during the current study seem indistinguishable from those obtained from the literature, especially those obtained from AV testing. Also, the NBCC period equation seems to provide a very rough average estimate of the measured data. In Phase 2, the measured data clusters around the building code equation for low rise buildings (1-2 storey), whereas for taller buildings the scatter is significantly larger. The lack of fit between the measured data points and that generated by the building code is not surprising, considering that the code period was developed based on measurements during "moderate" level of ground shaking based on records from reinforced concrete and steel buildings only.

With a few exceptions, the data measured using AVT (including those from the current study) produce lower period values than those measured during FVT or shake table simulations. The difference is especially pronounced for taller buildings due to softening of the lateral load resisting system by increasing the amplitude of shaking. 


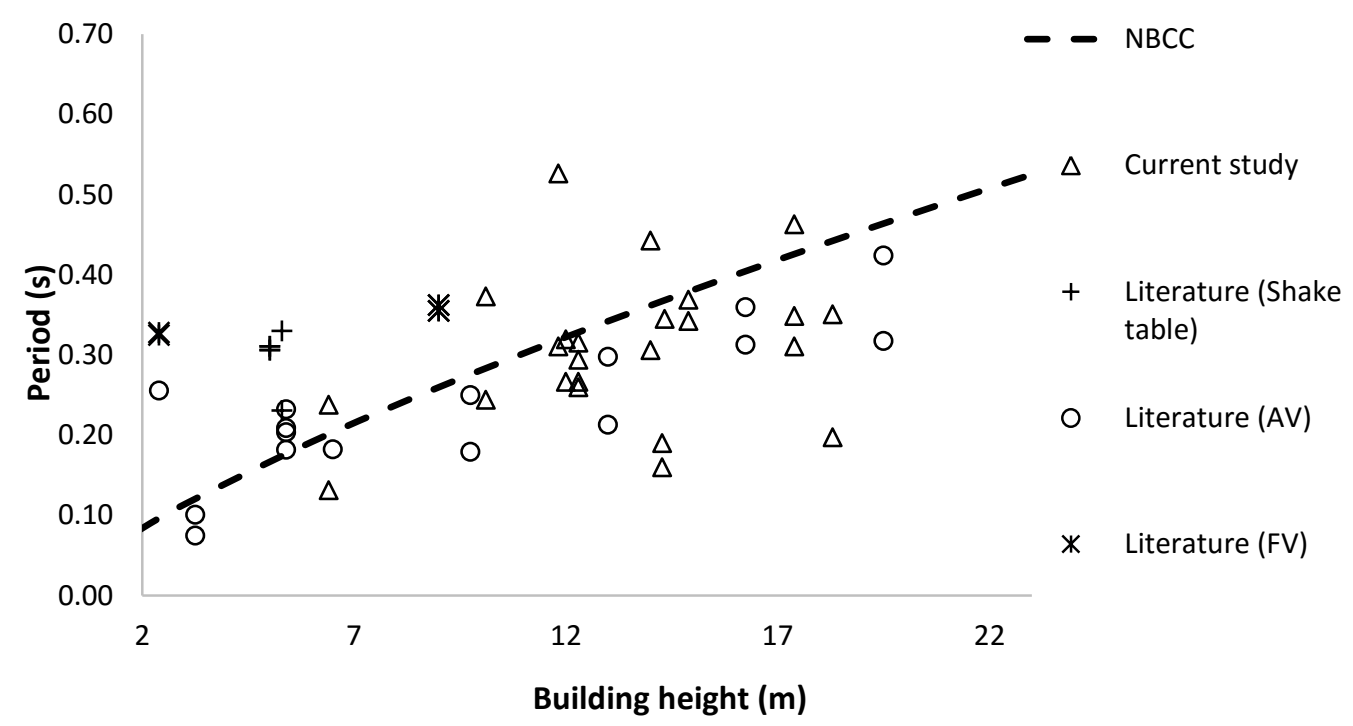

Figure 6-3 Fundamental periods available in the literature and from current study vs. building height (Phase 1)

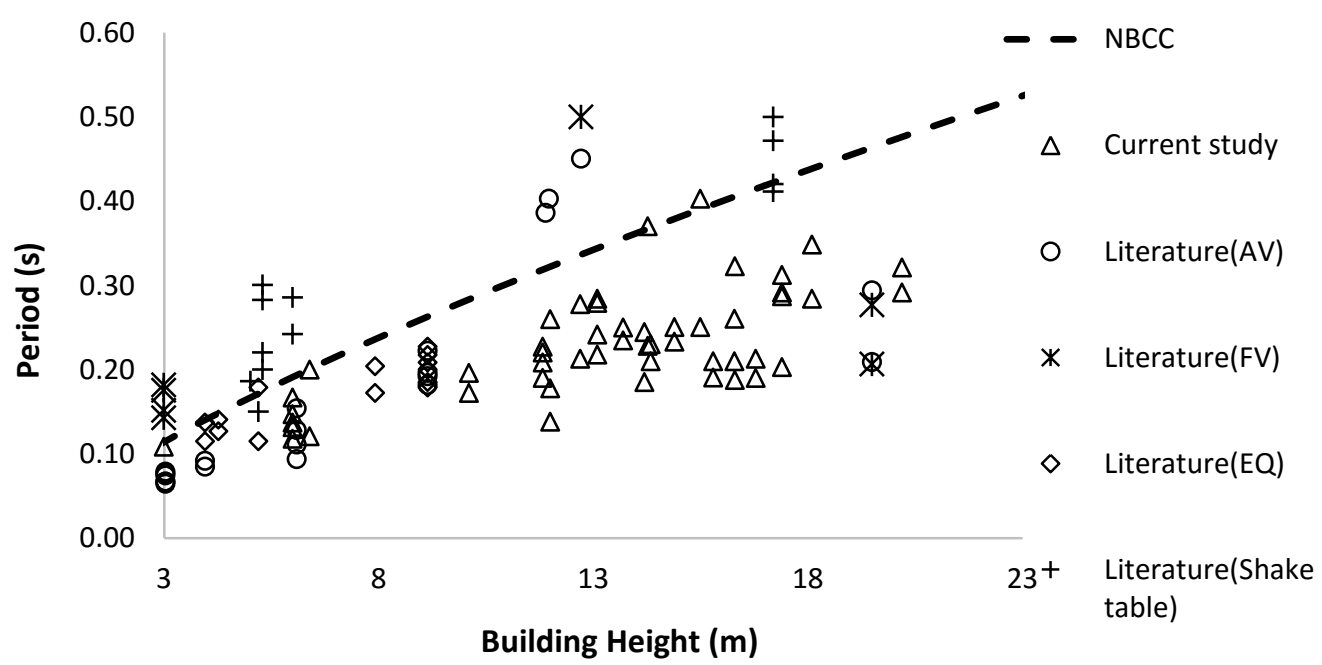

Figure 6-4 Fundamental periods available in the literature and from current study vs. building height (Phase 2)

Figure 6-4 Fundamental periods available in the literature and from current study vs. building height (Phase 2) also shows that the periods obtained from the current study are consistent with those reported in the literature for ambient vibration 
measurements. Data obtained through shake table and FVT records show higher period values. This observation is consistent with the expectation that the fundamental period of a structure increases with the excitation amplitude (e.g. Udwadia and Trifunac 1974) due to decrease in lateral stiffness (softening behavior) as the amplitude of lateral displacement increases and causes slight damage and/or nonlinear response.

The results from the current study were also compared to an expression developed based on data points obtained during low level earthquake shaking and (FV) test results (Camelo, 2003). Figure 6-5 shows a best fit line through the AVT data from the current study, as well as the same best fit line modified using Kharrazi's (2006) models to predict frequencies at low and high level ground shaking (Equation 2-6 and Equation 2-7). Also plotted in Figure 6-5 is NBCC building period equation for shear walls. 


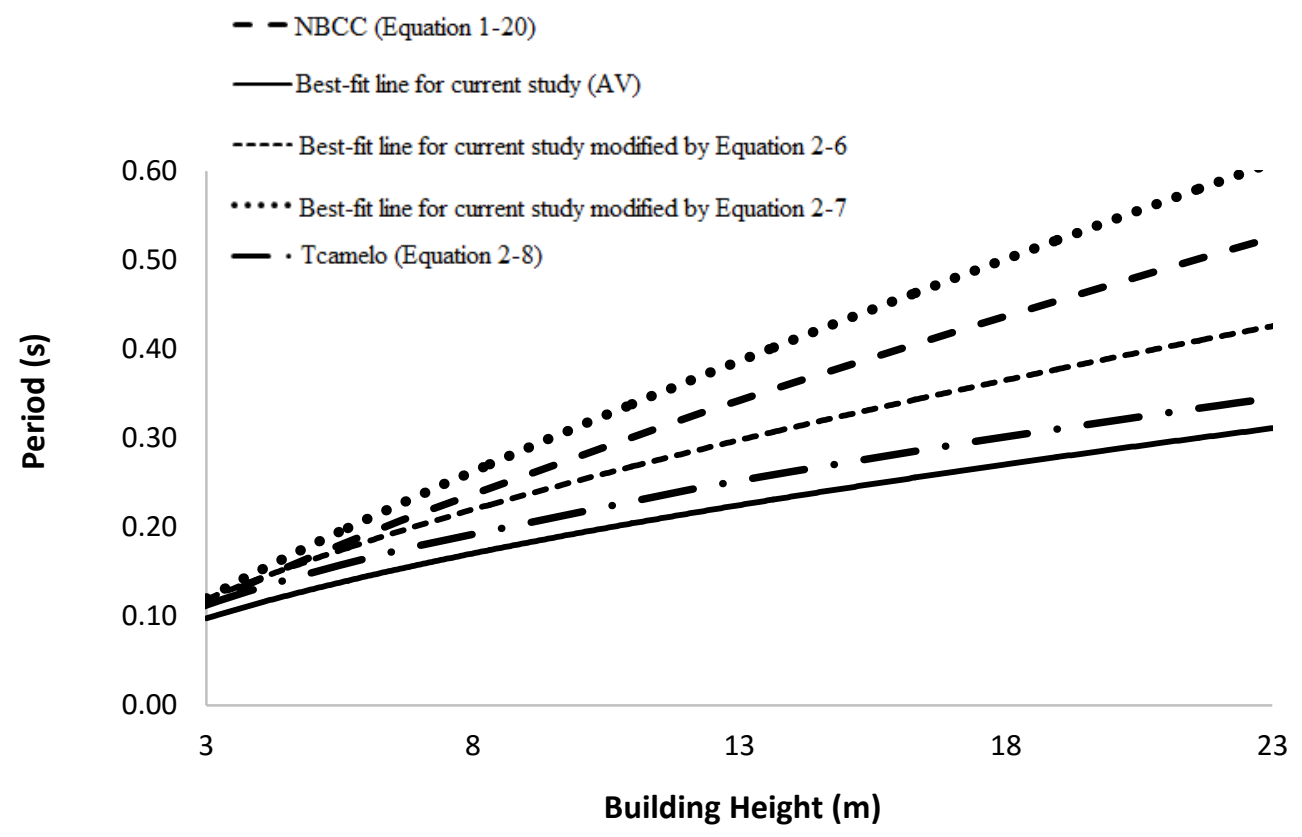

Figure 6-5 Comparison of fundamental periods obtained from NBCC equation, Equation 2-6, Equation 2-7, Equation 2-8 and current study (Phase 2) AVM test data

The figure shows that Equation 2-8 (Camelo, 2003) provides higher period magnitudes than those extracted from AVM tests. However, the expression provides smaller period magnitudes when compared with Equation 2-6 and Equation 2-7. This is expected because the equation is based on FVT and the measurements recorded at low amplitude shaking. The periods calculated using the NBCC equation yield higher magnitudes than the periods extracted from AVM tests, Equation 2-8 and Equation 2-6 (for low ground shaking). Also, the NBCC curve lies between the best fit lines of the two models for predicting earthquake periods representing low and strong ground shaking (Equation 2-6 and Equation 2-7). On one hand, this result is unexpected because, as mentioned earlier, the code equation was developed based on 
measurements that do not include any wood light frame buildings. On the other hand, this observation seems to be consistent with the fact that the NBCC formula is developed based on moderate-level of ground shaking and seems, on average, to provide reasonable fit to the data, with the main issue remaining being the large spread observed. The difficulty in comparing any level of vibration testing with the NBCC expression stems from the fact that the NBCC equation is not defined for a specific level of loading or vibration amplitude. From the comparison presented in Figure 6-5, Equation 2-6 seems to be reasonable and conservative for modifying the building period measured at ambient condition. The equation itself can of course not be used directly to estimate building periods, however such relationships for the development of empirical expressions to estimate the building period based on a developed database of ambient vibration measurements.

Whereas a modification of the measured periods at AVT level is needed for seismic design, the AVT data can be compared with expression for wind period expressions directly. In Figure 6-6, the natural frequencies of the tested structures (from current study and literature) are compared with the curve from EC 1 Part 1-4 (2010) (Equation 1-25). 


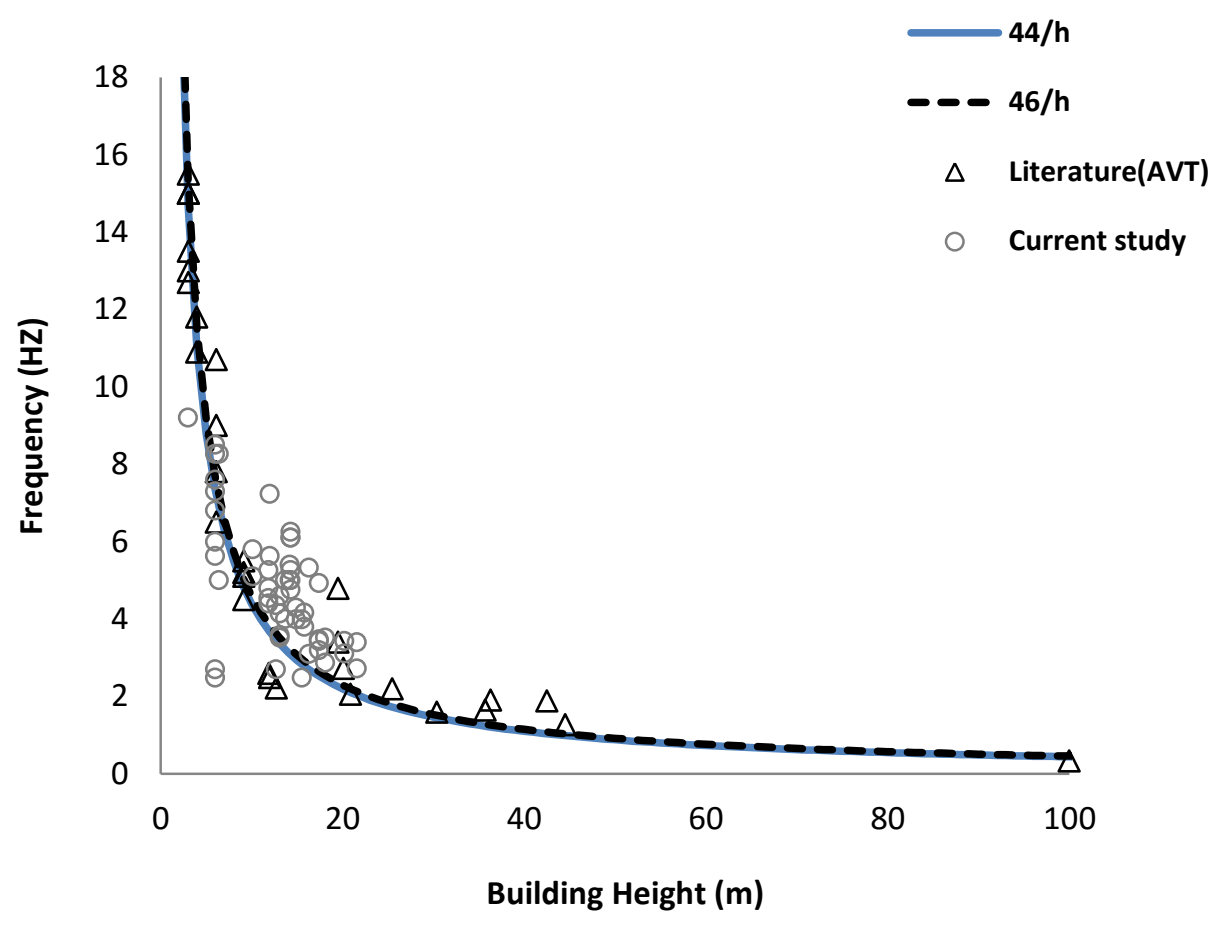

Figure 6-6 Frequency over height relationship representation of ambient vibration data points available in literature and from current study

Figure 6-6 shows that Equation 1-25 (EC 2010) provides a reasonable estimate of the fundamental frequencies when compared with the tested structures.

A least-square curve fit was used to approximate the measured points from the current study resulting in the expression (with $\mathrm{R}^{2}$ value of 0.74 ) provide in Equation 6-1.

$$
n_{1}=44 / h
$$

The best fit trend line for the tested structures in the current study provides a slightly lower fundamental frequency estimate than the Eurocode formula (EC 2010). Given the variability in measurements and the uncertainty associated with such crude 
estimate of the building period, it can be concluded that the Eurocode equation seems appropriate to estimate the building period for the purpose of wind design.

\subsubsection{Differences between Construction Phase 1 and 2}

Figure 6-7 and Figure 6-8 show the values of the measured periods for Phase 1 and Phase 2 from the same buildings in the transverse and longitudinal directions, respectively.

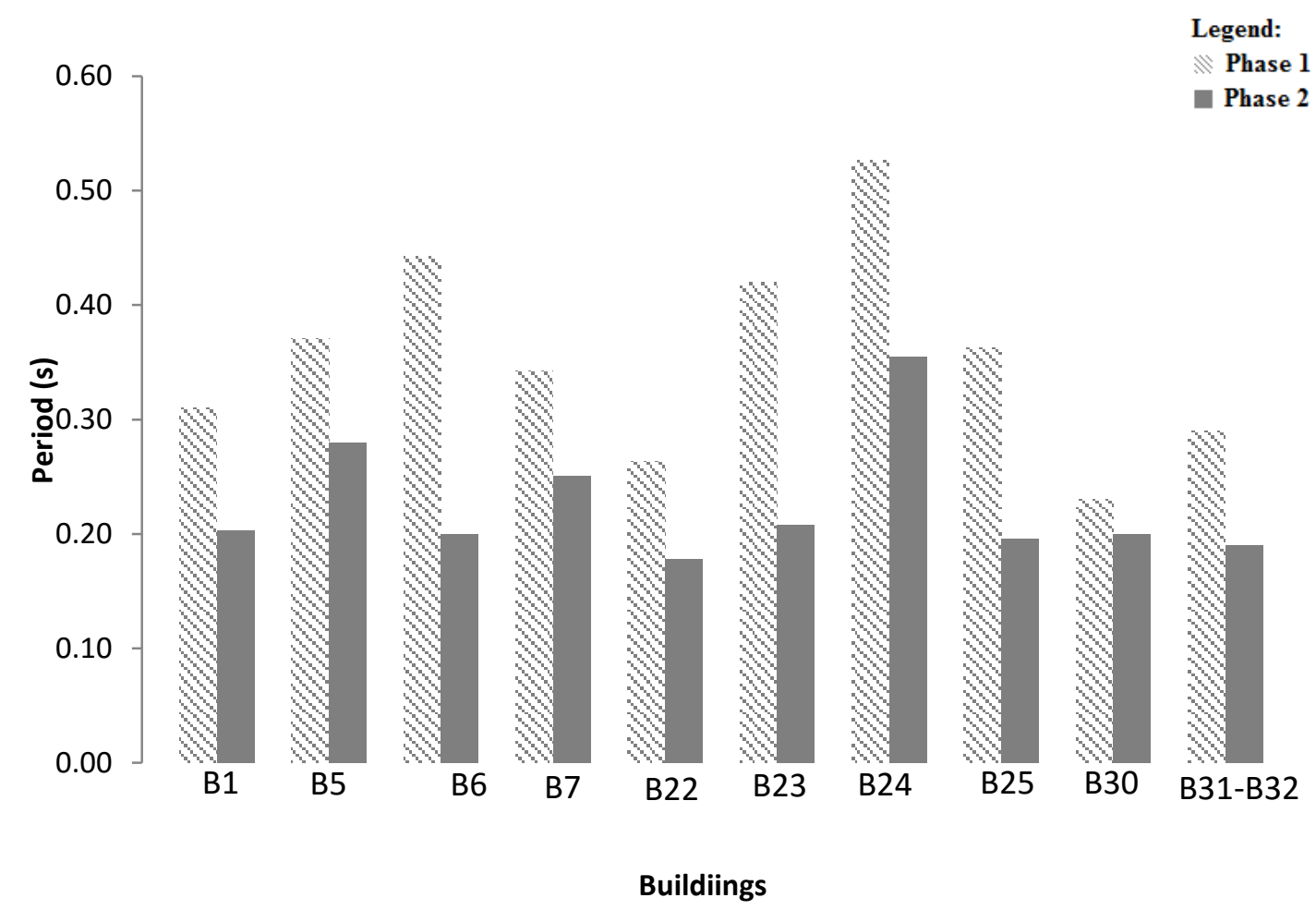

Figure 6-7 Difference between measured fundamental periods of Phase $1 \&$ Phase 2 (with all finishing), (Transverse direction) 


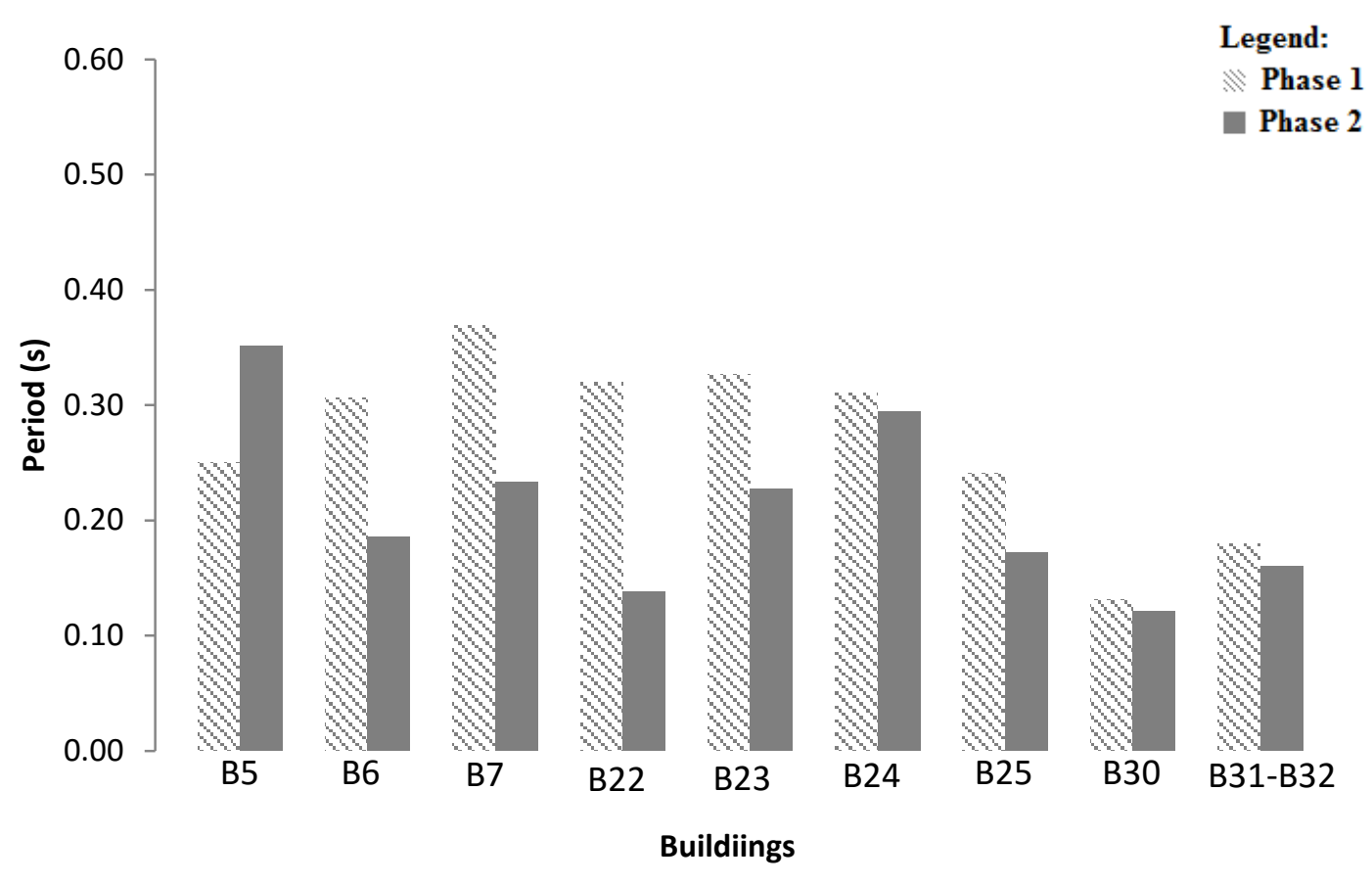

Figure 6-8 Difference between measured fundamental periods of Phase $1 \&$ Phase 2 (with all finishing), (Longitudinal direction)

With few exceptions, the increase in stiffness of finished buildings is dominant over the increase in building mass of the same buildings with only structural components. This resulted in periods in Phase 2 that are significantly lower in both directions than those obtained in Phase 1. The exception observed in the longitudinal direction of building B5 is due to the fact that this building has concrete suspended slabs (added mass) up to the second level and concrete retaining walls at ground level. Similar observations have been made in the literature by Reynolds et al. (2014), where an increase was observed in the fundamental period due to predominant increase in mass over the increase in stiffness. 
The increase in stiffness for finished buildings is significant because it is common practice for structural engineers to neglect the stiffness effect of non-structural components such as partition walls, external walls, parapet walls, stair walls, elevator shaft, etc but take their mass into account. This practice is common for other types of structures such as reinforced concrete and steel, however, as can be seen in Figure 6-7 and Figure 6-8, the stiffening effect of non-structural components is particularly significant for light frame wood buildings since the stiffness of the main lateral force resisting system is relatively low. Again, the fact that the building code is silent about the level of load that is appropriate to estimate the stiffness of a building for the purpose of calculating the building period to obtain a measure of base shear, makes it difficult to know how much of the non-structural elements should be accounted for in the stiffness calculations. The adverse effect of neglecting the stiffening contribution of these components when estimating the seismic base shear forces on wood lightframe buildings is that longer fundamental periods will result in lower design values of base shear.

In particular the effect of gypsum wallboard (GWB), which currently is ignored by designers for the purpose of estimating the shear wall stiffness, should be accounted for in design. There is typically a large presence of GWB walls in wood-frame structures and design engineers are required to evaluate whether or not to take the GWB shear strength and stiffness into consideration. Even if GWB is deemed to be 
"non-structural" by the design engineer, its contribution to the stiffness of the LLRS may still be significant. According to the National Building Code of Canada (NRC 2015), stiff elements that are not considered part of the lateral load resisting system (LLRS) shall be separated from all structural elements of the building so that no interaction takes place as the building undergoes deflections due to earthquake effects. However, if such separation is not feasible, the stiffness imparted to the structure from elements that are not part of the LLRS shall be accounted for in calculating the period of the structure for determining the lateral forces if the added stiffness decreases the fundamental lateral period by more than $15 \%$ (NBCC 2015). In typical light woodframe wall construction, the GWB panels are fastened directly to walls and therefore contribute to the strength, stiffness, and ductility, even if this contribution is not accounted for in design. As shown in Figure 6-7 and Figure 6-8, the overall reduction in the building period for the majority of building far exceeds the $15 \%$ required by the code. It can therefore be concluded that it is important and necessary to include the stiffness contribution of non-structural components (particularly GWB) in the building period estimate. This corroborate findings from the literature (Filiatrault et al., 2002)

\subsection{Effect of Fire-Separation Walls on Dynamic Properties of Wood Buildings}

In current design practice it is common to treat a building with fire-separation walls as individual buildings even though the building segments are nominally connected to 
the firewall. This assumption may be warranted at very high level of displacements where difference in building movement could induce forces in the connections that exceed their capacity. However, for the purpose of estimating the base shear forces for static analysis it is important to know whether the building segments should be treated as individual buildings or if the entire structure should be considered as one. Furthermore, the effect of incorporating the stiffness and mass of the firewall separation in the two principal directions is investigated and recommendations are provided next.

To conduct this investigation, two four-storey light-frame wood building complexes were investigated. One consisted of two building components (B31, B32) and the other of four building components (B14, B15, B16, and B17) separated by fire walls. A detailed description of the testing sequence and results at various stages of construction has been provided in chapters 3 and 4 .

From AV testing, it was observed that when the mode shapes of the combined buildings in both building complexes were compared to that obtained from individual buildings, the firewall seperation provided a strong connectivity between the various building components such that the sway of the entire building was observed with little to no localized sway modes. Introducing the firewall between two building sections adds to the stiffness in the direction of the wall orientation, which changes the dynamic characteristics of the building. An example is demontrated by Figure 6-9, 
where it can be seen that the transverse (along y direction) fire wall is stiffening building B31-B32 in that direction (at nodes 3 and 4). Similar observations are made for the field measurements of complex B14-B15-B16-B17.

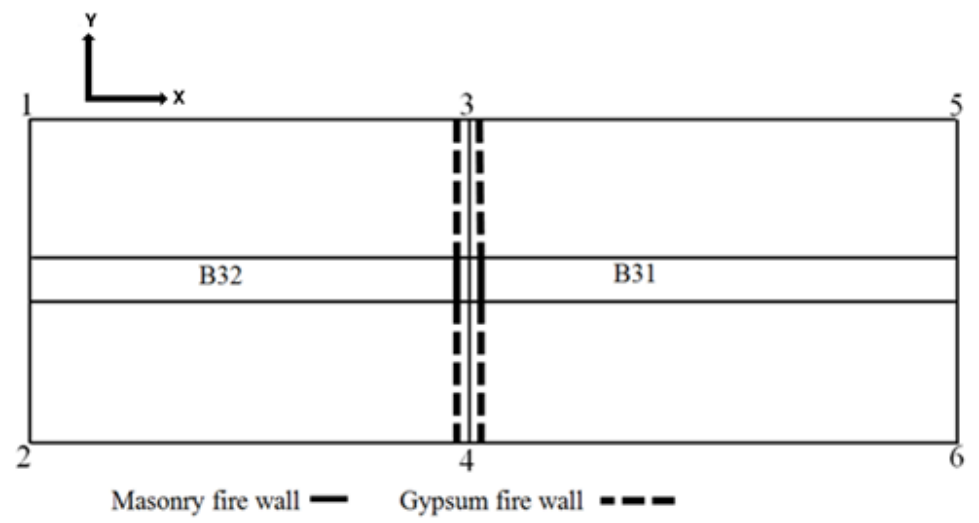

a) Building B31-B32

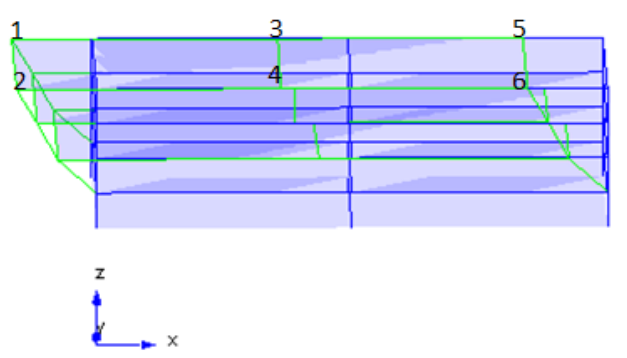

b) X-direction B31-B32 (Test 2)

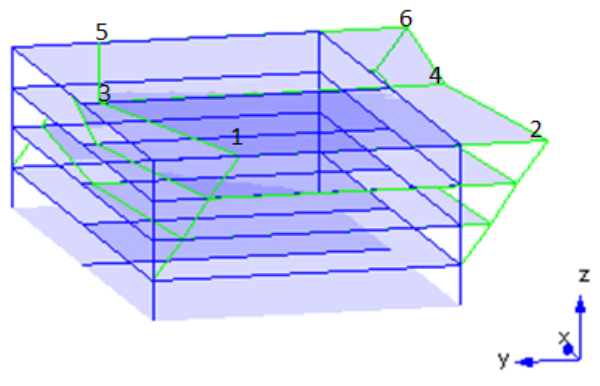

c) Y-direction B31-B32 (Test 2)

Figure 6-9 Plan view and mode shapes of building B31-B32

Where individual building sections that were regular in geometry and lateral stiffness did not experience torional modes, the combined buildings, due to their irregular overall geometry and connectivity through the firewalls, experience more pronounced torsional modes. Ignoring overall torsional effects by considering the individual building sections as separate buildings may lead to erroneous design. 
The connectivity between two building components separated by a firewall was even more pronounced by the application of exterior and interior finishing materials such as brick facades and GWB. For example, sway modes of buildings B31 and B32 show a uniform motion in y direction after the application of primary finishes (Test 3), as shown in Figure 6-10.

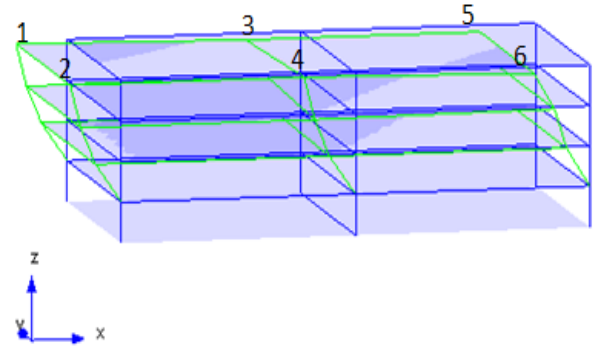

a) X-direction, B31-B32 (Test 3)

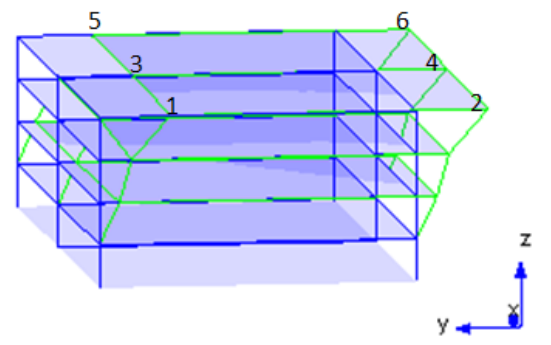

b) Y-direction, B31-B32 (Test 3)

Figure 6-10 Comparison between Test 2 and Test 3 (Transverse mode shapes of B31 and B32)

From this experimental investigation at low amplitude motion it can be concluded that even when building sections are only nominally connected to the firewall, the entire structure should be considered to behave as one.

\subsection{Numerical Results and Discussion}

\subsubsection{General}

An FE model similar to that described in chapter 5 was developed for 6 and 12 selected buildings of Phase 1 and Phase 2 stages to investigate its ability to capture 
the period and mode shapes as observed in the experimental investigation. Once validated at the AVT loading level, the model will then be used to extrapolate the period results to one that is more appropriate to earthquake design levels. The validated model will also be used to conduct parametric analysis to investigate the effects of using different shear wall stiffness models on the natural period of the buildings.

\subsubsection{Validation of Finite Element Models}

\subsubsection{Comparison with Measured Buildings in Phase 1 and Phase 2}

Figure 6-11 and Figure 6-12 compare the fundamental periods obtained from the numerical models with those from AVT records. The differences (in \%) between the measured and computed period of Phase 1 and Phase 2 buildings are provided in Appendix C, Table E- 1 and Table E- 2, respectively. The selection of those specific buildings was based on knowledge of their construction details (structural plans were provided). It can be seen from Figure 6-11 that the fit is reasonable and that the computed period slightly overestimate the building period compared to that obtained from AVT. This is expected since the estimate of the building reactive mass is anticipated to be fairly accurate, whereas the lateral stiffness is usually underestimated in numerical models. Models describing stiffness, especially at low load level (e.g. AVT) would lack the ability to include effects such as friction in connections, the contribution of lintels above and below opening, return walls, etc. 
$\diamond$ Transverse $\quad \Delta$ Longitudinal

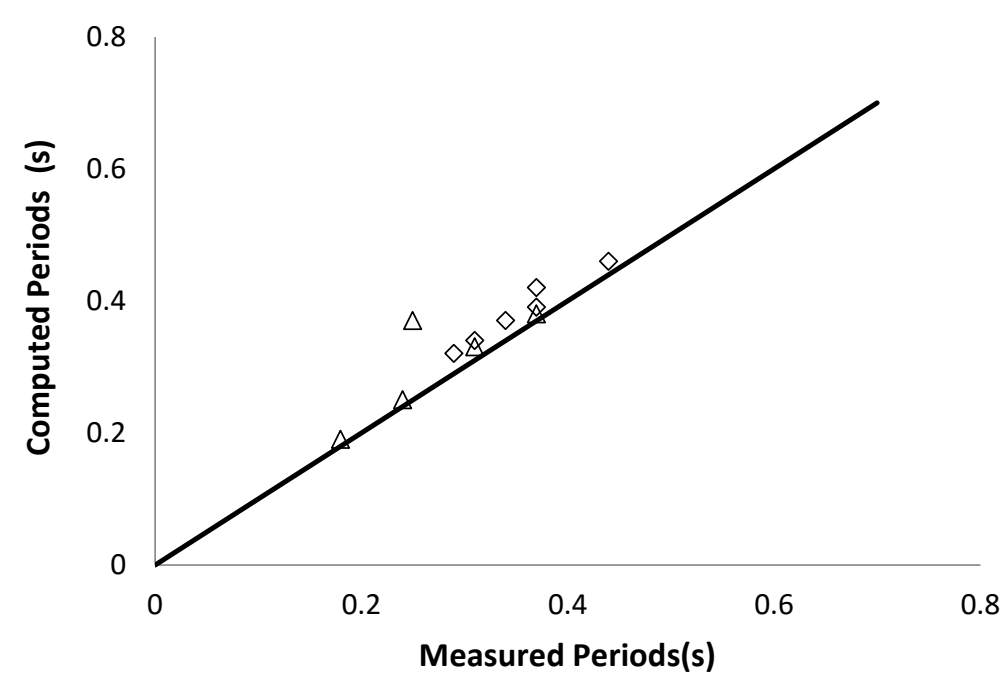

Figure 6-11 Measured periods vs. model periods (Phase 1)

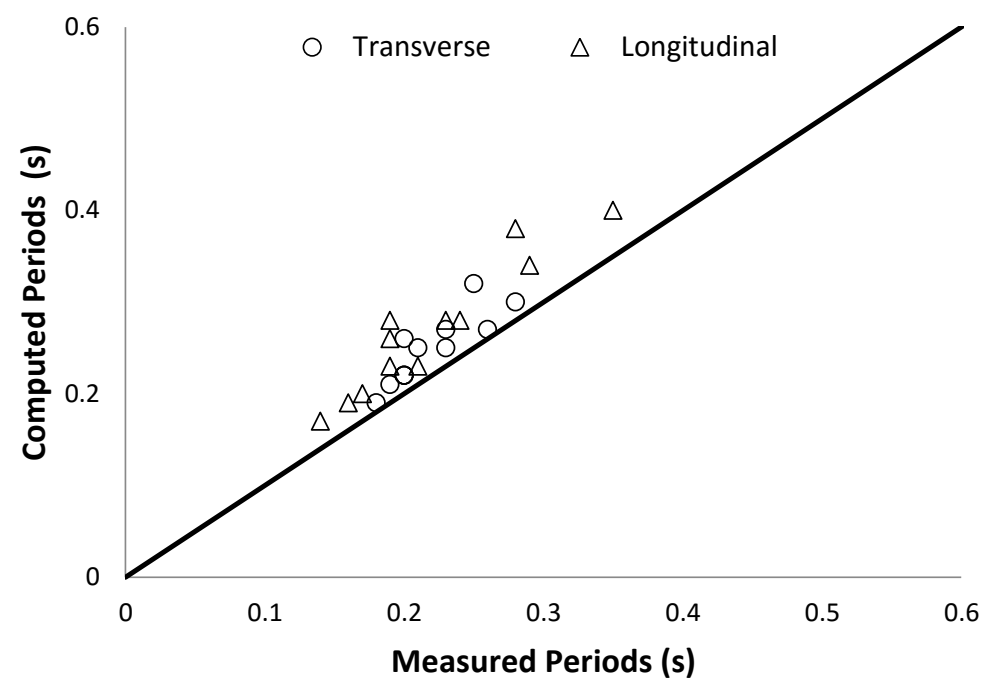

Figure 6-12 Measured periods vs. model periods (Phase 2)

Significant differences are observed in particular cases, such as the longitudinal period of building B5 in Phase 1 construction stage, and the transverse periods of buildings B1, B7 and longitudinal periods of B18-B19 and B9 in Phase 2 
measurements. These differences could be attributed to construction configuration or irregular plan shape. In general, larger differences between the numerical model and measured data were observed for irregular shape buildings and for those which are interconnected with firewall separations.

Comparatively, the differences are higher in Phase 2 (Figure 6-12), since the model does not account for the stiffening effect of components such as windows and doors.

\subsubsection{Model Verifications using Building at Different Stages of Construction}

The two building complexes that were tested at various stages of construction were modeled at each stage of testing to further validate the numerical models, and to verify the assumptions of connectivity between fire-wall seperated building components. Finite element modeling of the masonry firewall-seperated buildings was conducted in such a way that their connection to the firewall was simulated using a rigid link. It is not expected that these results would yield conclusions of general applicatbility about modeling or design considerations, beyond validation of the nummerical model.

Finite element modeling of the B31-B32 complex was conducted for seven construction stages in which mass and lateral stiffness were estimated according to the documentations made during the testing stages. Figure 6-13 shows the measured periods plotted against the computed periods. Table E- 3 in Appendix E shows the 
difference (in \%) between the measured and computed periods and mode shapes for the buildings. The results show that the model is able to capture the measured periods with an accuracy similar to that found in Figure 6-11 and Figure 6-12. It can also be noticed that the difference between calculated and measured natural periods is increasing as the buildings are progressing towards completion (Phase 2). A maximum difference of $43 \%$ (with refrence period set as measured period) is obtained for building B31.

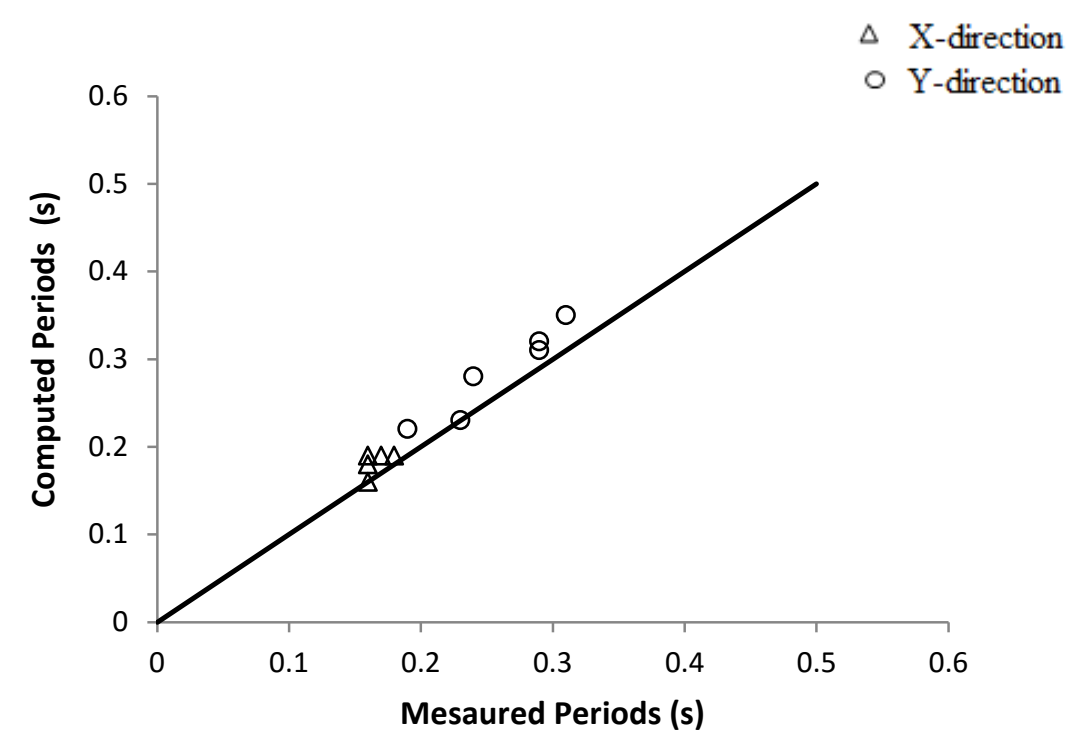

Figure 6-13 Measured periods vs. model periods (B31-B32)

Similarly, an FE model was analyzed for building complex B14-B15-B16-B17 in five different construction stages. The construction stages shown in Figure 6-14 represent the conditions where building B17 alone was constructed, B15-B16-B17 were constructed, as well as various stages where buildings B14-B15-B16-B17. The 
comparison of results is also provided in Table E- 4. Similar to building B31-B32, differences between measured and computed periods are gradually increasing with developed construction stages.

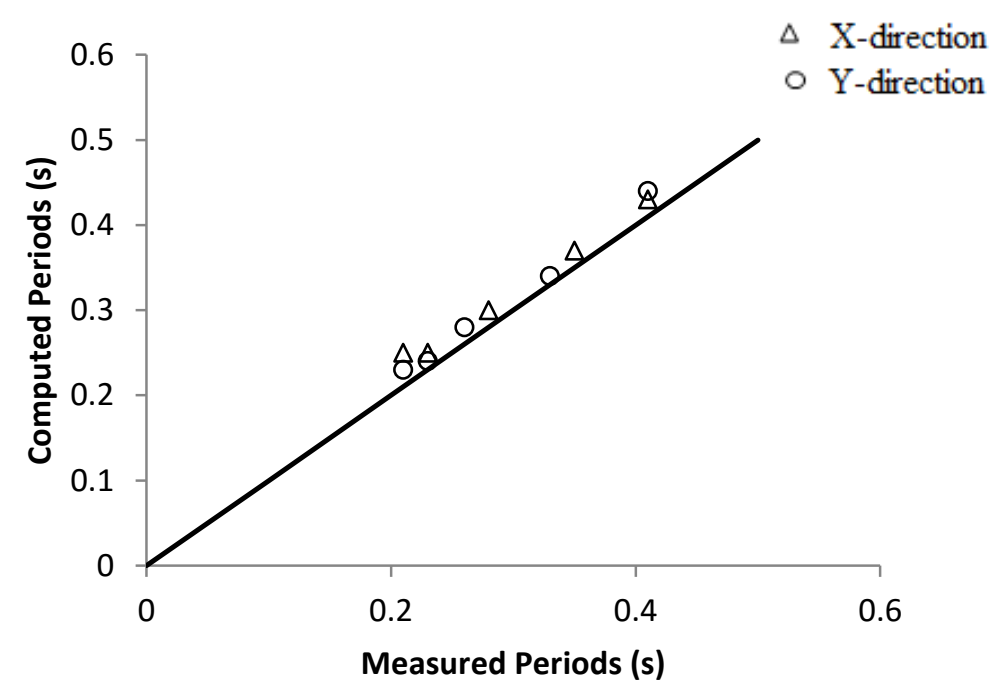

Figure 6-14 Computed period of different construction stages of the complex against measured period (validation of numerical model)

In general, it can be stated that the modeling technique presented in Chapter 5 is adequate in providing a reasonable estimate of the building period at AV level. Next, the validated model will be used to evaluate various construction parameters and also be used to provide period values suitable for seismic design.

\subsubsection{Variation of Computed Period during Idealized Construction Stages of} B14, B15, B16, B17

The previous section dealt with actual conditions documented at the time the testing took place. Where this provides useful information for model validation, the fact that 
the measured periods reflect the exact stage of construction makes it difficult to generalize the results to how the buildings behave in isolation versus as part of a building complex. Therefore, the validated FE model was extended to evaluate the effect of presence of the masonry firewall on the fundamental period variation in the construction sequence. The models were created for Phase 2 construction stage, to measure the effect of non-structural components. The variation in the computed period of the building complex was examined when a new building was added to the whole complex model in conjunction with a masonry firewall.

Model stage 4 is representative of the actual final on-site construction stage. Model stages 1, 2 and 3 are idealized construction stages, in which construction of B16 (in model stage 2) and B15 (in model stage 3) was assumed to happen in a sequence to study the effect of each building separately. Four model building stages are shown in Figure 6-15 and the corresponding computed periods are provided in Table 6-1, while the mode shapes are shown in Appendix D.

Table 6-1 Computed period of different modeled construction stages

\begin{tabular}{|c|c|c|c|}
\hline \multirow{2}{*}{$\begin{array}{c}\text { Model building } \\
\text { stage }\end{array}$} & $\begin{array}{c}\text { Model } \\
\text { geometry }\end{array}$ & $\mathbf{X}$ & Computed Period (s) \\
\cline { 3 - 4 } & $\mathrm{B} 17$ & 0.37 & 0.29 \\
\hline 1 & $\mathrm{~B} 16-\mathrm{B} 17$ & 0.28 & 0.21 \\
\hline 2 & $\mathrm{~B} 15-\mathrm{B} 16-\mathrm{B} 17$ & 0.24 & 0.27 \\
\hline 3 & $\mathrm{~B} 14-\mathrm{B} 15-\mathrm{B} 16-\mathrm{B} 17$ & 0.25 & 0.23 \\
\hline 4 &
\end{tabular}




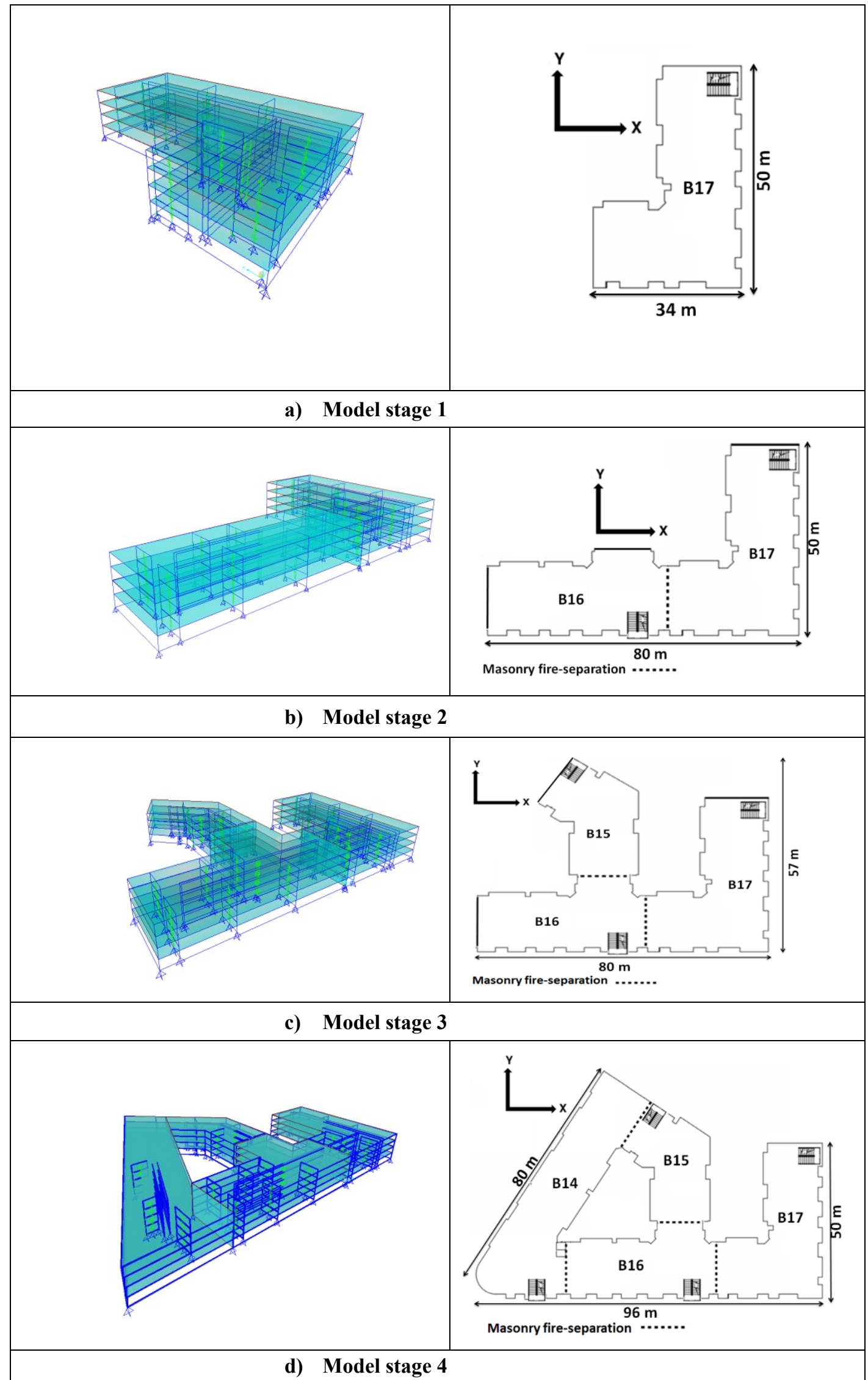

Figure 6-15 Model stages 
The results show that the addition of buildings along with fire-separation produced a new structure with unique characteristics. For example when B16 was added to B17, the new structure (B16-B17) showed a stiffer response in both orthogonal horizontal directions. Adding buildings would naturally introduce more mass as well as stiffness to the overall complex. The variation in period is expected to depend on which of these paramaters (mass and stiffness) is dominant. However, the genral trend shown in Table 6-1 seems to indicate that the effect of stiffness dominate the behaviour. This is also consistent with the trends observed in the actual complex.

\subsection{Effect of Different Stiffness Models}

As described in Chapter 5, three different stiffness models are presented which represent what a designer is likely to use when estimating the fundamental period of a wood building. Recalling from Chapter 5, this includes adjusting the deflection equation (Equation 5-1) to an earthquake force level (taken conservatively here as the $10-40 \%$ slope on the capacity-deflection curve, (ASTM E2126)) and considering three stiffness models: Model SM1 using all four terms of Equation 5-1 but accounting for no cummulative effects, Model SM2 considering the effect of cumulative frame bending, and Model SM3 including the cumulative bending and rotational effects. In the following, the AVT results are modified to periods suitable for earthquake level of loading (using Equation 2-6) and compared to periods estimated using the three stiffness models. Figure 6-16 and Figure 6-17 show the 
calculated periods using the stiffness models compared to the modified period from the experimental program and that provided by the NBCC equation (Equation 1-20) for the largest and smallest building periods, respectively. The results show that in general current design approaches overestimate the building period. In fact in some cases the period value using SM3 (B5, B7, and B26-B27) exceeds the upper limit of the NBCC (see Figure 6-16). Although directed by the code to limit the period at twice the value obtained from Equation 1-20), the trend observed in Figure 6-16 and Figure 6-17 indicates that estimate of base shear may be non-conservative in many design cases.

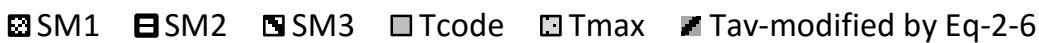

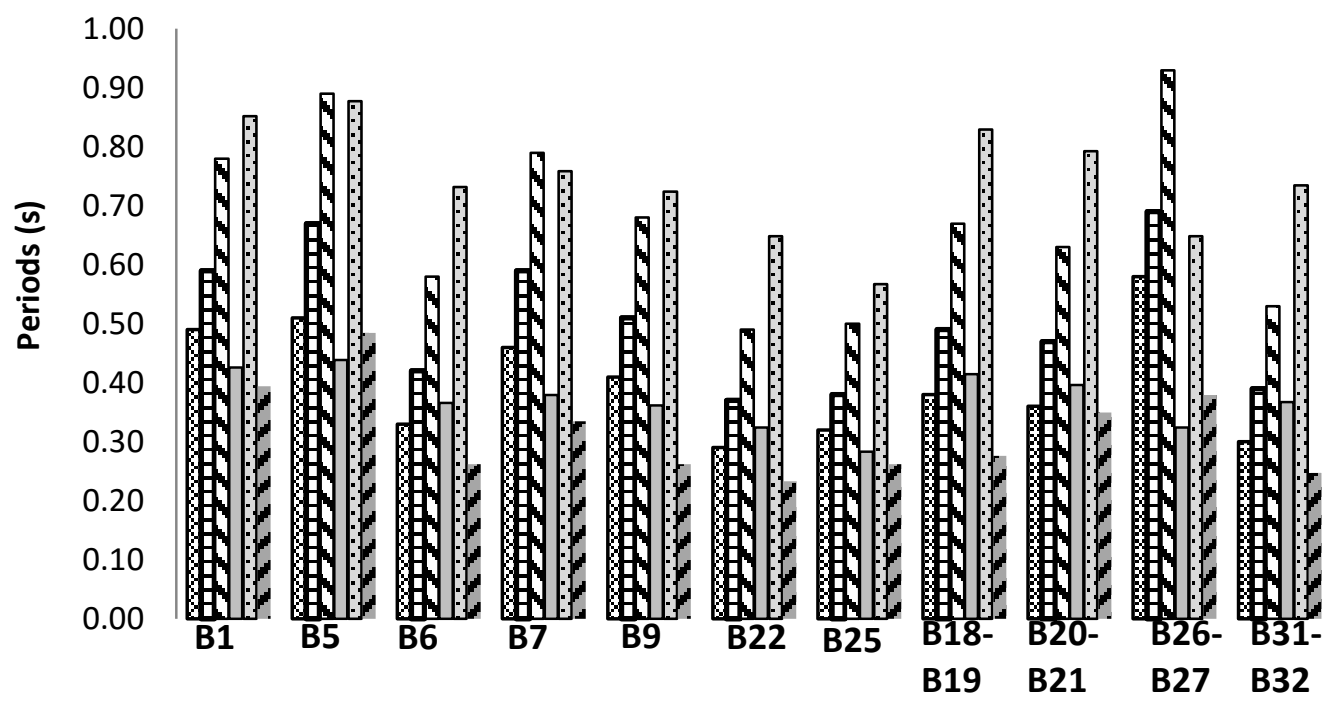

Figure 6-16 Comparison of longer of the two computed periods by different stiffness models with $\mathbf{T}_{\max }$ and $\mathbf{T}_{\text {code }}$ 


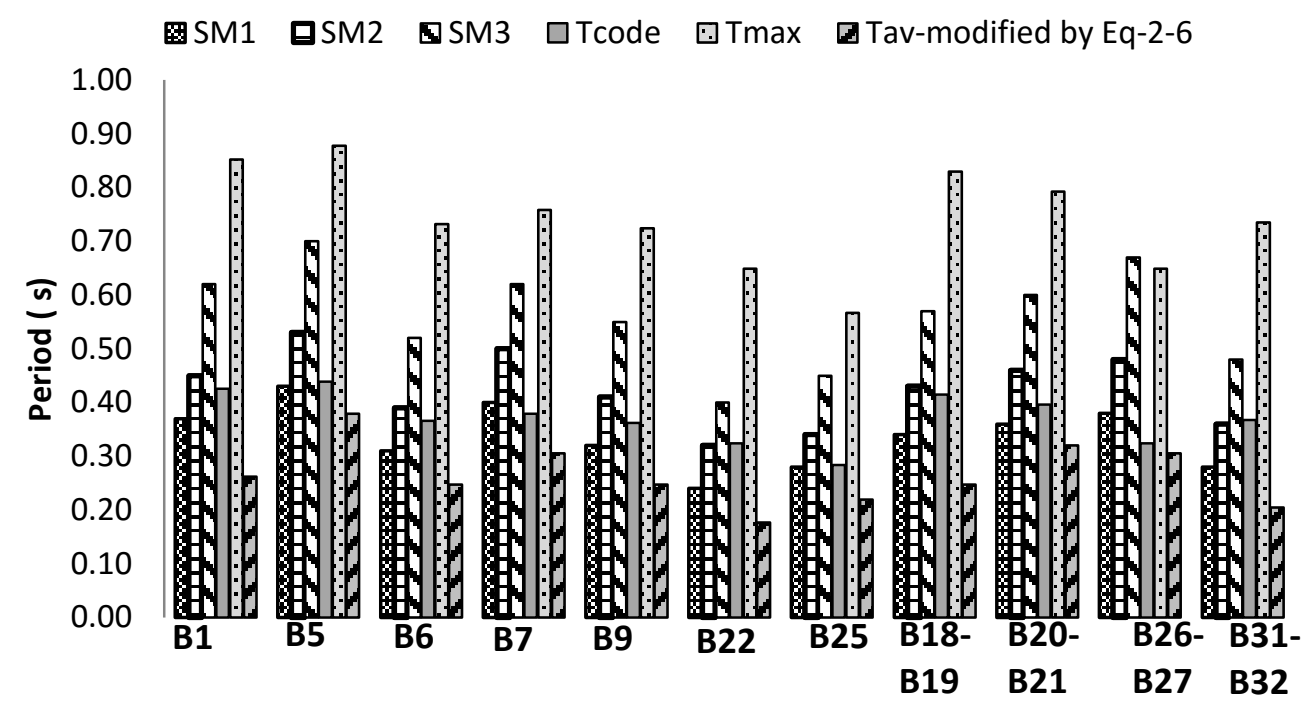

Figure 6-17 Comparison of smaller of the two computed periods by different stiffness models with $\mathbf{T}_{\max }$ and $\mathbf{T}_{\text {code }}$

It is crucial that a designer does not use both design level forces as well as cumulative effects to evaluate the building period. The next section proposes a simple approach to estimate the stiffness that does not require exact knowledge about the building construction details.

\subsection{Estimating the Period Formula for Light-Frame Wood Buildings}

The current study shows that Equation 1-20 provides higher period estimates than the measured (AV) for wood shear wall buildings, and that considering the building height in the period equation is not sufficient as the only variable to describe the dynamic characteristic of light frame wood structures. The NBCC (2015) allows the use of rational methods other than the empirical equation (Equation 1-20) with the limit that the calculated period shall not exceed twice the value obtained from 
Equation 1-20. It has been shown in the past (Goel and Chopra (1998), Lee et al. (2000) and Morales (2000)) that considering the other dimensions of concrete shear wall buildings for period estimate improves the accuracy of the prediction (See Section 2.1 for details). In this part of the research, a simplified method of period estimation is suggested for light-frame wood buildings, based on the Raleigh approximation method of Equation 6-2.

$$
T=2 \pi \sqrt{\frac{\sum_{x=1}^{n}\left(W_{x} \delta_{x}^{2}\right)}{g \sum_{x=1}^{n}\left(F_{x} \delta_{x}\right)}}
$$

Where $W_{x}, F_{x}$, are seismic weight, and force at level $\mathrm{x}$ and $\delta_{x}$ is elastic lateral displacement due to force $F_{x}, \mathrm{~g}$ is acceleration due to gravity.

Nine buildings with known geometric and structural information, were studied for the assessment of whether the stiffness of shear walls can be replaced by their length. Figure E- 1 in Appendix E shows the relationship between wall stiffness and length. In Equation $6-2, \delta_{x}$ is taken as $1 / k$, where $k$ is stiffness of shear wall.

This simple method of estimating the period for wood shear wall buildings was validated by comparing the periods calculated by Raleigh approximation $\left(\mathrm{T}_{\text {Raleigh }}\right)$ with those obtained using the ambient vibration field measurements ( $\left.\mathrm{T}_{\text {measured }}\right)$. The correlation between $\mathrm{T}_{\text {Raleigh }}$ and $\mathrm{T}_{\text {measured }}$ is displayed in Figure 6-18. 


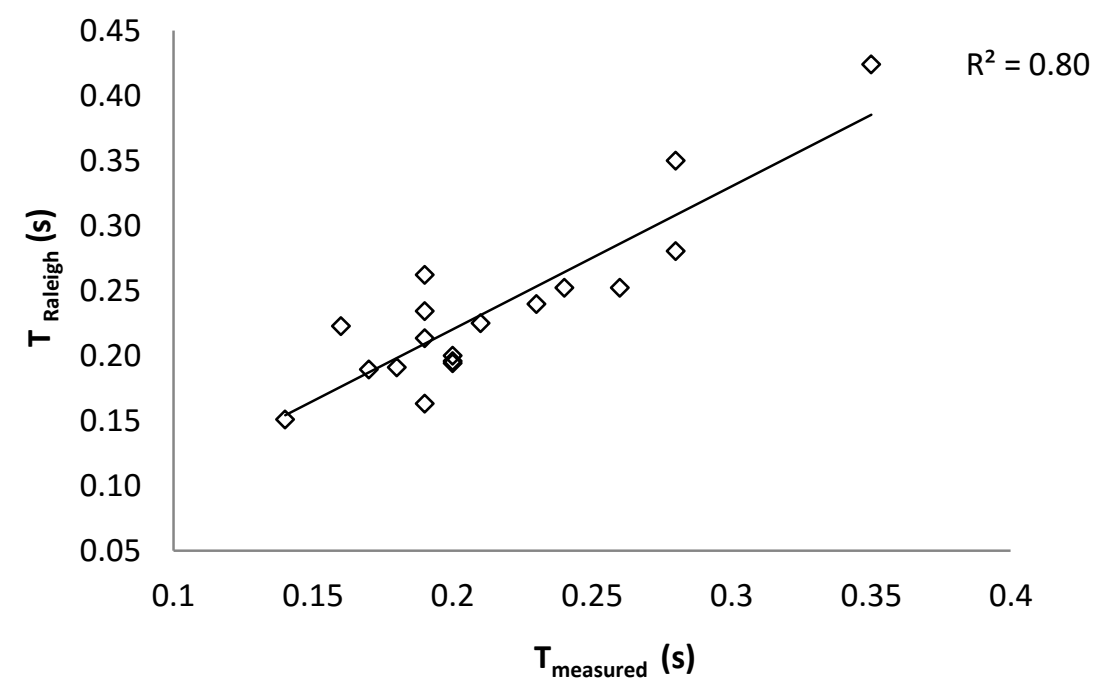

Figure 6-18 Correlation between measured and Raleigh periods

$\mathrm{T}_{\text {Raleigh }}$ is compared with fundamental periods obtained by finite element modeling $\left(\mathrm{T}_{\text {model }}\right)$. The comparative results between ambient vibration measurements $\left(\mathrm{T}_{\text {maesured }}\right)$, Raleigh approximation $\left(\mathrm{T}_{\text {Raleigh }}\right)$ and finite element modeling $\left(\mathrm{T}_{\text {model }}\right)$ are shown in Table 6-2.

Table 6-2 Periods from AV measurements, finite element modeling and Raleigh approximation

\begin{tabular}{|c|c|c|c|c|c|c|}
\hline \multirow{2}{*}{$\begin{array}{c}\text { Buildings } \\
\text { Id }\end{array}$} & \multicolumn{6}{|c|}{ Periods (s) } \\
\cline { 2 - 7 } & \multicolumn{2}{|c|}{ Measured } & \multicolumn{2}{c|}{ Raleigh } & \multicolumn{2}{c|}{ Model } \\
\cline { 2 - 7 } & Trans & Long & Trans & Long & Trans & Long \\
\hline B5 & 0.28 & 0.35 & 0.28 & 0.42 & 0.30 & 0.40 \\
\hline B6 & 0.20 & 0.19 & 0.19 & 0.21 & 0.22 & 0.23 \\
\hline B9 & 0.20 & 0.19 & 0.20 & 0.26 & 0.22 & 0.28 \\
\hline B22 & 0.18 & 0.14 & 0.19 & 0.15 & 0.19 & 0.17 \\
\hline B25 & 0.20 & 0.17 & 0.20 & 0.19 & 0.22 & 0.2 \\
\hline B18-B19 & 0.21 & 0.19 & 0.22 & 0.23 & 0.25 & 0.26 \\
\hline B20-B21 & 0.26 & 0.24 & 0.25 & 0.25 & 0.27 & 0.28 \\
\hline B26-B27 & 0.23 & 0.28 & 0.24 & 0.35 & 0.27 & 0.38 \\
\hline B31-B32 & 0.19 & 0.16 & 0.16 & 0.22 & 0.21 & 0.19 \\
\hline
\end{tabular}

Figure 6-19 shows a reasonable correlation $\left(R^{2}=0.91\right)$ between the periods obtained 
by Raleigh approximation using shear wall length to represent stiffness and by finite element model.

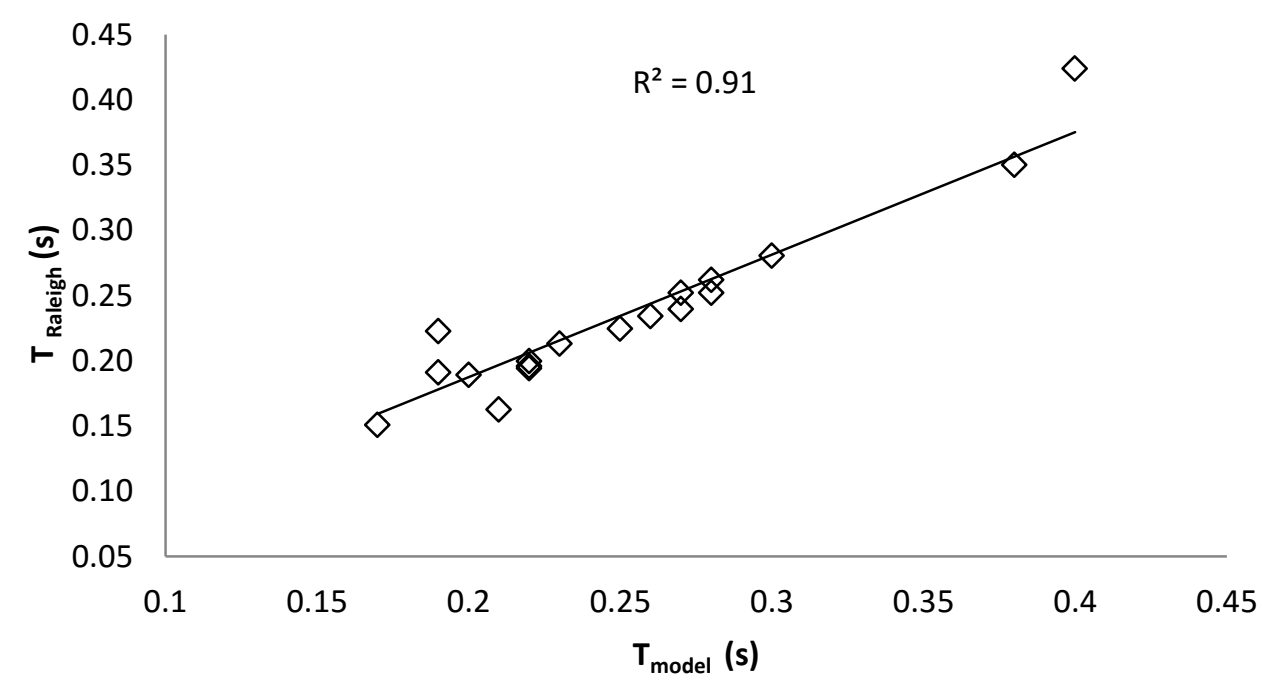

Figure 6-19 Correlation between model and Raleigh periods

It can be concluded that the simple method of Raleigh approximation, considering stiffness as a function of the length of wood shear walls provides a reasonable period estimate for light-frame wood buildings.

\subsubsection{Proposed Period Formula for Light-Frame Wood Buildings}

As discussed in section 6.2.1, a large spread was observed in the measured data when plotted against the building code expression, which is solely a function of the building height. Figure 6-20 reiterates this observation, while also providing the $\mathrm{R}^{2}$ for the best fit power expression through the measured data. 


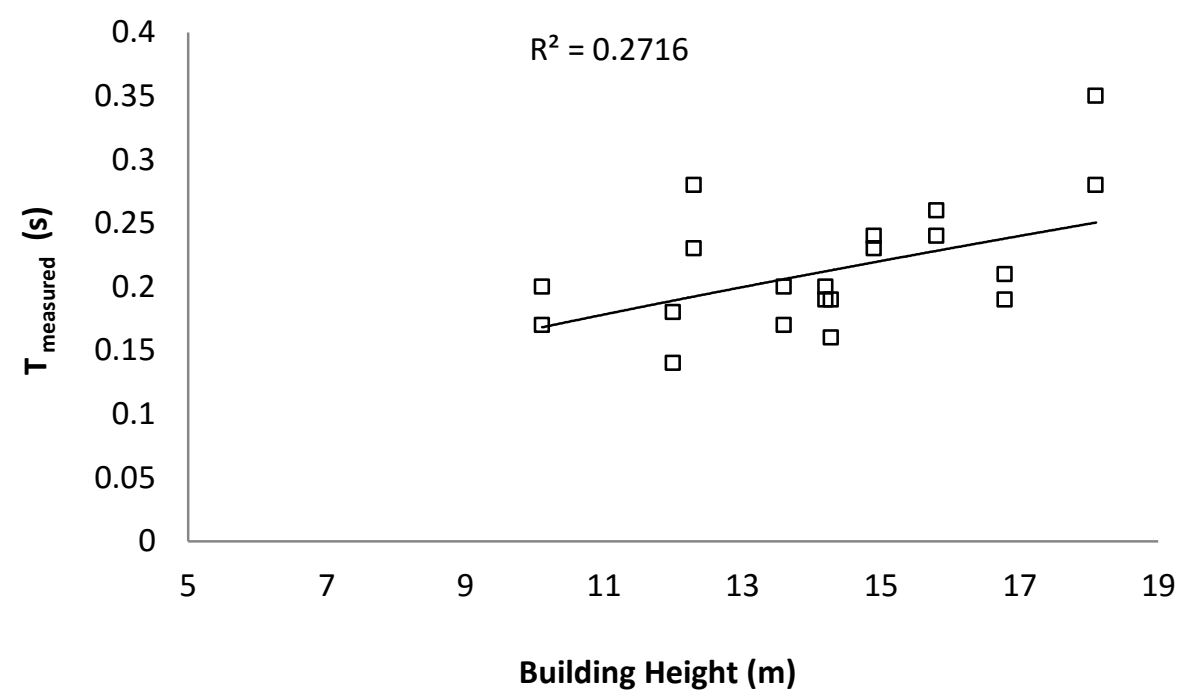

Figure 6-20 $\mathrm{T}_{\text {measured }}$ of selected buildings versus building height

It is well known that a building period is a function of the building height as well as the building mass and stiffness. The building mass can be estimated with reasonable accuracy but since the majority of the mass is concentrated in the floor (walls are assumed to contribute little to the overall building mass) the floor area can be used as an approximate estimate of the mass. Similarly, the wall stiffness can be approximated by its length. These simplifications allow the designer to evaluate a preliminary design of a building before specific details are decided. To evaluate the period dependency on these variables (height, stiffness and mass), the measured period of the 9 buildings devalued in section 6.6 is plotted against $\left(\frac{h}{l} * A\right)$ for the two orthogonal directions, as shown in Figure 6-21. 


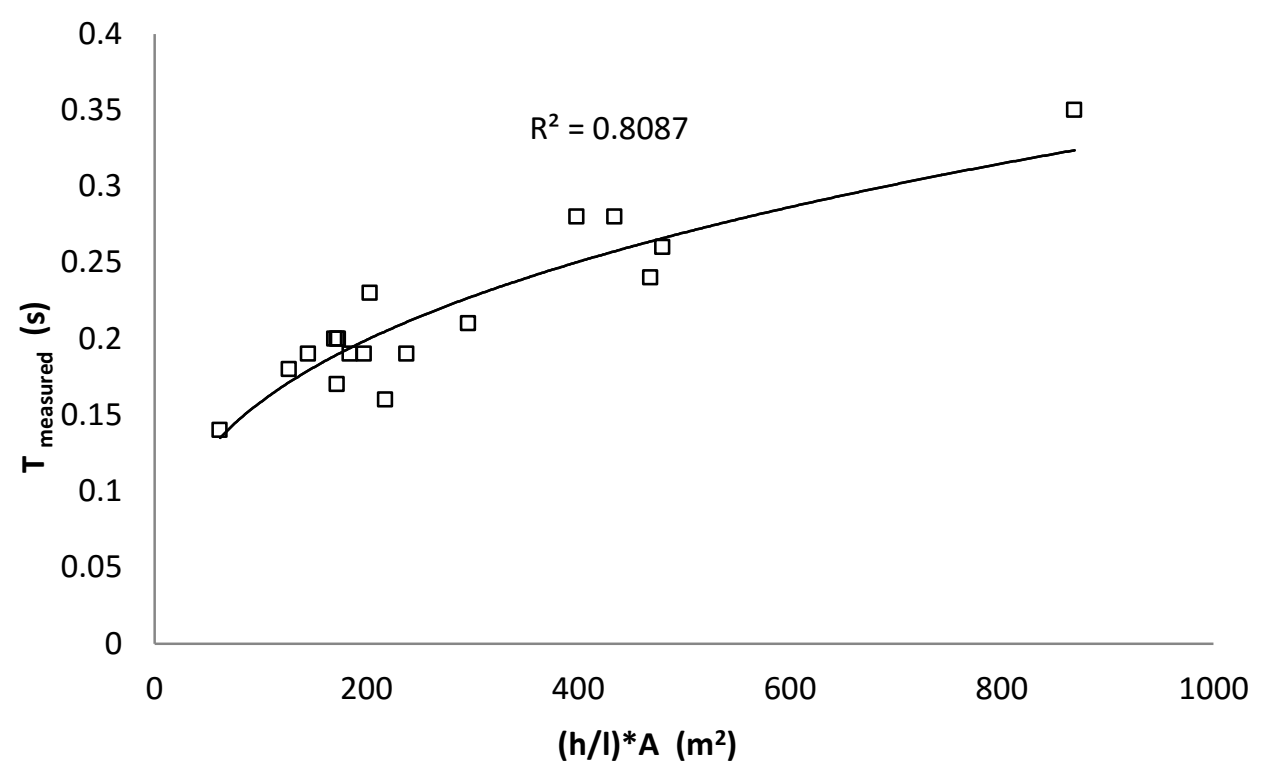

Figure 6-21 $\mathbf{T}_{\text {measured }}$ of selected buildings versus building height $\left(\frac{h}{l} * A\right)$

It can clearly be seen from Figure 6-21 that the scatter in the measured data is less $\left(\mathrm{R}^{2}\right.$ value of 0.81 ) than that presented in Figure 6-20 where only the building height was considered ( $\mathrm{R}^{2}$ value of 0.27). Table E- 5 in Appendix E shows the values of $\left(\frac{h}{l} * A\right)$ for each considered building.

The relationship found in Figure 6-21 presents a significant improvement over that found in the building code for wood shearwalls, however, since the best fit equation is based on measurements at ambient vibration level, it cannot be used directly for estimating building period for the purpose of calculating base shear. In order to shift the proposed period expression to a level appropriate for seismic design, the expression developed by Kharrazi (Equation 2-6) was used. The form of expression developed is presented in Equation 6-3, where values for $\alpha=0.045$ and $\beta=0.36$ are 
obtained by regression analysis that minimizes the error between the data points and the fit expression.

$$
T=\alpha\left(\frac{h}{l} * A\right)^{\beta}
$$

Comparison between the periods obtained by ambient vibration measurements, NBCC formula (Equation 1-20), Camelo's period formula (Equation 2-8) and that estimated using Equation 6-3, is presented in Figure 6-22 and Figure 6-23 for the transverse and longitudinal building direction, respectively.

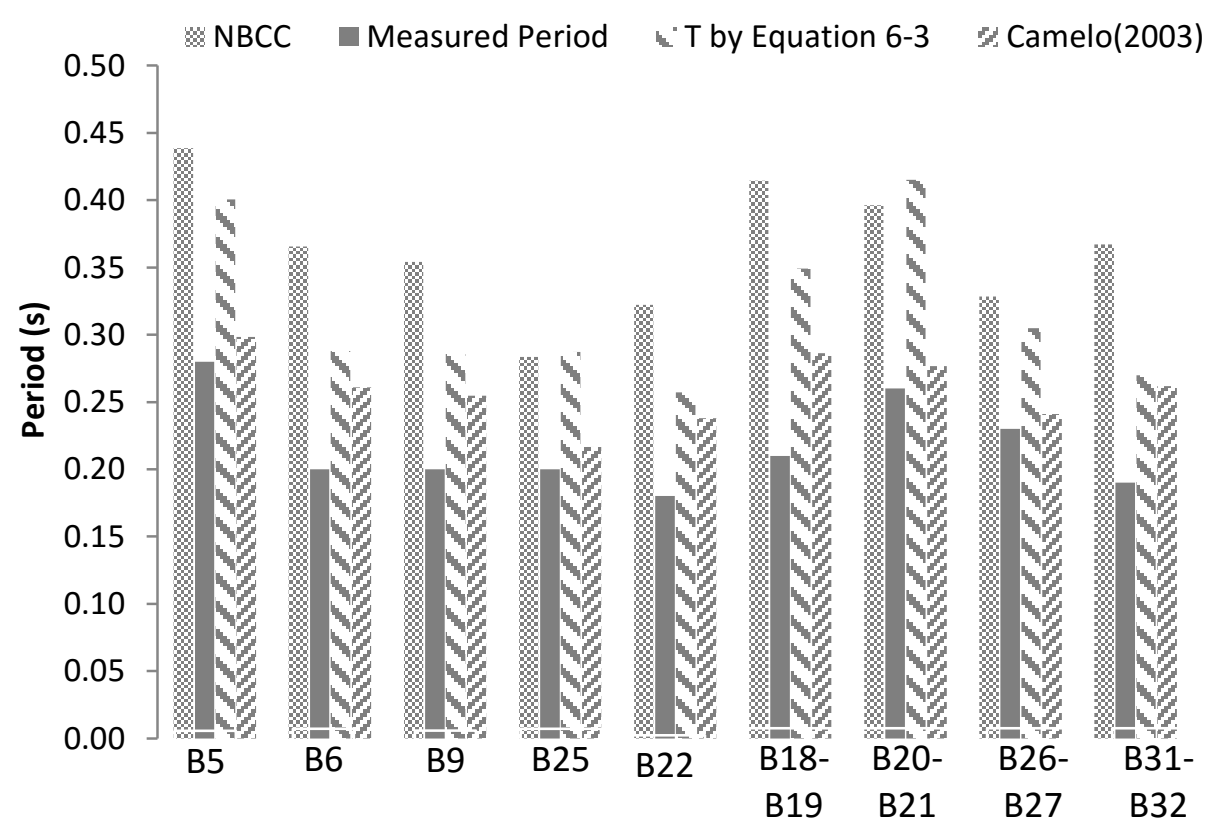

Figure 6-22 Comparison of measured periods, code periods and periods by Equation 6-4 (Transverse direction of the buildings) 


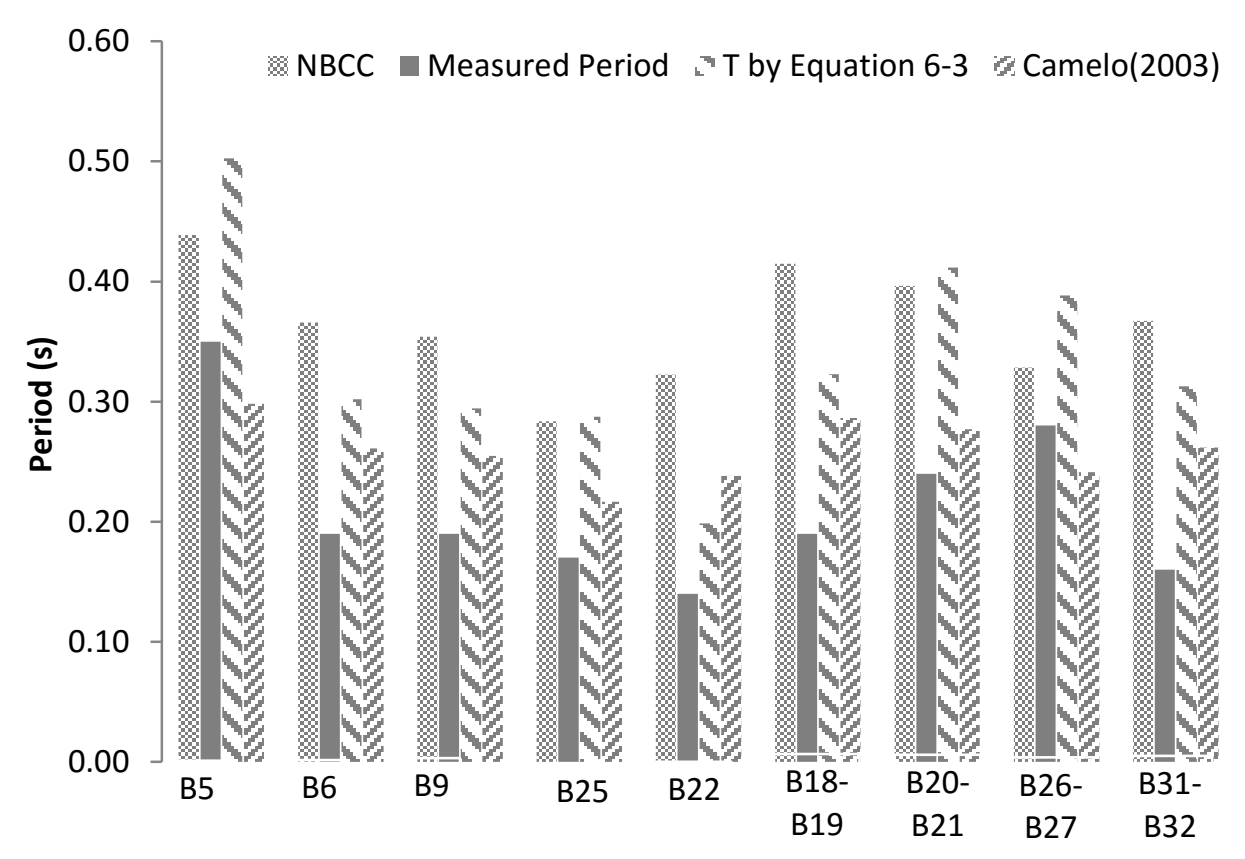

Figure 6-23 Comparison of measured periods, code periods and periods by Equation 6-4 (Longitudinal direction of the buildings)

With a few exceptions, it can be observed from the figures that the proposed expression yields period values that are lower than those obtained using the NBCC formula (Equation 1-20) and higher than Camelo's period formula (Equation 2-8).

It should be emphasized that the above analysis and proposed new expression is predicated on the fact that Kharrazi's equation (Equation 2-6) is appropriate to modify AVT measurements to earthquake level values. Furthermore, the methodology used here extrapolates Kharrazi's equation and assumes it valid for taller buildings (up to six storey) than it was developed for (1-2 storeys). Whether a higher (or lower) level of loading is suitable for estimating the level at which the period should be calculated is therefore still unresolved. 
Also, the proposed expression is based on 9 buildings only and it therefore should be considered as a rough estimate. When more buildings with known construction details are added to the database a more refined expression can be developed. 


\section{CHAPTER 7}

\section{Conclusion}

The main objective of this study was to evaluate the adequacy of the NBCC formula for estimating the fundamental period of wood buildings, and develops a reliable method of predicting the fundamental period of light-frame wood buildings. A comprehensive data base of measured dynamic properties of light-frame wood building has been compiled based on ambient vibration tests. The measured buildings include a variety of geometries and occupancies. Commercial software, ARTeMIS Extractor (Structural Vibration Solutions, 2011) for frequency domain decomposition analysis was used to extract the dynamic parameters from recorded measurements. The results include fundamental natural frequencies, and corresponding damping ratios and mode shapes, of the measured buildings. Frequencies obtained at ambient vibration levels ranged from $1.9 \mathrm{~Hz}$ to $7.6 \mathrm{~Hz}(0.53-0.13 \mathrm{~s})$ for Phase 1 (in which buildings were measured bare frame) and $2.5 \mathrm{~Hz}$ to $9.1 \mathrm{~Hz}(0.40-0.11 \mathrm{~s})$ for Phase 2 (in which buildings were measured in their finished stage). Damping ratios were measured from $1.1 \%$ to $5.0 \%$ and, $1.1 \%$ to $7.3 \%$ for Phase 1 and Phase 2 respectively.

Specifically, the following conclusions can be drawn from the current study:

- Significant scatter is observed in the measured data as a function of building 
height for both phases. This clearly indicates that relying on the building height alone to describe the building period is not sufficient to provide accurate estimates.

- In general, the period in the transverse direction is greater than that obtained for the same building in the longitudinal direction for Phase 1. This trend is less clear when all non-structural components are installed in Phase 2.

- The periods obtained from the current study are consistent with those reported in the literature for ambient vibration measurements. Data obtained through shake table and FVT records show higher period values, which can be attributed to the increase in excitation amplitude.

- When comparing to the wind period in the Eurocode, the best fit trend line for the tested structures in the current study provides a slightly lower fundamental frequency estimate than the Eurocode formula. However, given the variability in measurements and the uncertainty associated with such crude estimate of the building period, it was concluded that the Eurocode equation seems appropriate to estimate the building period for the purpose of wind design.

- With few exceptions, the increase in stiffness of finished buildings was found to be dominant over the increase in building mass of the same buildings with only structural components leading to a significant reduction in the measured 
period. In particular the effect of gypsum wallboard (GWB), which currently is ignored by designers for the purpose of estimating the shear wall stiffness, should be accounted for in design.

- An investigation of the effect of firewalls on the behavior of building complexes showed that at low amplitude motion it can be observed that even when building sections are only nominally connected to the firewall, the entire structure should be considered to behave as one.

- FE models were developed and their ability to capture the period and mode shapes observed in the experimental study was investigated. The results showed that the FE models were able to predict the dynamic behaviour of the buildings with reasonable fit while the computed period slightly overestimate the building period compared to that obtained from AVT. This was attributed to the lack in ability to estimate the stiffness with high accuracy and to the models' lack of ability to include effects such as friction in connections, the contribution of lintels above and below opening, return walls, etc. In general, larger differences between the numerical model and measured data were observed for irregular shape buildings and for those which are interconnected with firewall separations. Comparatively, the differences are higher in Phase 2, since the model does not account for the stiffening effect of components such as windows and doors. 
- Using the validated FE models to examine different commonly used stiffness models showed that in general current design approaches overestimate the building period, with some even exceeding the upper limit defined by the NBCC. It is crucial that a designer does not use both, design level forces as well as cumulative effects to evaluate the building period.

- Using a simplified method of period estimation based on the Raleigh approximation while using the building mass and replacing the stiffness of shear walls by their length showed reasonable fit when compared with the FE model results and experimentally measured periods.

- Regression analysis on the measured data showed that better estimate of the building period can be obtained when the building height, area and shearwall length is included in the analysis. A proposed formula was developed based on this relationship and it was shown to significantly reduce the variability in the results. In general, it can be observed from the figures that the proposed expression yields period values that are lower than those obtained using the NBCC formula. More buildings with known construction details are needed to refine the proposed expression.

\subsection{Original Research Contributions}

Following is a summary of the original contributions of this research 
1) This is the first effort to establish a comprehensive database for natural periods and damping ratios of forty six light-frame wood shear wall buildings up to six storeys, which will help to enhance the knowledge about their dynamic response.

2) A simplified model is proposed to estimate the fundamental period of lightframe wood buildings for the purpose of calculating base shear, based on height, shear wall length and building area.

3) This is the first comprehensive study on the effect of fire-separation at various stages of construction to investigate the connectivity between the buildings, and to evaluate the effect of fire-separation on the dynamic properties of the buildings.

4) This comprehensive study documents the important contribution of nonstructural components on the dynamic properties of wood-frame buildings (ten buildings measured in two stages of construction).

5) The study also reports a brief database of dynamic properties of nine beam and post construction buildings of regular and L-shape and multiple storeys (four to eight storeys) with variable plan dimension. 


\section{APPENDIX A}

Table A- 1 Geometric details of measured buildings

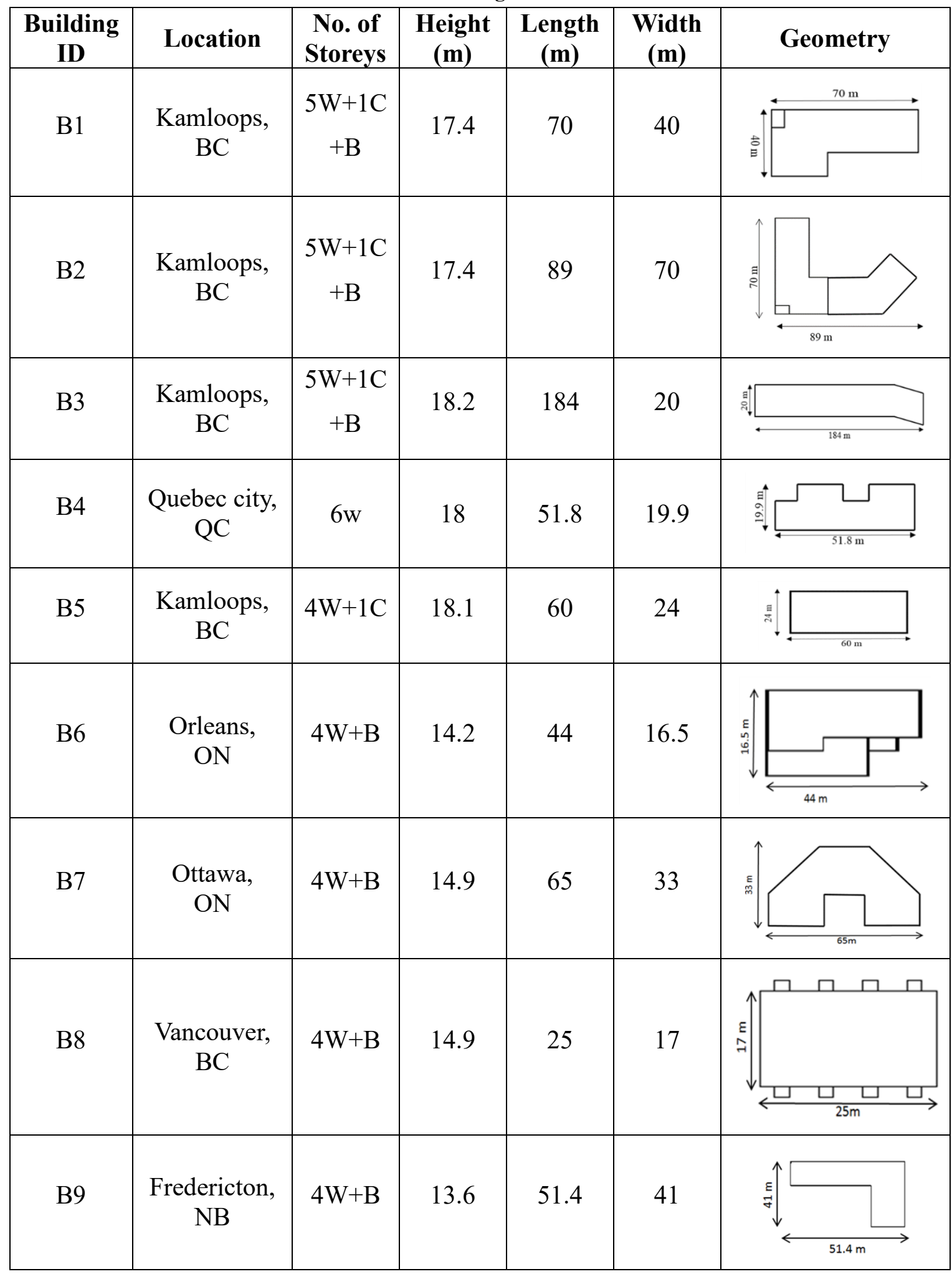




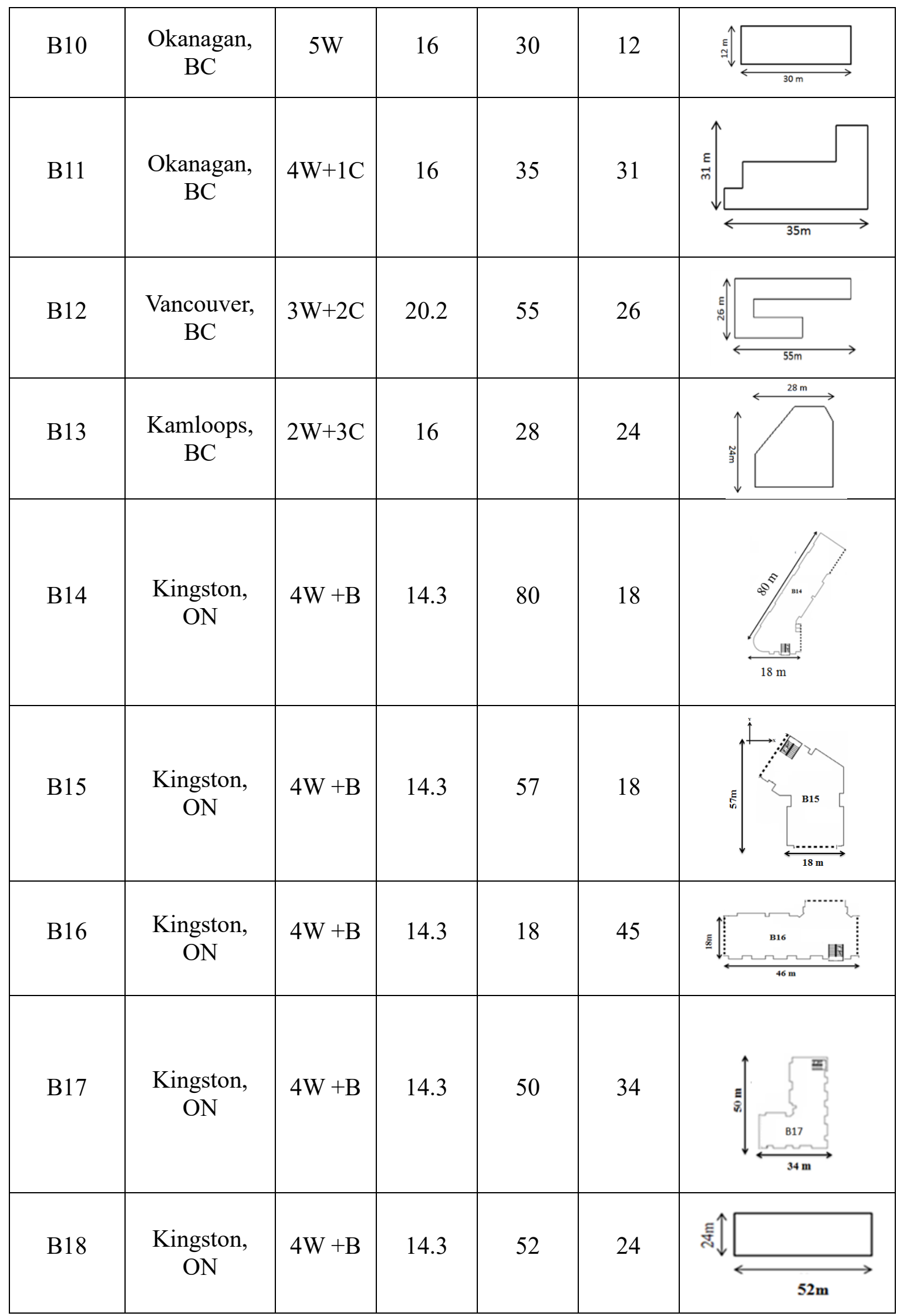




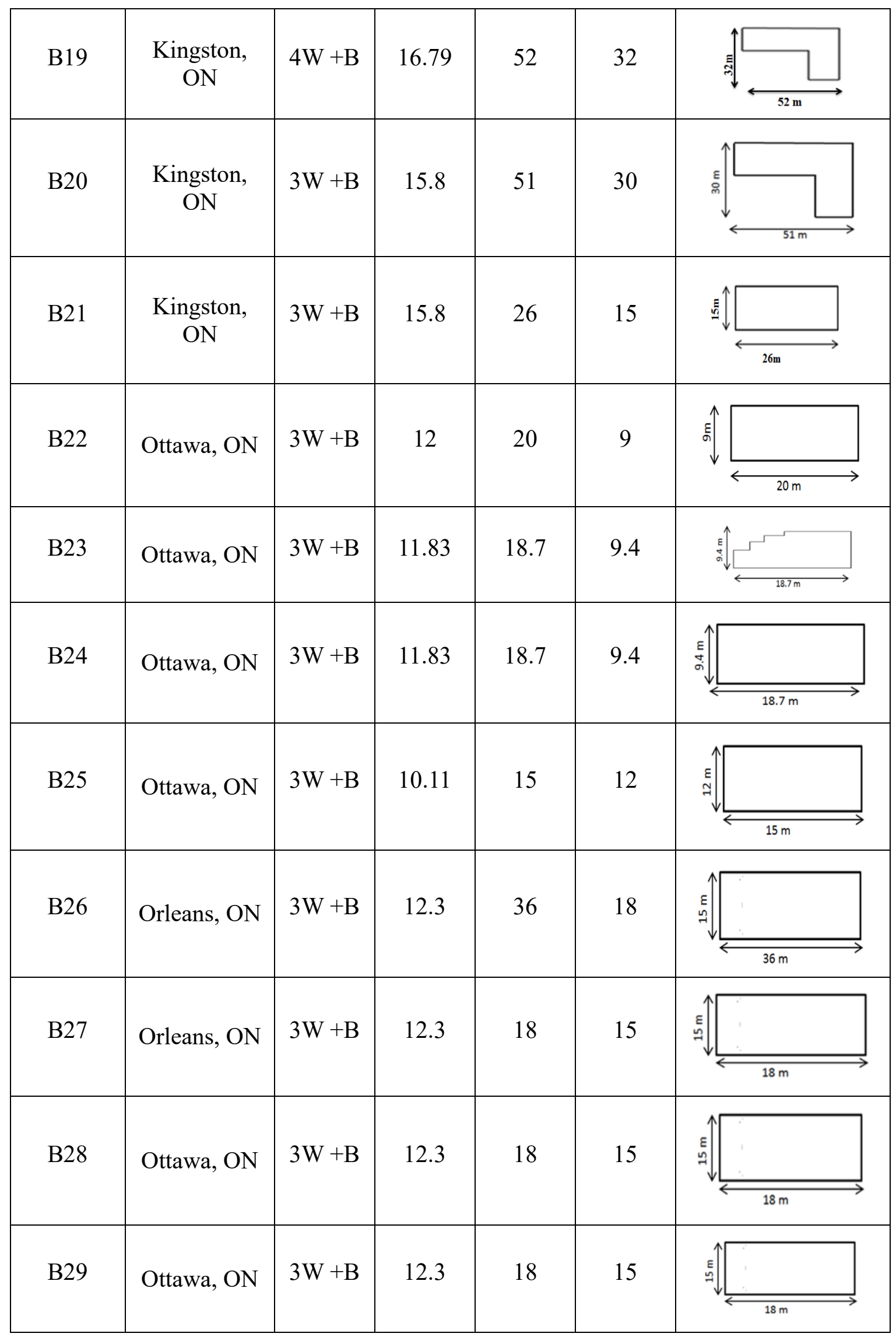




\begin{tabular}{|c|c|c|c|c|c|c|c|}
\hline B30 & Ottawa, ON & $2 W+B$ & 6.4 & 20 & 7.6 & | & \\
\hline B31 & Orleans, ON & $4 \mathrm{~W}$ & 14.28 & 50 & 24 & 㩆 & \\
\hline B32 & Orleans, ON & $4 \mathrm{~W}$ & 14.28 & 41 & 24 & 蛋 & \\
\hline B33 & Orleans, ON & $3 W+B$ & 13.1 & 18 & 15 & ઘ & \\
\hline B34 & Orleans, ON & $3 \mathrm{~W}+\mathrm{B}$ & 13.1 & 18 & 15 & $\begin{array}{c}\varepsilon \\
\varrho\end{array}$ & \\
\hline B35 & Boucherville & $2 \mathrm{~W}$ & 6 & 9.7 & 9.4 & 早 & \\
\hline B36 & Longueuil, & $2 \mathrm{~W}$ & 6 & 9.1 & 6.7 & 5 & \\
\hline B37 & $\begin{array}{c}\text { Brossard, } \\
\text { OC }\end{array}$ & $2 \mathrm{~W}$ & 6 & 8.5 & 7.3 & 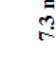 & \\
\hline B38 & $\begin{array}{c}\text { Brossard, } \\
\text { QC }\end{array}$ & $2 \mathrm{~W}$ & 6 & 9.7 & 9.4 & & \\
\hline B39 & $\begin{array}{c}\text { Brossard, } \\
\text { OC }\end{array}$ & $2 \mathrm{~W}$ & 6 & 9.1 & 7.3 & 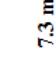 & \\
\hline B40 & Brossard, & $1 \mathrm{~W}$ & 3 & 10.3 & 8.5 & $\infty$ & \\
\hline B41 & $\begin{array}{c}\text { Kamloops, } \\
\text { BC }\end{array}$ & $4 \mathrm{~W}$ & 3 & 70 & 50 & 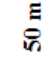 & \\
\hline & & & & & & & 70 \\
\hline
\end{tabular}




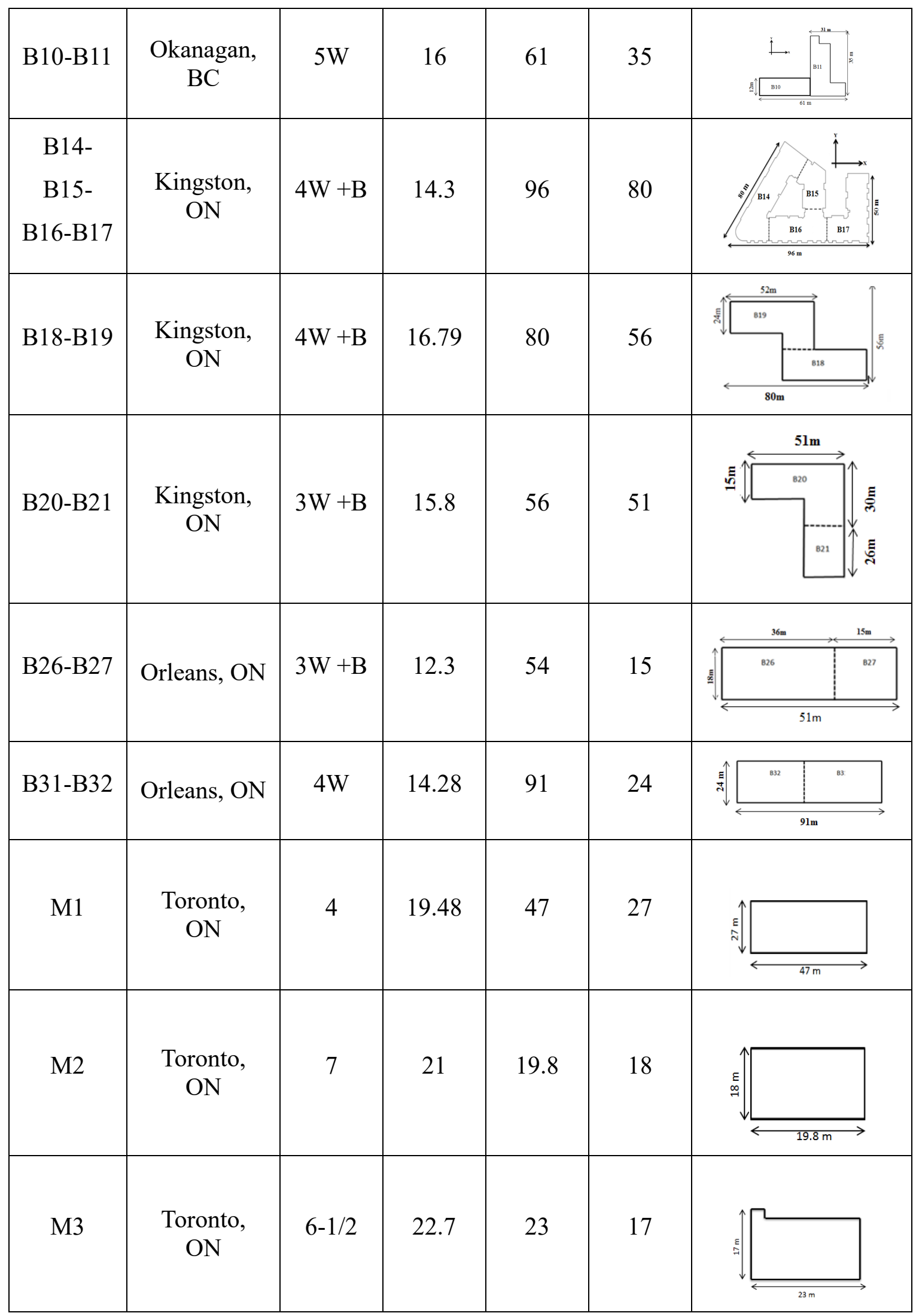




\begin{tabular}{|c|c|c|c|c|c|c|c|}
\hline M4 & $\begin{array}{c}\text { Toronto, } \\
\text { ON }\end{array}$ & 5 & 22.7 & 56 & 18 & $\underset{\substack{E \\
\sim}}{E}$ & $56 \mathrm{~m}$ \\
\hline M5 & $\begin{array}{c}\text { Toronto, } \\
\text { ON }\end{array}$ & 7 & 21 & 27 & 18 & 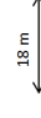 & $27 m$ \\
\hline M6 & $\begin{array}{c}\text { Toronto, } \\
\text { ON }\end{array}$ & 4 & 14.96 & 106 & 30 & & \\
\hline M7 & $\begin{array}{c}\text { Toronto, } \\
\text { ON }\end{array}$ & 4 & 18 & 43 & 11 & & \\
\hline M8 & $\begin{array}{c}\text { Toronto, } \\
\text { ON }\end{array}$ & 5 & 19.2 & 30 & 20 & ई & $30 \mathrm{~m}$ \\
\hline M9 & $\begin{array}{c}\text { Toronto, } \\
\text { ON }\end{array}$ & $4-1 / 2$ & 20.4 & 34 & 19 & & $34 \mathrm{~m}$ \\
\hline
\end{tabular}

Letters W, C and B in the "No. of stories" represent wood, concrete and basement. 


\section{APPENDIX B}

Building Measured in Phase 1 and Phase 2 Construction Stages

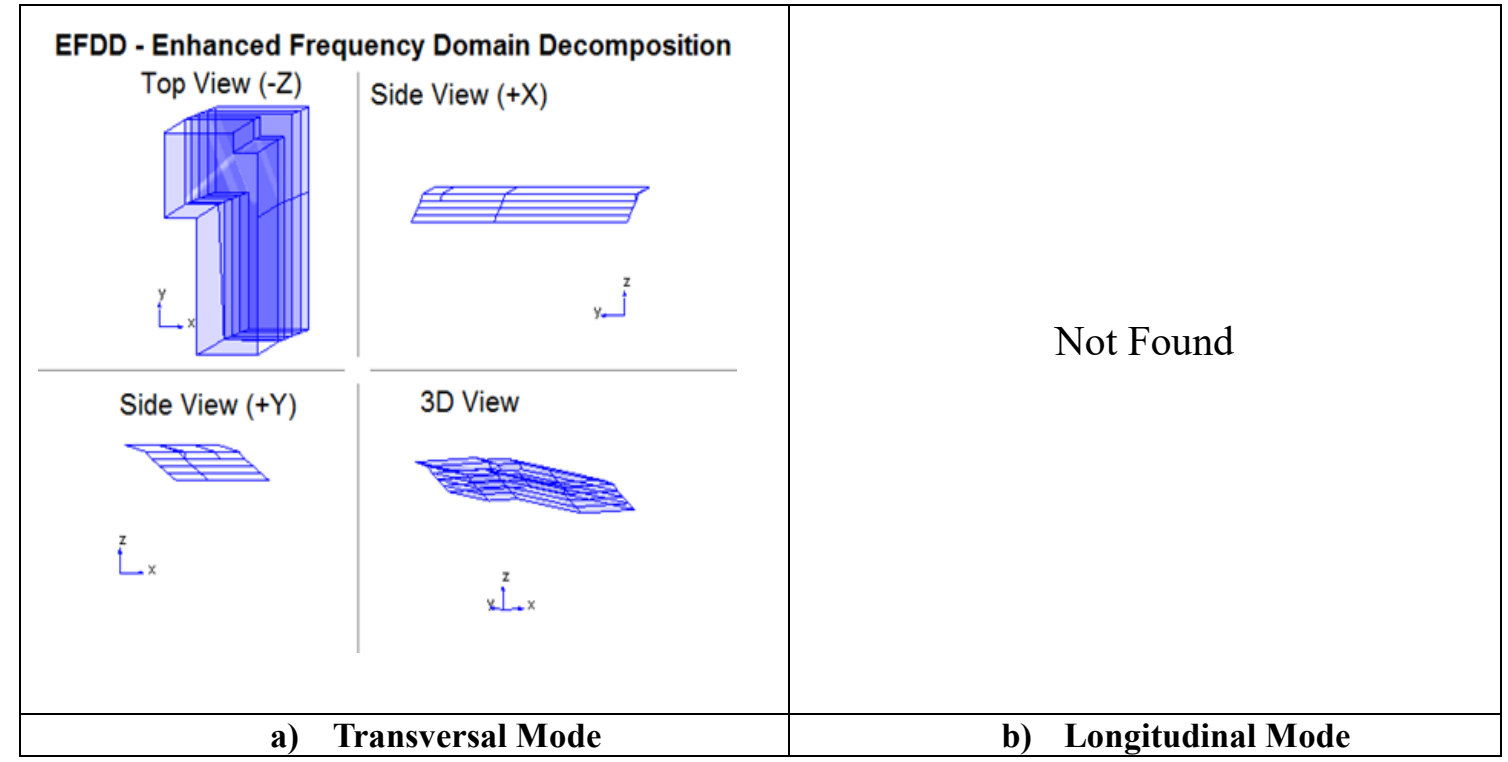

Figure B- 1 Mode shapes of B1 (Phase 1)

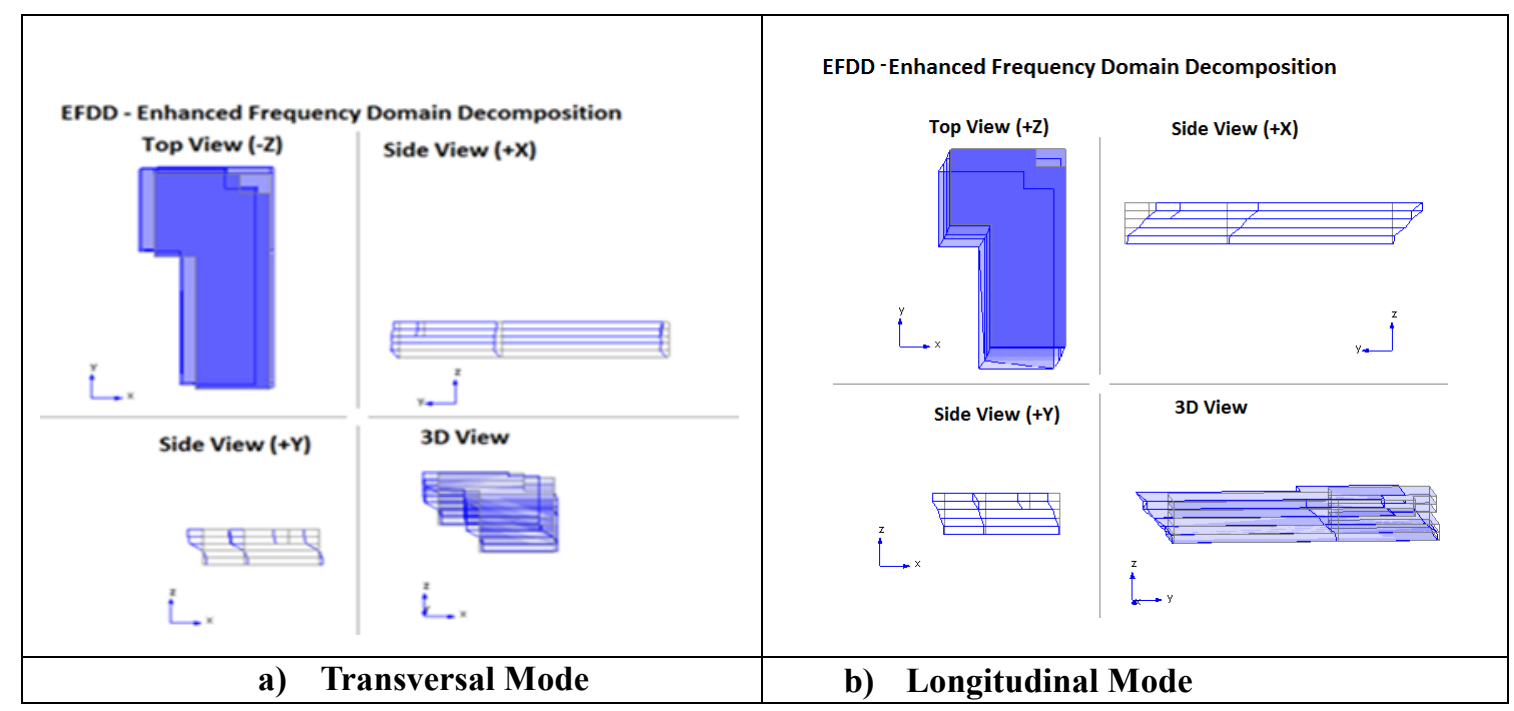

Figure B- 2 Mode shapes of B1 (Phase 2) 


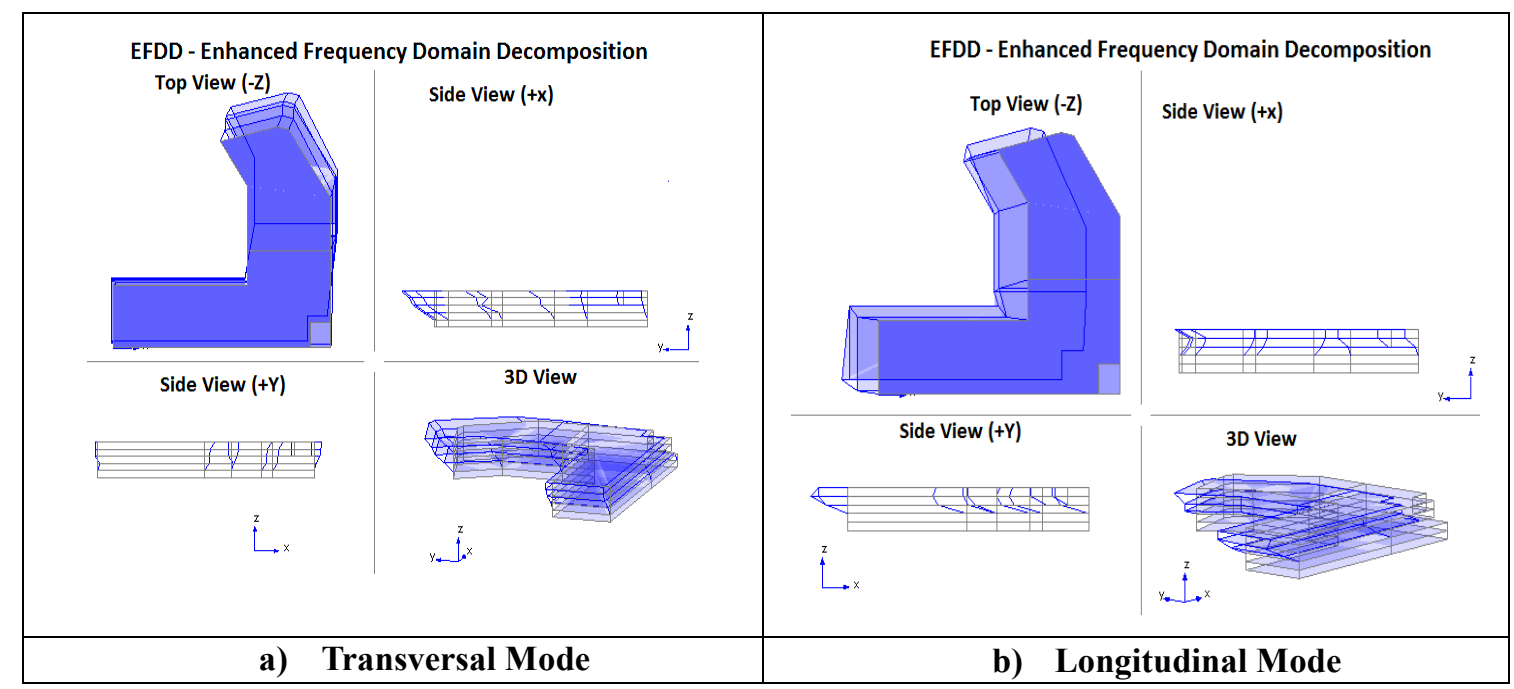

Figure B- 3 Mode shapes of B2 (Phase 1)

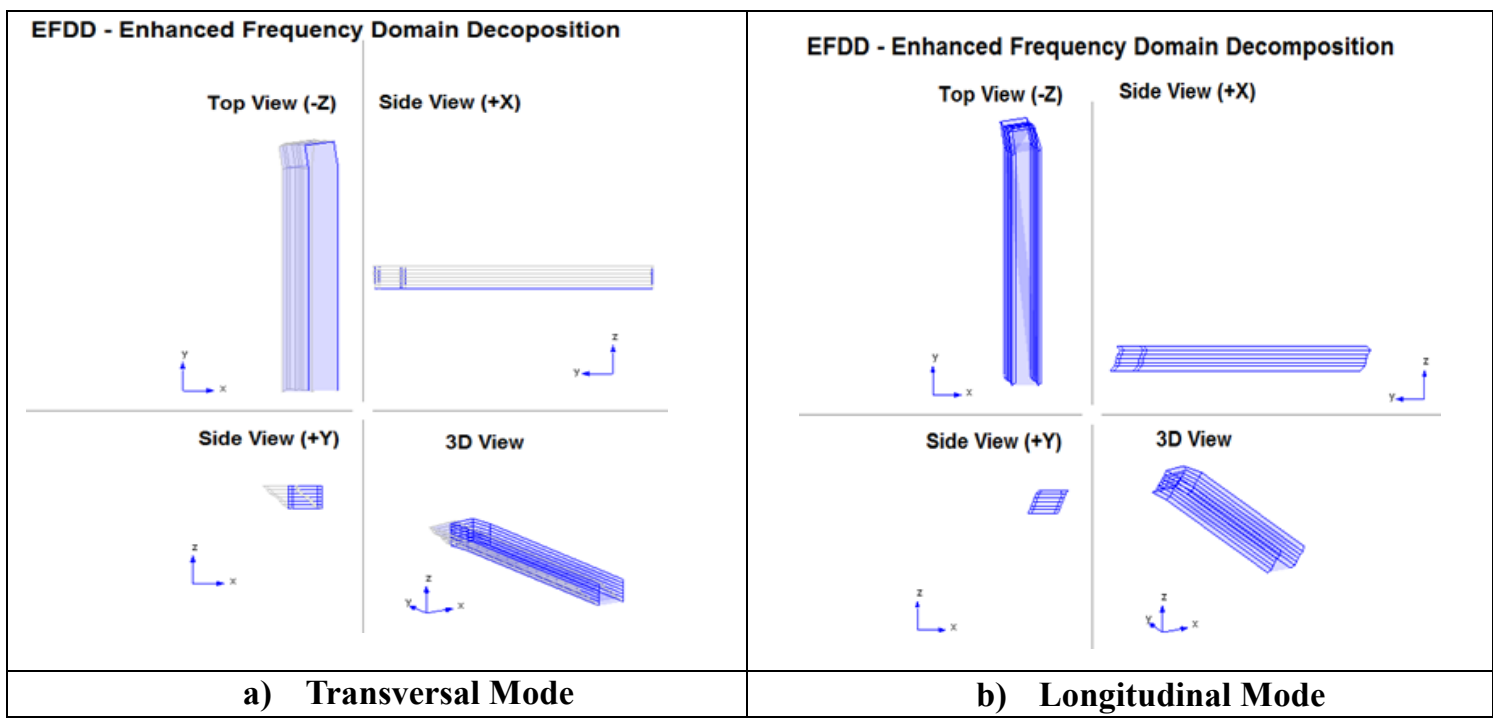

Figure B- 4 Mode shapes of B3 (Phase 1)

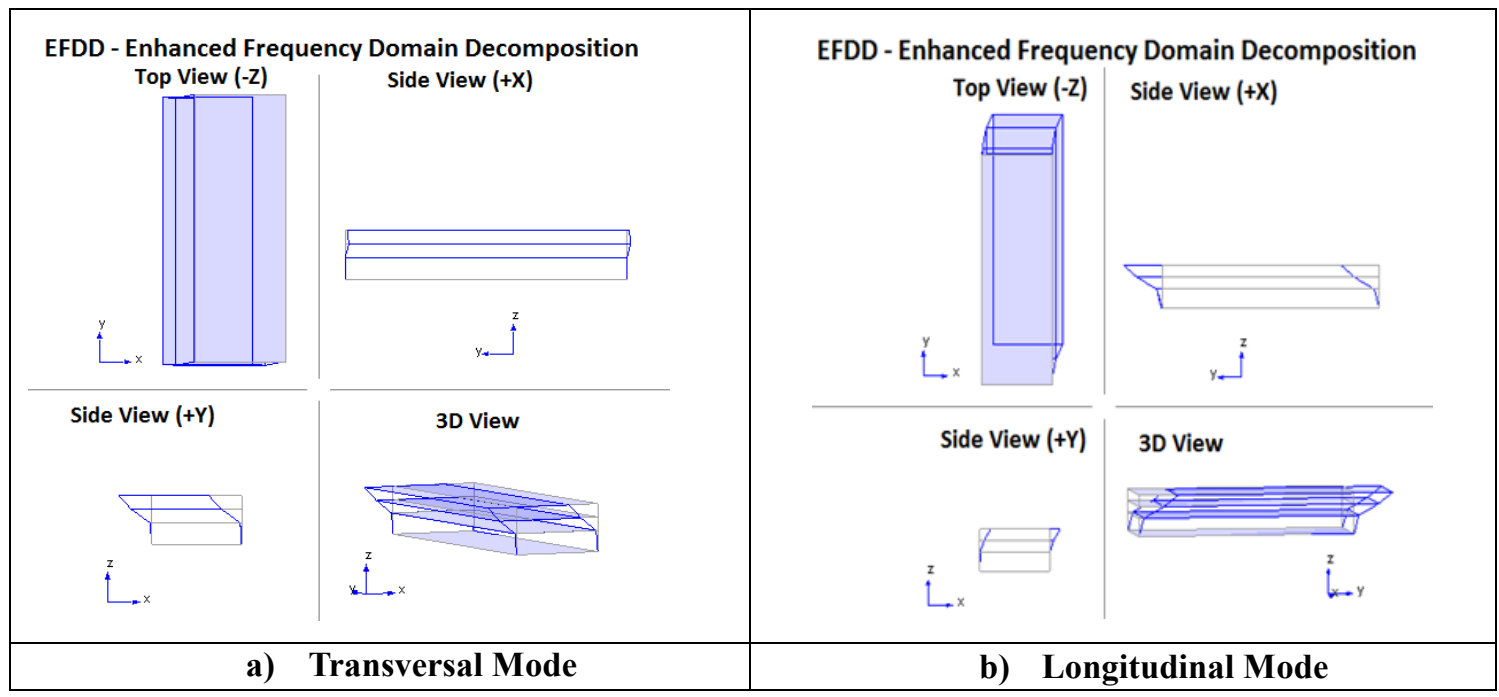

Figure B- 5 Mode shapes of B5 (Phase 1) 


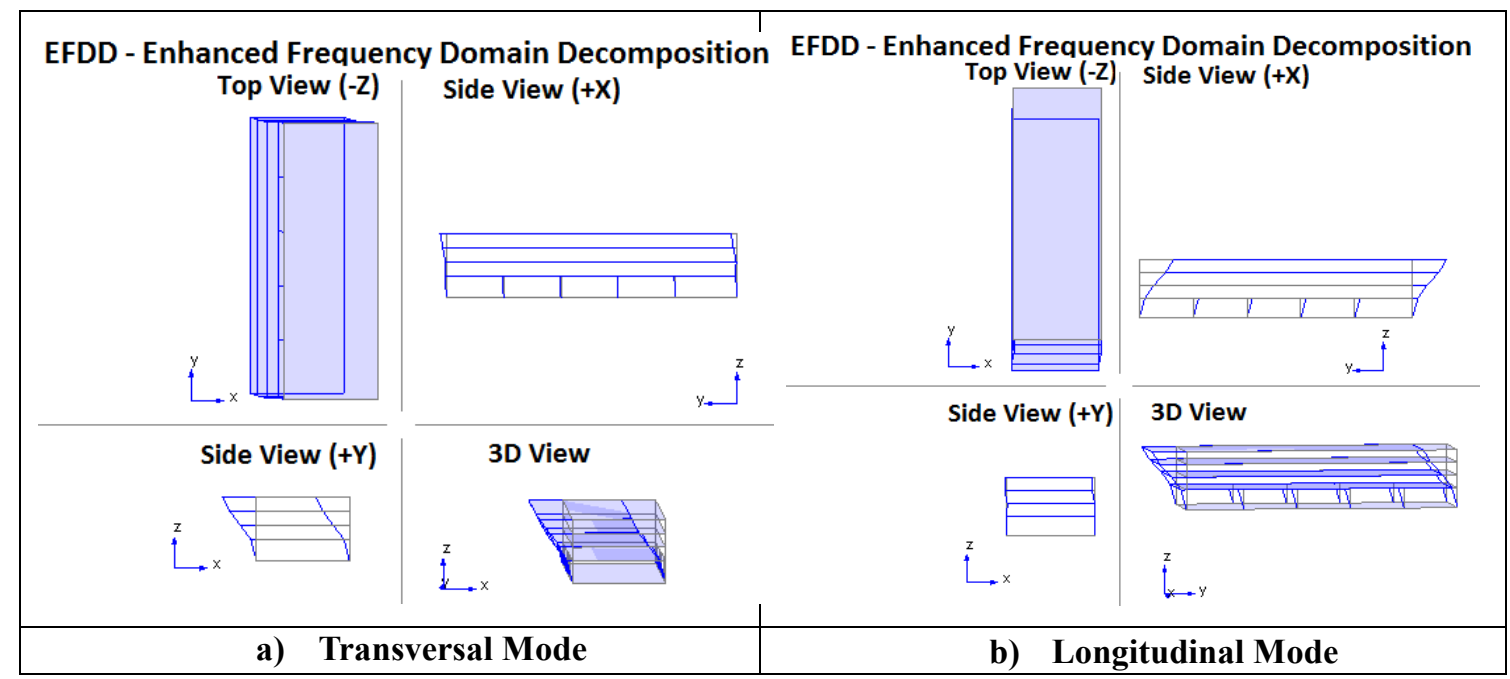

Figure B- 6 Mode shapes of B5 (Phase 2)

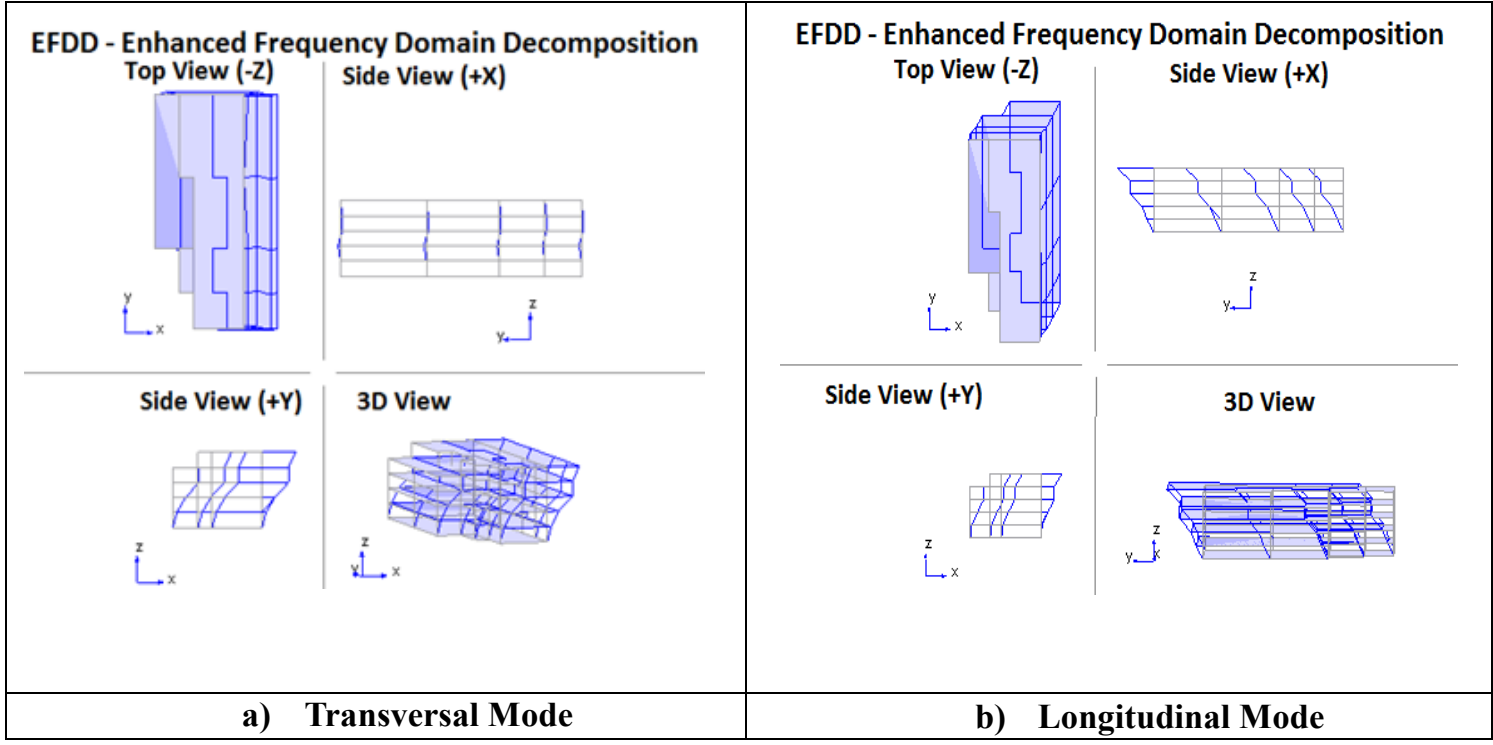

Figure B- 7 Mode shapes of B6 (Phase 1)

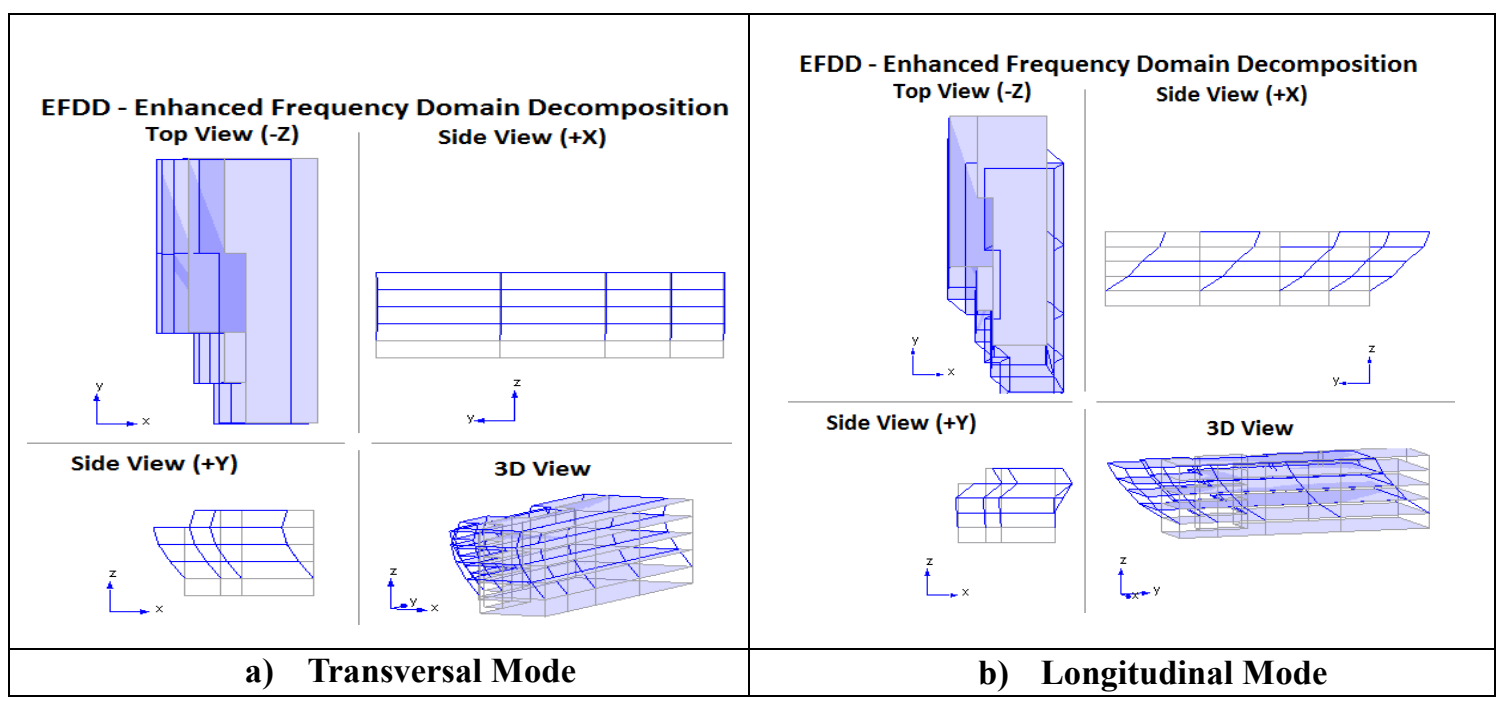

Figure B- 8 Mode shapes of B6 (Phase 2) 


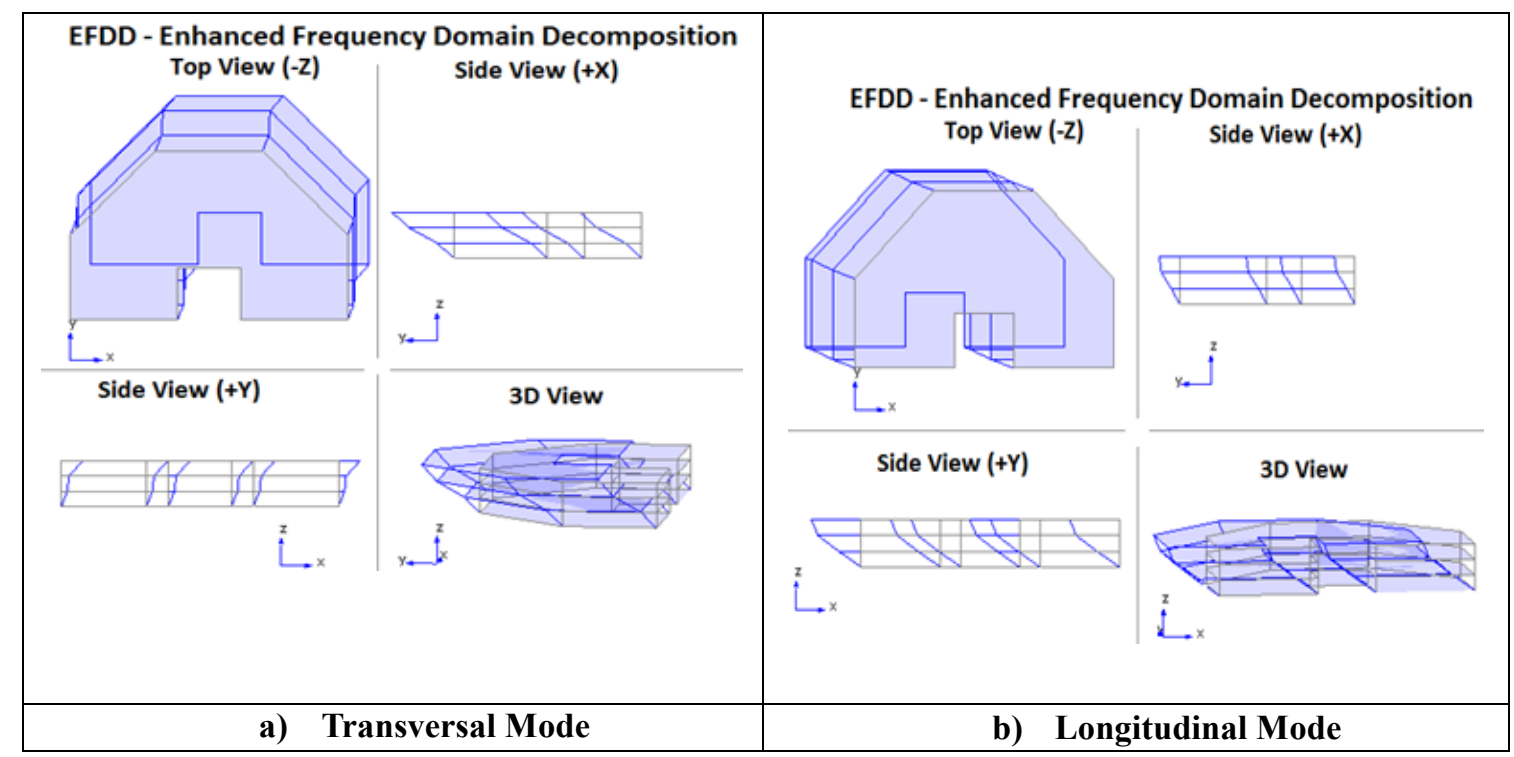

Figure B- 9 Mode shapes of B7 (Phase 1)

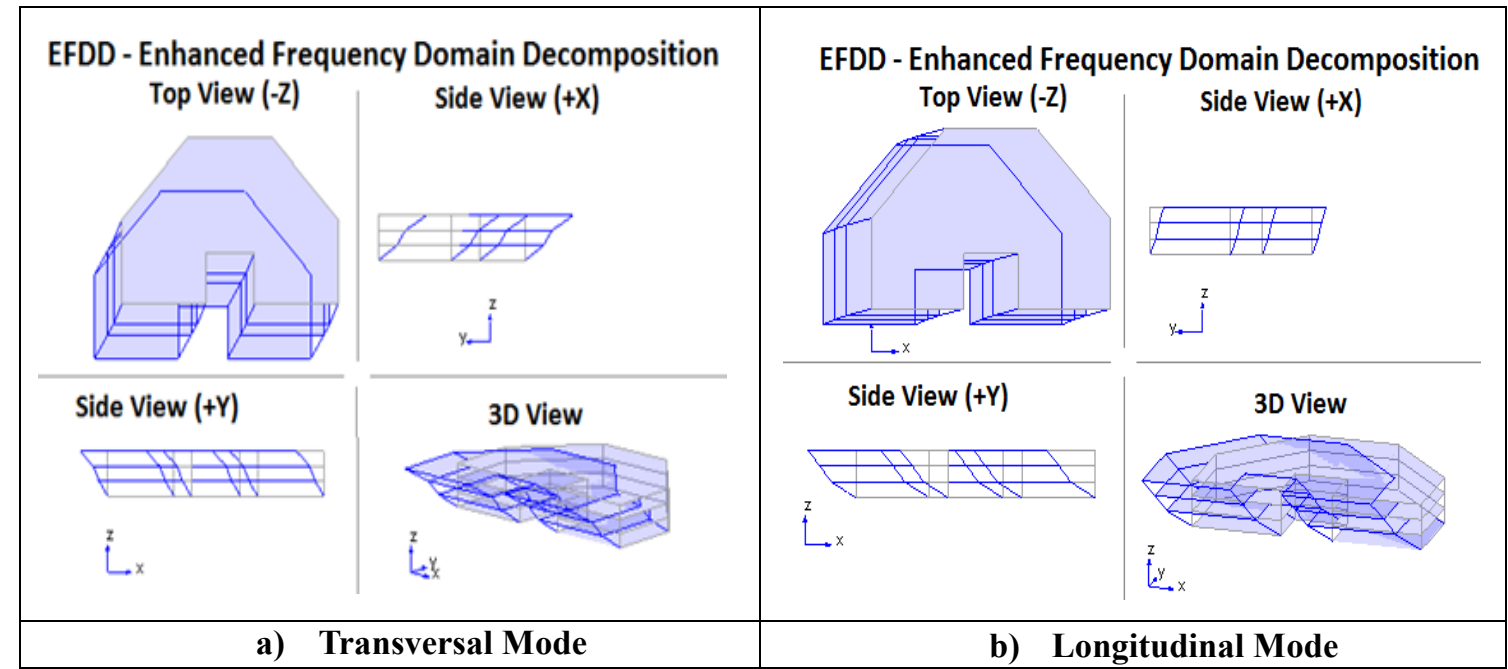

Figure B- 10 Mode shapes of B7 (Phase 2)

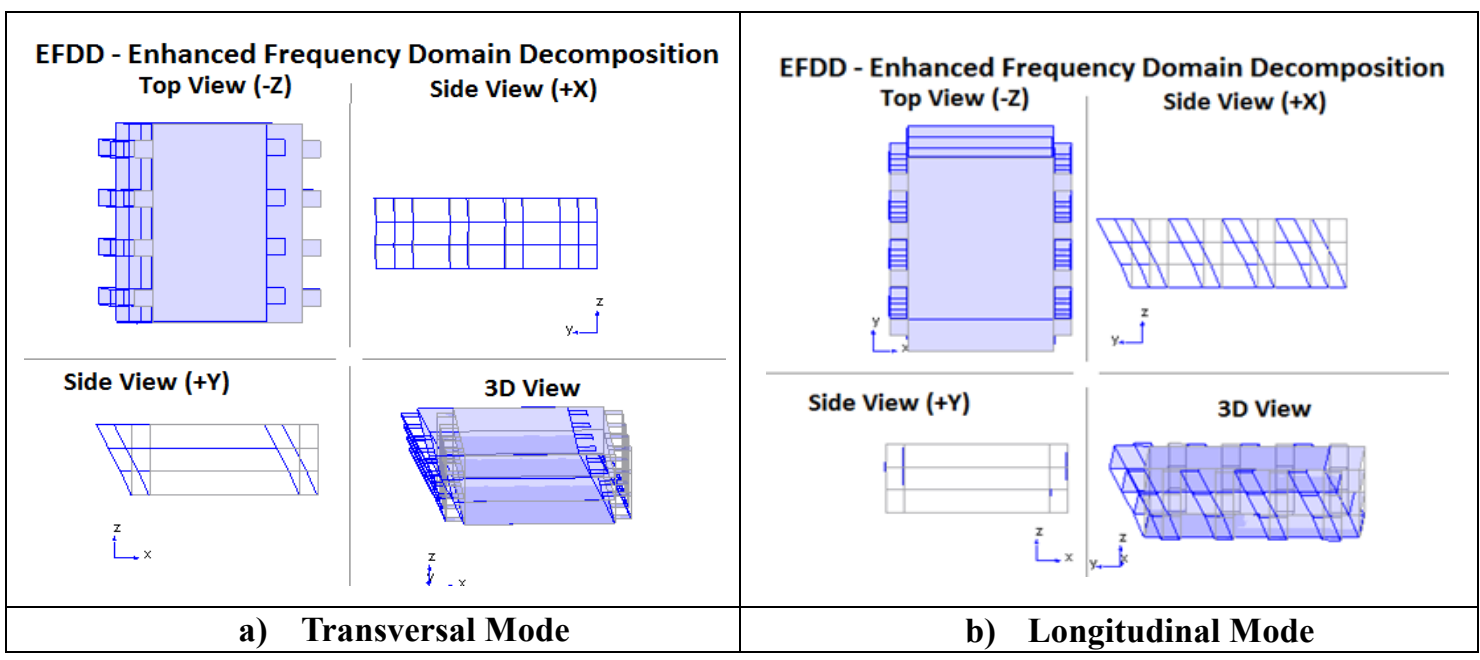

Figure B- 11 Mode shapes of B8 (Phase 2) 


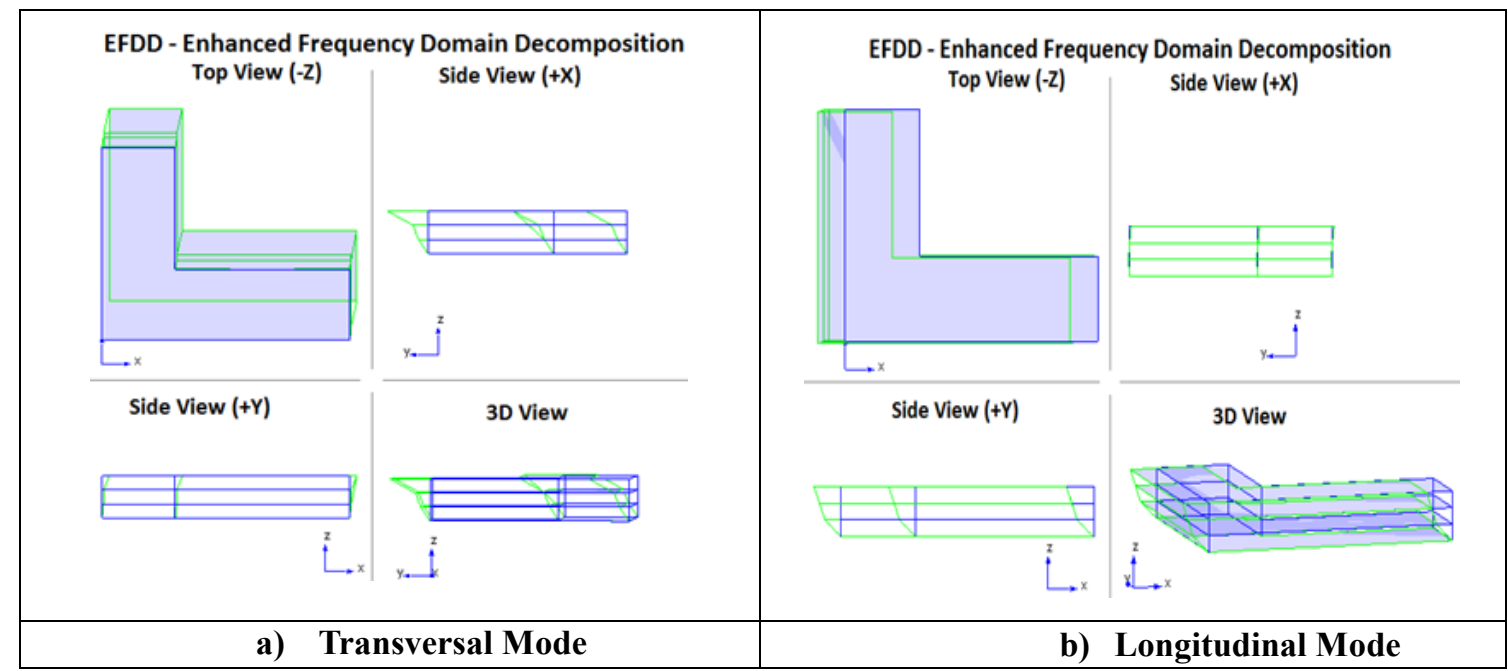

Figure B- 12 Mode shapes of B9 (Phase 2)

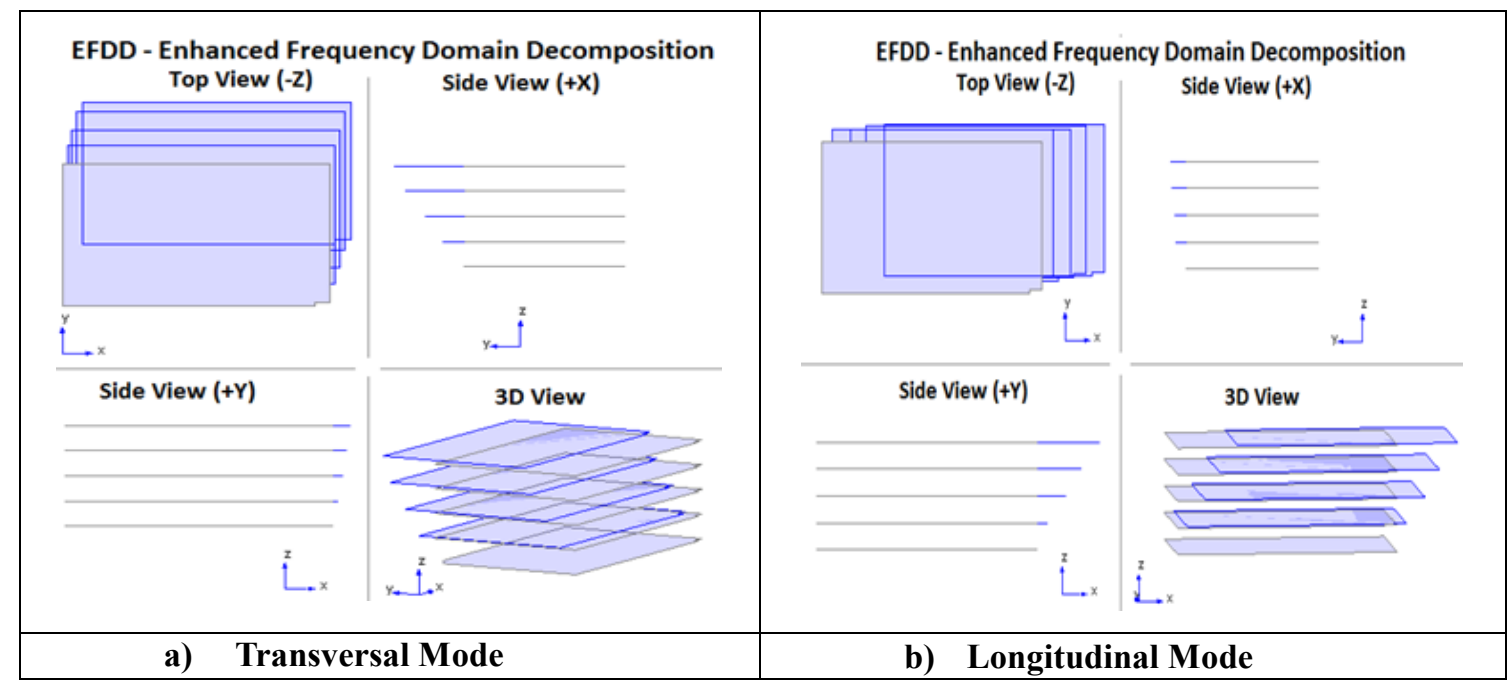

Figure B- 13 Mode shapes of B10 (Phase 2)

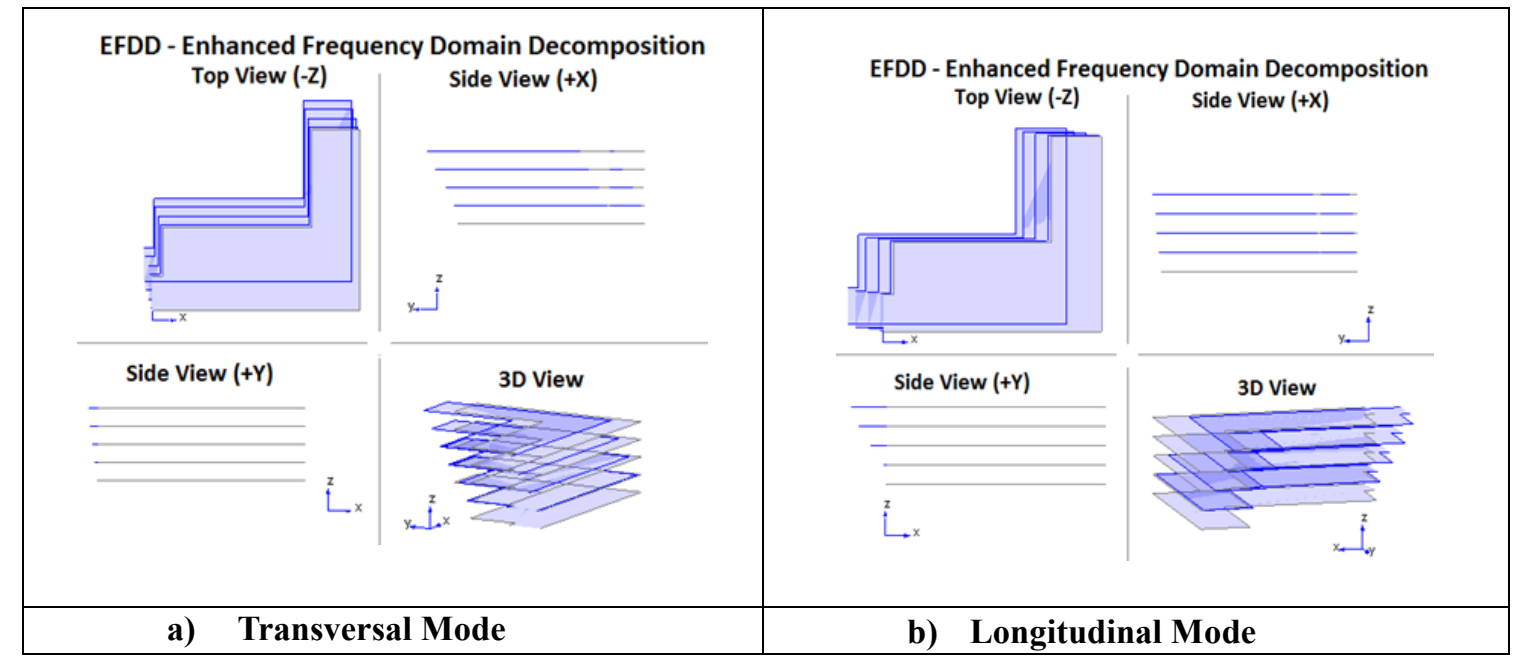

Figure B- 14 Mode shapes of B11 (Phase 2) 


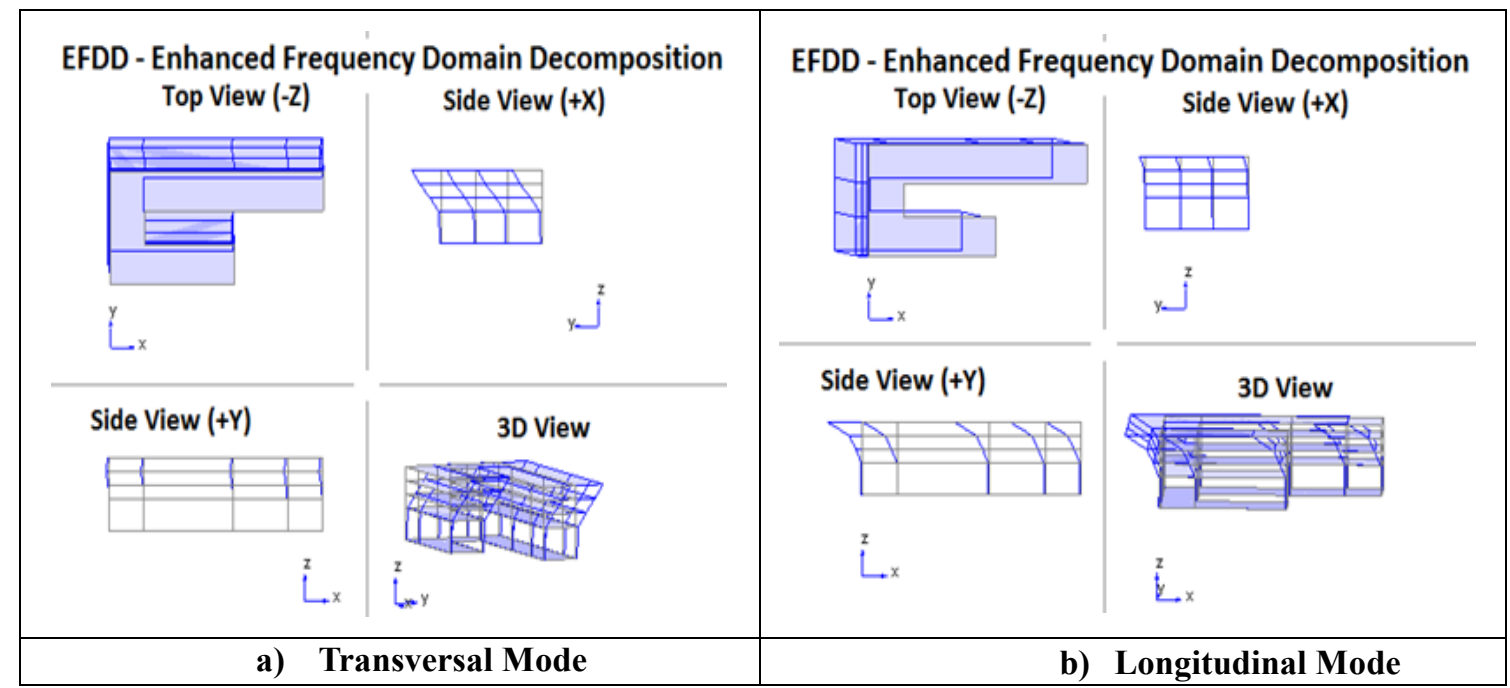

Figure B- 15 Mode shapes of B12 (Phase 2)

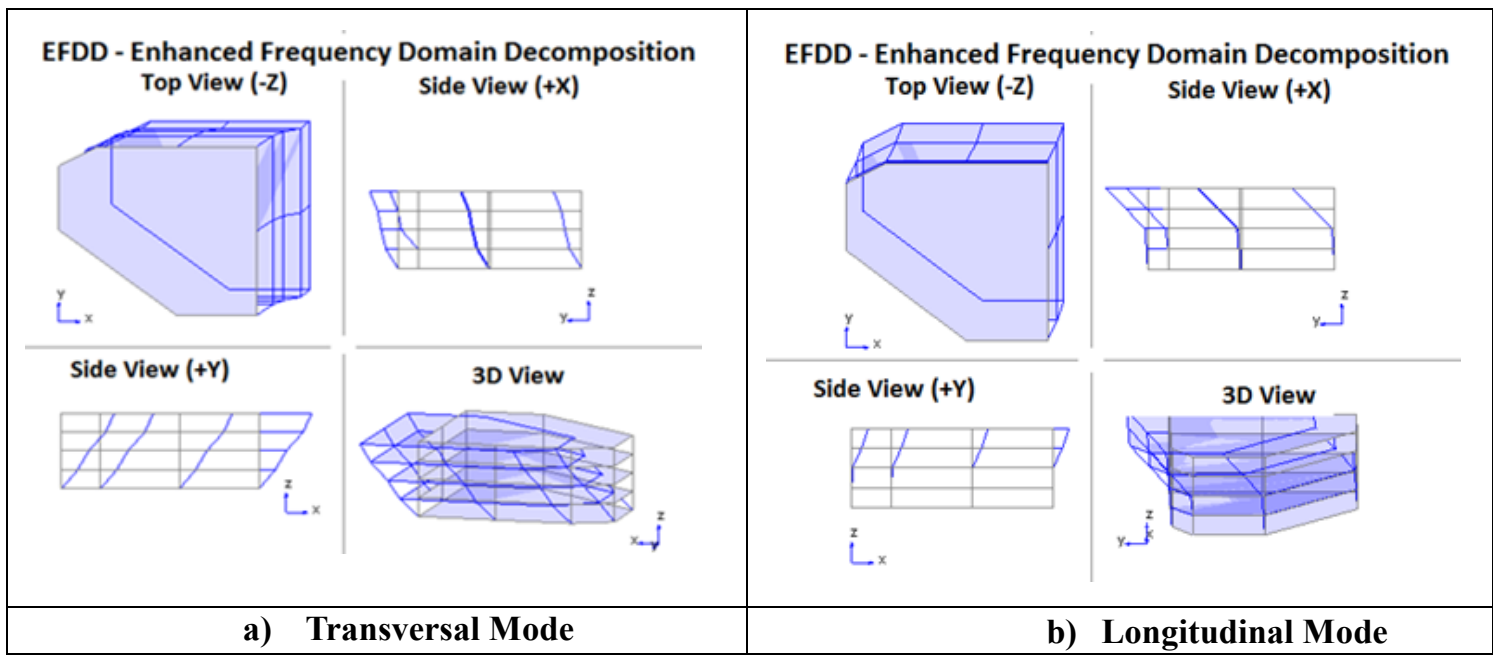

Figure B- 16 Mode shapes of B13 (Phase 2)

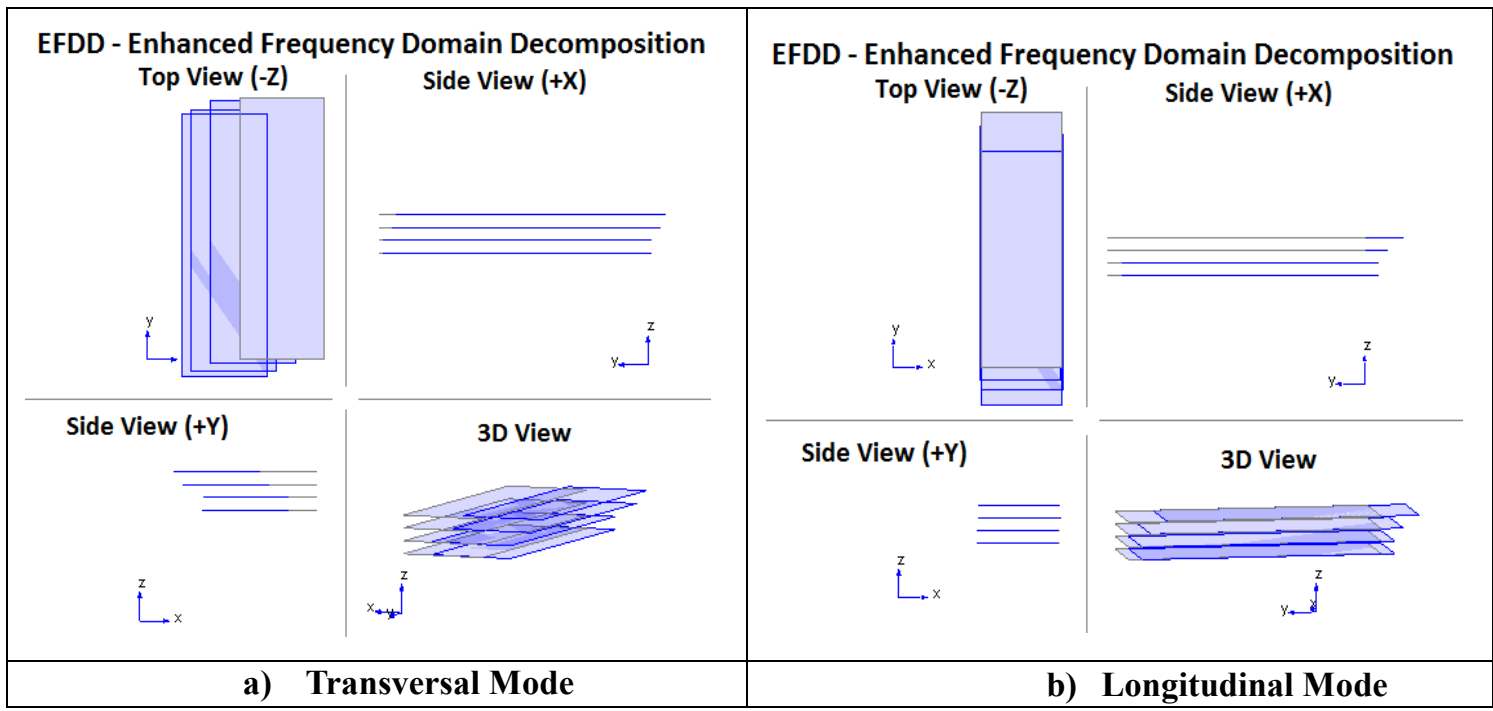

Figure B- 17 Mode shapes of B18 (Phase 2) 


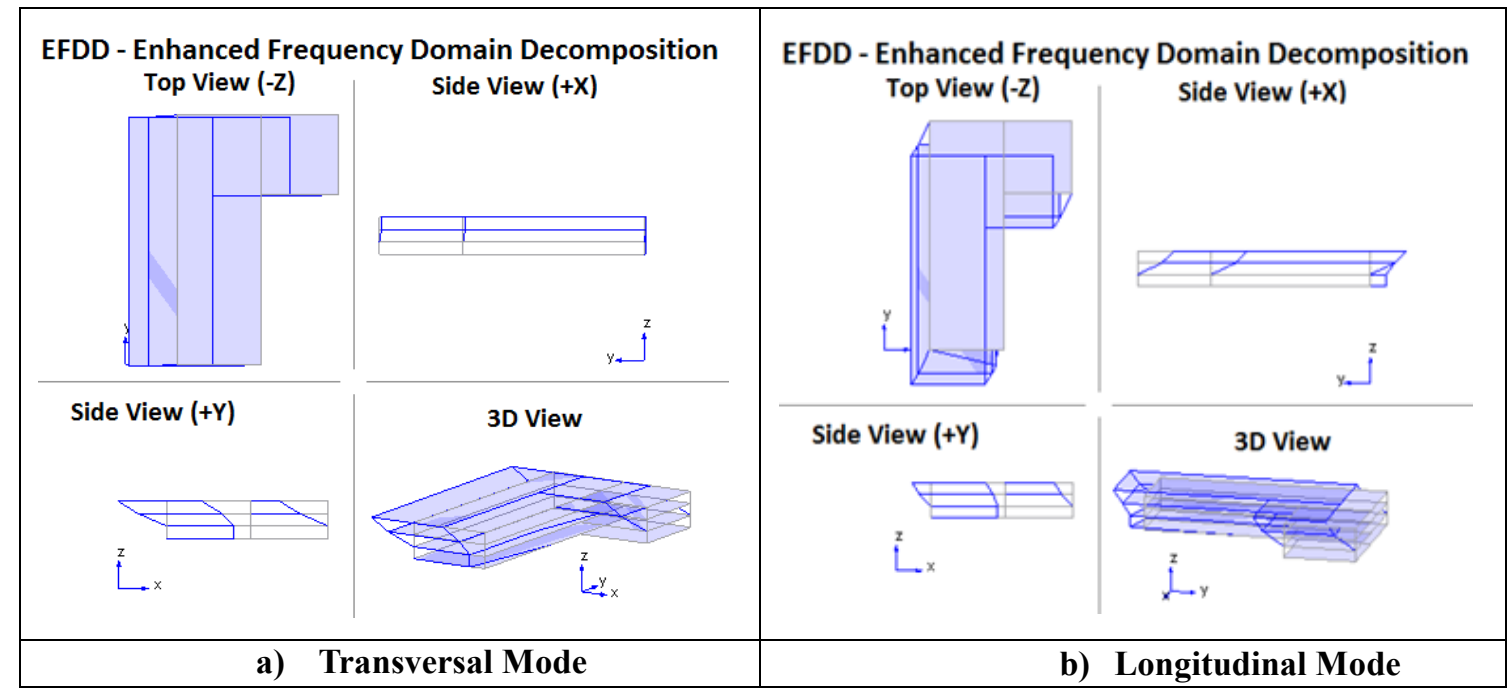

Figure B- 18 Mode shapes of B19 (Phase 2)

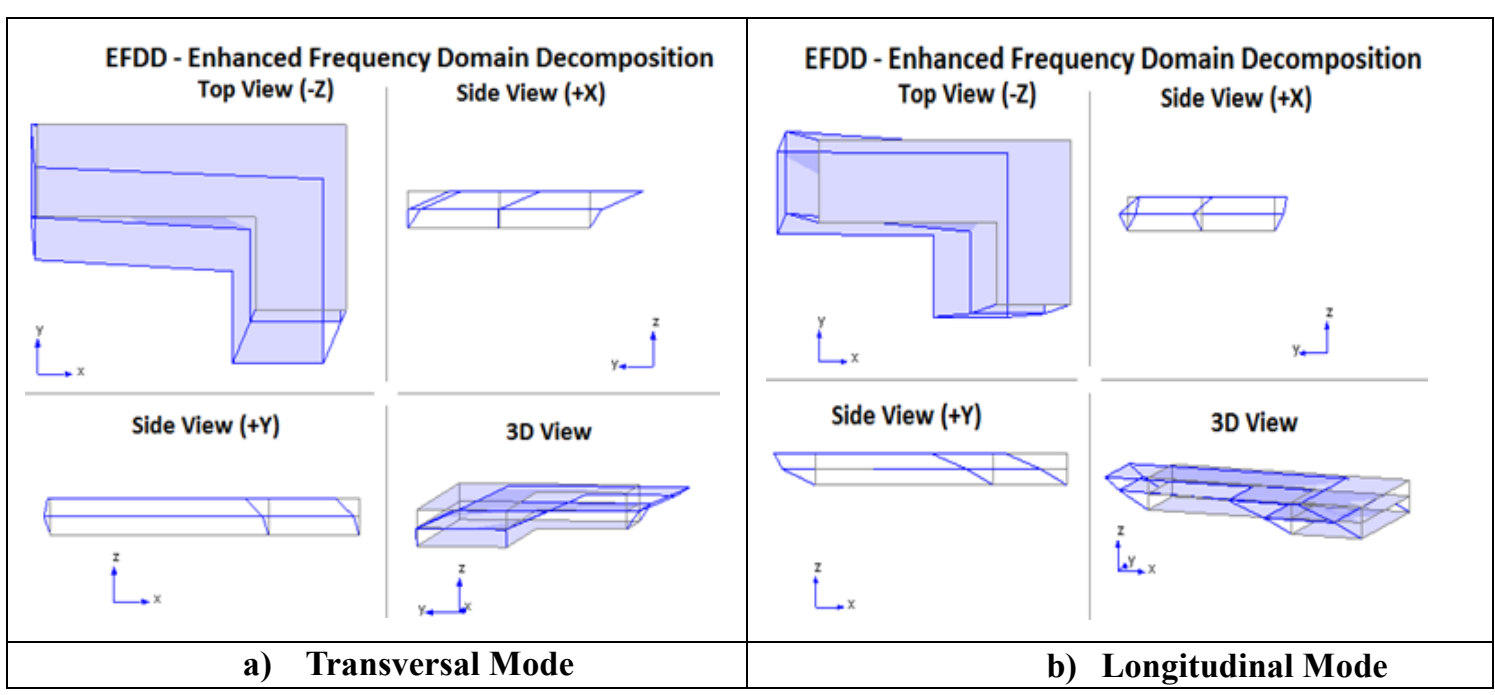

Figure B- 19 Mode shapes of B20 (Phase 2)

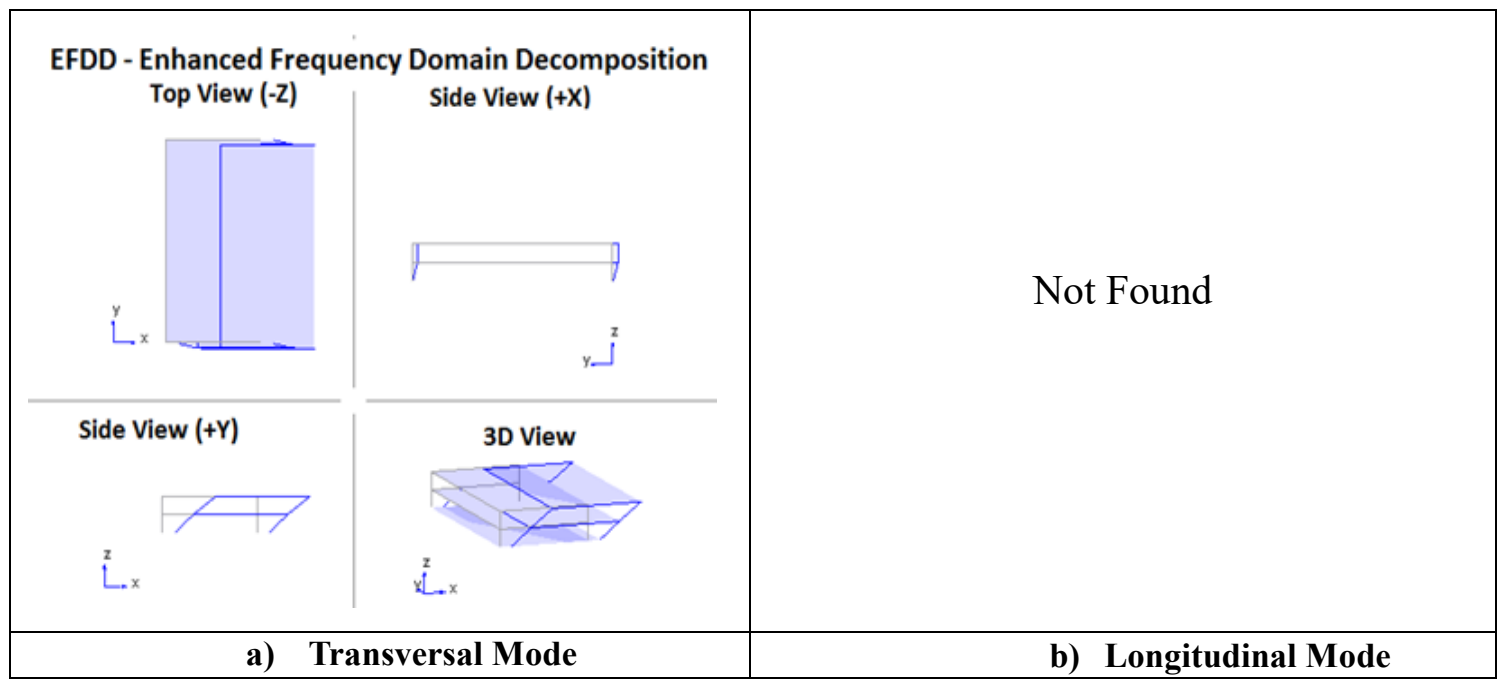

Figure B- 20 Mode shapes of B21 (Phase 2) 


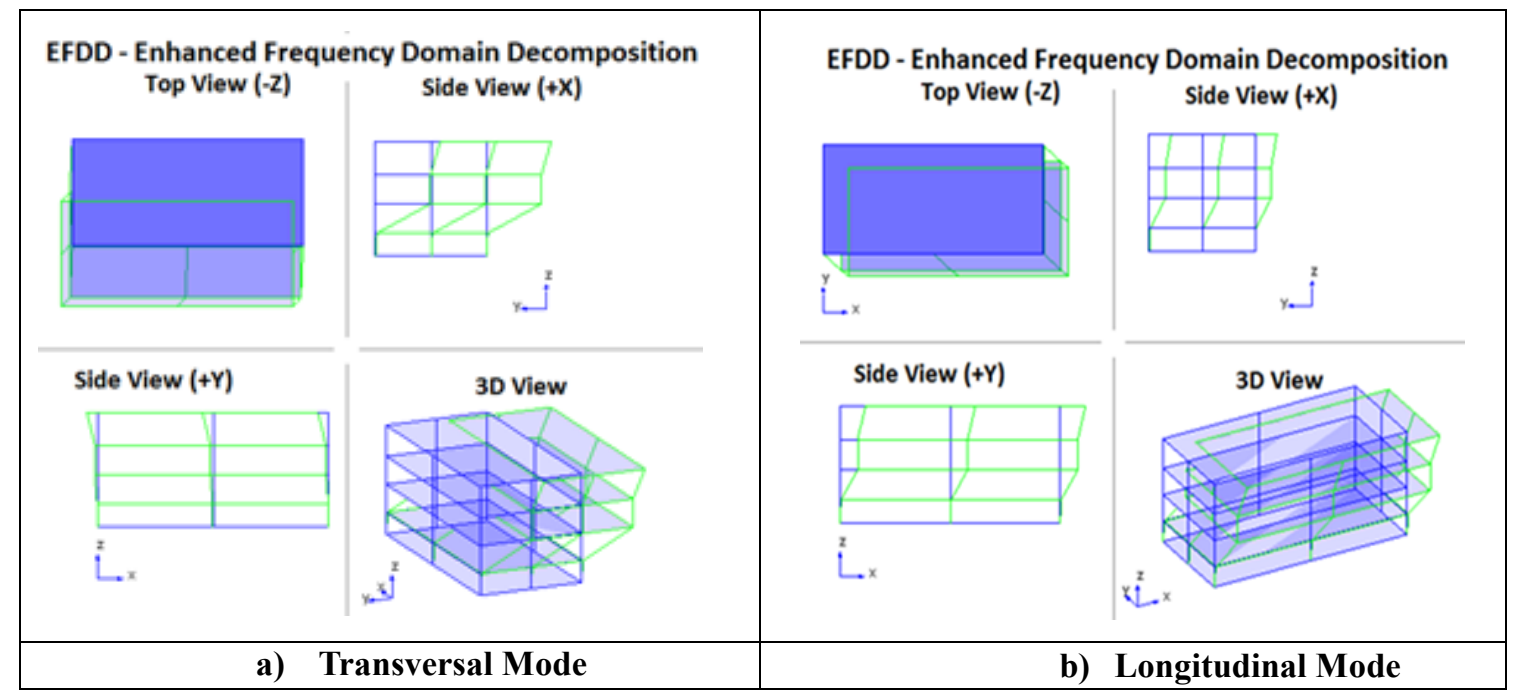

Figure B- 21 Mode shapes of B22 (Phase 1)

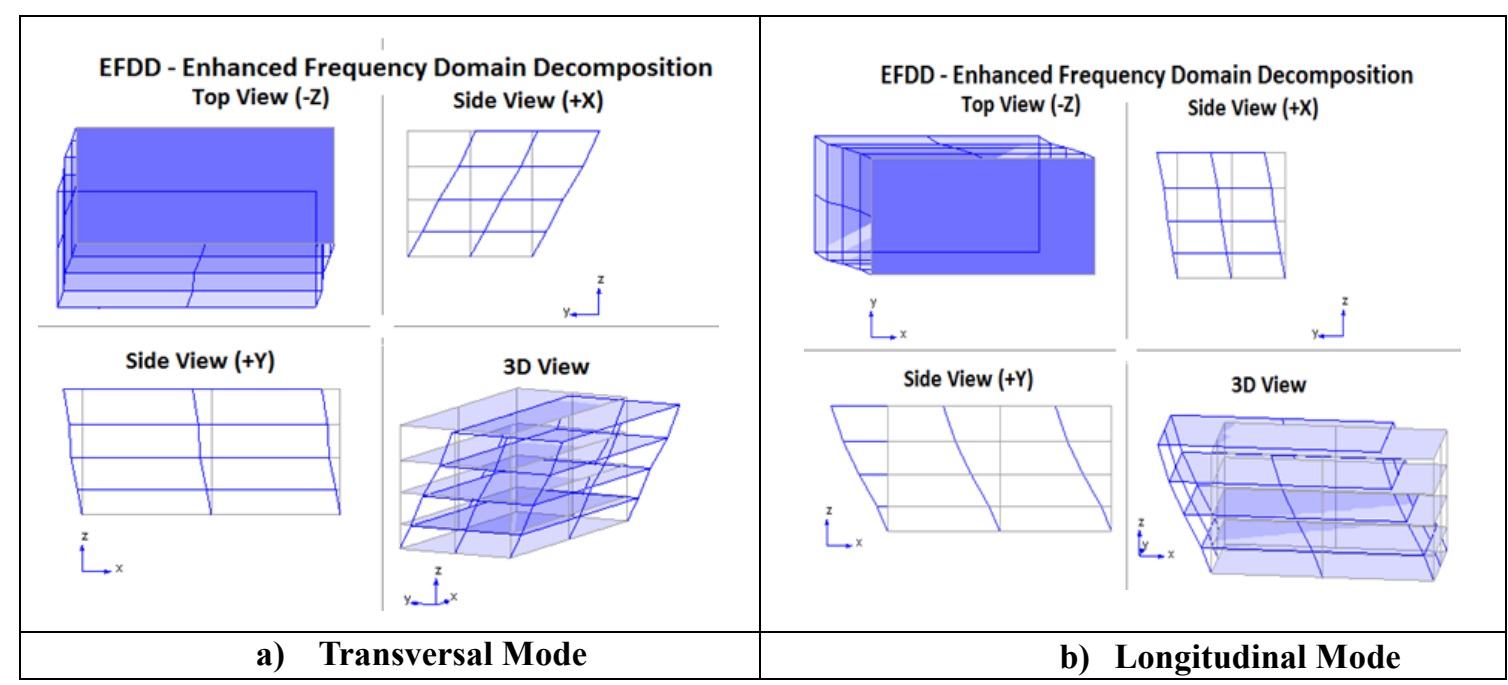

Figure B- 22 Mode shapes of B22 (Phase 2)

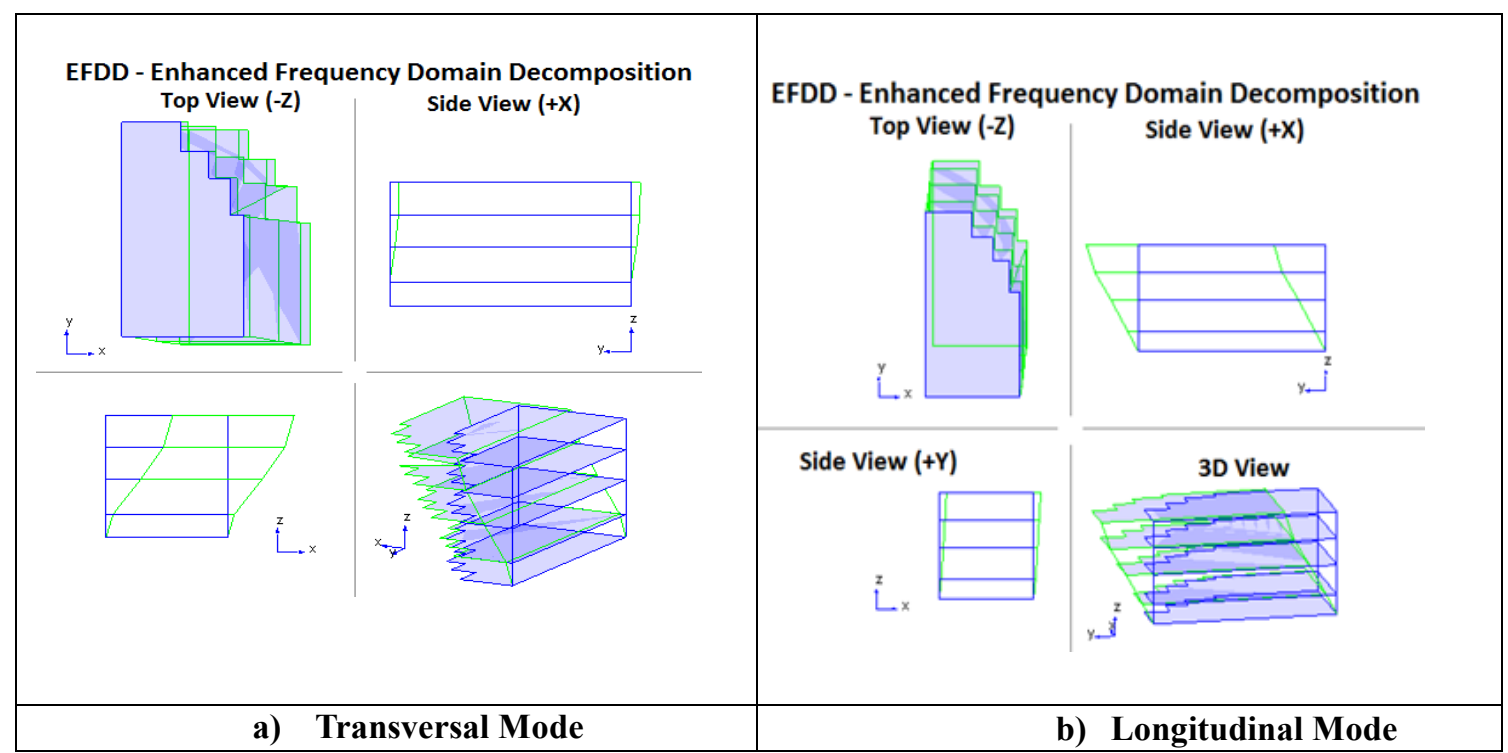

Figure B- 23 Mode shapes of B23 (Phase 1) 


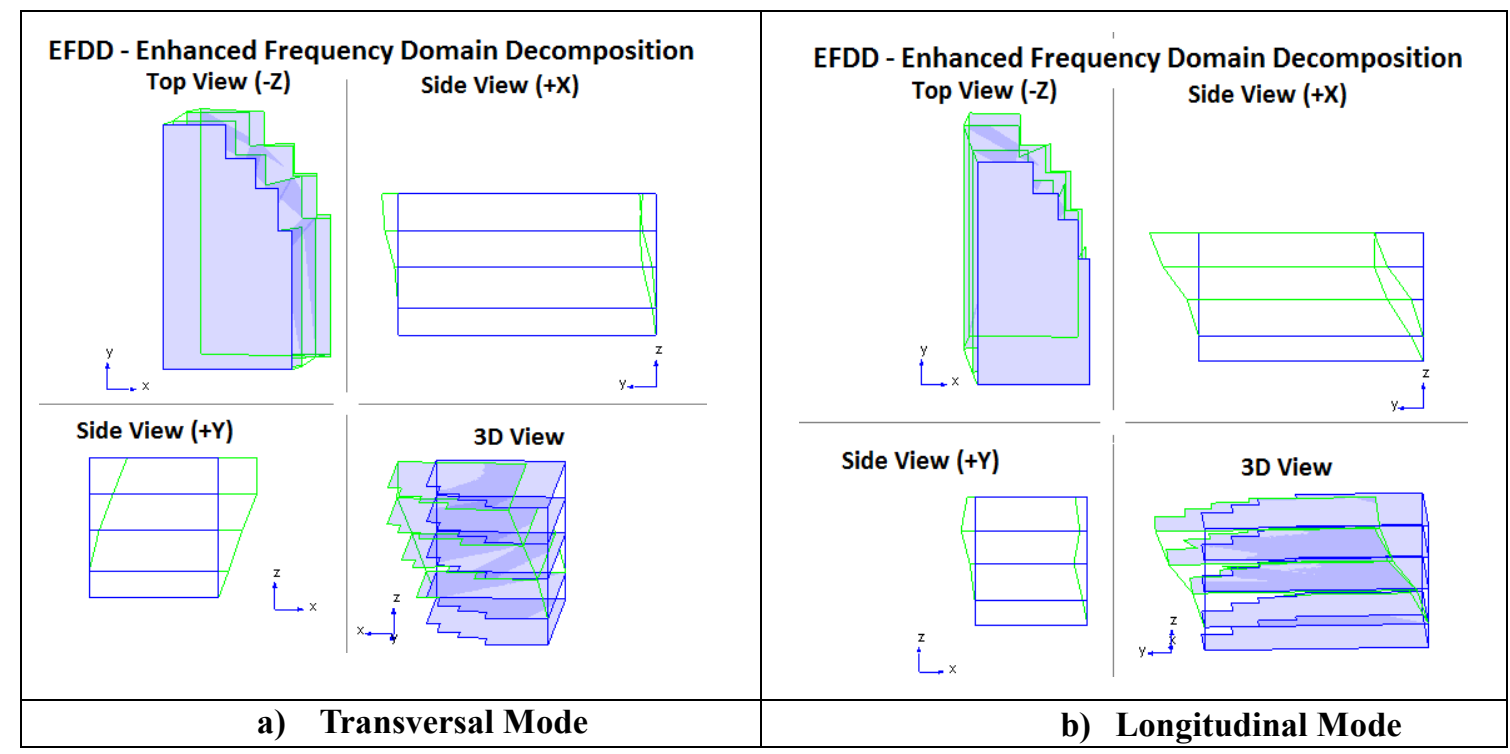

Figure B- 24 Mode shapes of B23 (Phase 2)

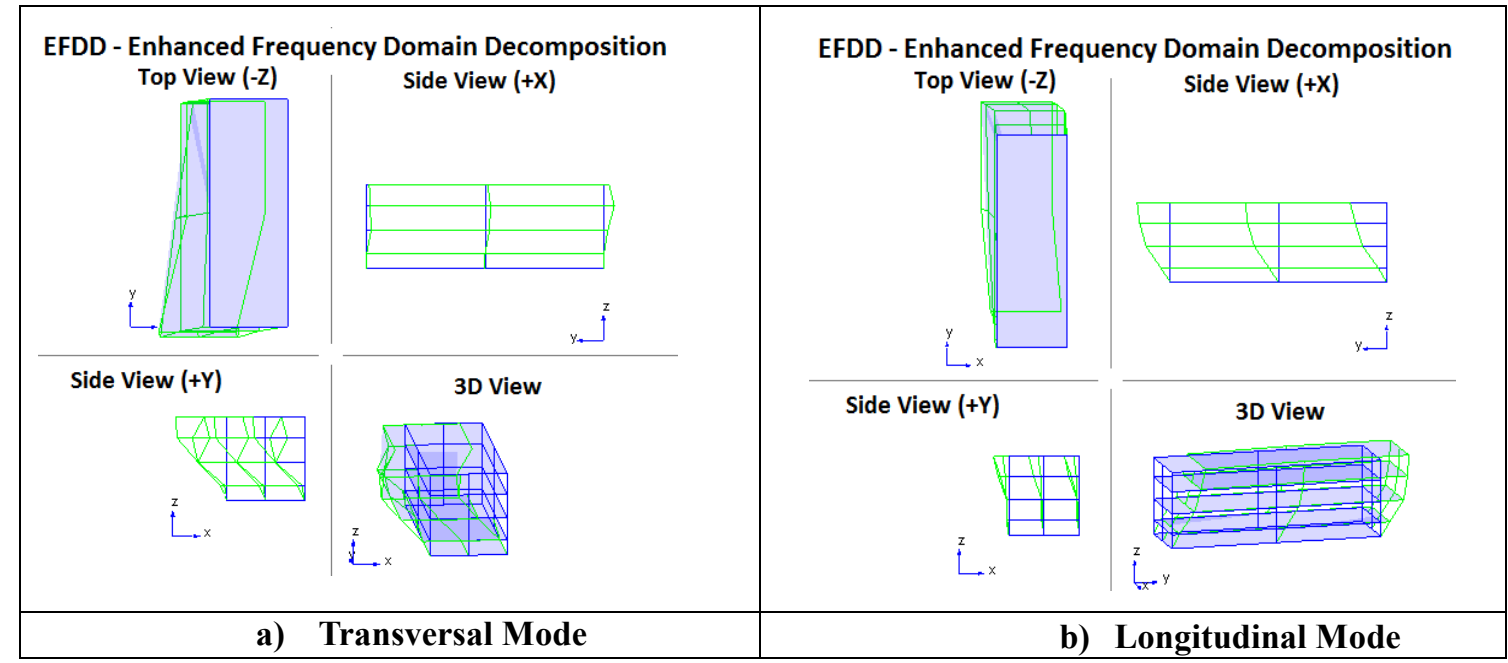

Figure B- 25 Mode shapes of B24 (Phase 1)

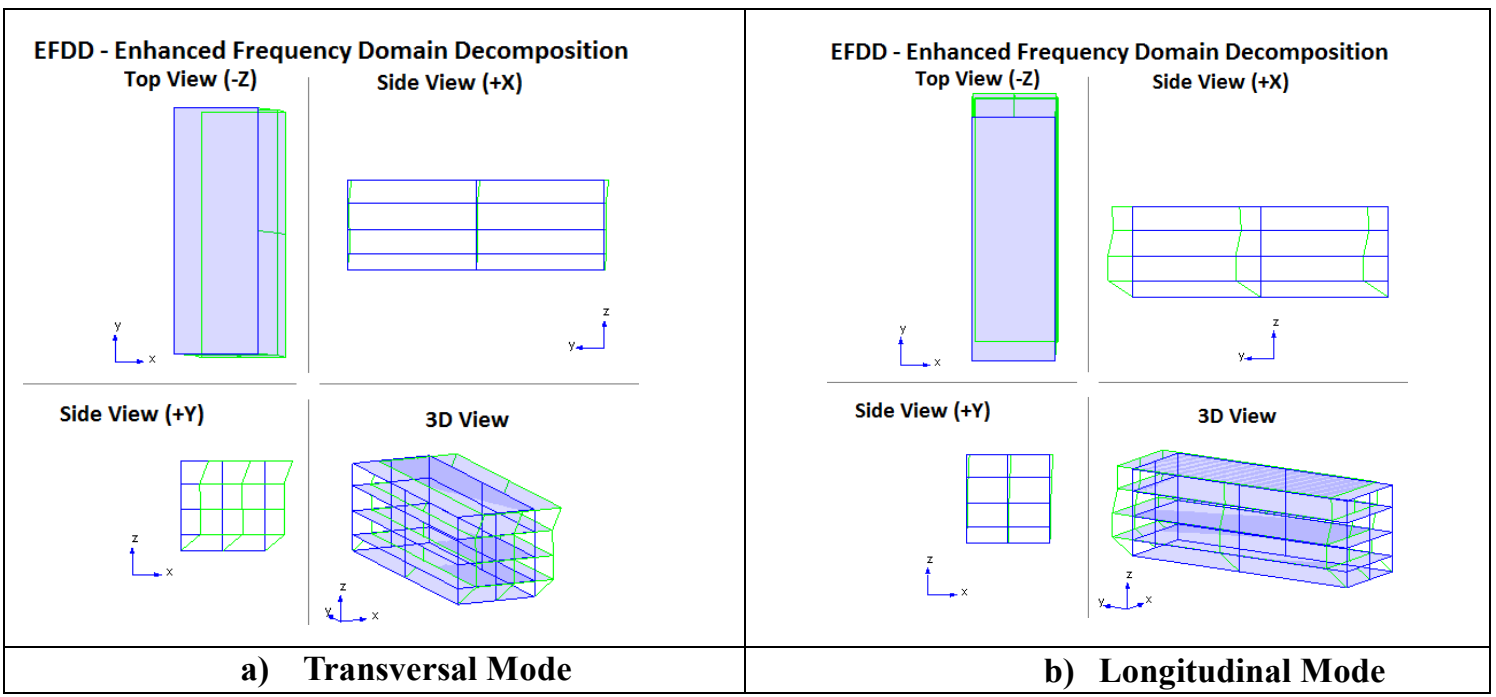

Figure B- 26 Mode shapes of B24 (Phase 2) 


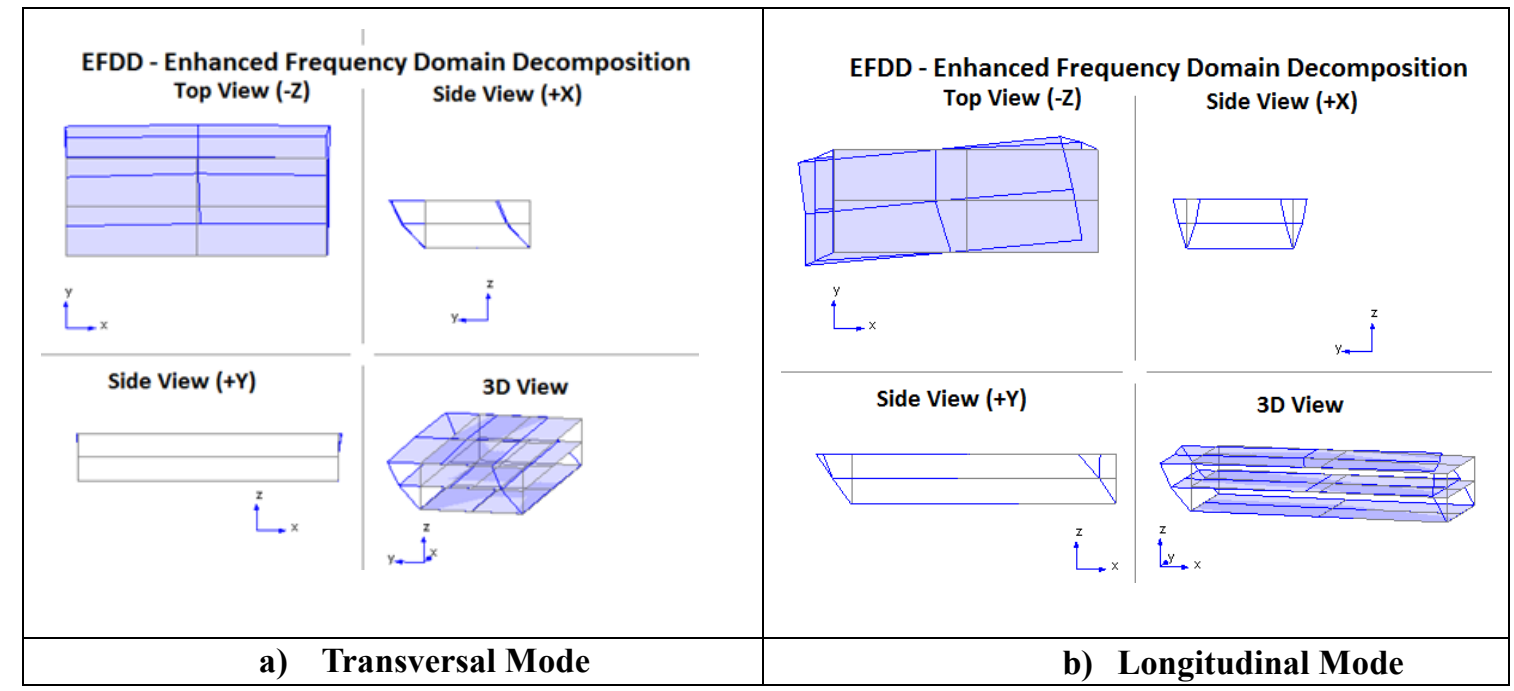

Figure B- 27 Mode shapes of B25 (Phase 1)

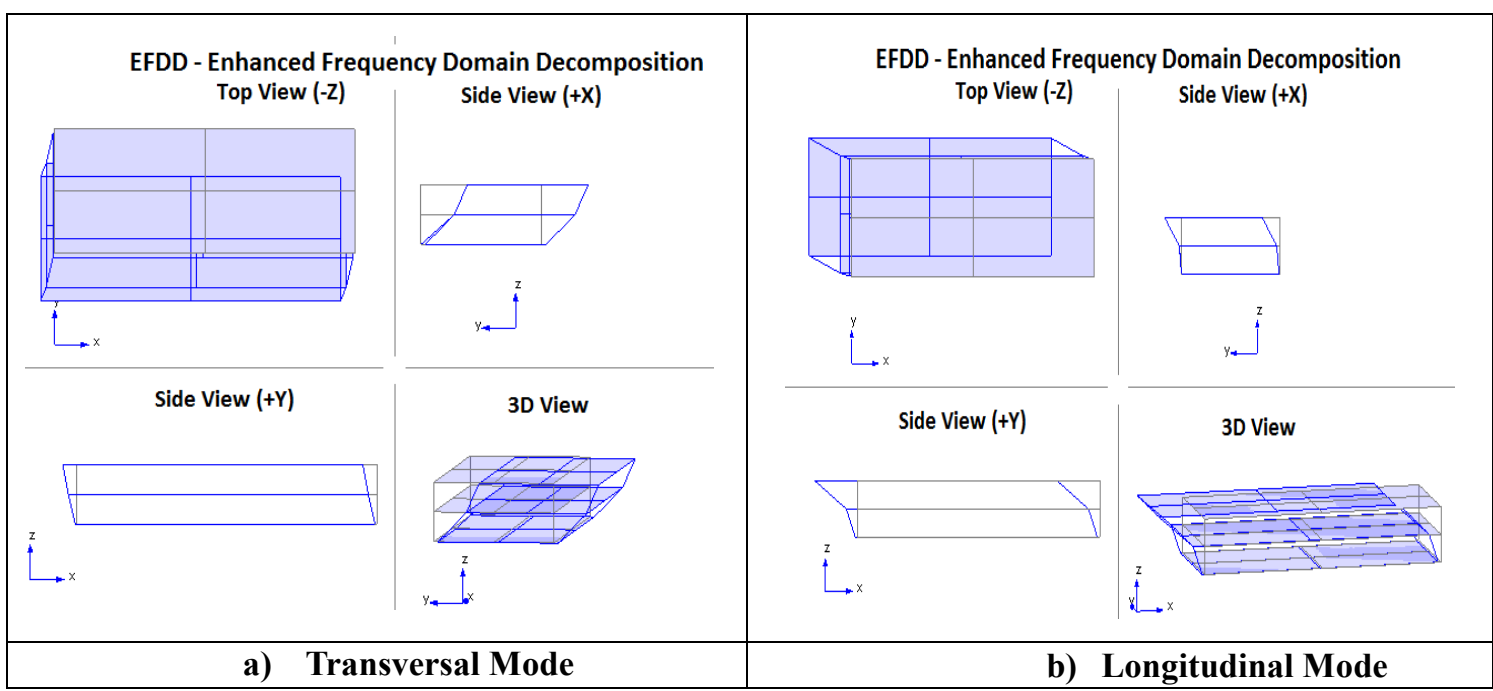

Figure B- 28 Mode shapes of B25 (Phase 2)

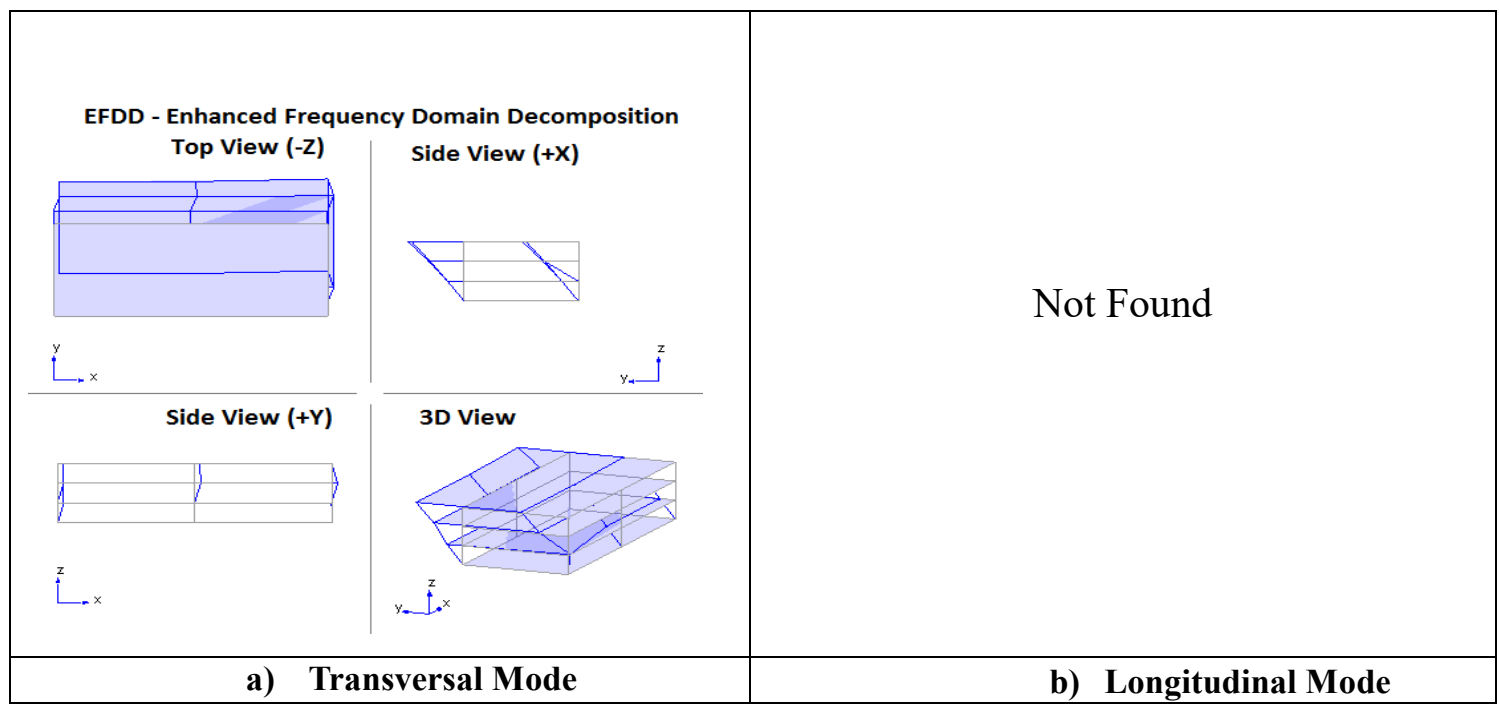

Figure B- 29 Mode shapes of B26 (Phase 2) 


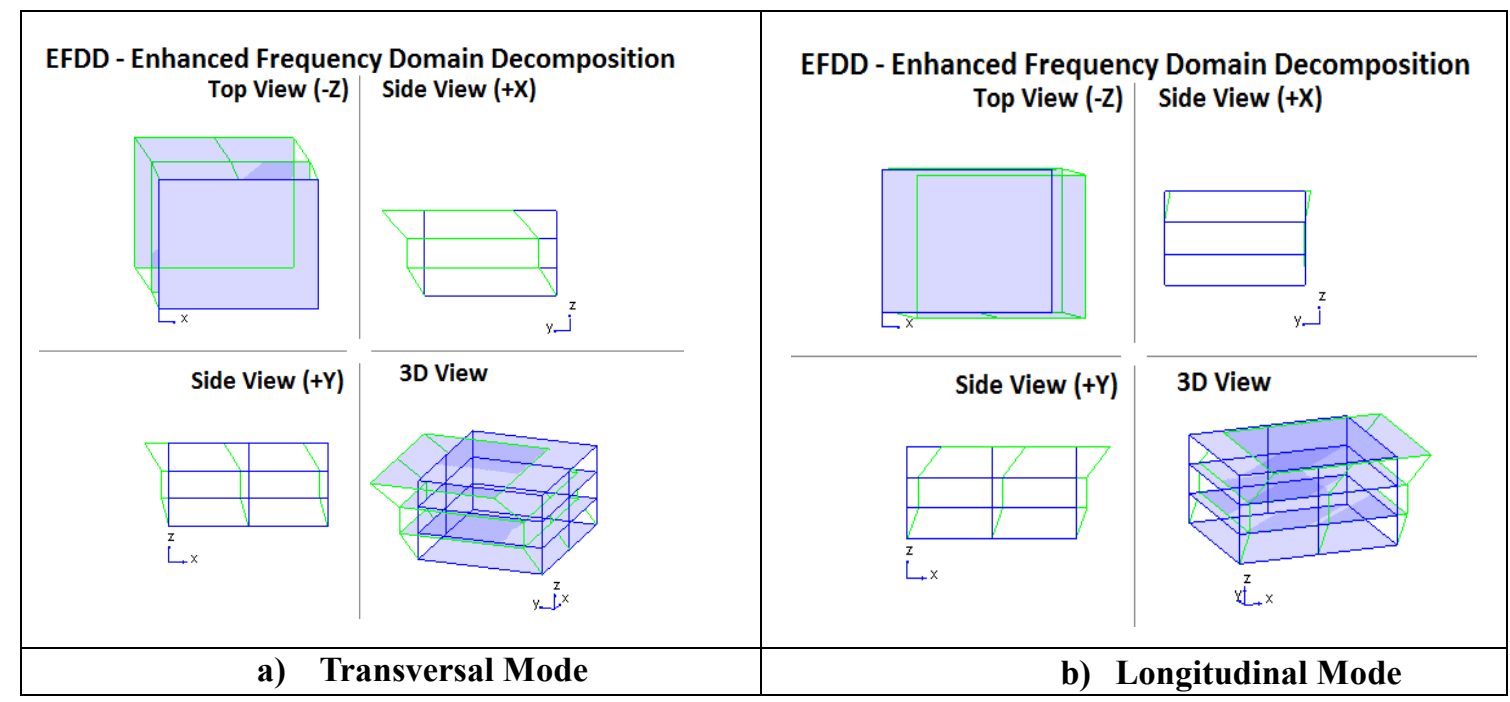

Figure B- 30 Mode shapes of B27 (Phase 2)

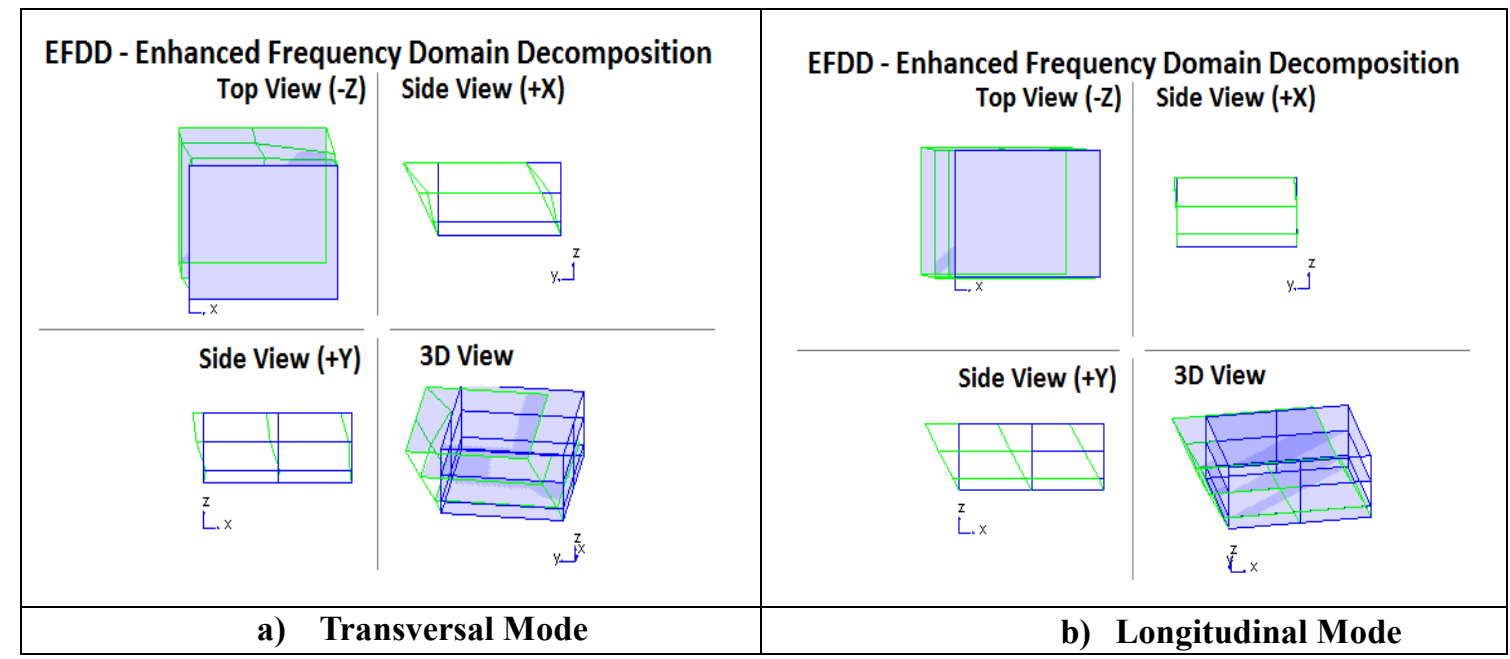

Figure B- 31 Mode shapes of B28 (Phase 1)

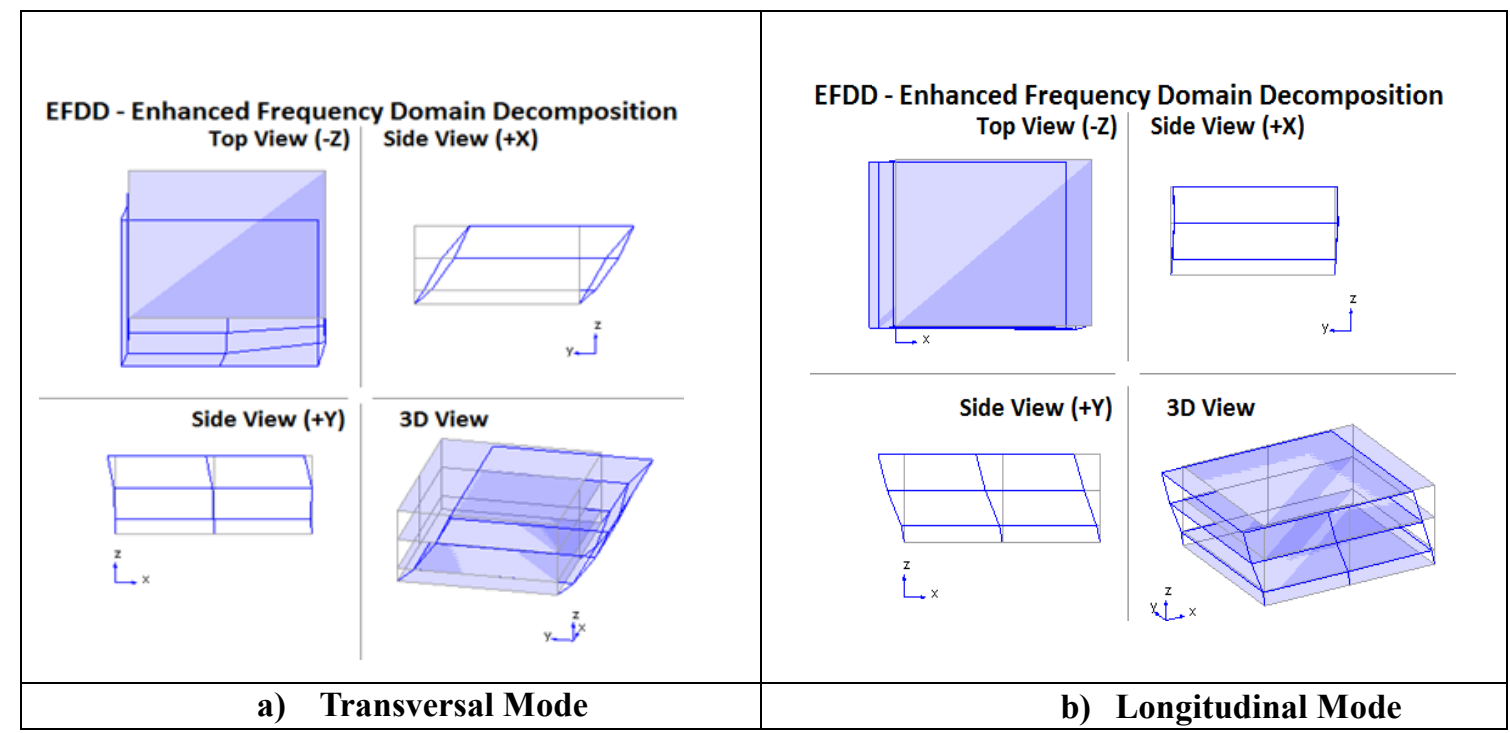

Figure B- 32 Mode shapes of B29 (Phase 1) 


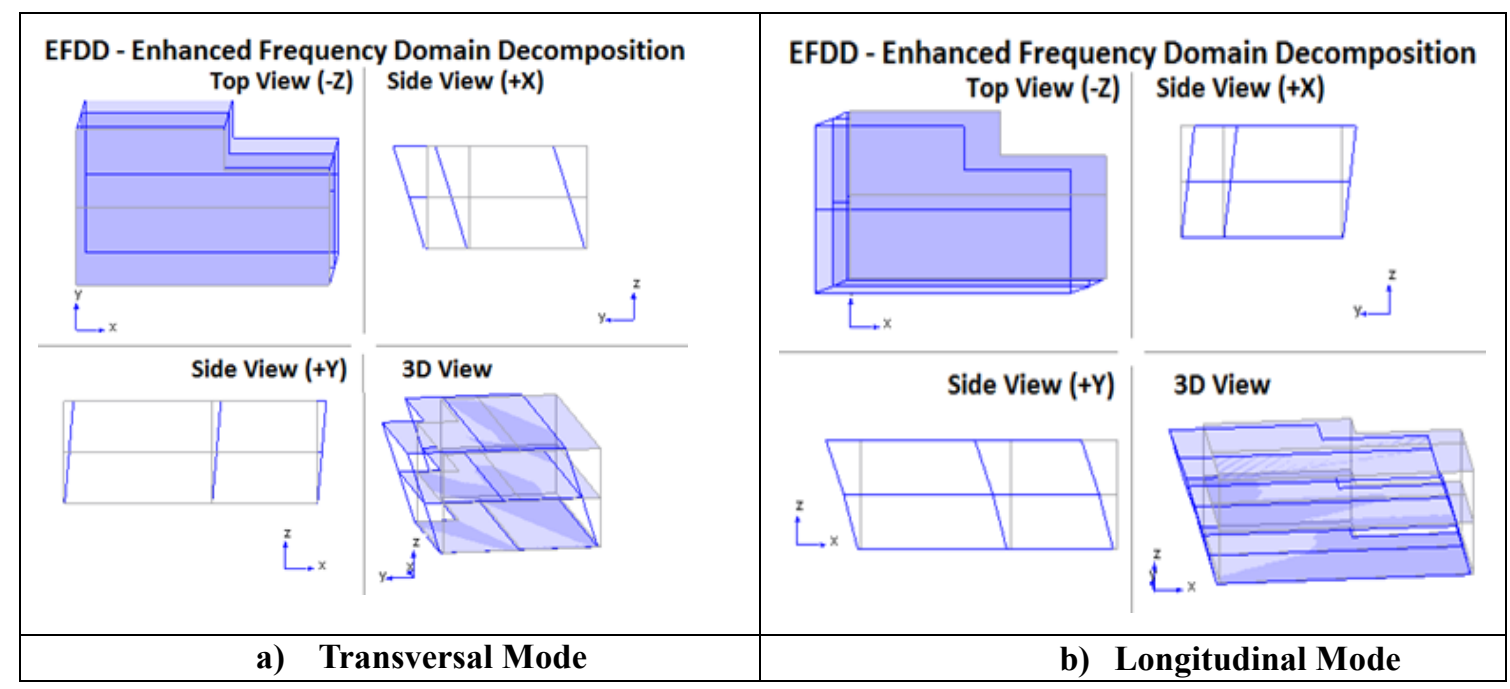

Figure B- 33 Mode shapes of B30 (Phase 1)

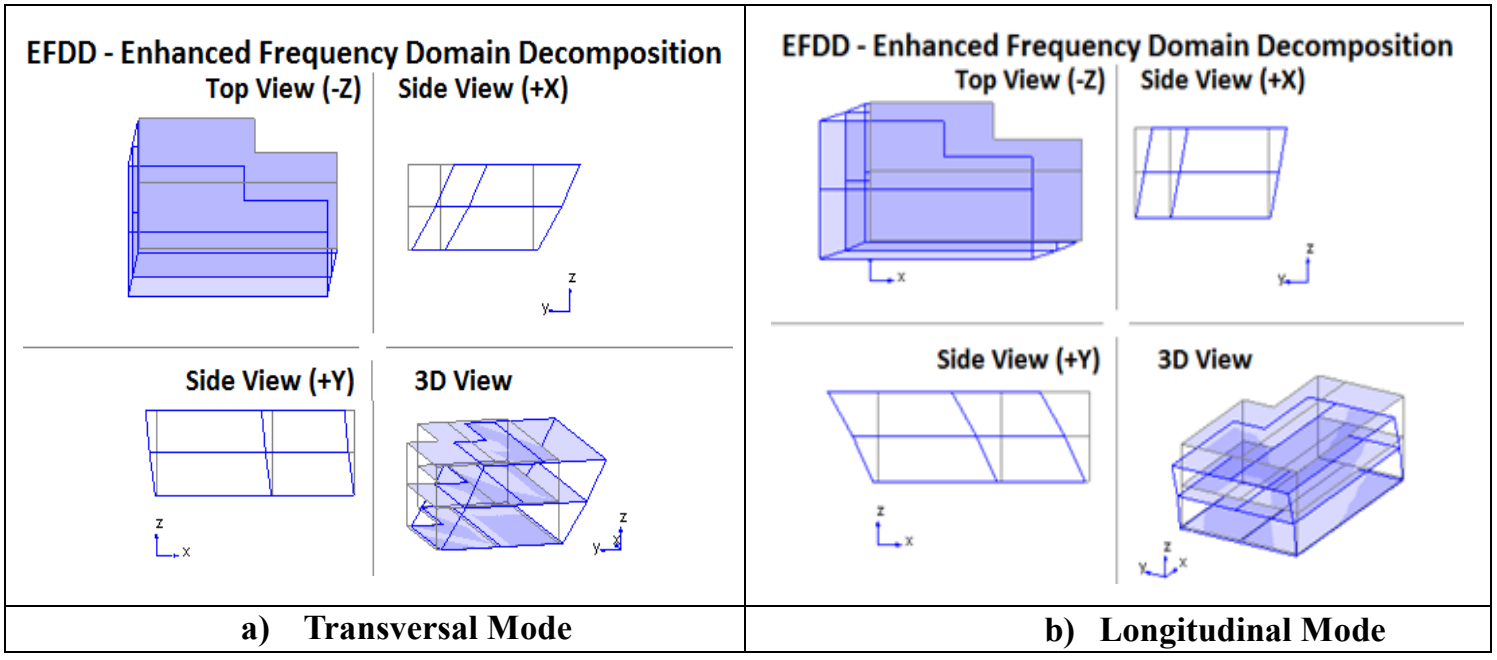

Figure B- 34 Mode shapes of B30 (Phase 2)

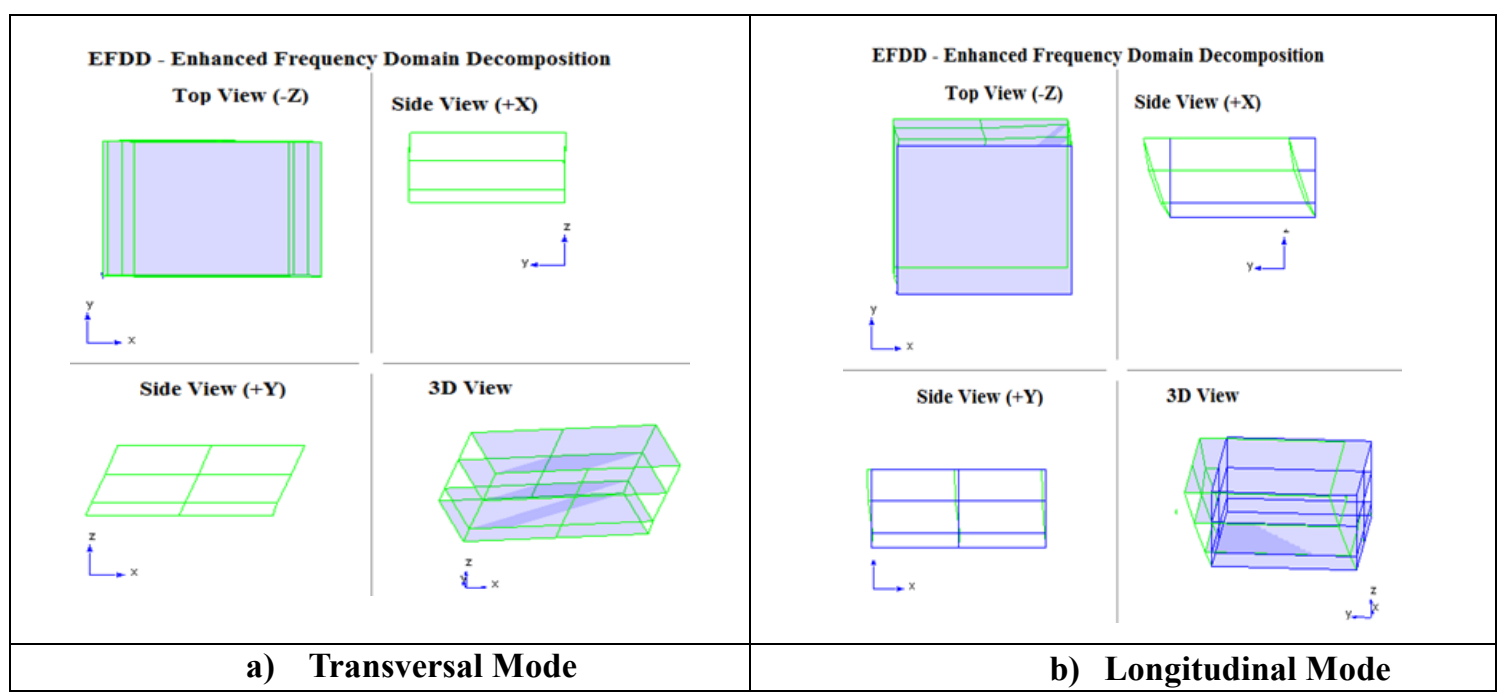

Figure B- 35 Mode shapes of B33 (Phase 2) 


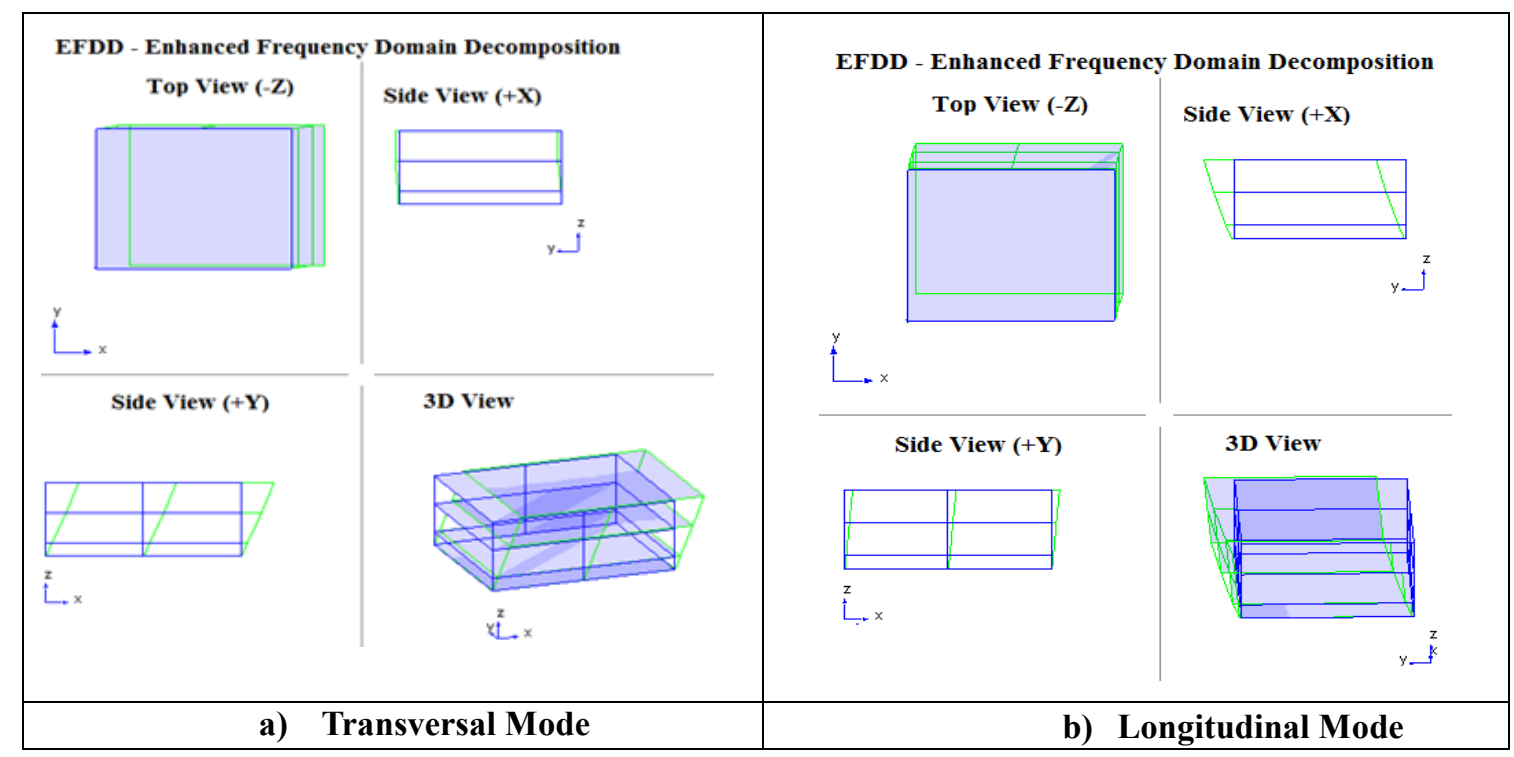

Figure B- 36 Mode shapes of B34 (Phase 2)

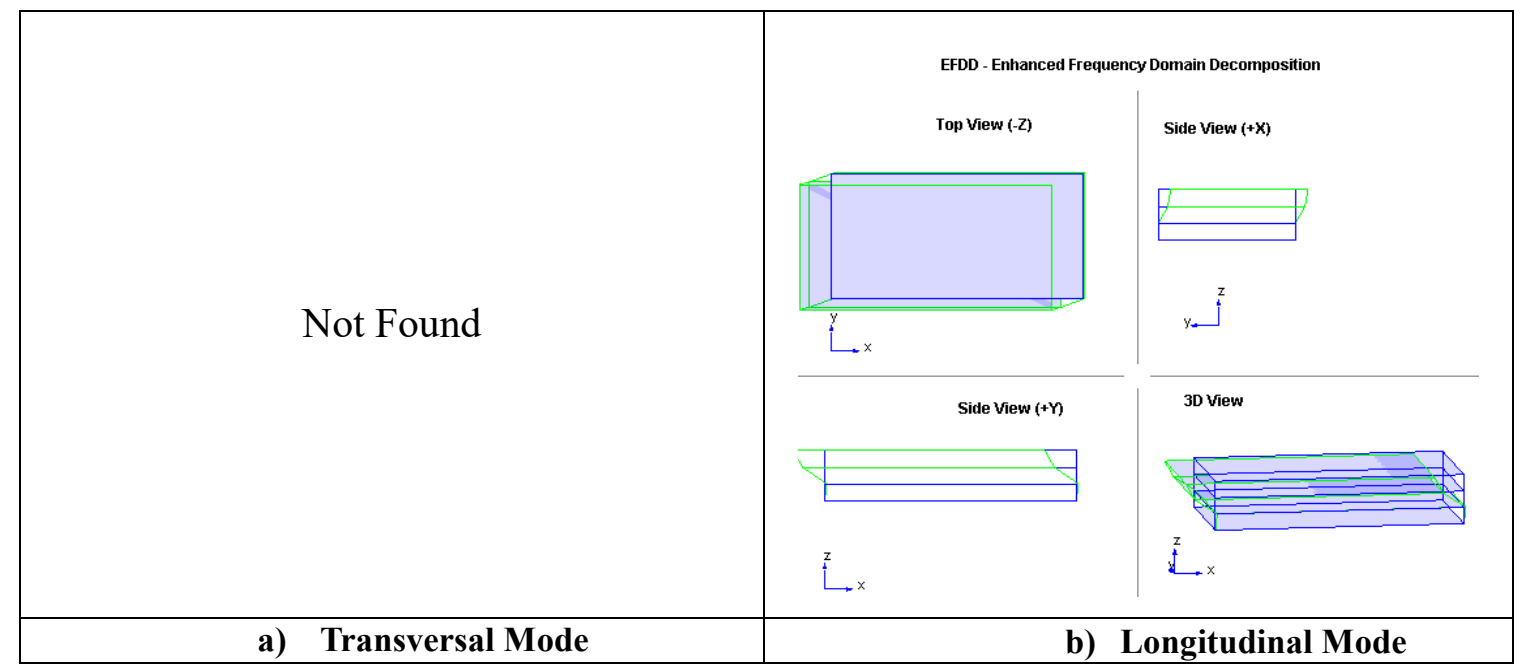

Figure B- 37 Mode shapes of B41 (Phase 2)

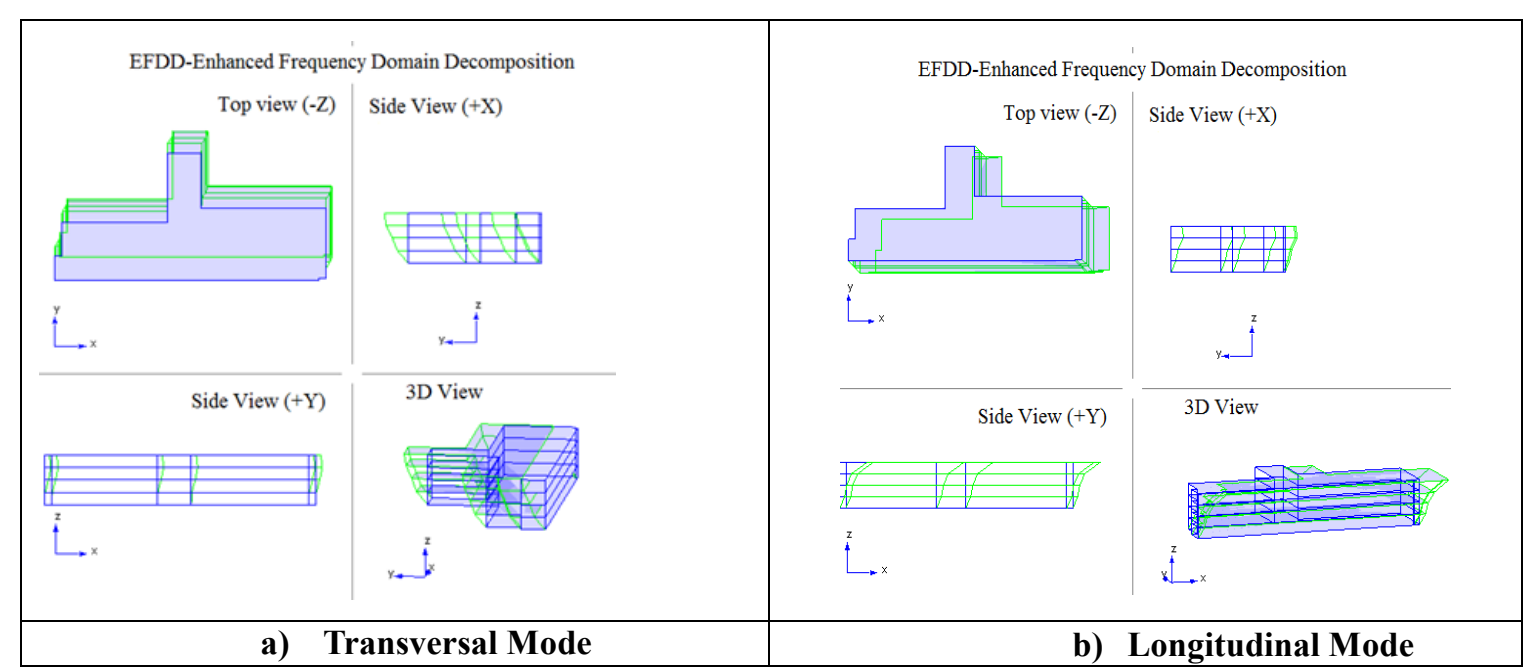

Figure B- 38 Mode shapes of B10-B11 (Phase 2) 


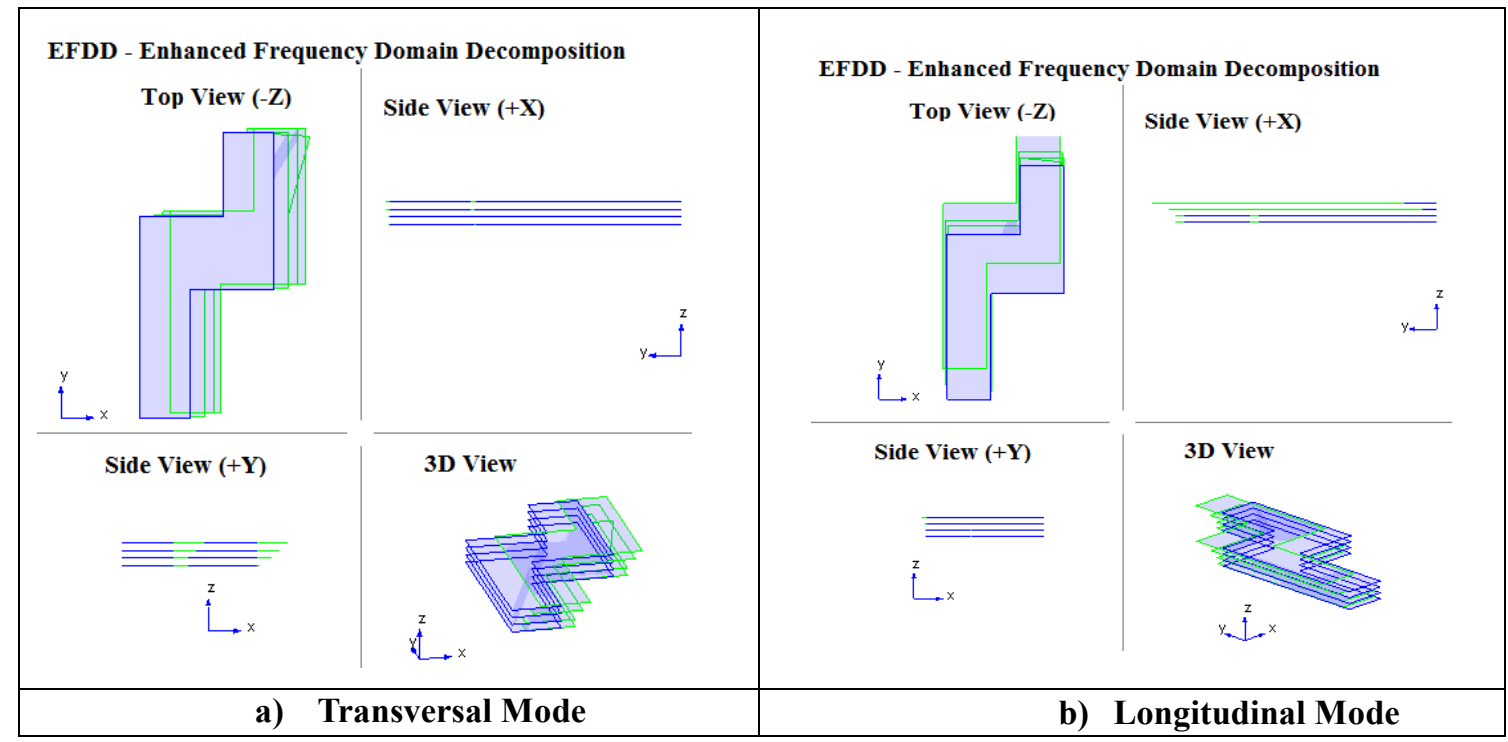

Figure B- 39 Mode shapes of B18-B19

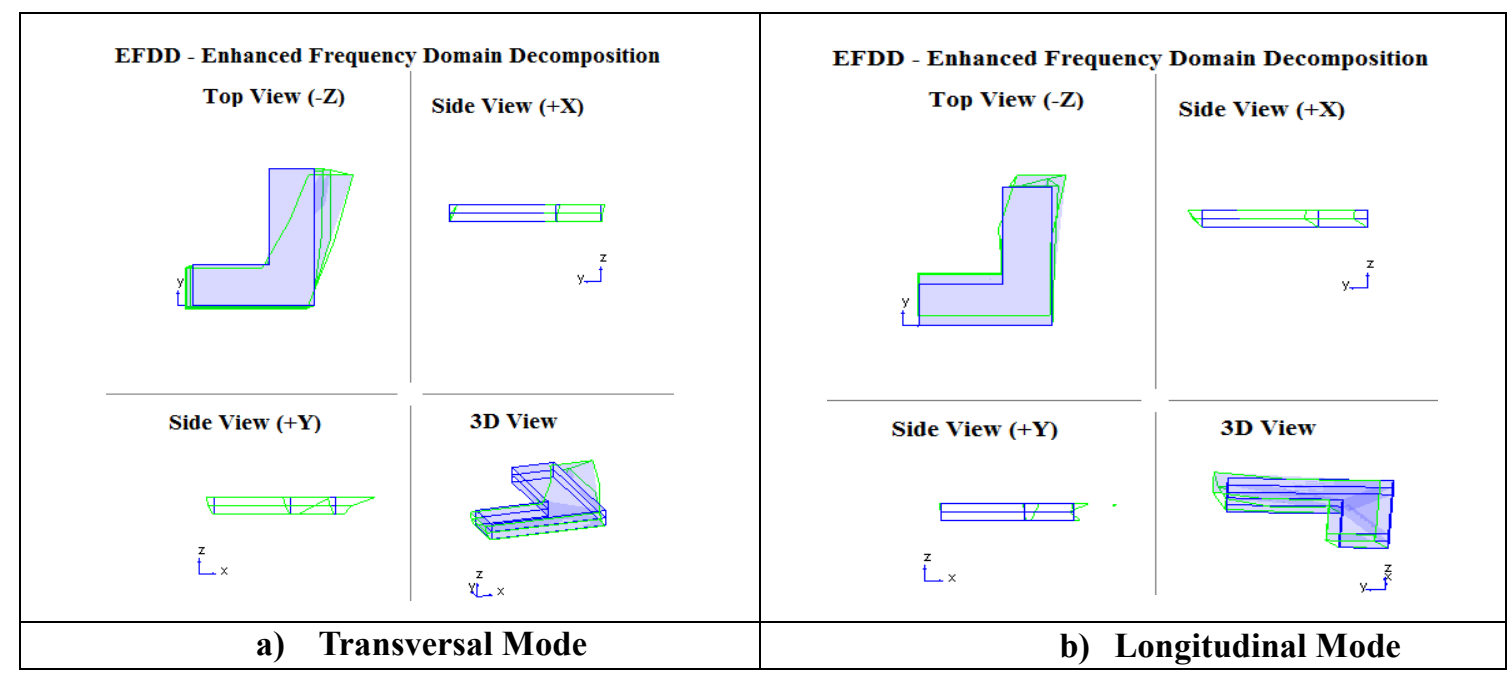

Figure B- 40 Mode shapes of B20-B21

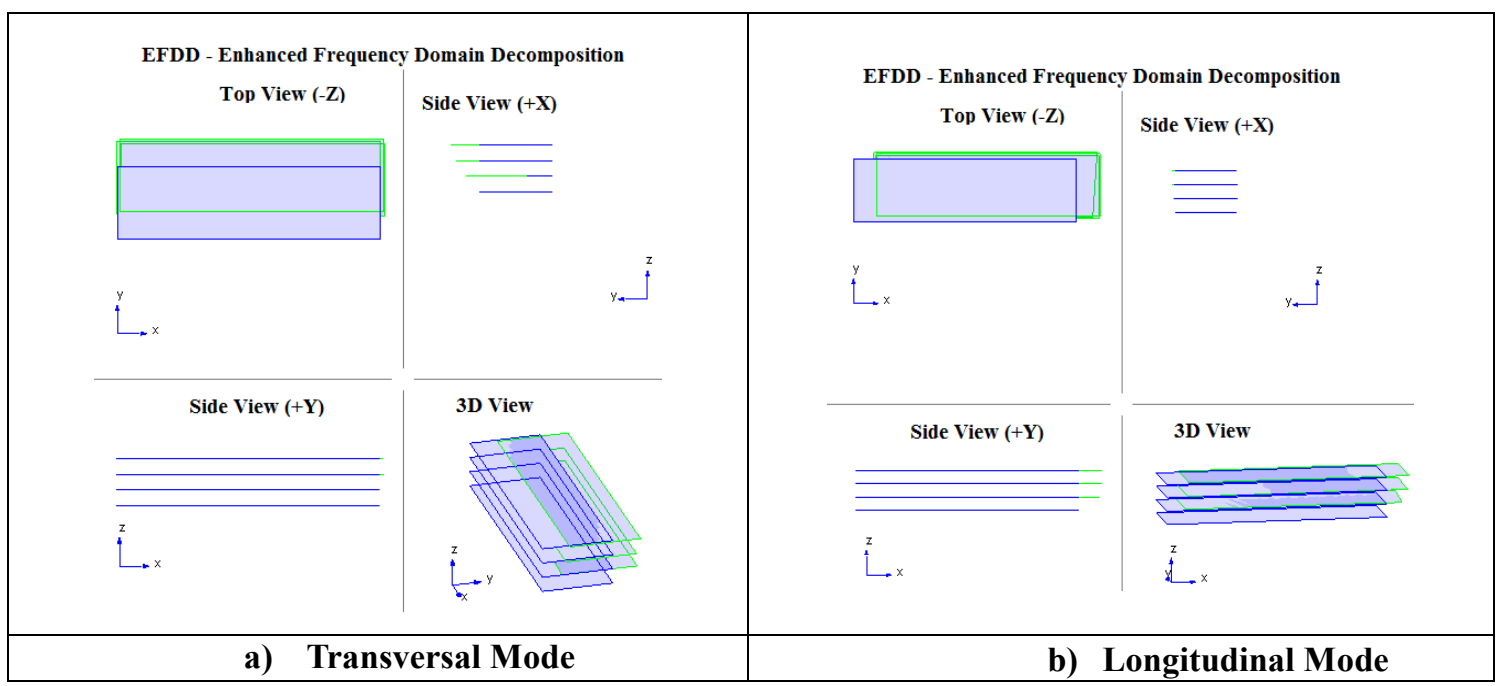

Figure B- 41 Mode shapes of B26-B27 


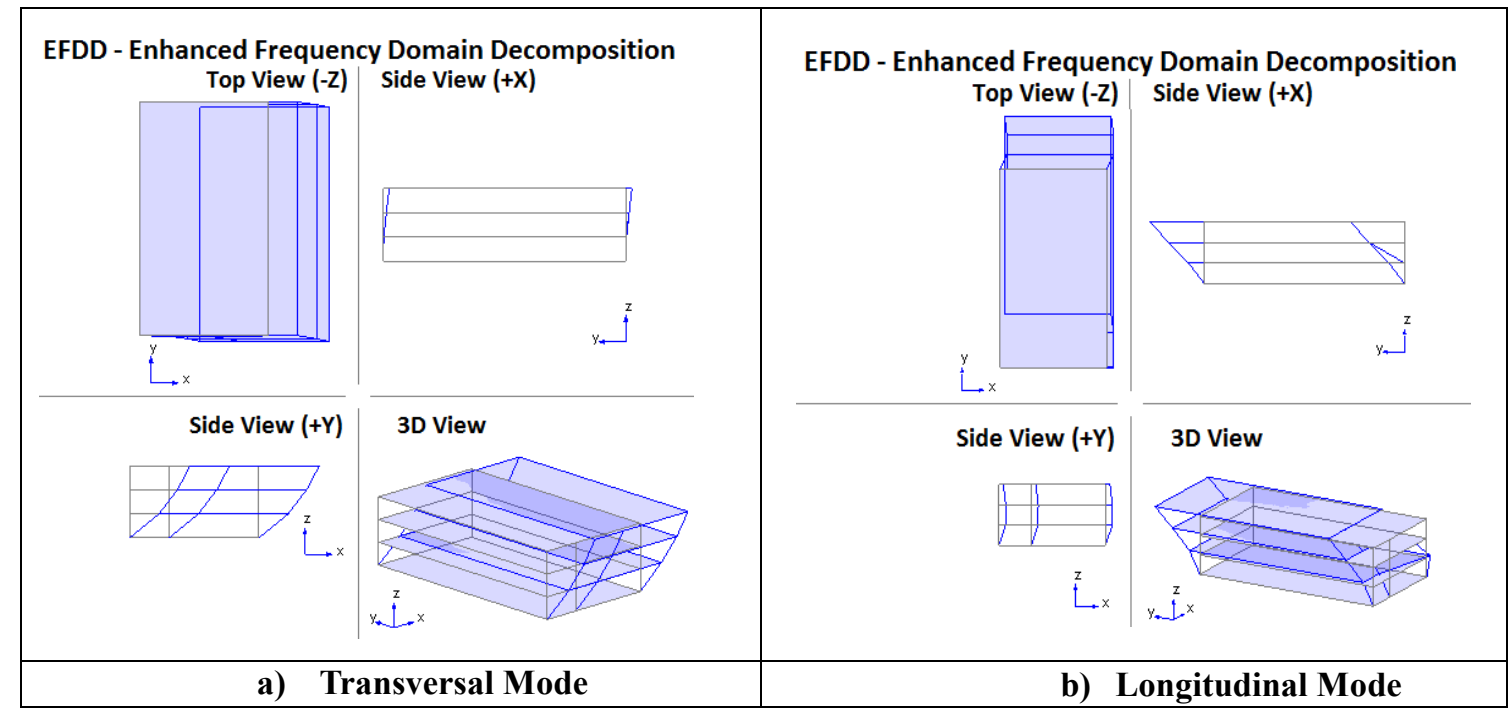

Figure B- 42 Mode shapes of M1 (Phase 2)

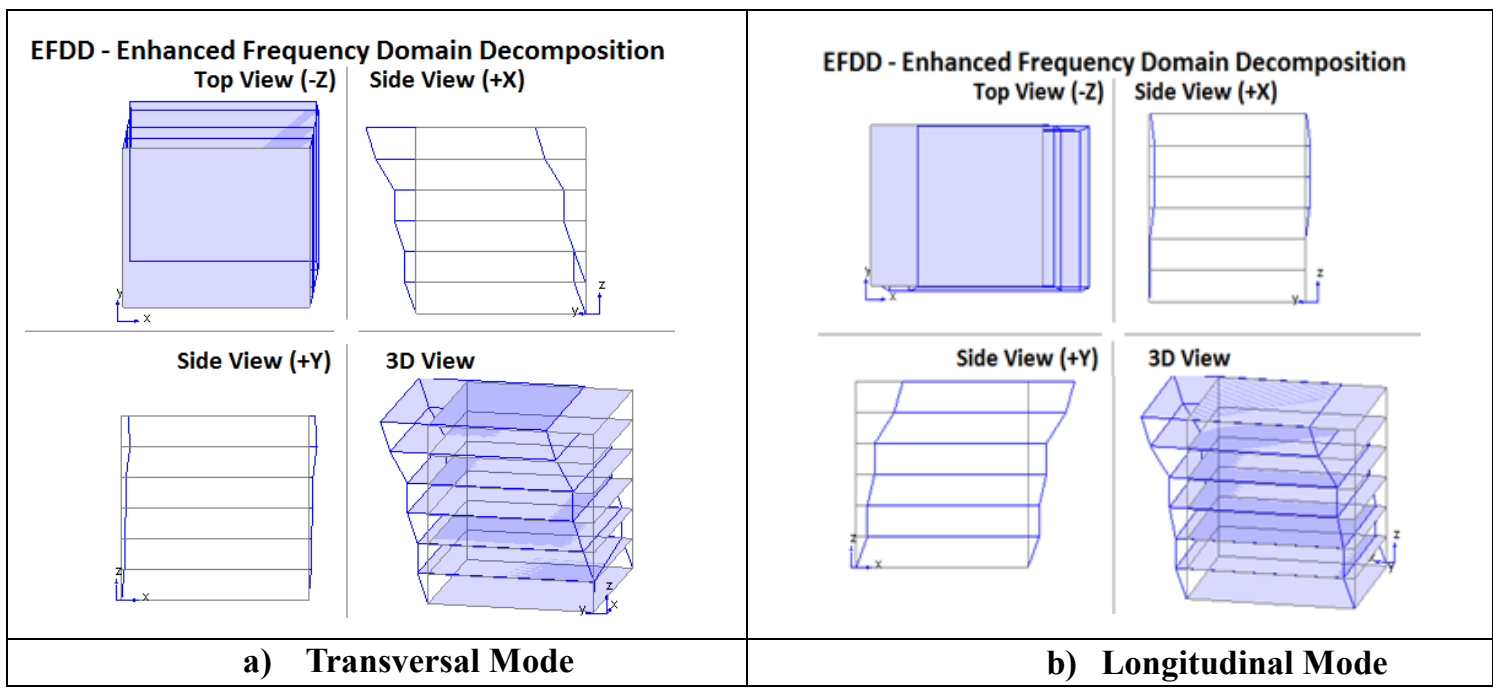

Figure B- 43 Mode shapes of M2 (Phase 2)

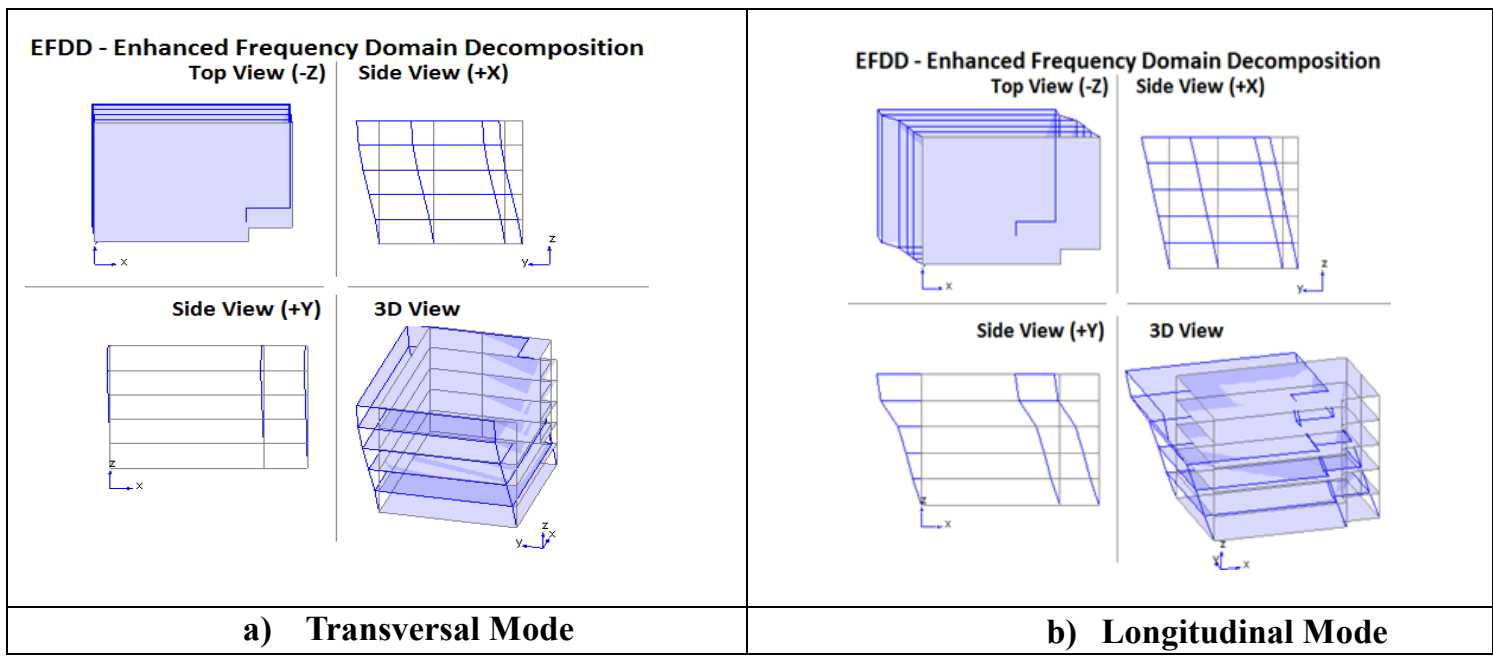

Figure B- 44 Mode shapes of M3 (Phase 2) 


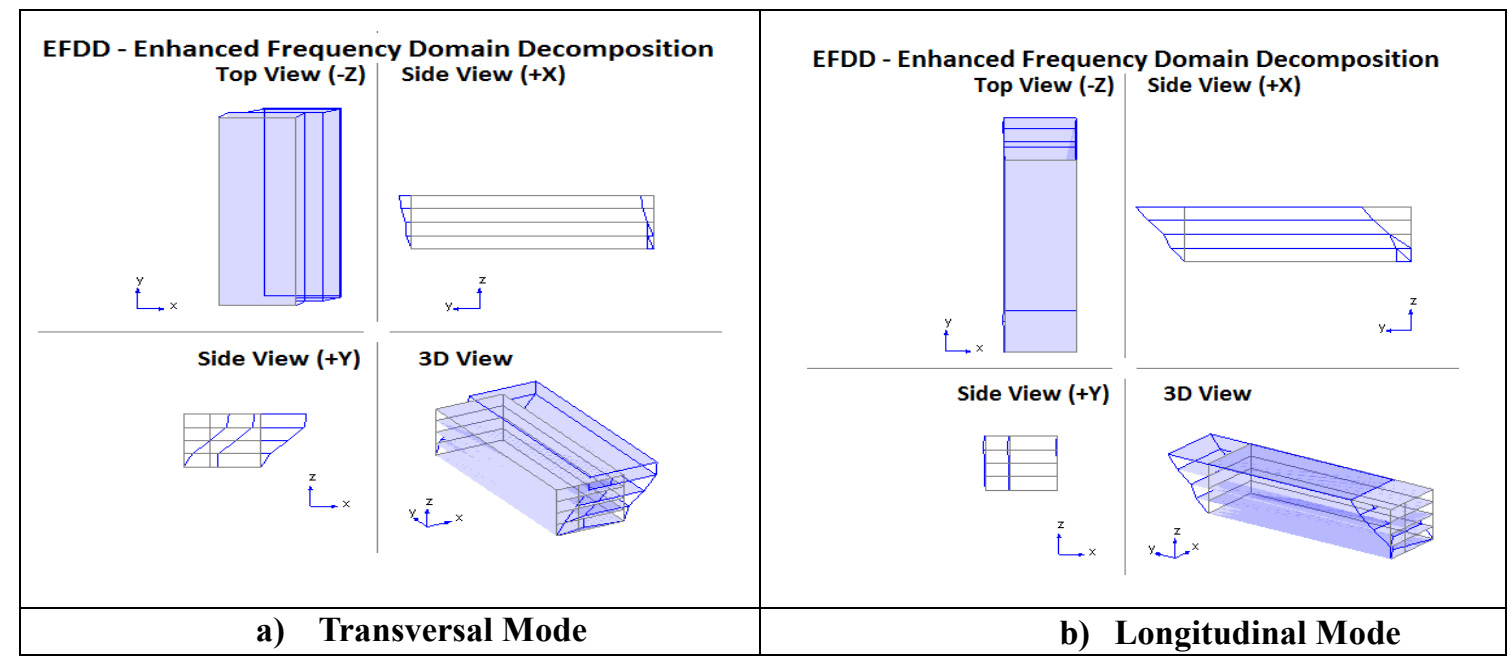

Figure B- 45 Mode shapes of M4 (Phase 2)

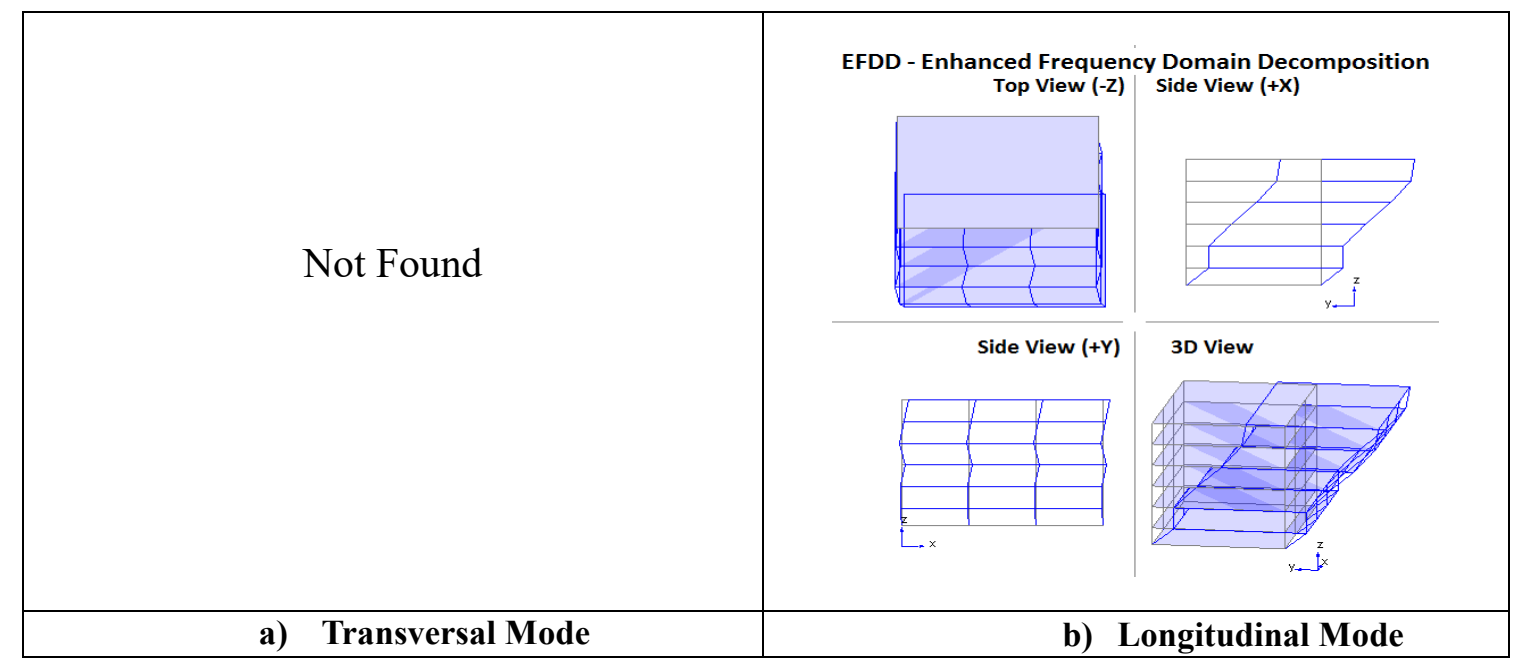

Figure B- 46 Mode shapes of M5 (Phase 2)

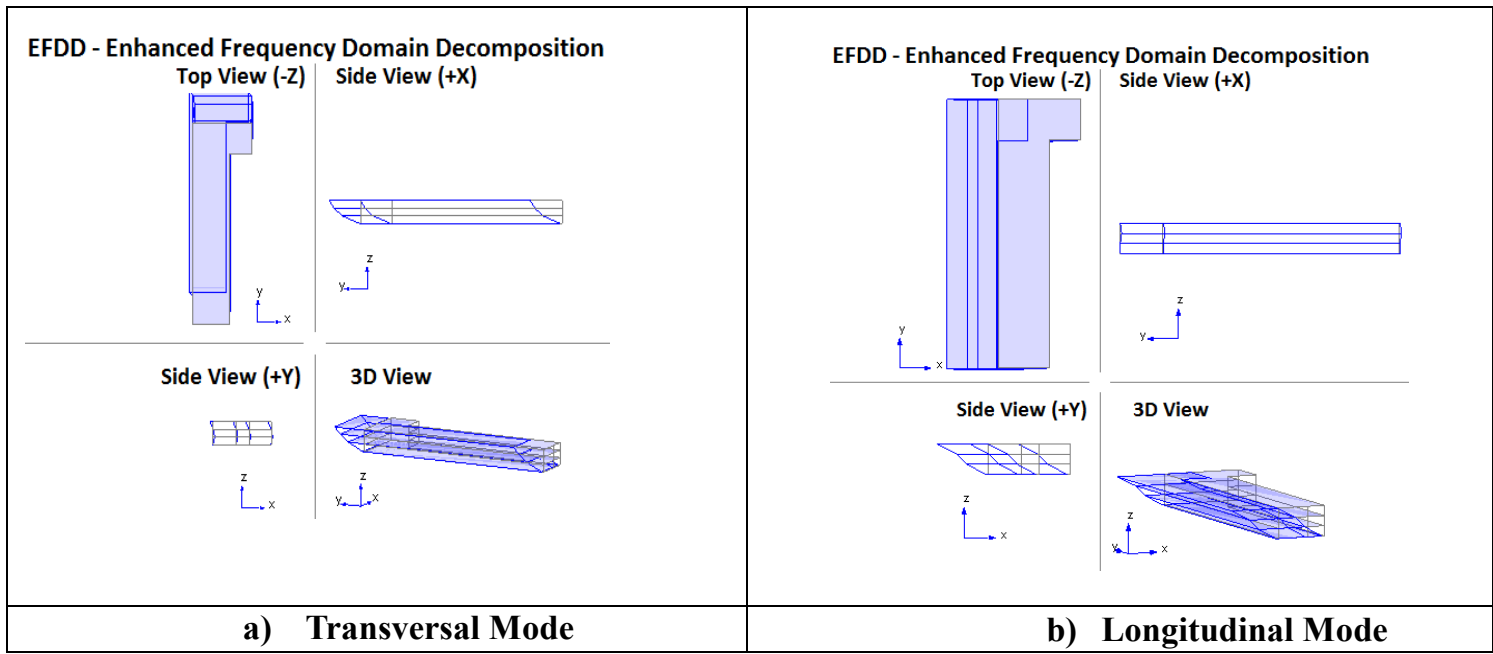

Figure B- 47 Mode shapes of M6 (Phase 2) 


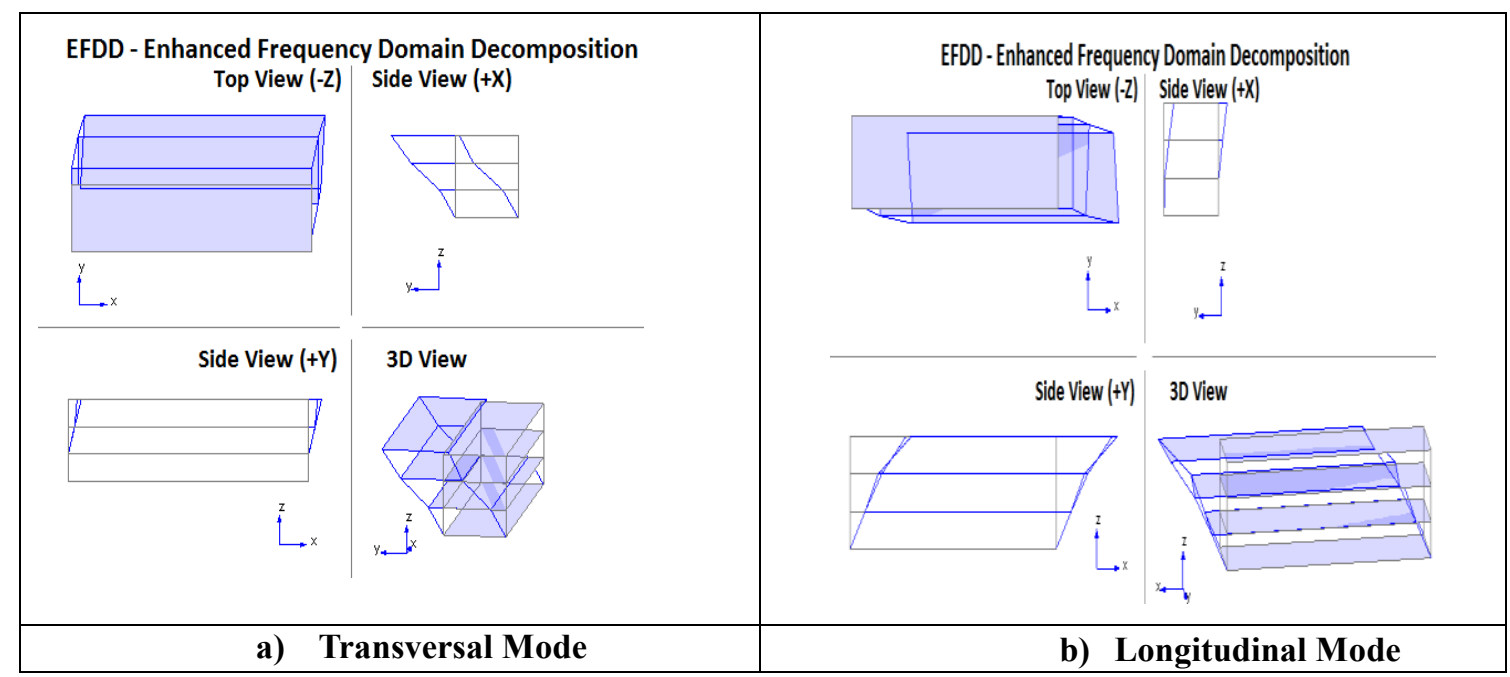

Figure B- 48 Mode shapes of M7 (Phase 2)

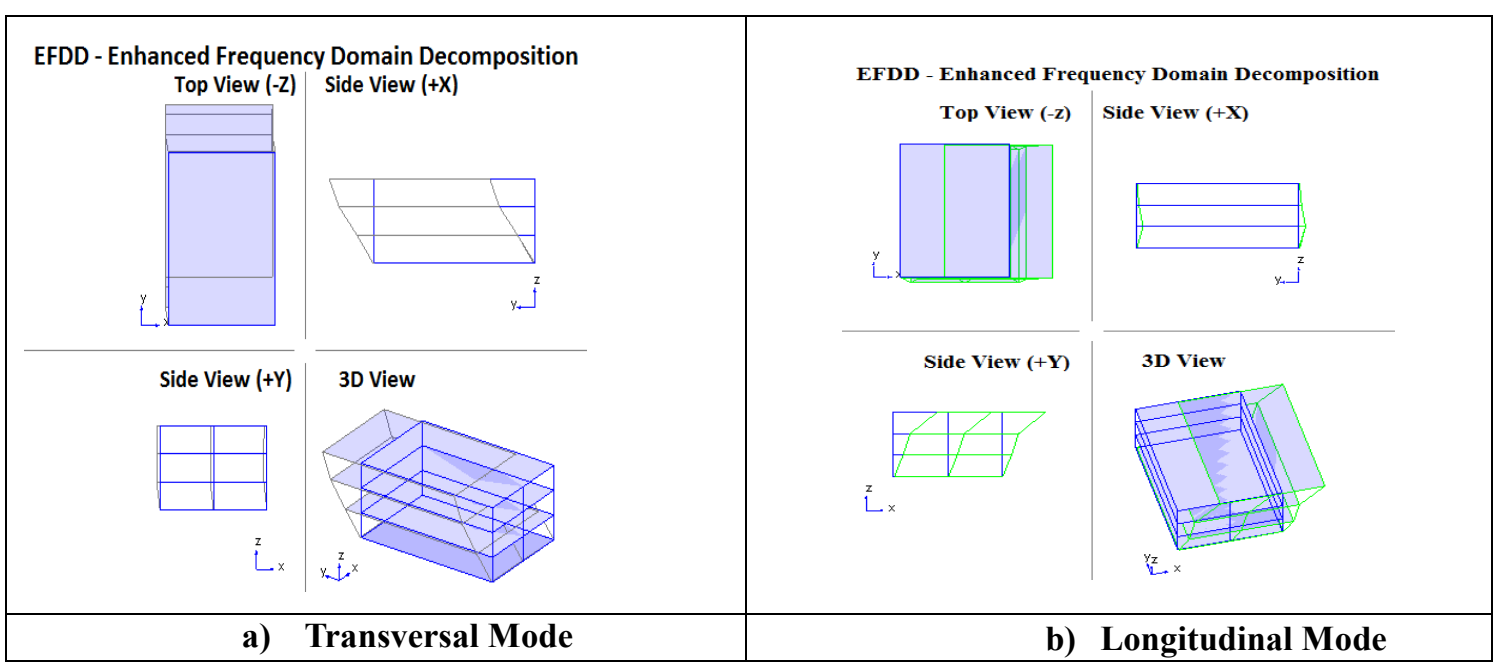

Figure B- 49 Mode shapes of M8 (Phase 2)

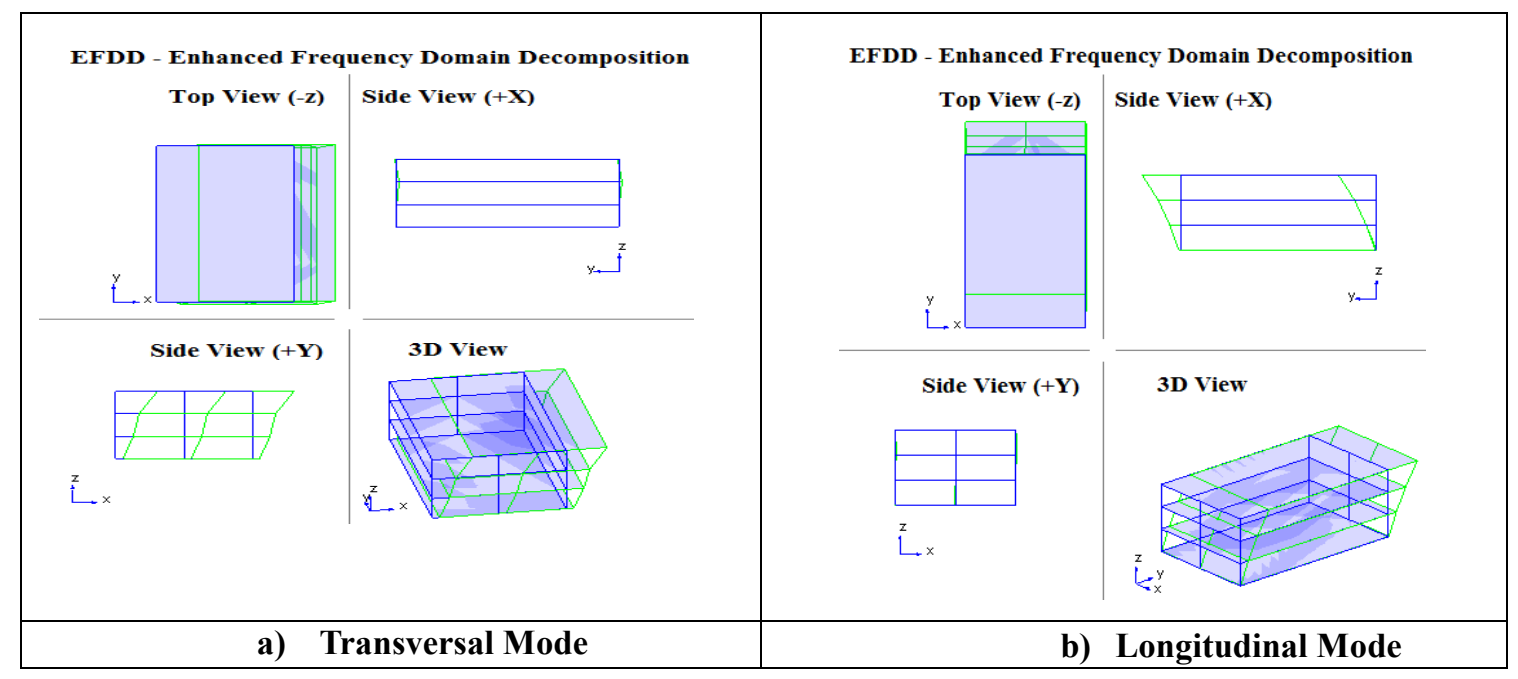

Figure B- 50 Mode shapes of M9 (Phase 2) 


\section{Building Measured in Various Stages of Construction}

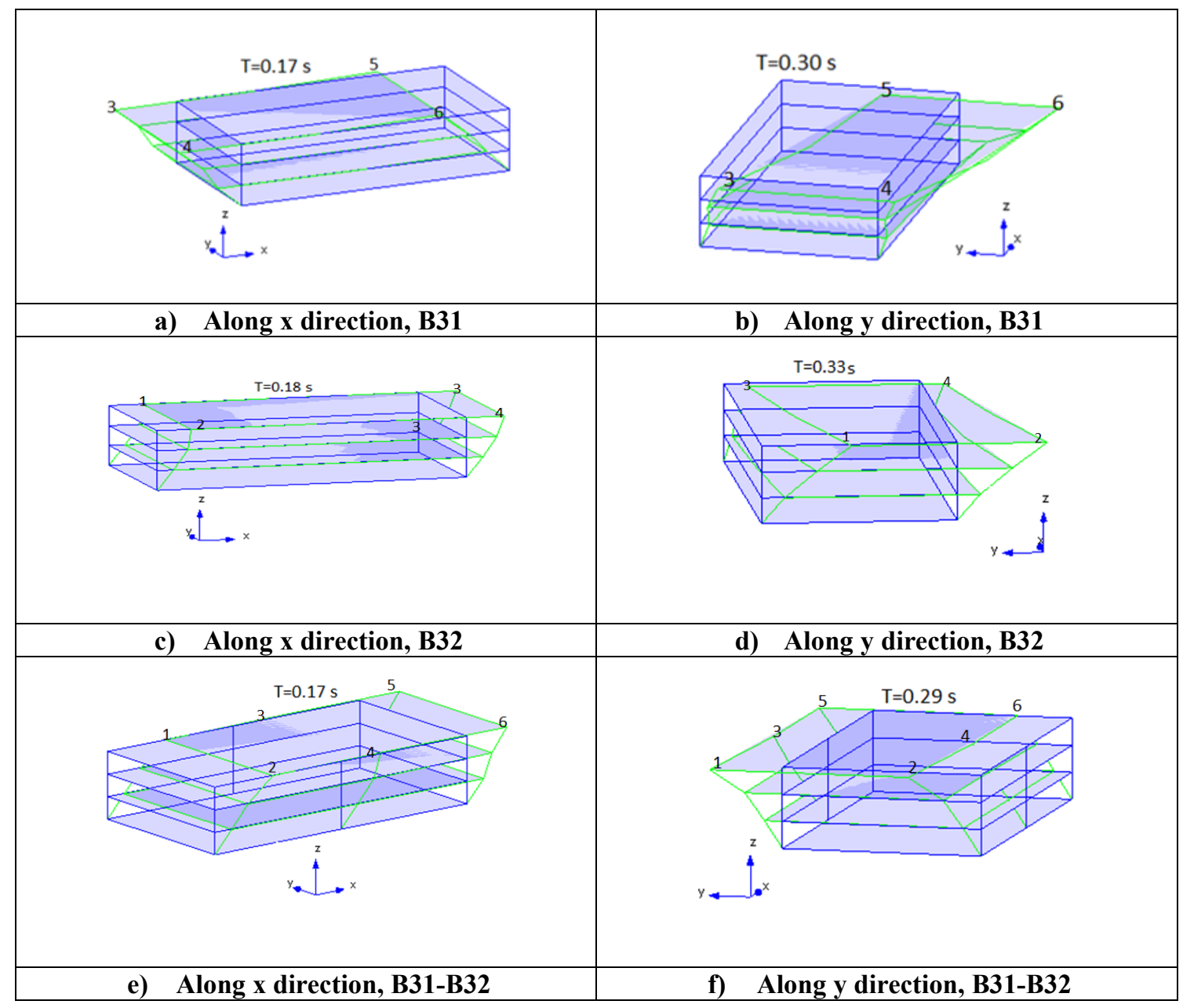

Figure B- 51 Mode shapes of the buildings measured in Test 1 


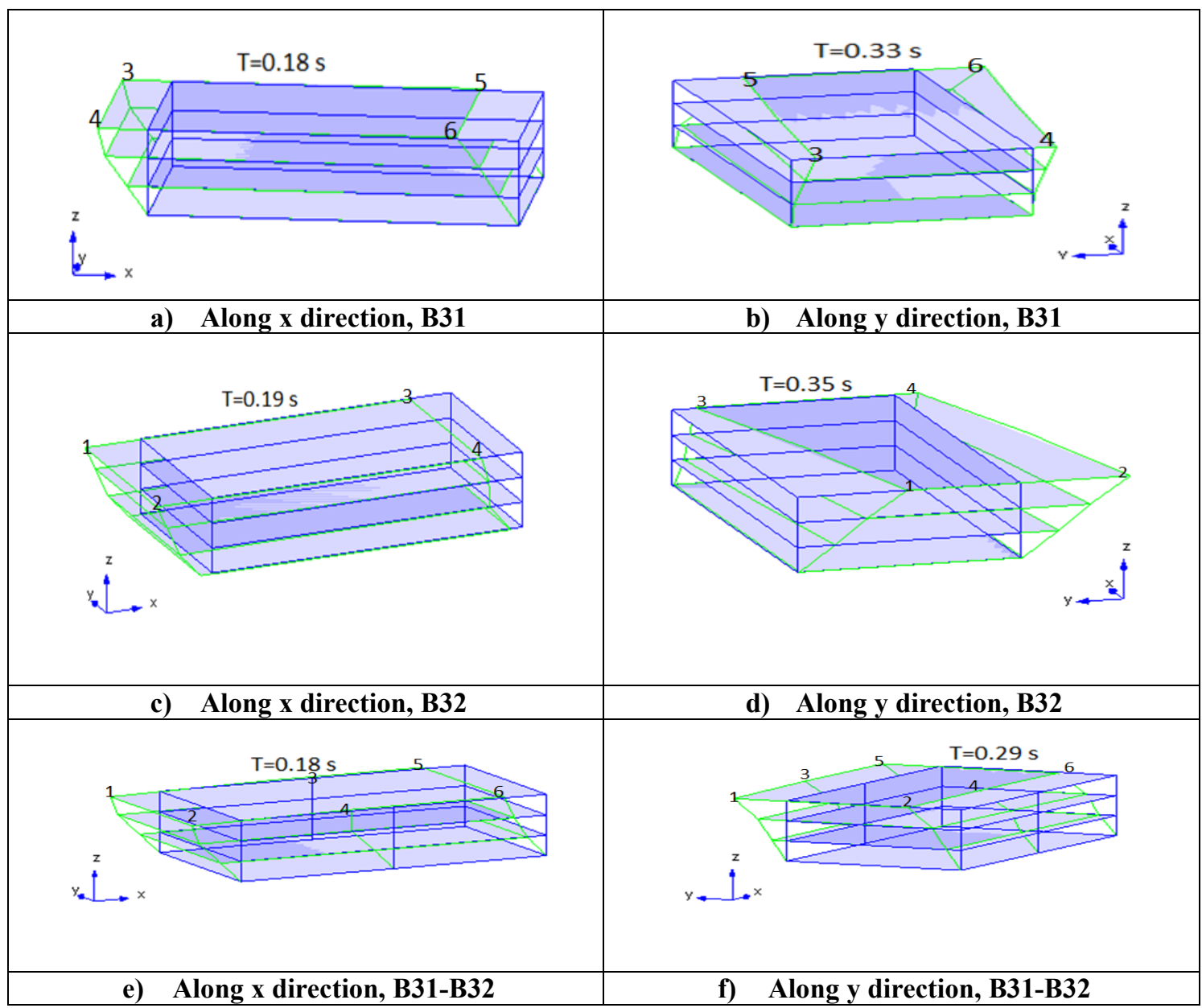

Figure B- 52 Mode shapes of the buildings measured in Test 2 


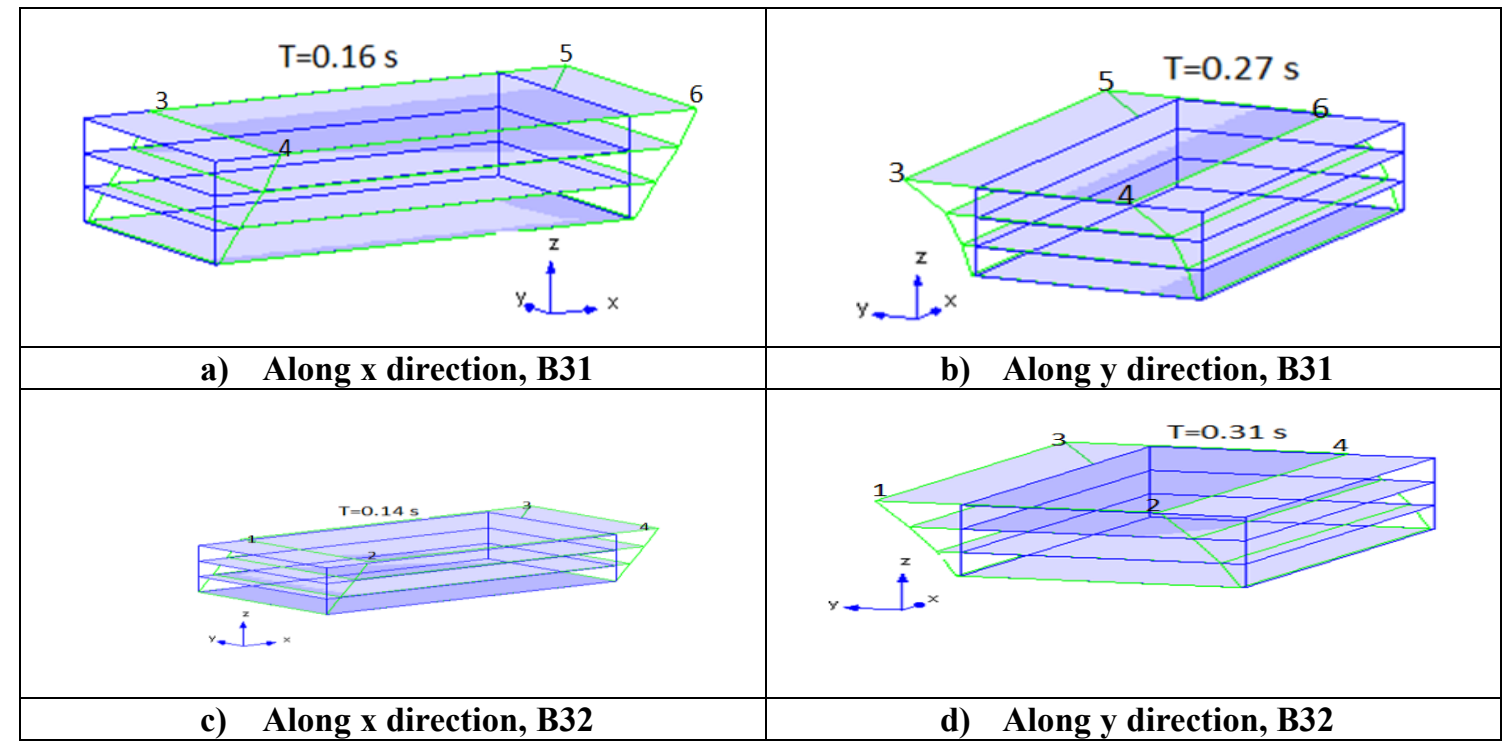

Figure B- 53 Mode shapes of the buildings measured in Test 3

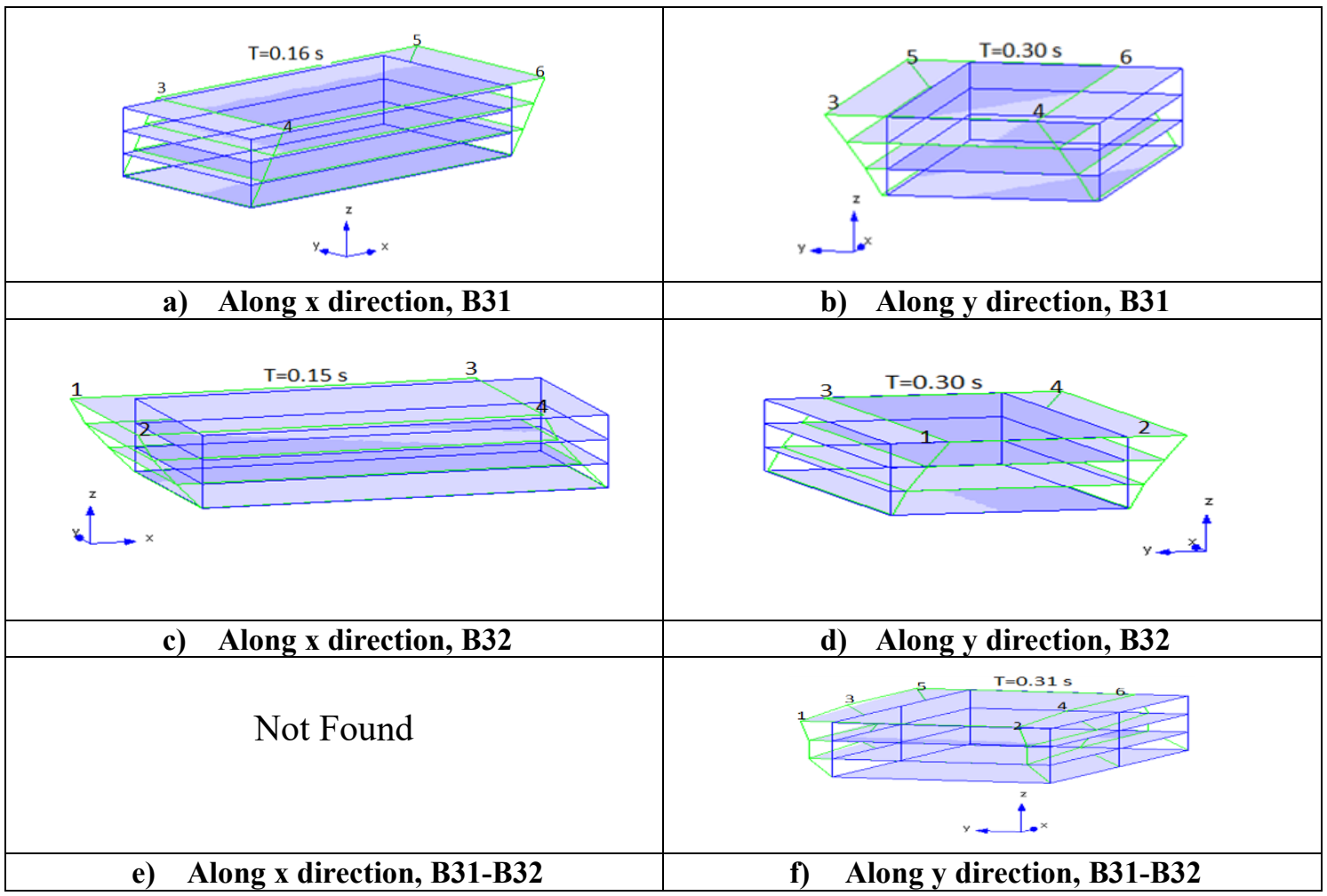

Figure B- 54 Mode shapes of the buildings measured in Test 4 


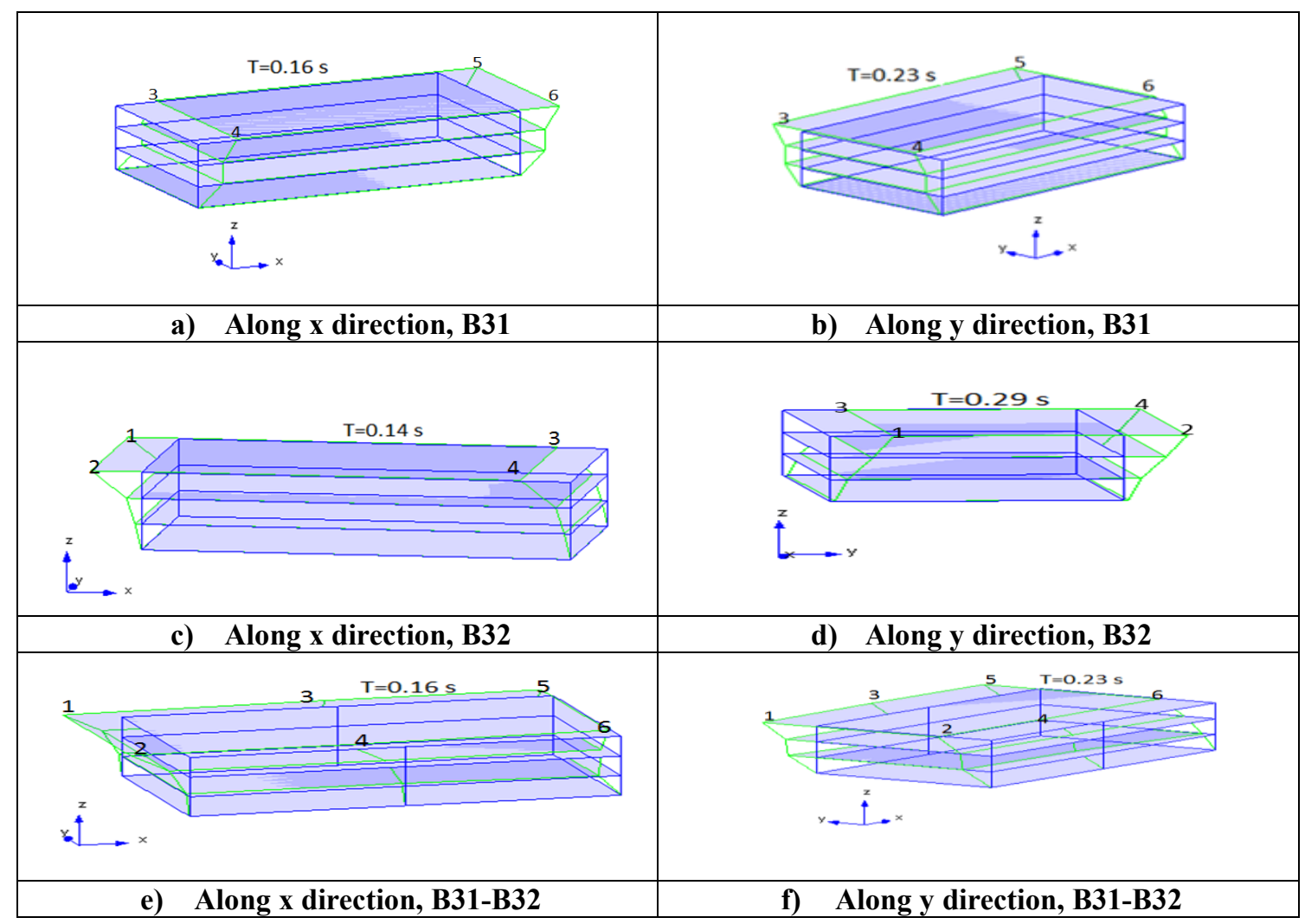

Figure B- 55 Mode shapes of the buildings measured in Test 5

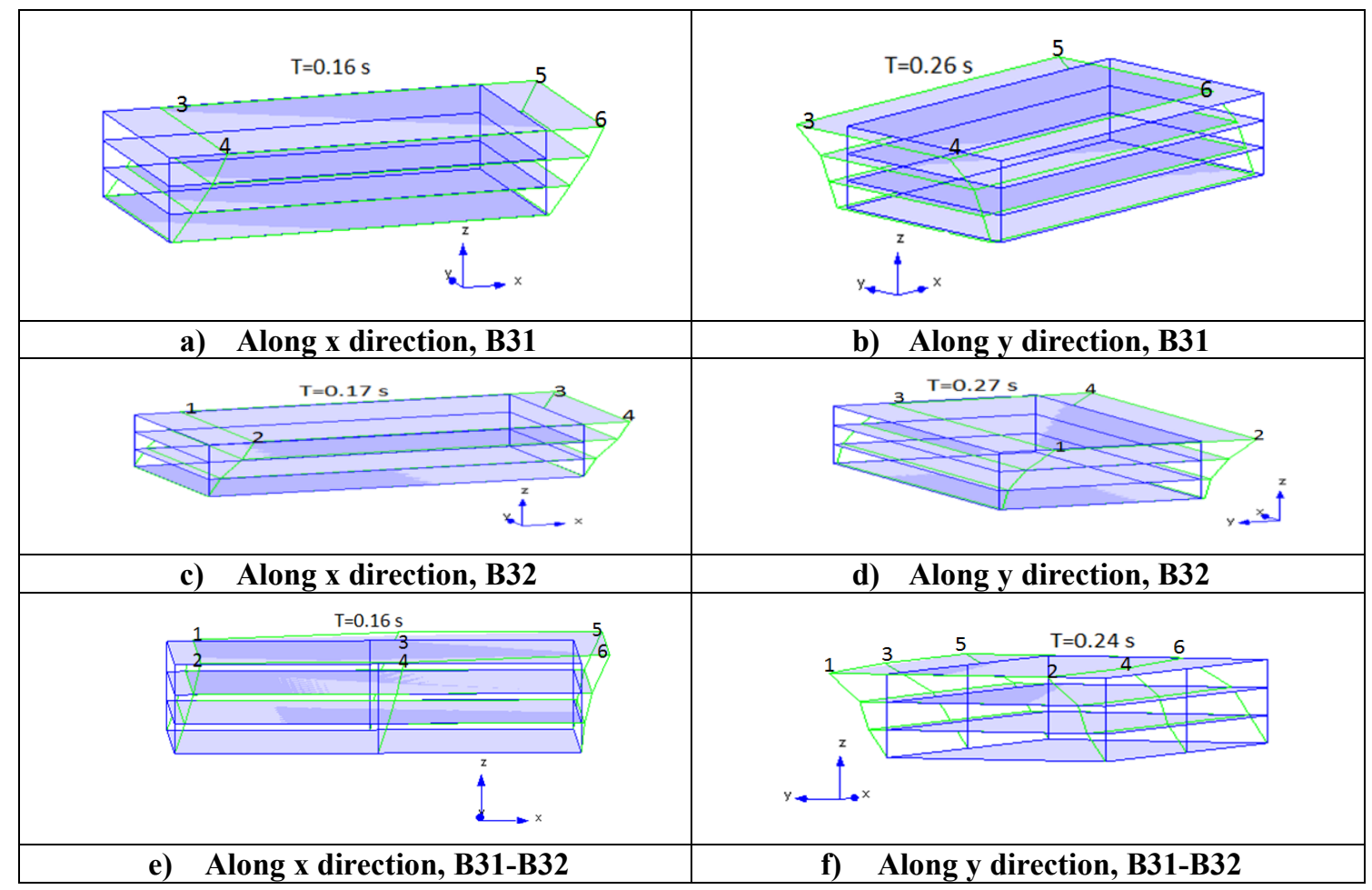

Figure B- 56 Mode shapes of the buildings measured in Test 6 


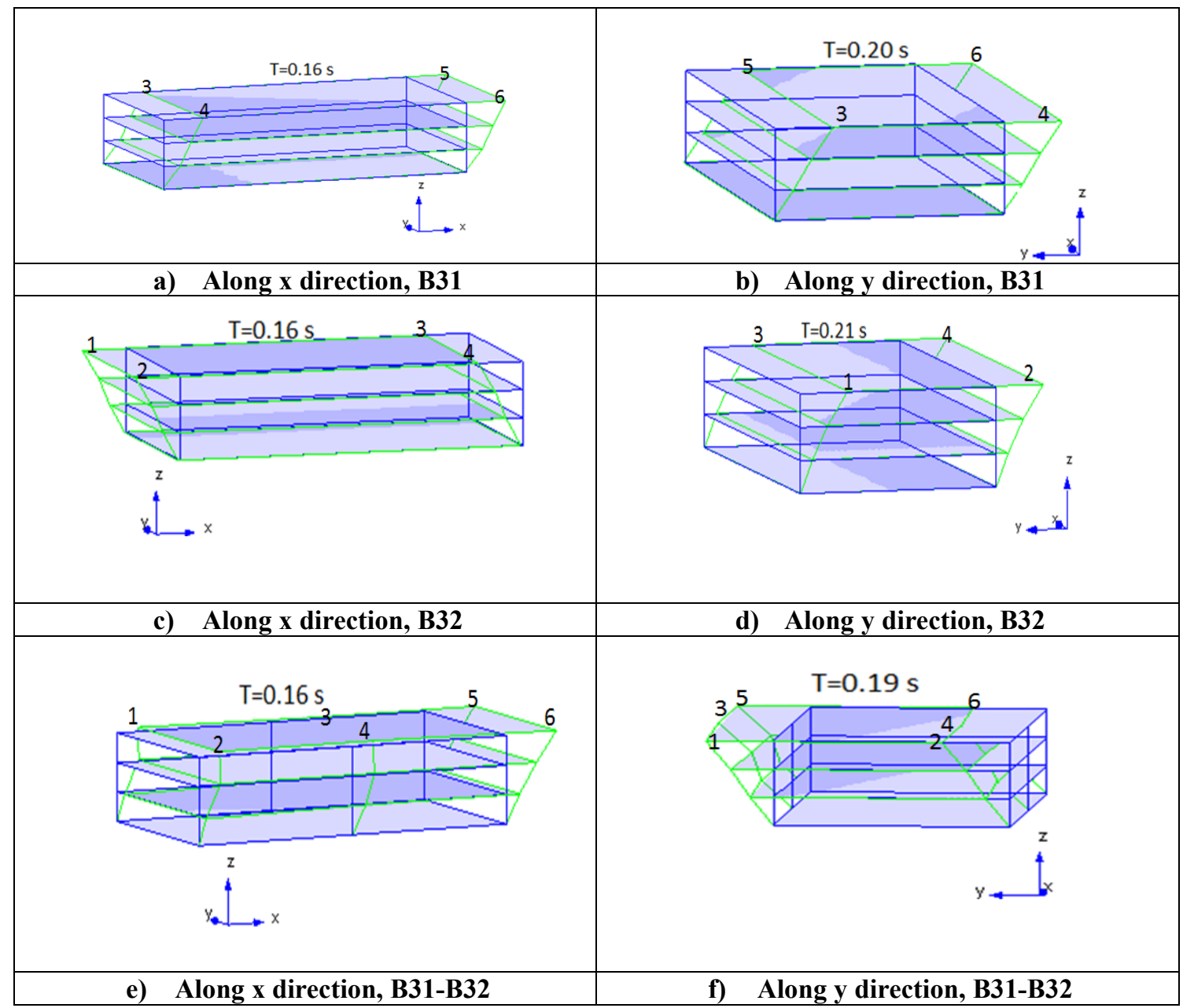

Figure B- 57 Mode shapes of the buildings measured in Test 7

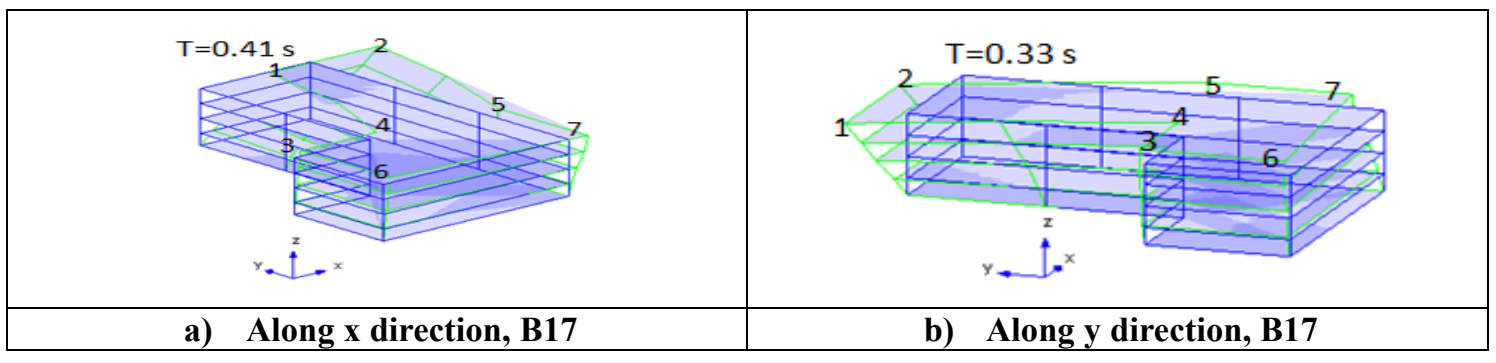

Figure B- 58 Mode shapes of the buildings measured in (Test 1) 


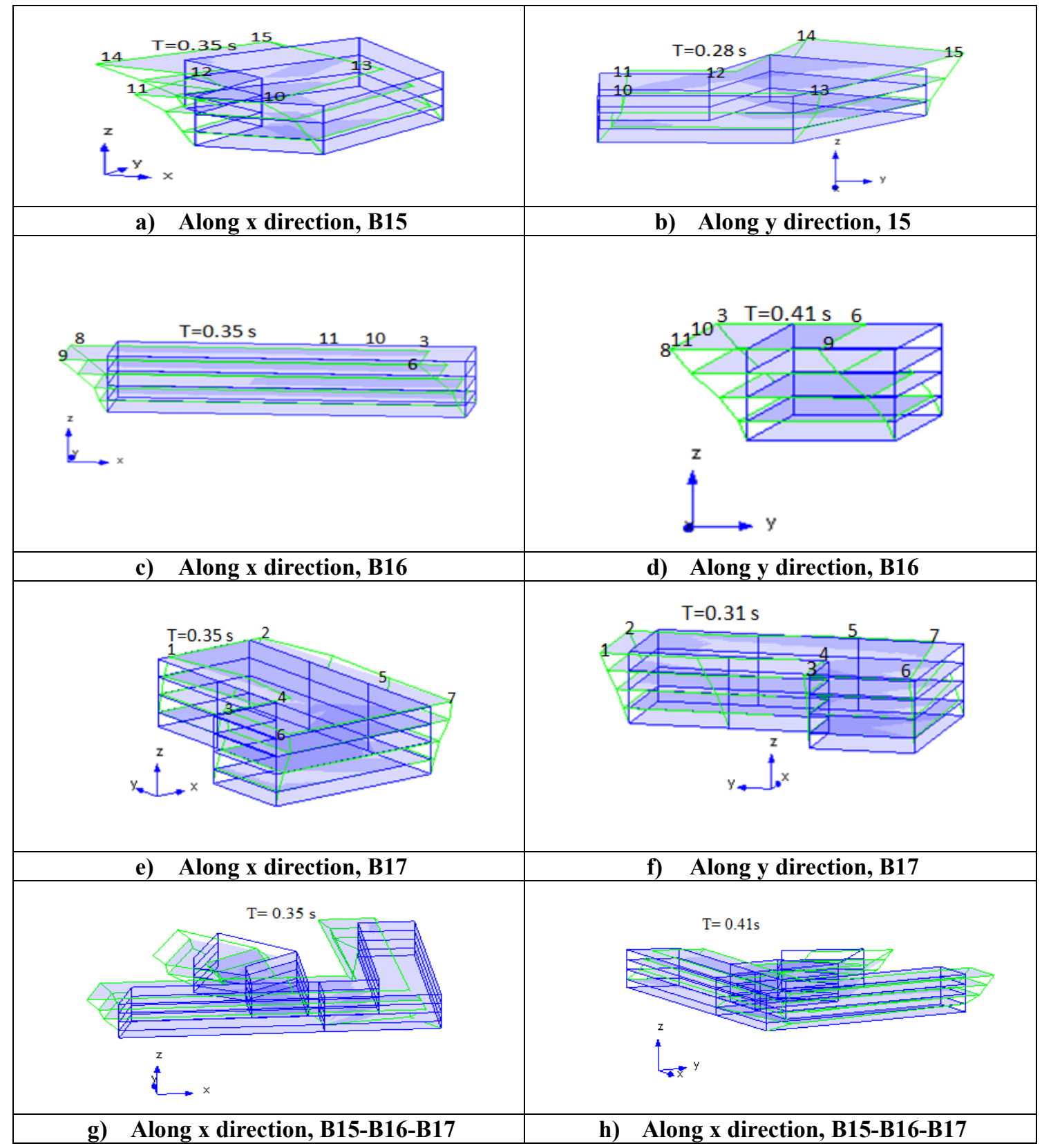

Figure B- 59 Mode shapes of the buildings measured in (Test 2) 


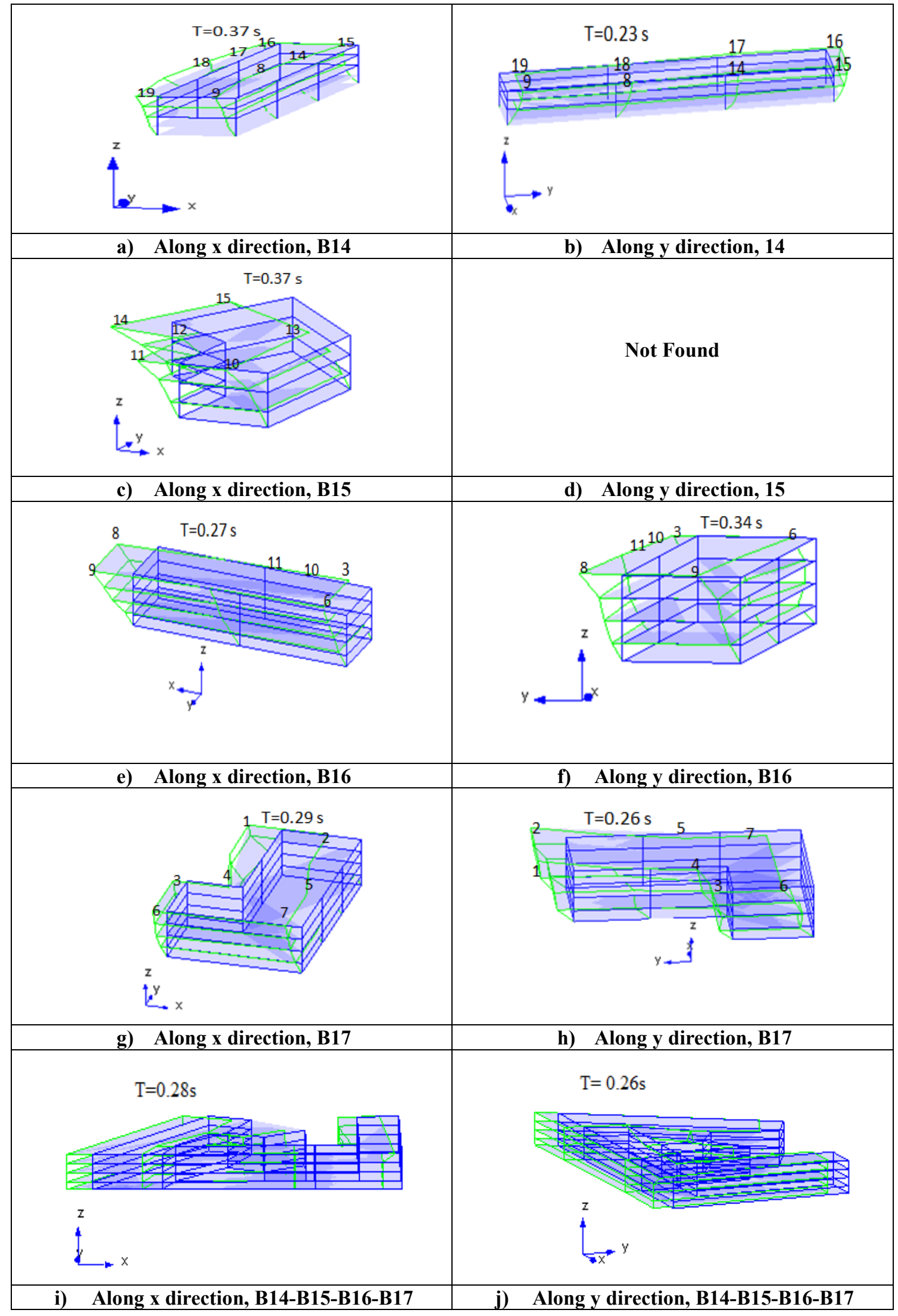

Figure B- 60 Mode shapes of the buildings measured in (Test 3) 


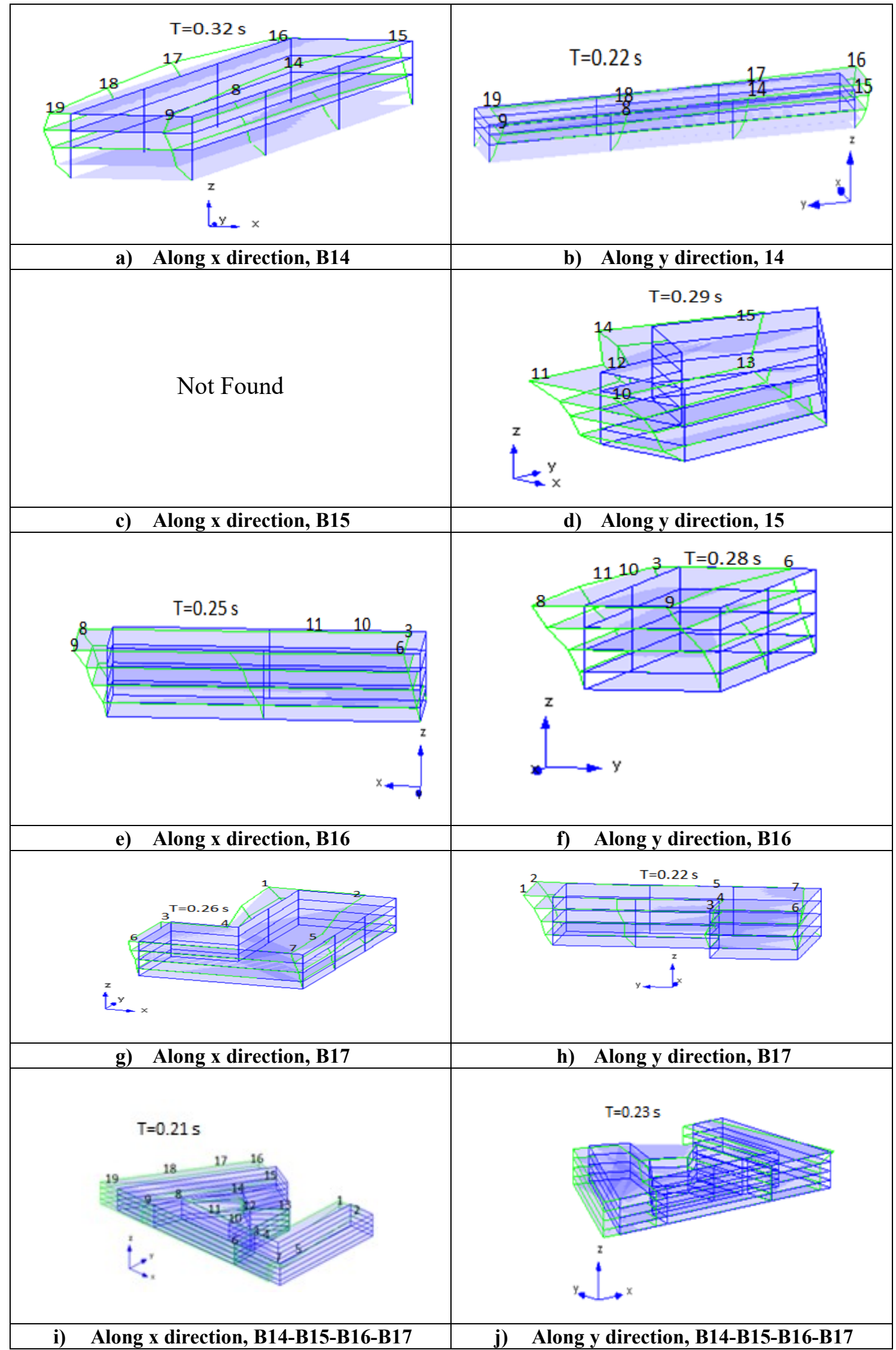

Figure B- 61 Mode shapes of the buildings measured in (Test 4) 


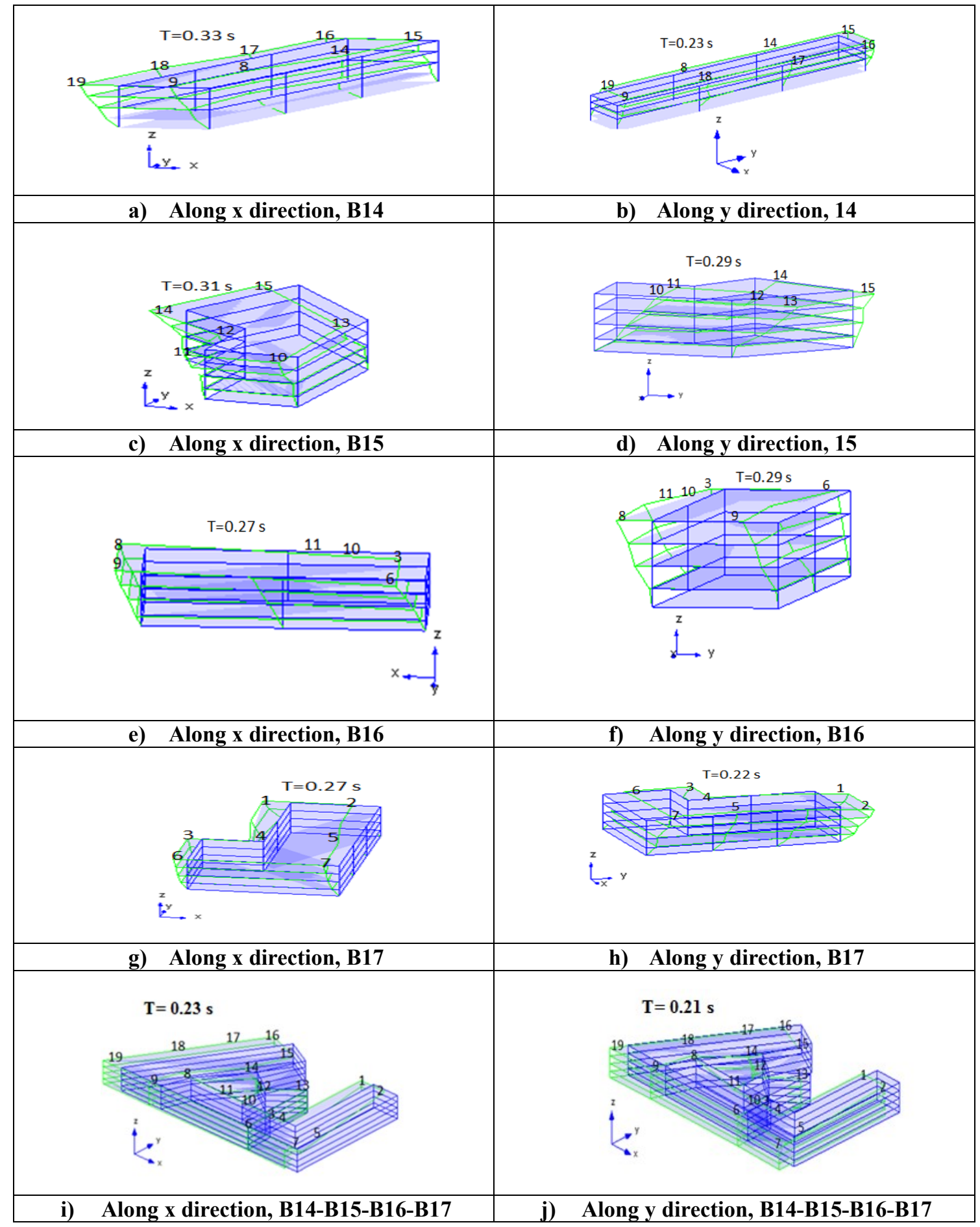

Figure B- 62 Mode shapes of the buildings measured in (Test 5) 


\section{APPENDIX C}

\section{Building Measured in various Stages of Construction}

Table C- 1 Construction stages and observations of buildings B31, B32 and B31-B32

\begin{tabular}{|c|c|c|}
\hline Test \# & Construction stage & Observations \\
\hline $\begin{array}{l}\text { Test } 1 \\
\text { April 7th, } 2015\end{array}$ & 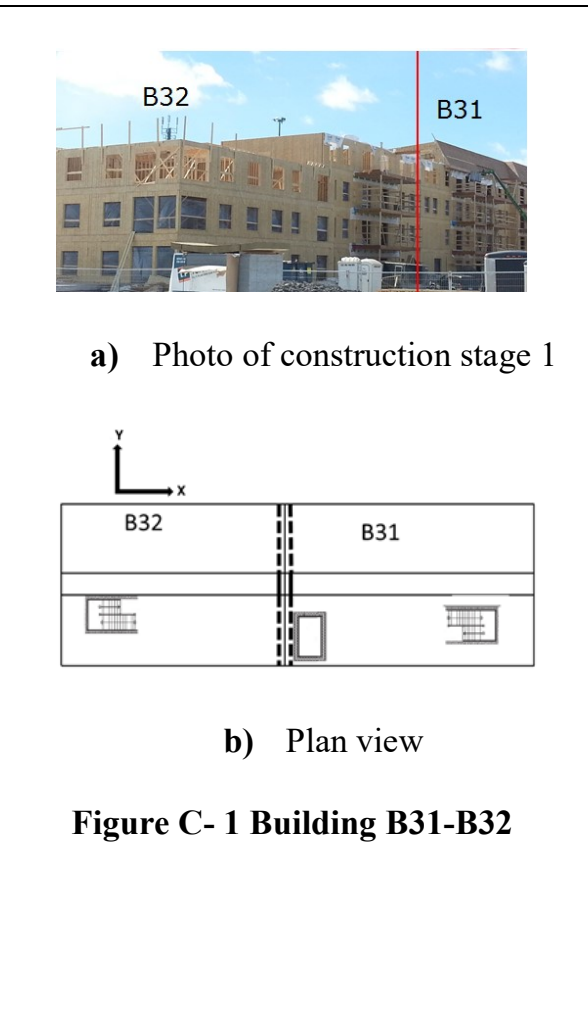 & $\begin{array}{l}\text { Construction stage 1: the roof was not up } \\
\text { yet for both buildings. B31 had bare } \\
\text { frame with some of the balconies under } \\
\text { construction. For B32, the fourth storey } \\
\text { was partially built, and some of the } \\
\text { balconies were under construction. } \\
\text { When B31-B32 were measured together, } \\
\text { approximately similar fundamental period } \\
\text { was found in the x directions as measured } \\
\text { for individual buildings. }\end{array}$ \\
\hline $\begin{array}{l}\text { Test } 2 \\
\text { May 15th, } 2015\end{array}$ & 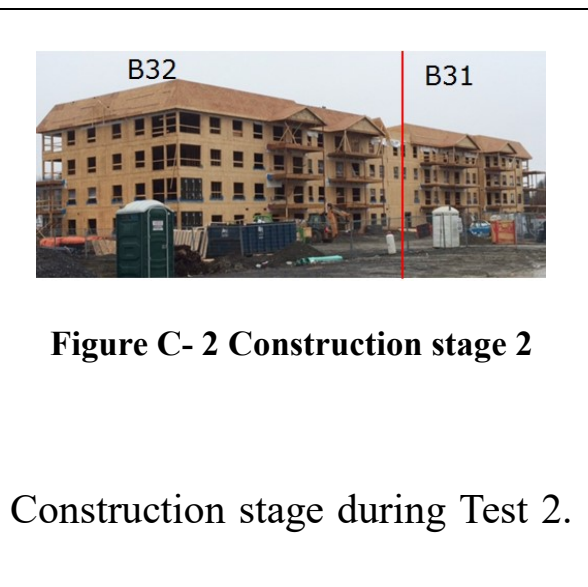 & $\begin{array}{l}\text { Results presented an increase in the } \\
\text { measured periods, and B32 yielded } \\
\text { longest periods in both orthogonal } \\
\text { directions. The increase in the measured } \\
\text { periods could be attributed to increase in } \\
\text { mass due to the roof compared to the }\end{array}$ \\
\hline
\end{tabular}




\begin{tabular}{|c|c|c|}
\hline & $\begin{array}{l}\text { For B31, the roof was completely } \\
\text { built. For B32 the fourth storey } \\
\text { and roof were completely built. }\end{array}$ & $\begin{array}{l}\text { structures in Test } 1 . \text { The results suggested } \\
\text { that the buildings behaved as one } \\
\text { structure. }\end{array}$ \\
\hline $\begin{array}{l}\text { Test } 3 \\
\text { July 6th, } 2015\end{array}$ & $\begin{array}{l}\text { B31: Completely insulated, only } \\
\text { the first floor was dry-walled } \\
\text { excluding staircase and the } \\
\text { corridor, doors and windows } \\
\text { were fixed at certain locations on } \\
\text { third and fourth storey levels. } \\
\text { B32: Insulated up to the third } \\
\text { floor. Only doors and windows } \\
\text { were installed at the top three } \\
\text { levels. }\end{array}$ & $\begin{array}{l}\text { At this construction stage, windows and } \\
\text { doors were installed at most places in the } \\
\text { top three levels of B32 and at the second } \\
\text { and third levels of B31. Shingles were } \\
\text { installed on the roofs of both buildings. } \\
\text { Shorter natural periods resulted from the } \\
\text { stiffening of both buildings in which B32 } \\
\text { seems stiffer than B31 (more windows in } \\
\text { place) in the x direction. The sway mode } \\
\text { shapes of B31 and B32 in two orthogonal } \\
\text { directions show that all nodes are } \\
\text { undergoing uniform modal motion along } \\
\text { x and y directions. }\end{array}$ \\
\hline $\begin{array}{l}\text { Test } 4 \\
\text { July 22nd, } 2015\end{array}$ & $\begin{array}{l}\text { B31: Completely dry walled up } \\
\text { to the second floor, partially dry } \\
\text { walled at third floor, more } \\
\text { balconies were installed, outside } \\
\text { brick was attached up to the }\end{array}$ & $\begin{array}{l}\text { A comparison of the results of Test } 4 \text { with } \\
\text { Test } 3 \text { shows } 7 \% \text { and } 3 \% \text { increases in the } \\
\text { fundamental period of } \mathrm{B} 32 \text { in the } \mathrm{x} \text { and } \mathrm{y} \\
\text { directions respectively. For B31, the } \\
\text { period in y direction showed an increase }\end{array}$ \\
\hline
\end{tabular}




\begin{tabular}{|c|c|c|}
\hline & $\begin{array}{l}\text { second level, corridors were not } \\
\text { dry walled at any floor. } \\
\text { B32: Insulated up to 4th floor, } \\
\text { outside brick was applied on one } \\
\text { perimeter wall in longitudinal } \\
\text { direction (up to the first floor), } \\
\text { one perimeter wall in transverse } \\
\text { direction (up to the second floor) } \\
\text { and at some part of the other } \\
\text { walls }\end{array}$ & $\begin{array}{l}\text { of } 11 \% \text { while in } \mathrm{x} \text { direction the period } \\
\text { found consistent with Test } 3 \text {. When the } \\
\text { building is tested as one whole complex, } \\
\text { B31-B32, no significant difference (only } \\
3 \% \text { ) was seen in the period along y } \\
\text { direction. No significant differences were } \\
\text { found when comparing the sway motion } \\
\text { with the results of Test } 3 \text {. }\end{array}$ \\
\hline $\begin{array}{l}\text { Test } 5 \\
\text { Aug. 5th, } 2015\end{array}$ & $\begin{array}{l}\text { B31: The third floor was } \\
\text { completely dry walled excluding } \\
\text { corridor; the fourth floor was } \\
\text { partially dry walled. At first and } \\
\text { second floors all units have } \\
\text { concrete topping, outside was } \\
\text { completely covered with bricks } \\
\text { up to third floor } \\
\text { B32: First floor more than half } \\
\text { dry walled, outside was } \\
\text { completely covered with bricks } \\
\text { up to second floor }\end{array}$ & $\begin{array}{l}\text { For B31 a period reduction of } 6 \% \text { was } \\
\text { found in the x direction and a reduction of } \\
23 \% \text { in the y direction, when compared to } \\
\text { previous measurements in Test } 4 \text {. For } \\
\text { B32, the periods along } x \text { and y direction } \\
\text { decreased by } 6 \% \text { and } 3 \% \text {, respectively. A } \\
\text { decrease in the period of B31-B32 (in y } \\
\text { directions) indicates overall stiffening of } \\
\text { the structure, as expected. During this test } \\
\text { a temporary connection between the } \\
\text { corridors of B31 and B32 through } \\
\text { oriented strand board (OSB) sheathing } \\
\text { was observed, which may have an effect }\end{array}$ \\
\hline
\end{tabular}




\begin{tabular}{|c|c|c|}
\hline & & $\begin{array}{l}\text { on the periods and mode shapes in } \mathrm{x} \\
\text { direction. }\end{array}$ \\
\hline $\begin{array}{l}\text { Test } 6 \\
\text { Aug. 30th, } 2016\end{array}$ & $\begin{array}{l}\text { B31: Corridors were not dry } \\
\text { walled, at third and fourth floors } \\
\text { concrete was not placed in one } \\
\text { unit only, windows have been } \\
\text { fully installed, finishing of } \\
\text { balconies were underway. } \\
\text { B32: First floor completely dry } \\
\text { walled. Four units at second floor } \\
\text { underwishes were applied up to third } \\
\text { were not dry walled, windows } \\
\text { have been fully installed, outside } \\
\text { floor, finishing of balconies were } \\
\text { undion stage } 6\end{array}$ & $\begin{array}{l}\text { The periods were observed to be longer } \\
\text { or remained consistent when comparing } \\
\text { to those of Test } 5 \text {. An exception to the } \\
\text { period trend is seen for B32 in the y } \\
\text { direction, where the period reduced by } \\
7 \% \text { compared to Test } 5 \text { results. This } \\
\text { reduction in period could attribute to } \\
\text { installation of the gypsum boards entirely } \\
\text { on the first floor and partially on the } \\
\text { second floor, where more walls in the } y \\
\text { direction were seen to be covered with } \\
\text { gypsum than in } x \text { direction. In the } x \\
\text { direction tests on B31-B32 generated a } \\
\text { shorter period than in the tests on the } \\
\text { individual buildings. } \\
\text { buildings were measured separately and } \\
\text { as one complex. }\end{array}$ \\
\hline $\begin{array}{l}\text { Test } 7 \\
\text { Sept.4th, } 2015\end{array}$ & & $\begin{array}{l}\text { The periods reduced in } y \text { directions and } \\
\text { stayed consistent with Test } 6 \text { in } \mathrm{x}\end{array}$ \\
\hline
\end{tabular}




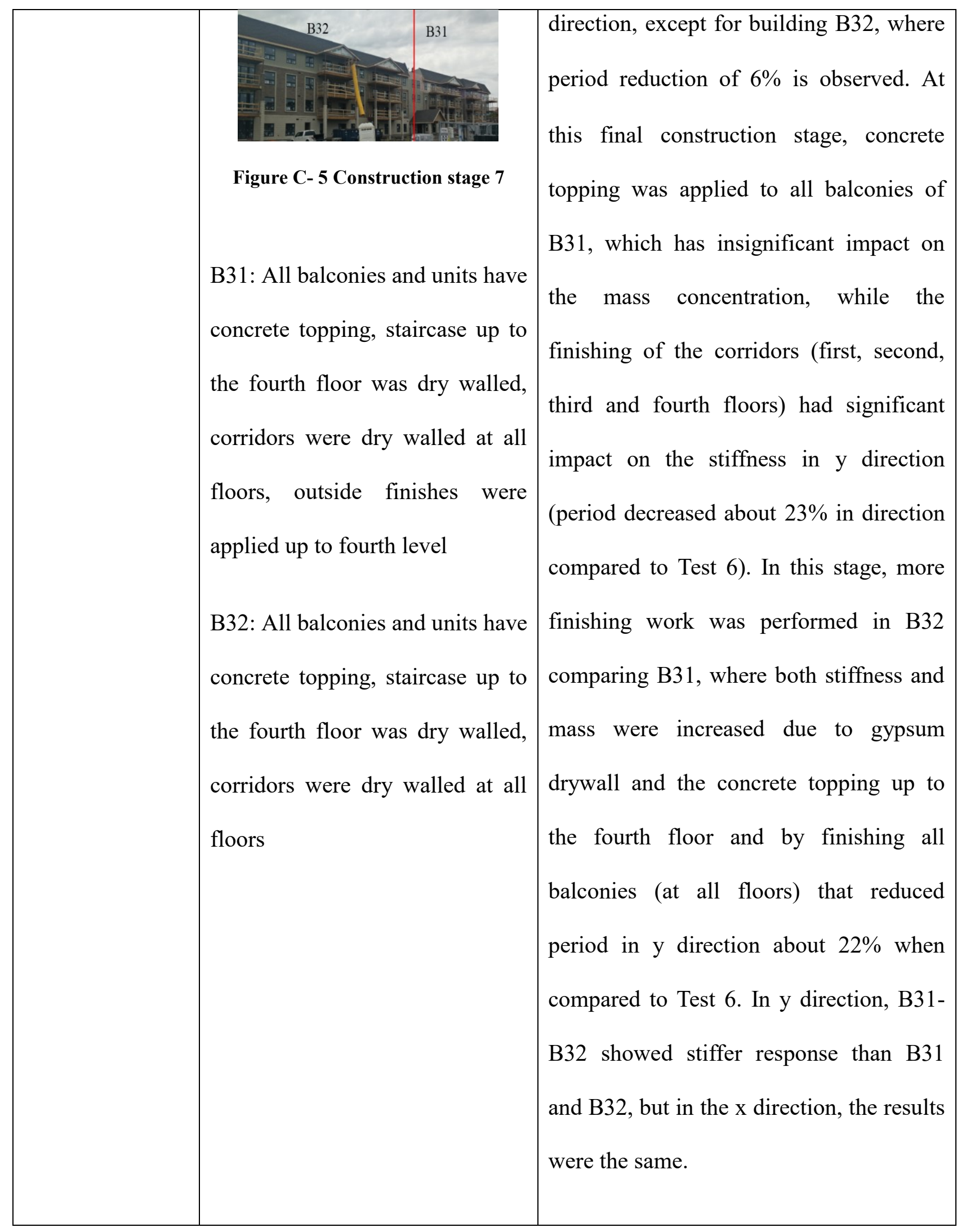


Table C- 2 Construction stages and observations of buildings B14, B15, B16, B17 and B14-B15-

B16-B17

\begin{tabular}{|c|c|c|}
\hline Test \# & Construction Stage & Observations \\
\hline $\begin{array}{l}\text { Test } 1 \\
\text { June 12th, } 2014\end{array}$ & Figure C- 6 Construction stage 1 & $\begin{array}{l}\text { Building B17 was the only one } \\
\text { constructed at the time of the first } \\
\text { ambient vibration test. The building } \\
\text { was tested without roof during this } \\
\text { stage. The measured period in the } x \\
\text { direction was found to be greater than } \\
\text { that obtained for the y direction. The } \\
\text { effect of torsion was significant due to } \\
\text { the irregular in-plane geometry of the } \\
\text { building. }\end{array}$ \\
\hline $\begin{array}{l}\text { Test } 2 \\
\text { Sept.12th, } 2014\end{array}$ & a) 3D sketch of B15-B16-B17 & $\begin{array}{l}\text { During this test B17 and B16 were } \\
\text { measured in their Phase } 1 \text { construction } \\
\text { stage, and B15 was measured for the } \\
\text { first time with its roof partially } \\
\text { installed. When comparing the results }\end{array}$ \\
\hline
\end{tabular}




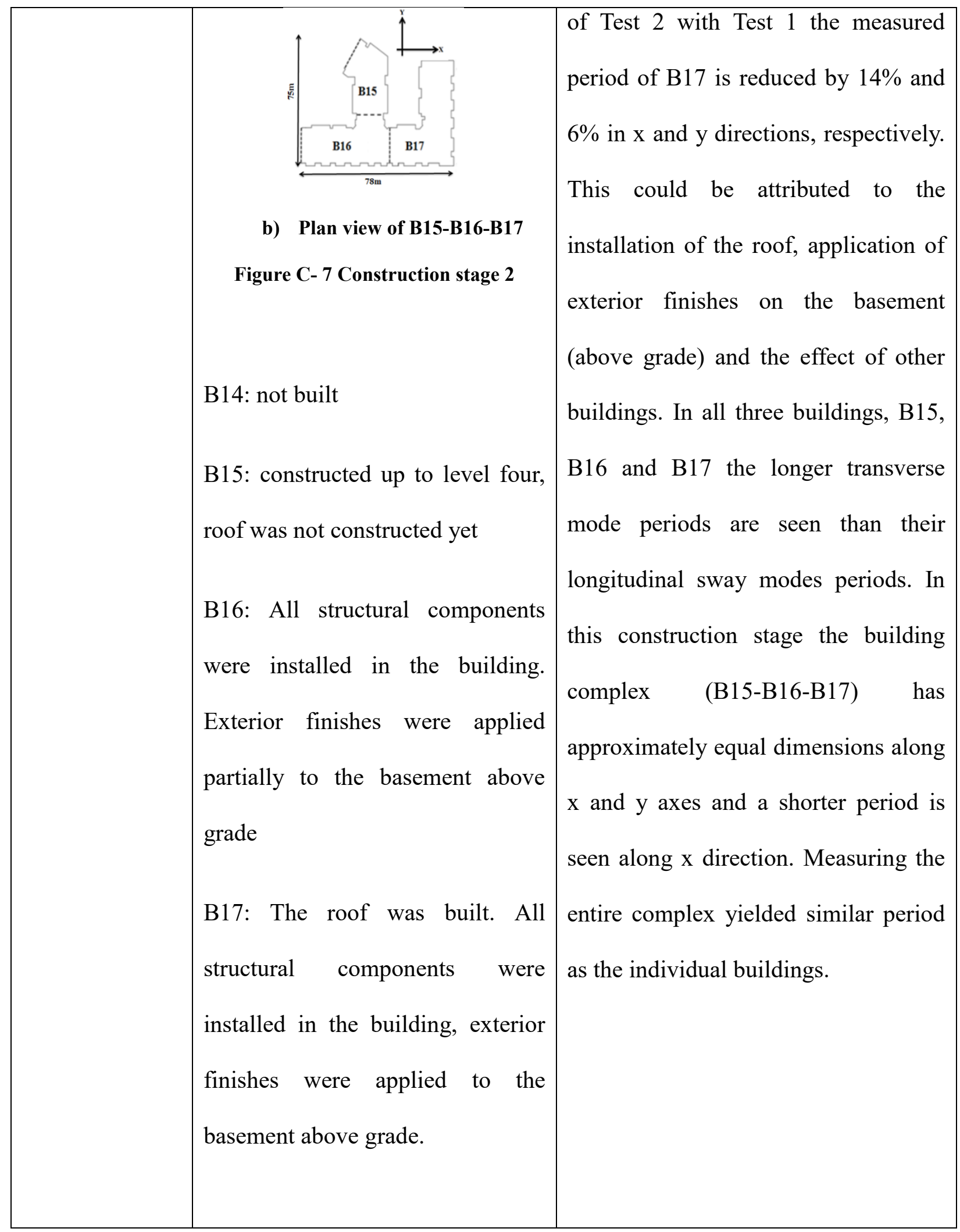




\begin{tabular}{|c|c|c|}
\hline $\begin{array}{l}\text { Test } 3 \\
\text { May 22nd, } 2015\end{array}$ & $\begin{array}{l}\text { Figure C- } 8 \text { Plan view of B14-B15-B16- } \\
\text { B14: Basement and fourth level } \\
\text { were not finished. Brick was } \\
\text { applied to the third level. } \\
\text { Balconies were mounted at all } \\
\text { levels. Concrete was applied to the } \\
\text { corridor floors up to third level. } \\
\text { B16: Only the basement was not } \\
\text { finished } \\
\text { one and two. Outside brick was installed } \\
\text { up to the fourth level. Concrete } \\
\text { was applied to the units at level } \\
\text { to the was applied }\end{array}$ & $\begin{array}{l}\text { Overall, a period reduction is obtained } \\
\text { in all measured cases except for B } 15 \\
\text { in the } x \text { directions, where } 6 \% \text { increase } \\
\text { is obtained, in the period. The } \\
\text { fundamental mode shapes of the } \\
\text { measured buildings in this test series } \\
\text { were found to be similar than those } \\
\text { obtained in previous measurements. }\end{array}$ \\
\hline $\begin{array}{l}\text { Test } 4 \\
\text { Aug. 8th, } 2015\end{array}$ & $\begin{array}{l}\text { B14: Only five units on the fourth } \\
\text { level were not finished }\end{array}$ & $\begin{array}{l}\text { In general, the fundamental periods } \\
\text { were reduced for all measured cases } \\
\text { when compared with the results of }\end{array}$ \\
\hline
\end{tabular}




\begin{tabular}{|c|c|c|}
\hline & $\begin{array}{l}\text { B15: three unit on third level and } \\
\text { two units on top level were } \\
\text { finished } \\
\text { B16: Only basement was not } \\
\text { finished, units have hardwood } \\
\text { floor, some units did not have } \\
\text { gypcrete yet } \\
\text { B17: Completely finished from } \\
\text { inside and outside }\end{array}$ & $\begin{array}{l}\text { Test 3. The modal response in } \mathrm{x} \\
\text { direction was not identified for B15. } \\
\text { The fundamental mode shapes of the } \\
\text { buildings identified in Test } 4 \text { showed } \\
\text { no significant differences when } \\
\text { compared to the mode shapes obtained } \\
\text { in Test } 3 \text {. }\end{array}$ \\
\hline $\begin{array}{l}\text { Test } 5 \\
\text { Aug. 24th, } 2015\end{array}$ & $\begin{array}{l}\text { B14: Completely finished and } \\
\text { some units on each level were } \\
\text { occupied } \\
\text { B15: Completely finished and } \\
\text { some units on each level were } \\
\text { occupied } \\
\text { B16: Completely finished and } \\
\text { some units on each level were } \\
\text { occupied } \\
\text { B17: Completely finished and } \\
\text { some units on each level were } \\
\text { occupied }\end{array}$ & $\begin{array}{l}\text { In this test series, all the buildings are } \\
\text { completely finished and partially } \\
\text { occupied. In general, only small } \\
\text { increases in fundamental periods are } \\
\text { observed. The building fundamental } \\
\text { mode shapes identified in Test } 5 \text { show } \\
\text { no significant differences with the } \\
\text { results obtained in Test } 4 \text {. }\end{array}$ \\
\hline
\end{tabular}




\section{APPENDIX D}

\section{Computed Mode Shapes of Measured Buildings}

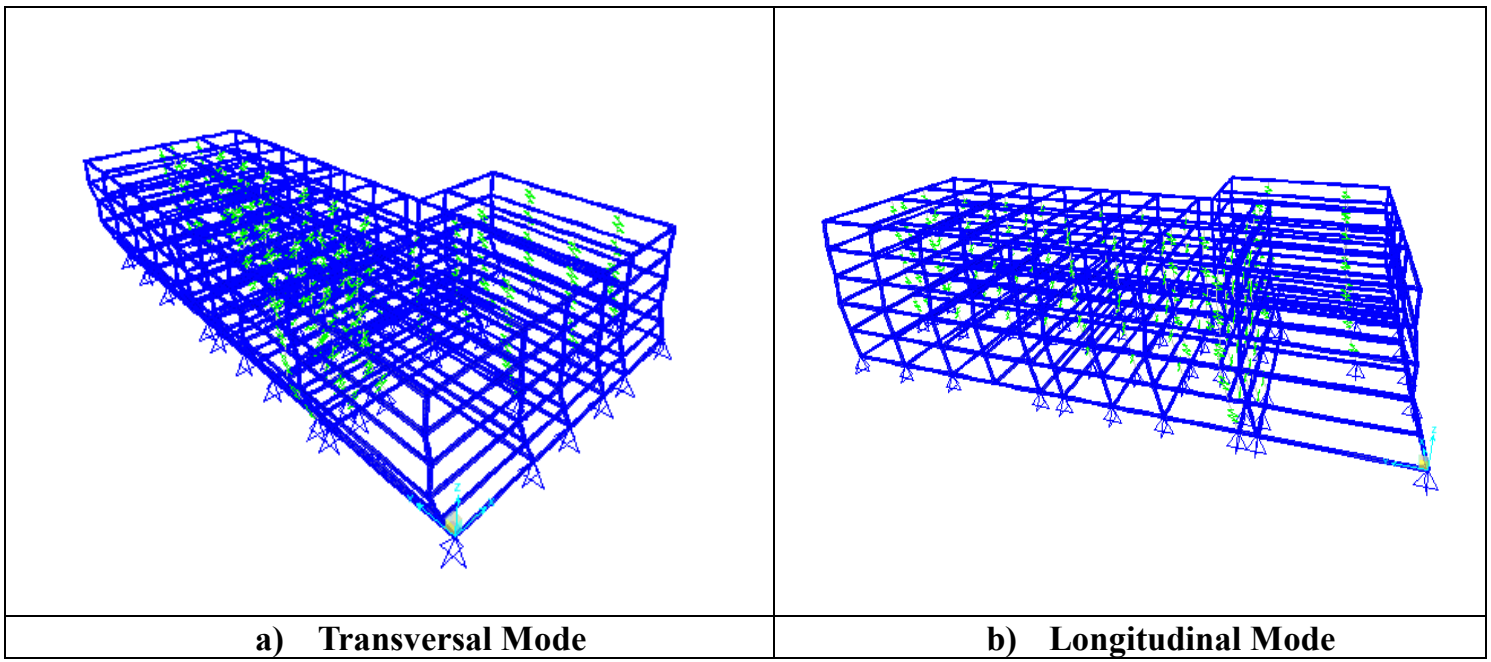

Figure D- 1 Mod shapes of building B1 (Phase 1)

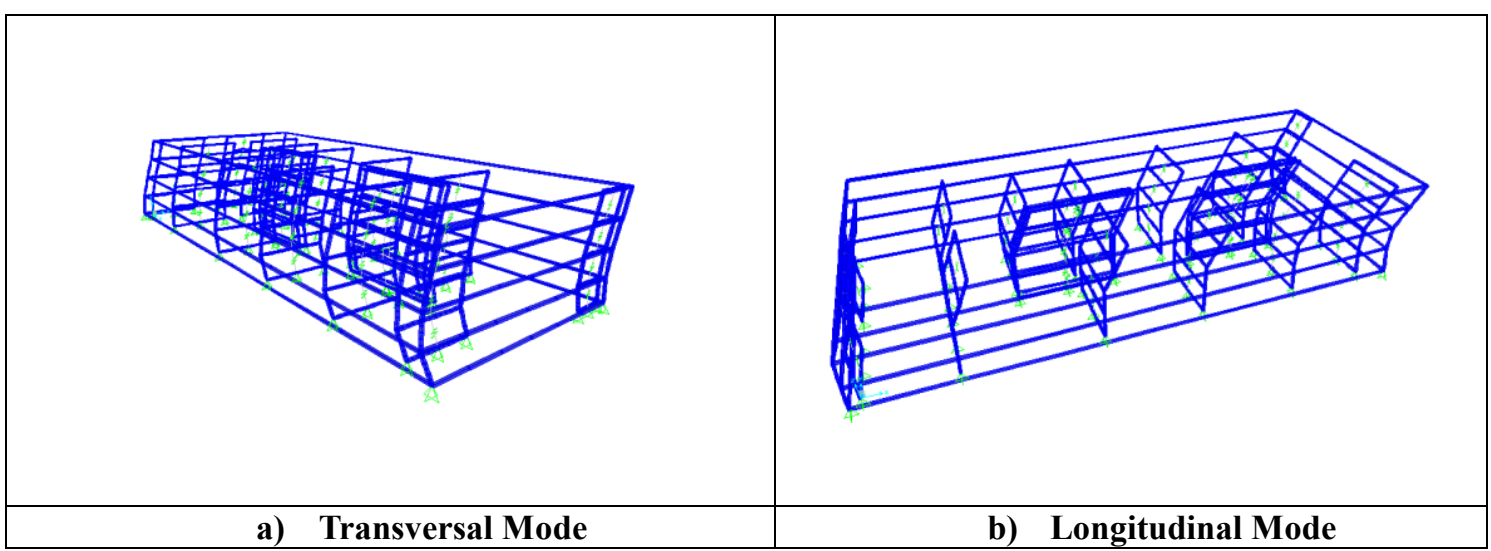

Figure D- 2 Mod shapes of building B5 (Phase 1)

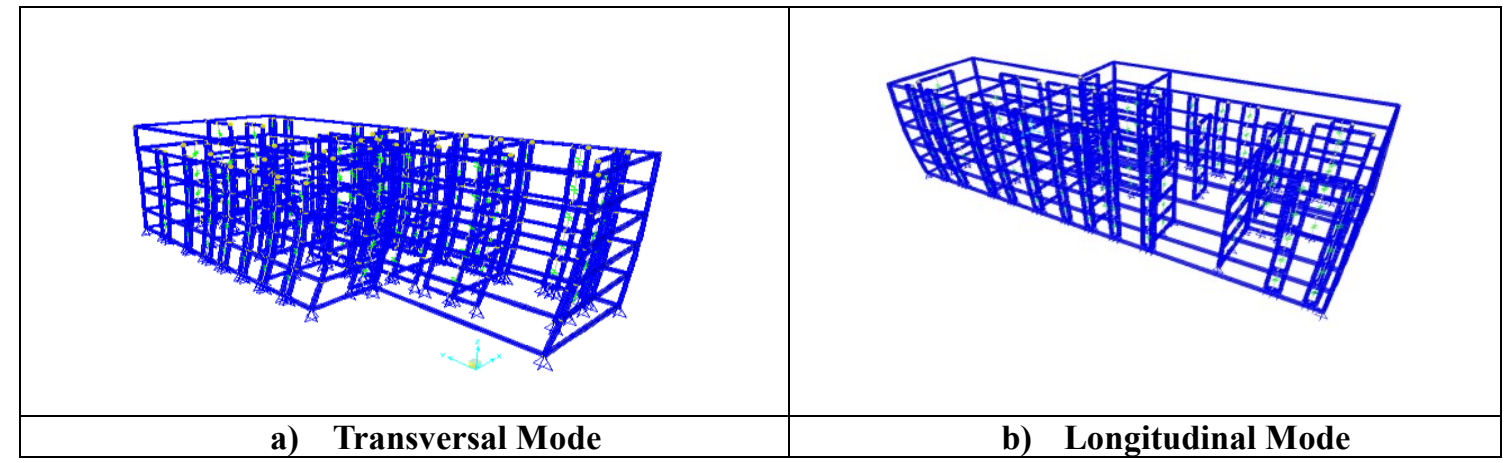

Figure D- 3 Mod shapes of building B6 (Phase 1) 


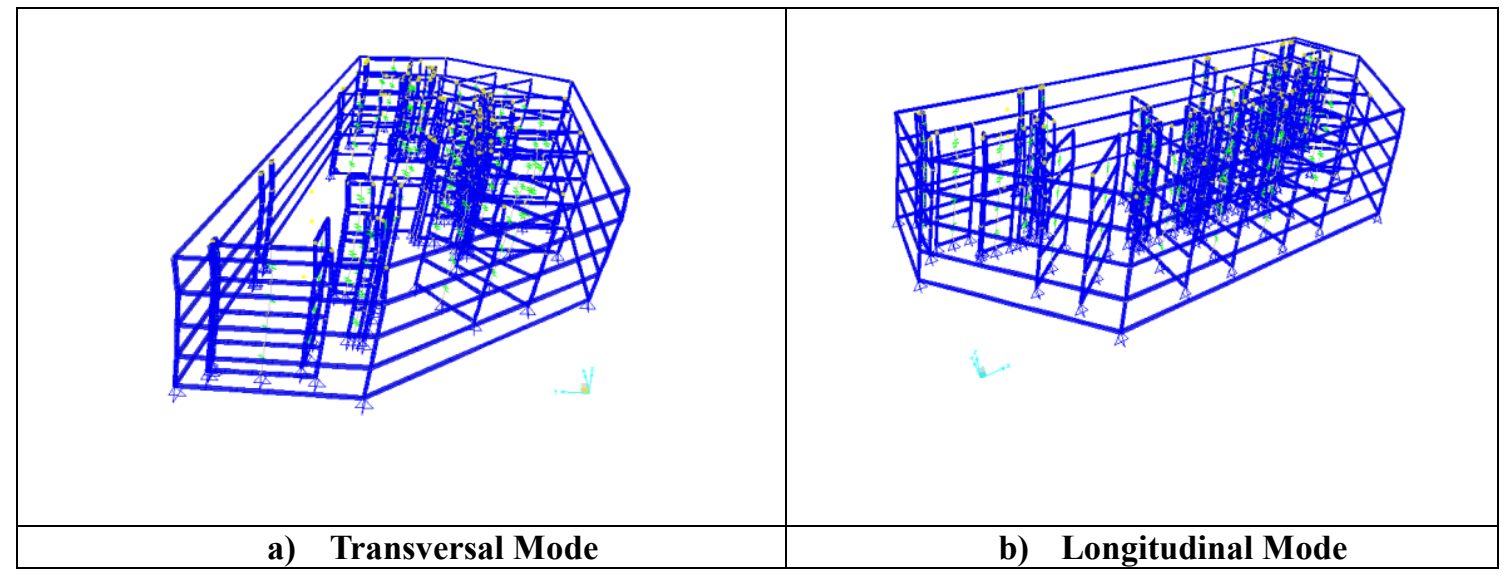

Figure D- 4 Mod shapes of building B7 (Phase 1)

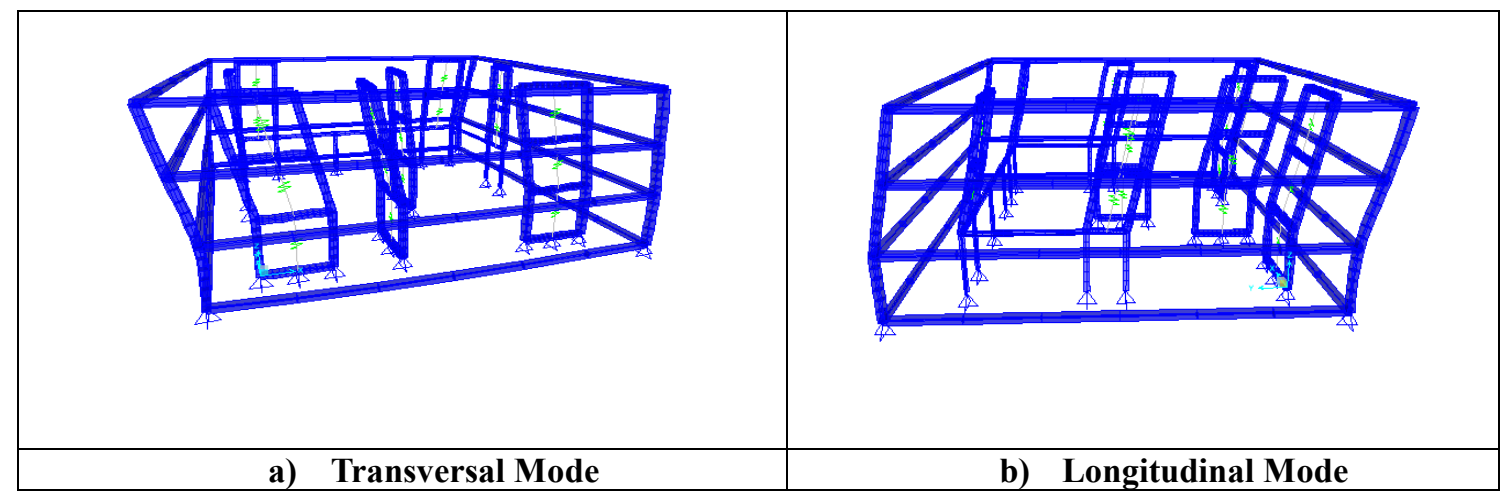

Figure D- 5 Mod shapes of building B25 (Phase 1)

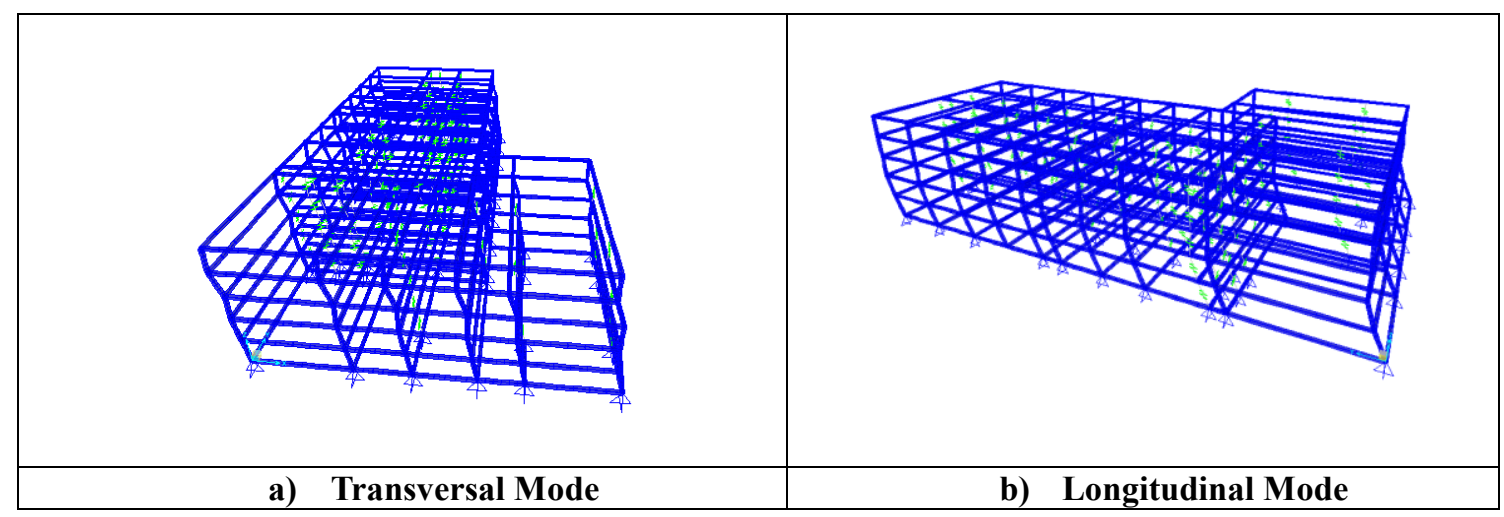

Figure D- 6 Mod shapes of building B1 (Phase 2)

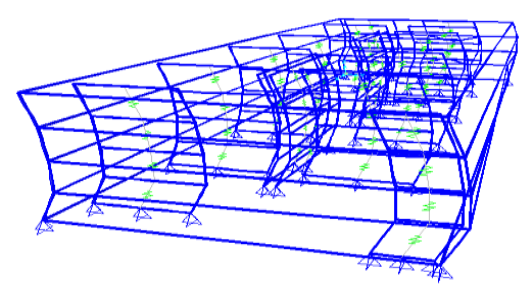

a) Transversal Mode

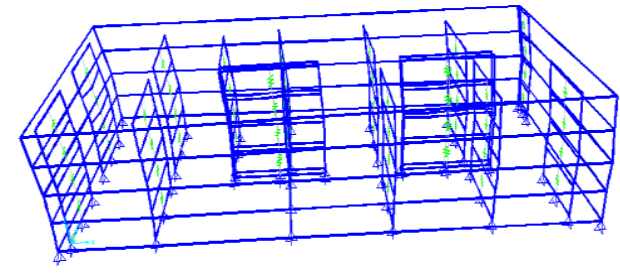

b) Longitudinal Mode

Figure D- 7 Mod shapes of building B5 (Phase 2) 


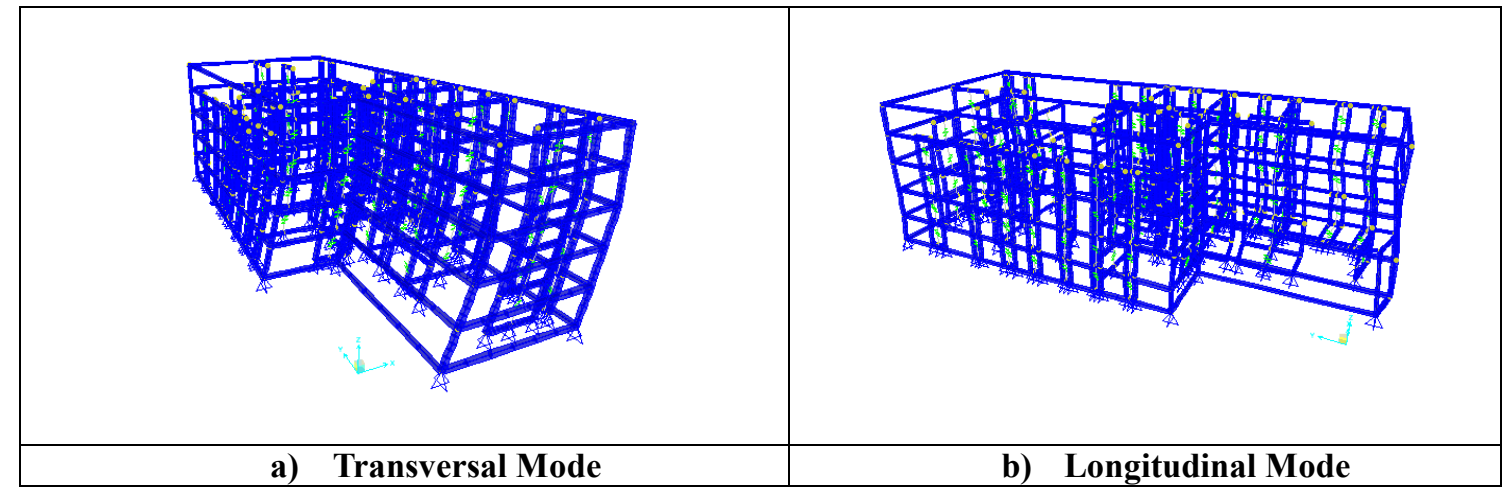

Figure D- 8 Mod shapes of building B6 (Phase 2)

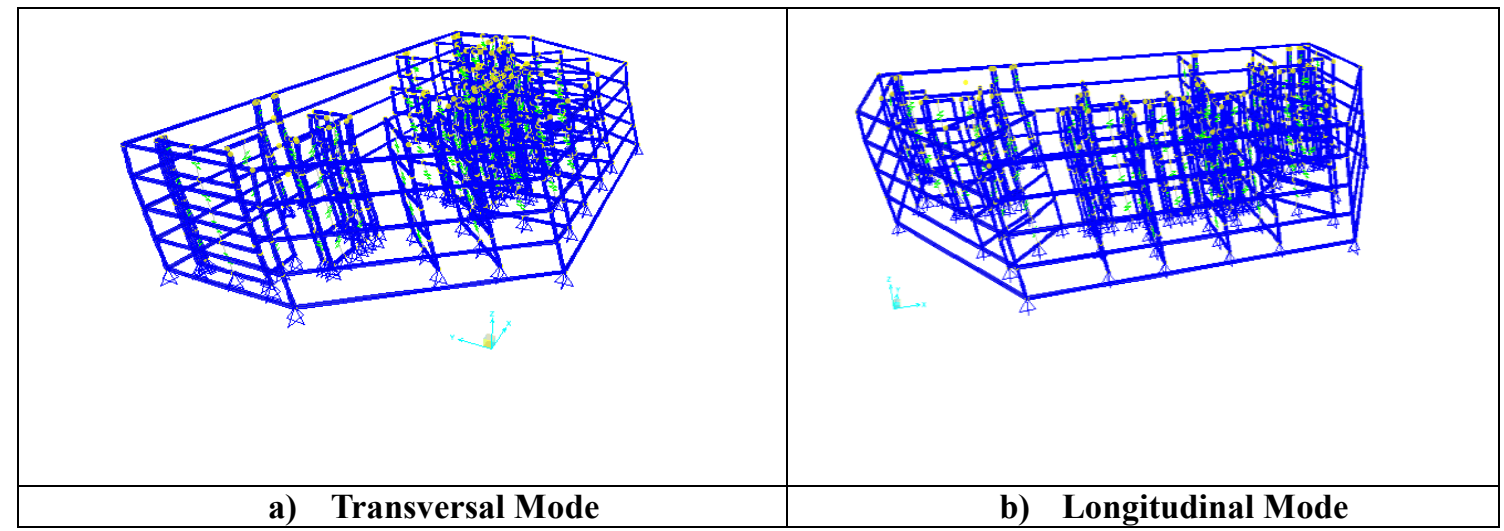

Figure D- 9 Mod shapes of building B7 (Phase 2)

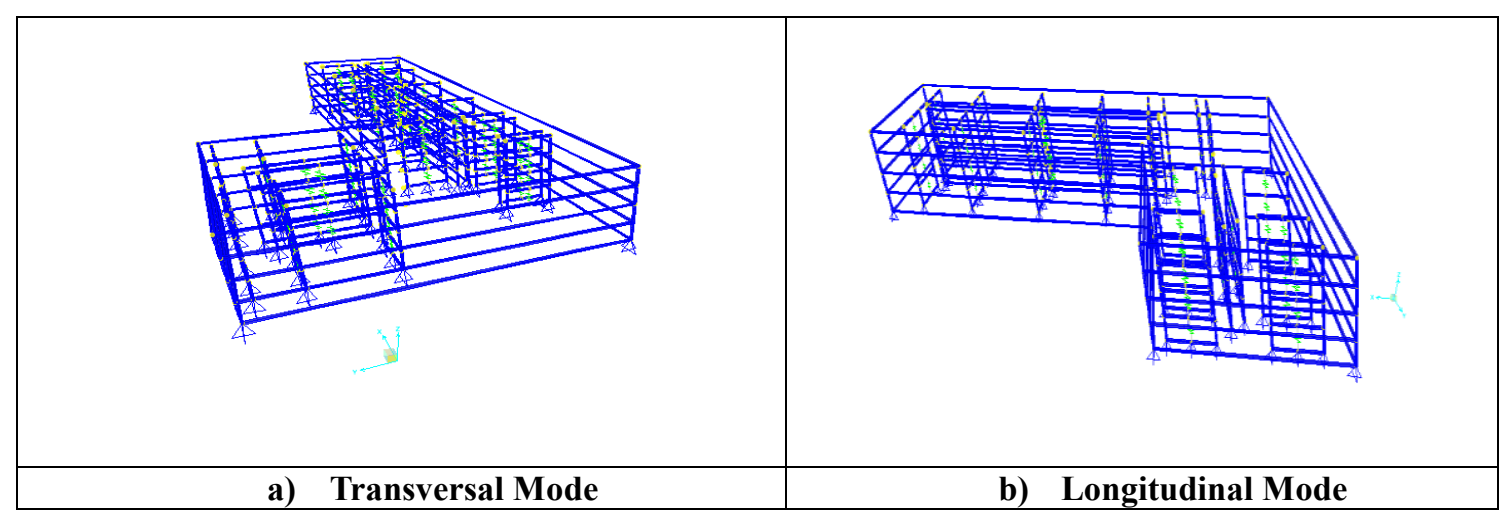

Figure D- 10 Mod shapes of building B9 (Phase 2)

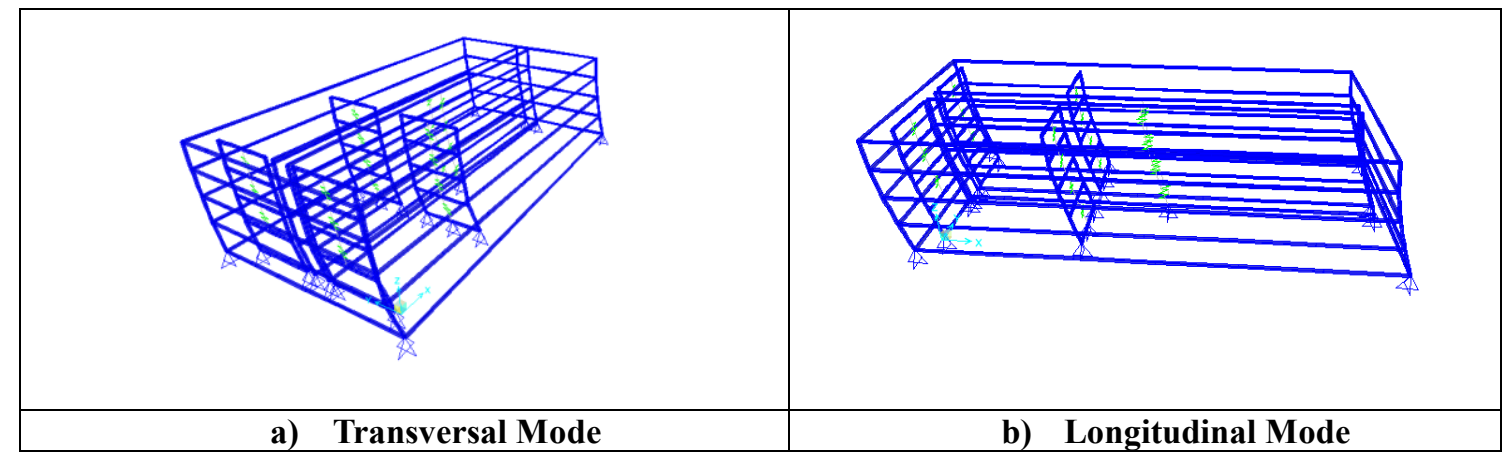

Figure D- 11 Mod shapes of building B22 (Phase 2) 


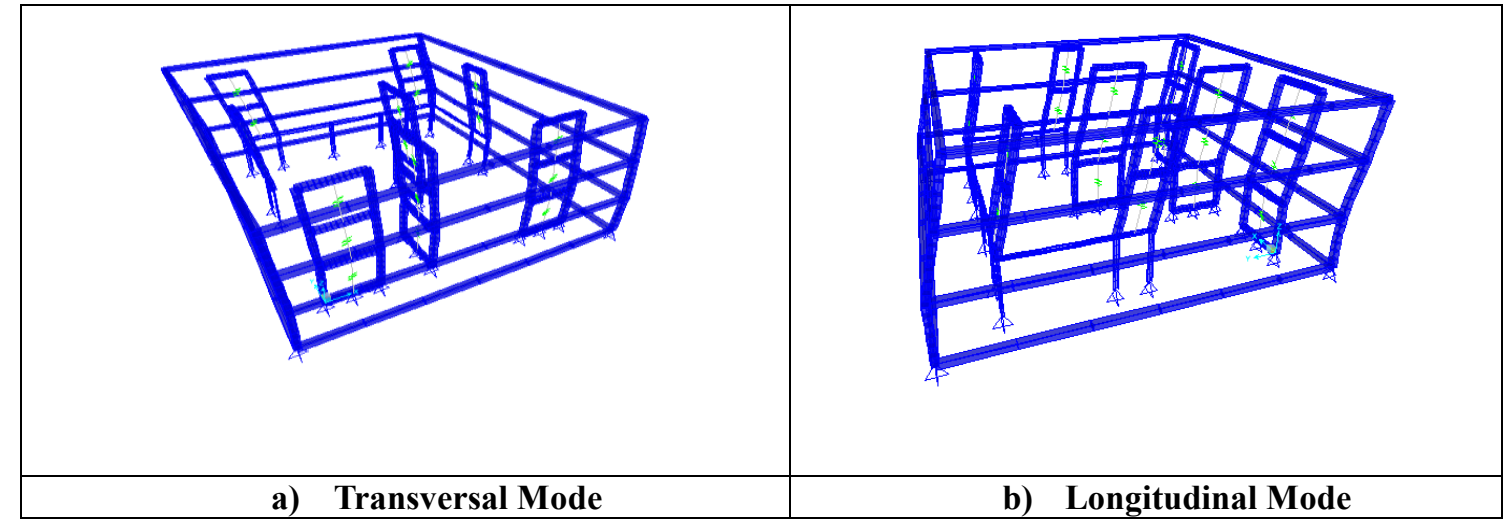

Figure D- 12 Mod shapes of building B25 (Phase 2)

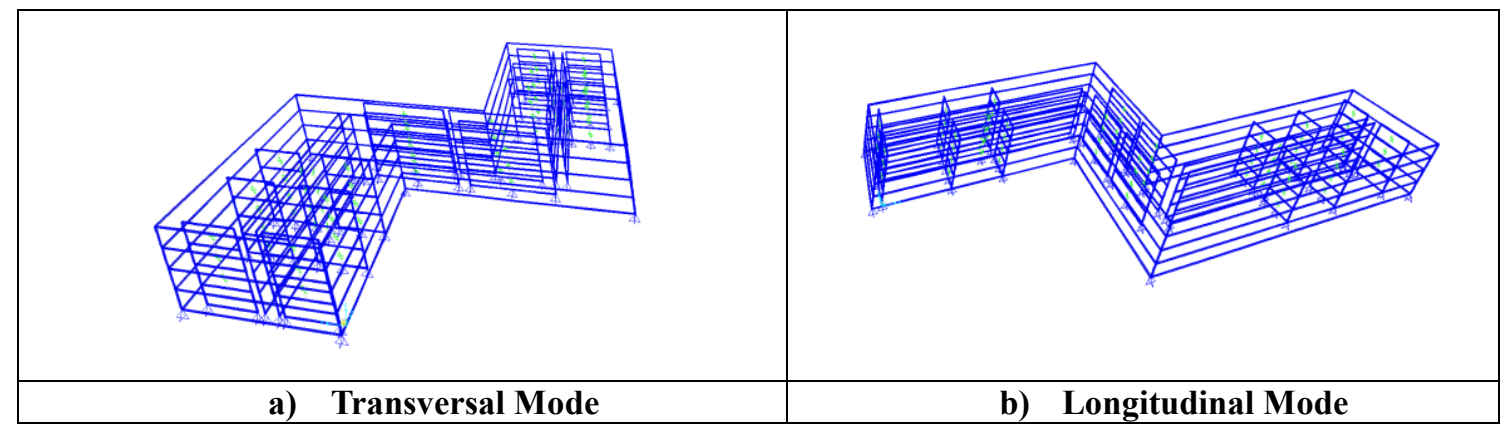

Figure D- 13 Mod shapes of building B18-B19 (Phase 2)

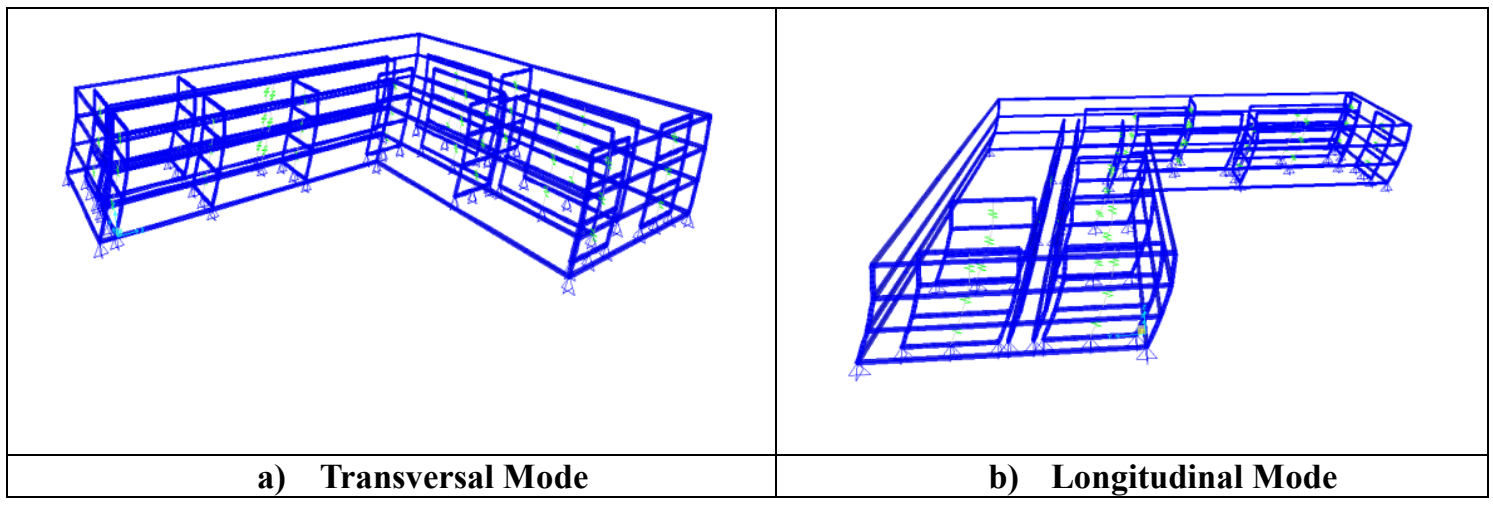

Figure D- 14 Mod shapes of building B20-B21 (Phase 2)

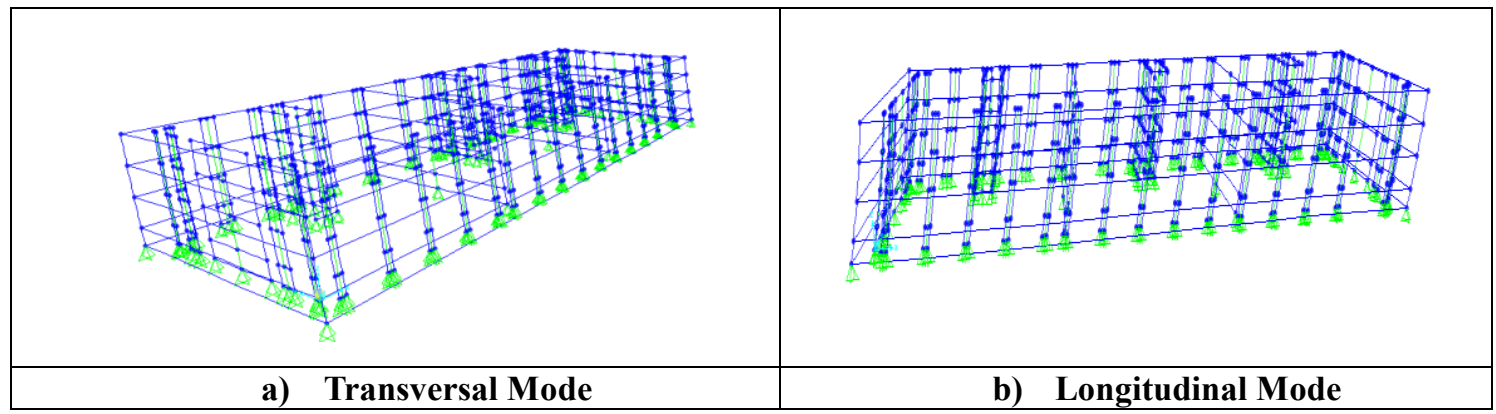

Figure D- 15 Mod shapes of building B26-B27 (Phase 2) 


\section{Buildings in Various Stages of Construction}

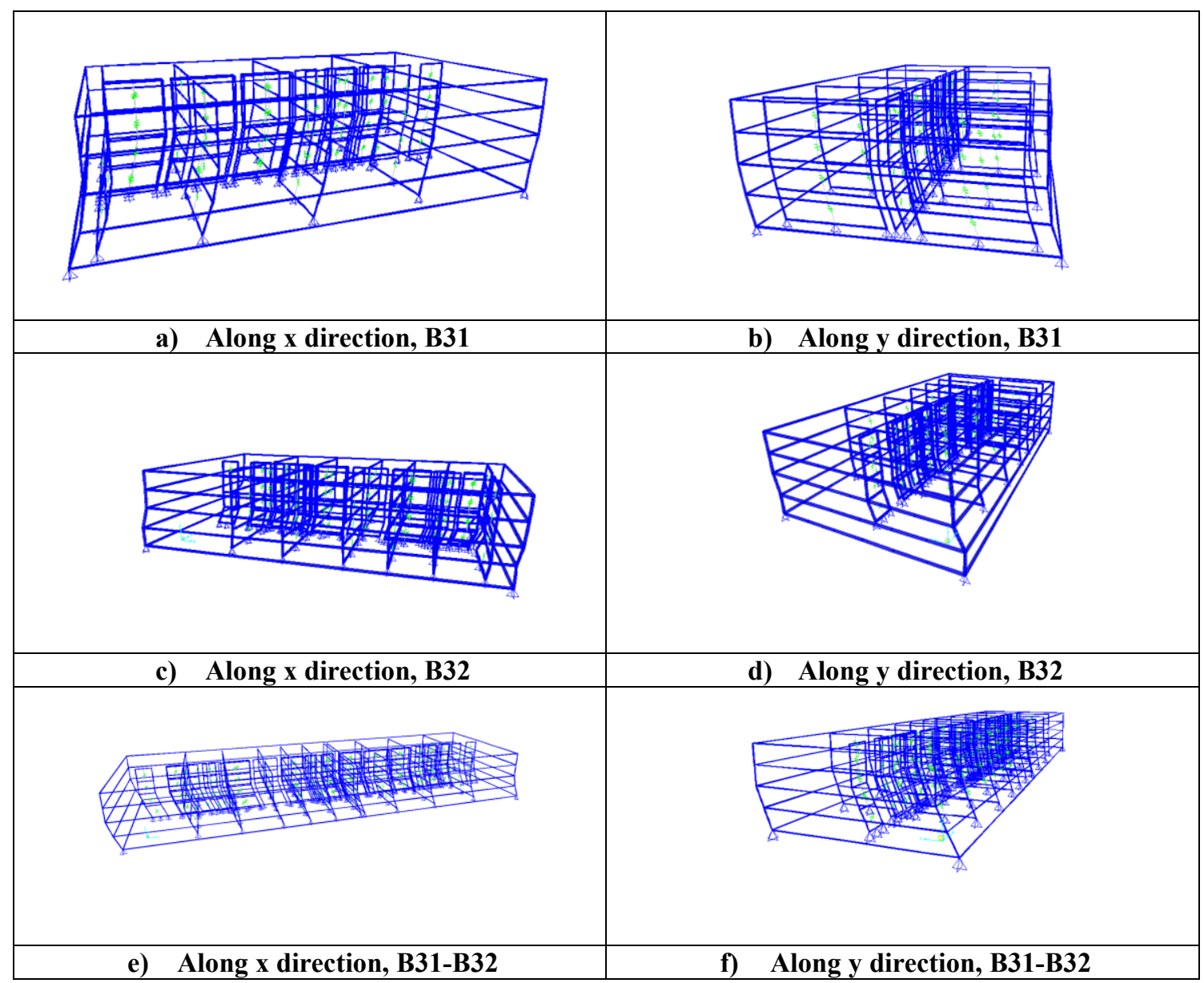

Figure D- 16 Mode shapes of the buildings measured in Test 1 


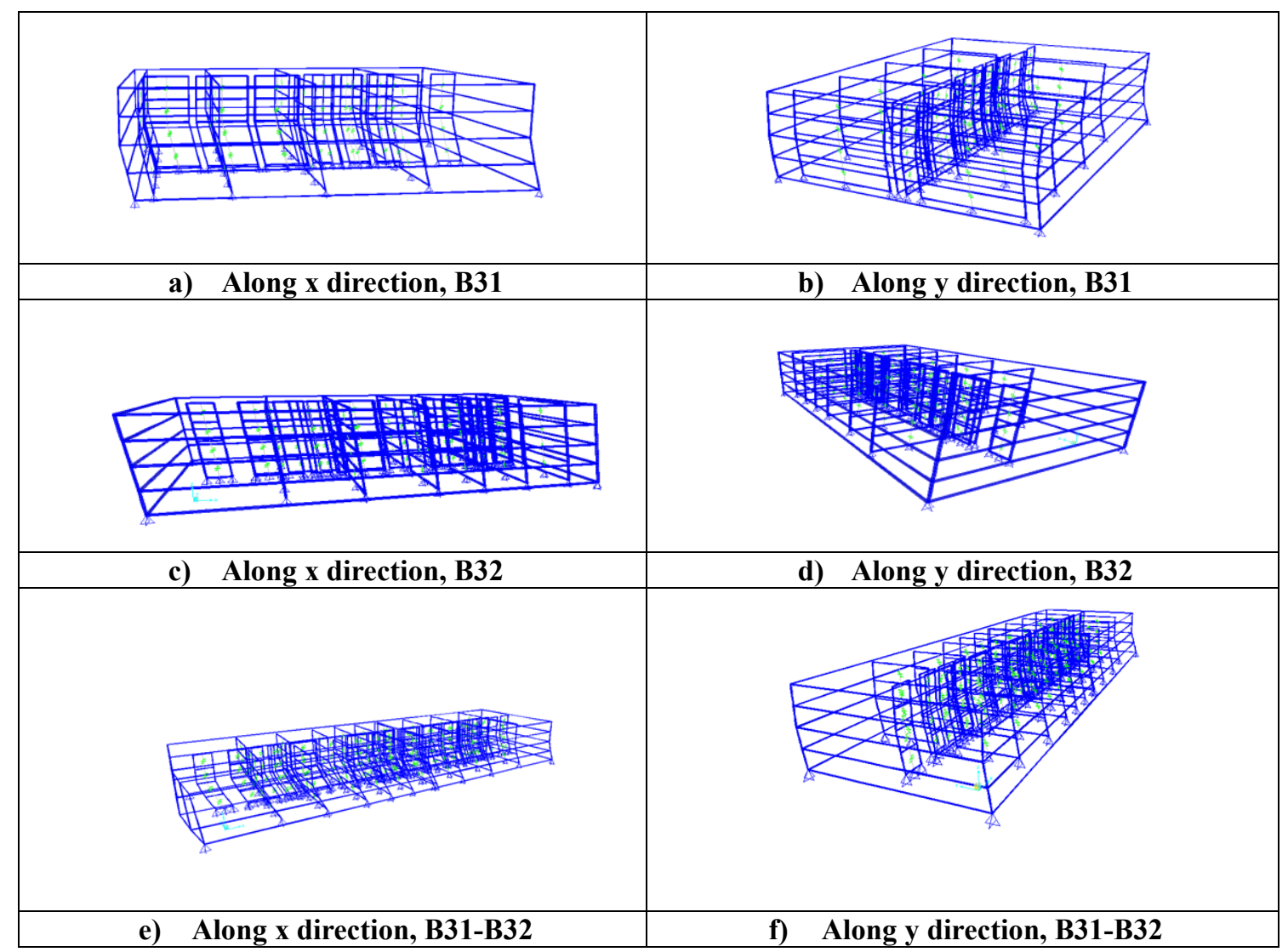

Figure D- 17 Mode shapes of the buildings measured in Test 2 


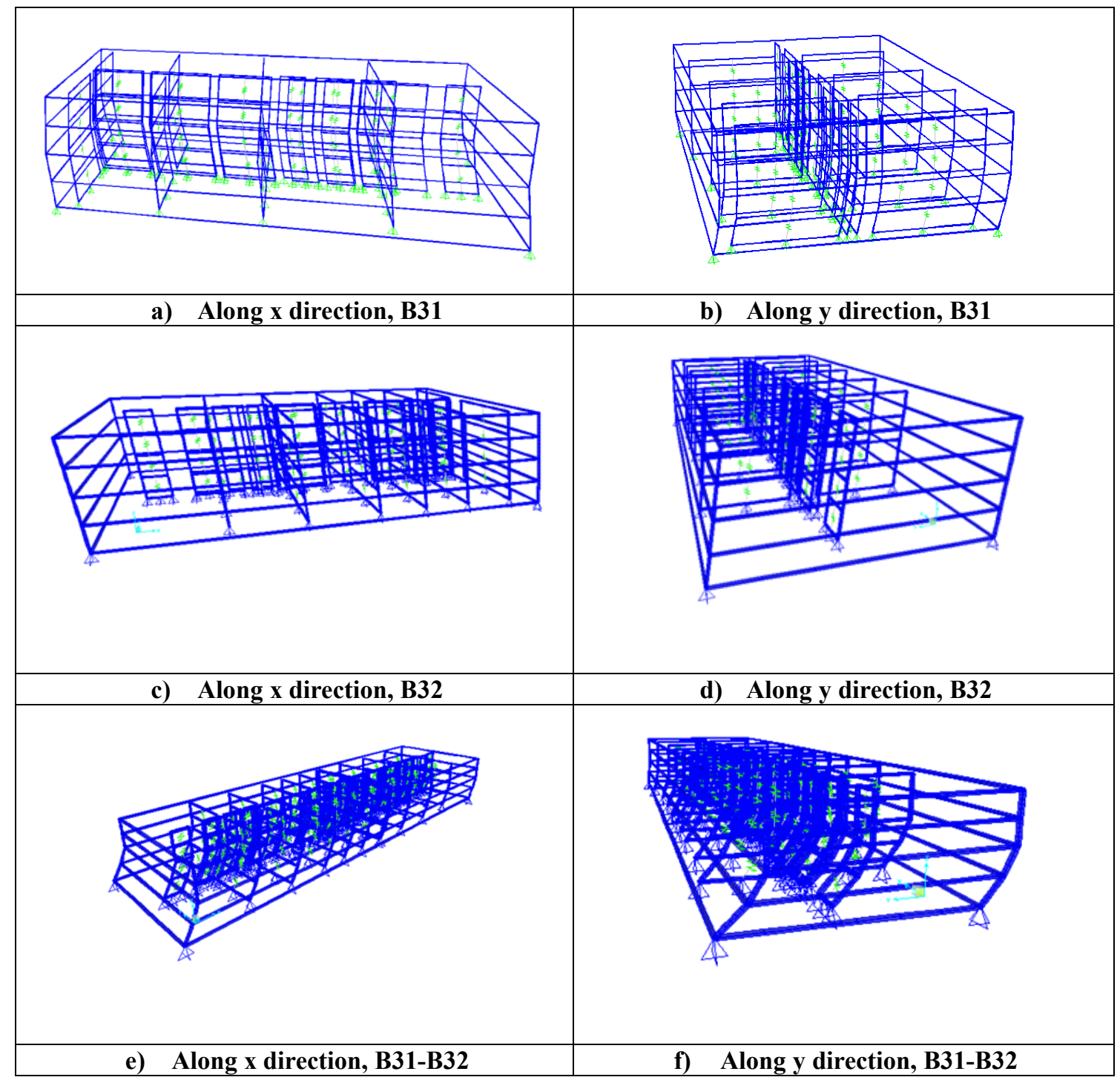

Figure D- 18 Mode shapes of the buildings measured in Test 3 


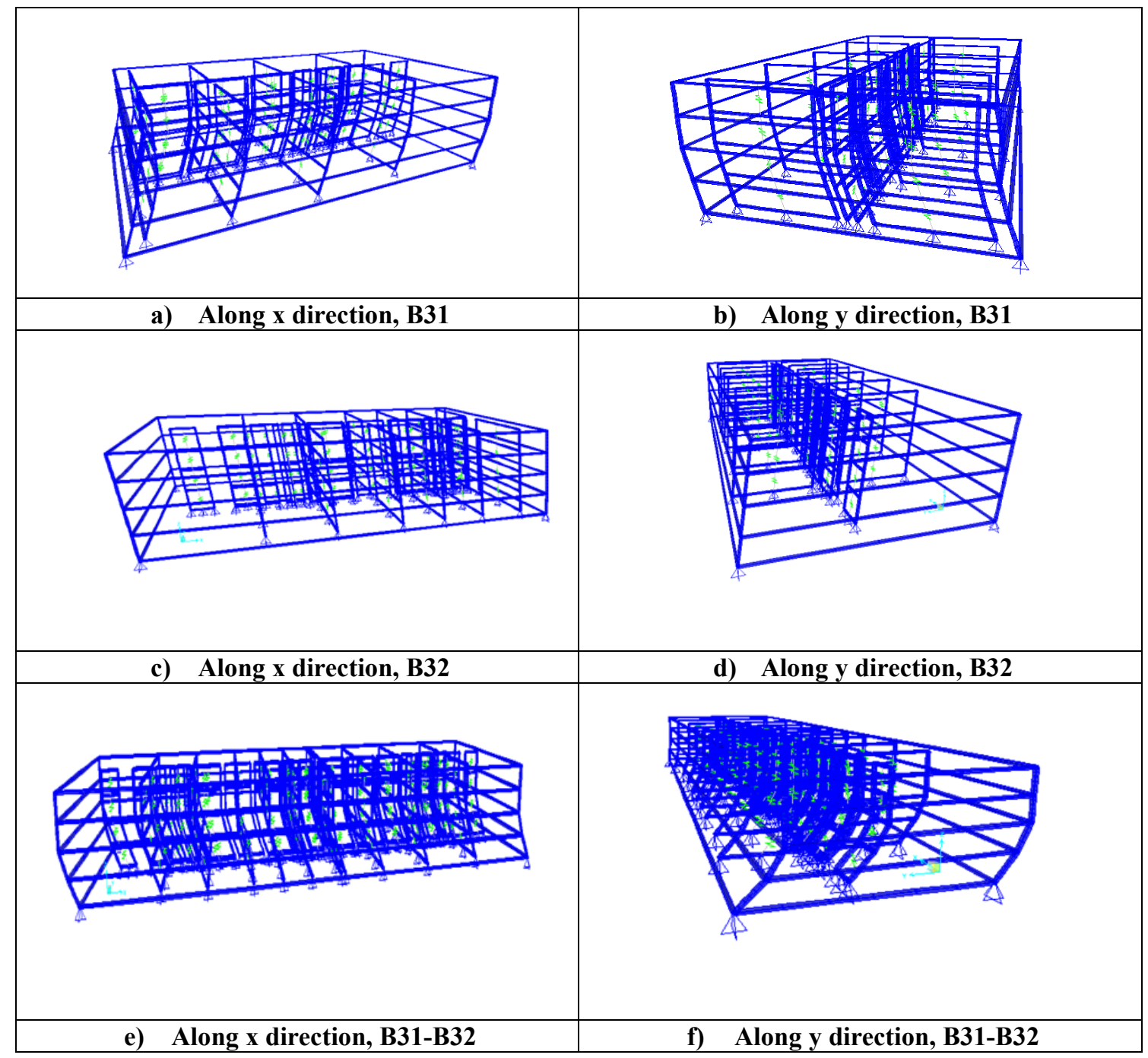

Figure D- 19 Mode shapes of the buildings measured in Test 4 




Figure D- 20 Mode shapes of the buildings measured in Test 5 


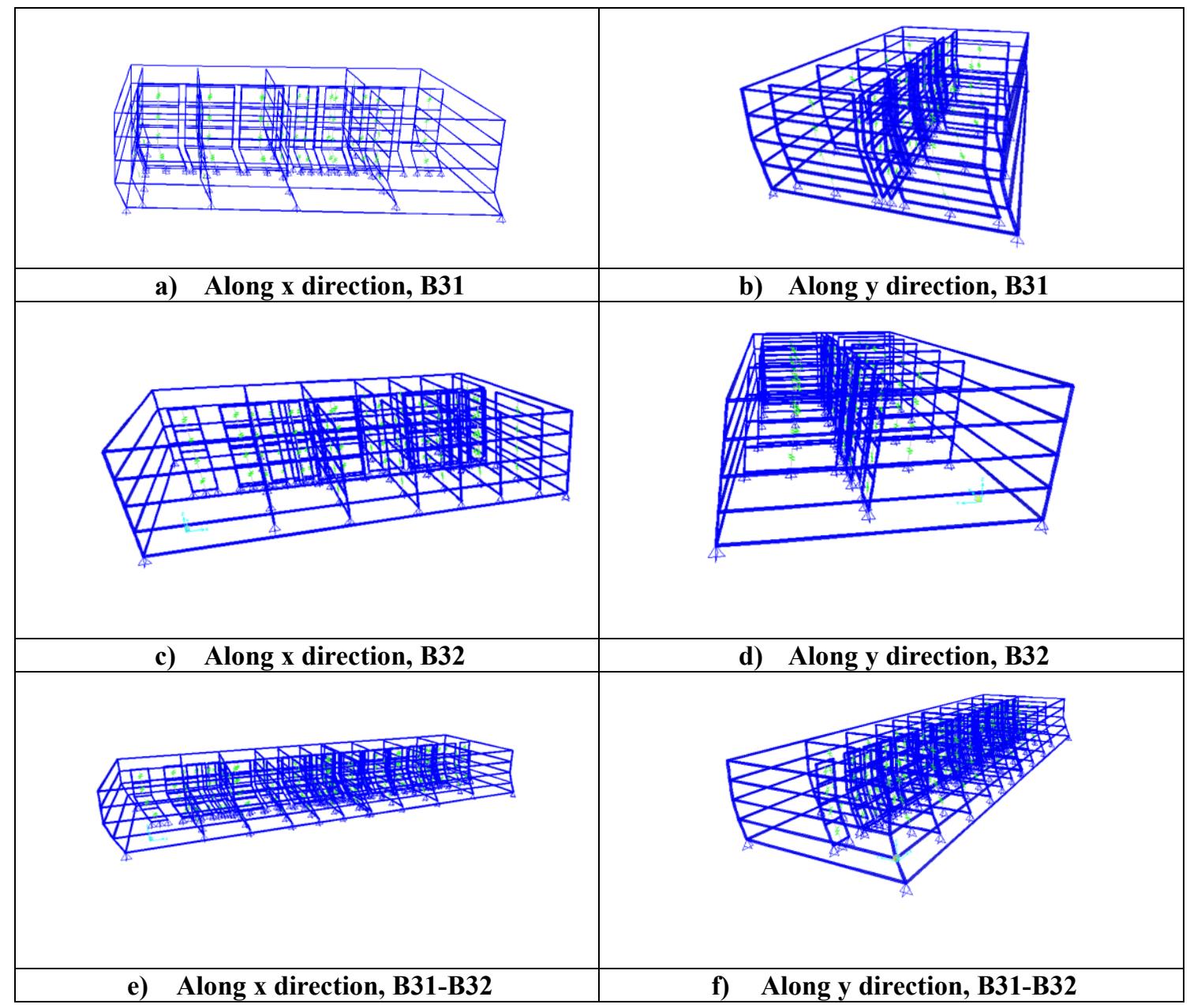

Figure D- 21 Mode shapes of the buildings measured in Test 6 


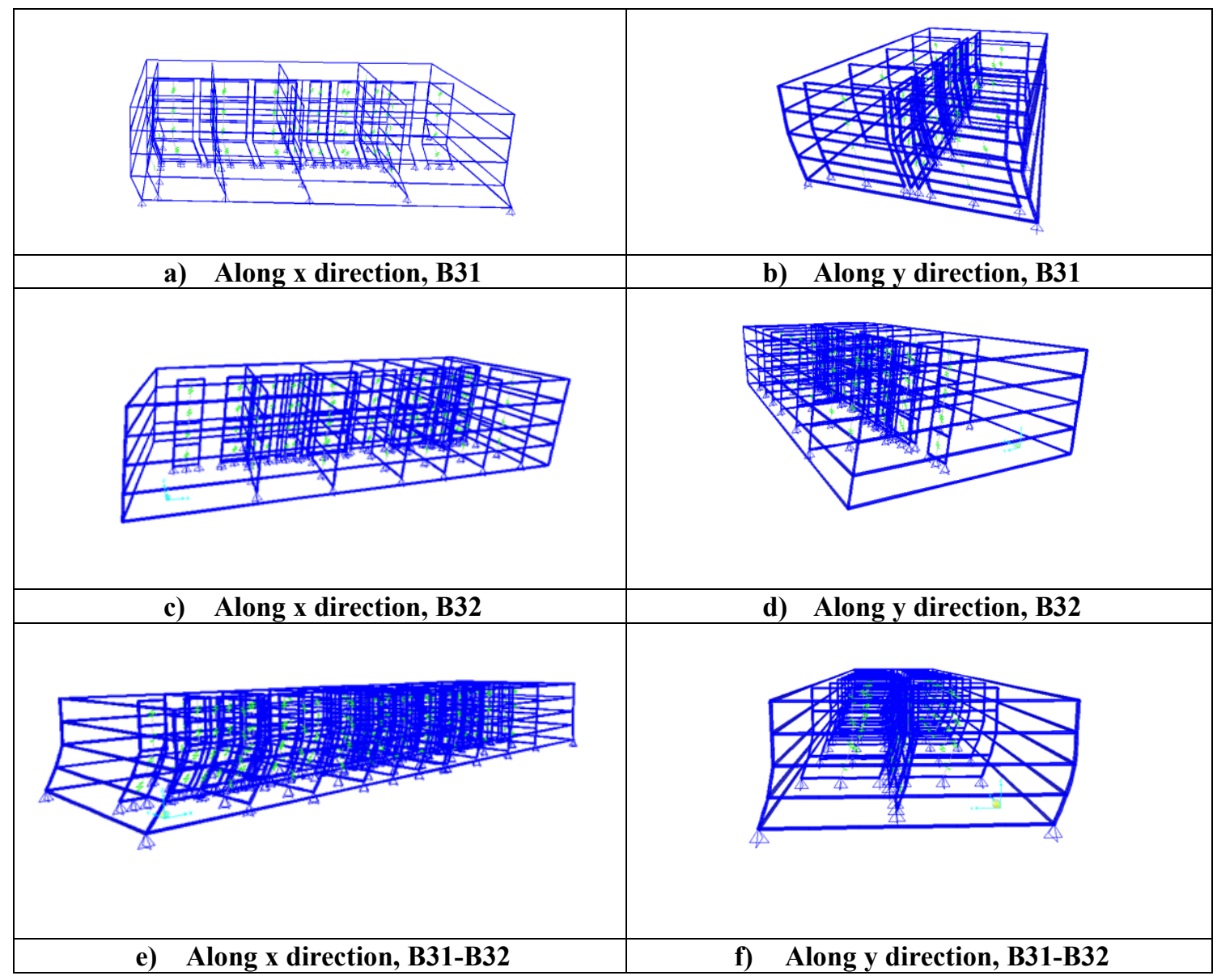

Figure D- 22 Mode shapes of the buildings measured in Test 7 


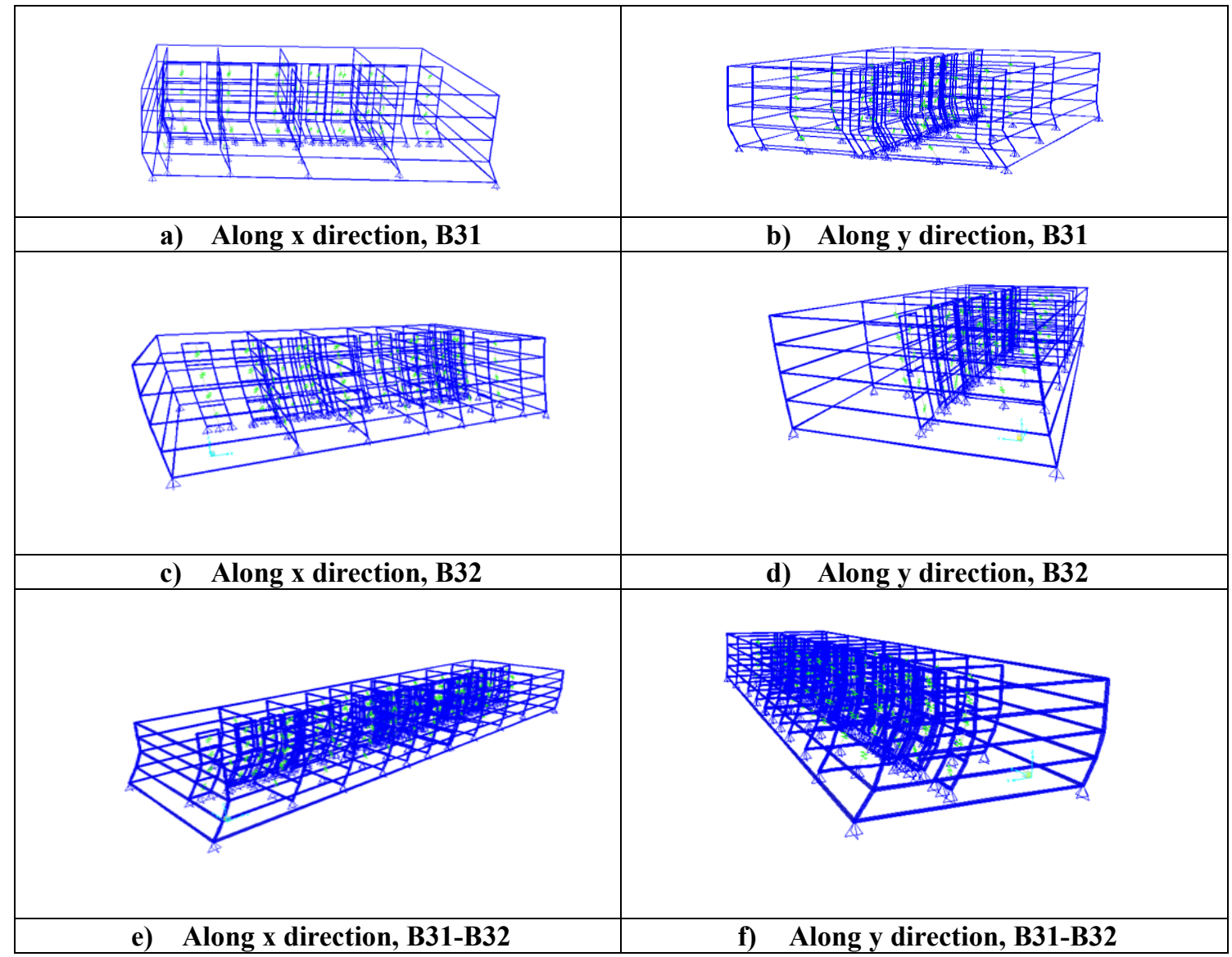

Figure D- 23 Mode shapes of the buildings measured in Test 7

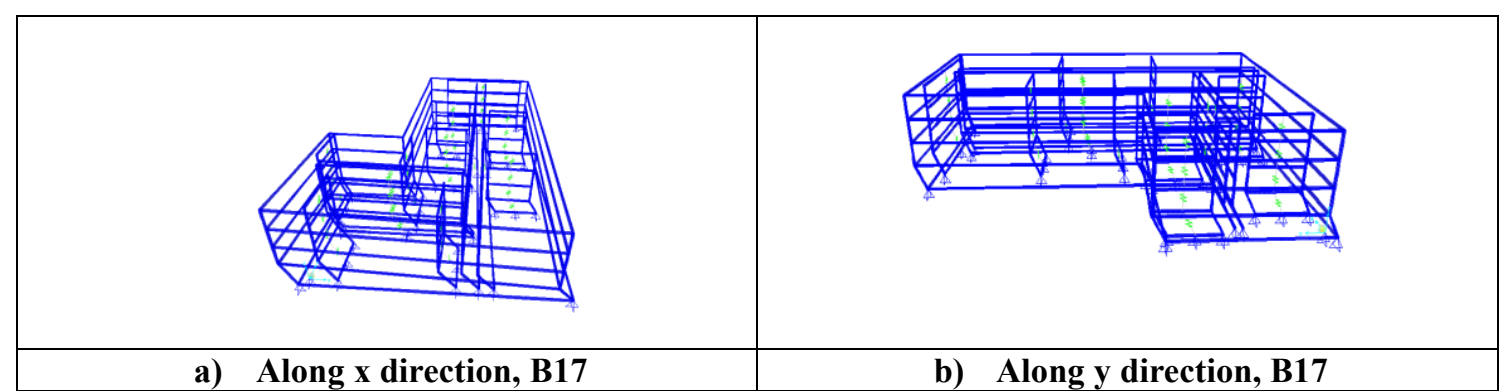

Figure D- 24 Mode shapes of the buildings measured in Test 1 


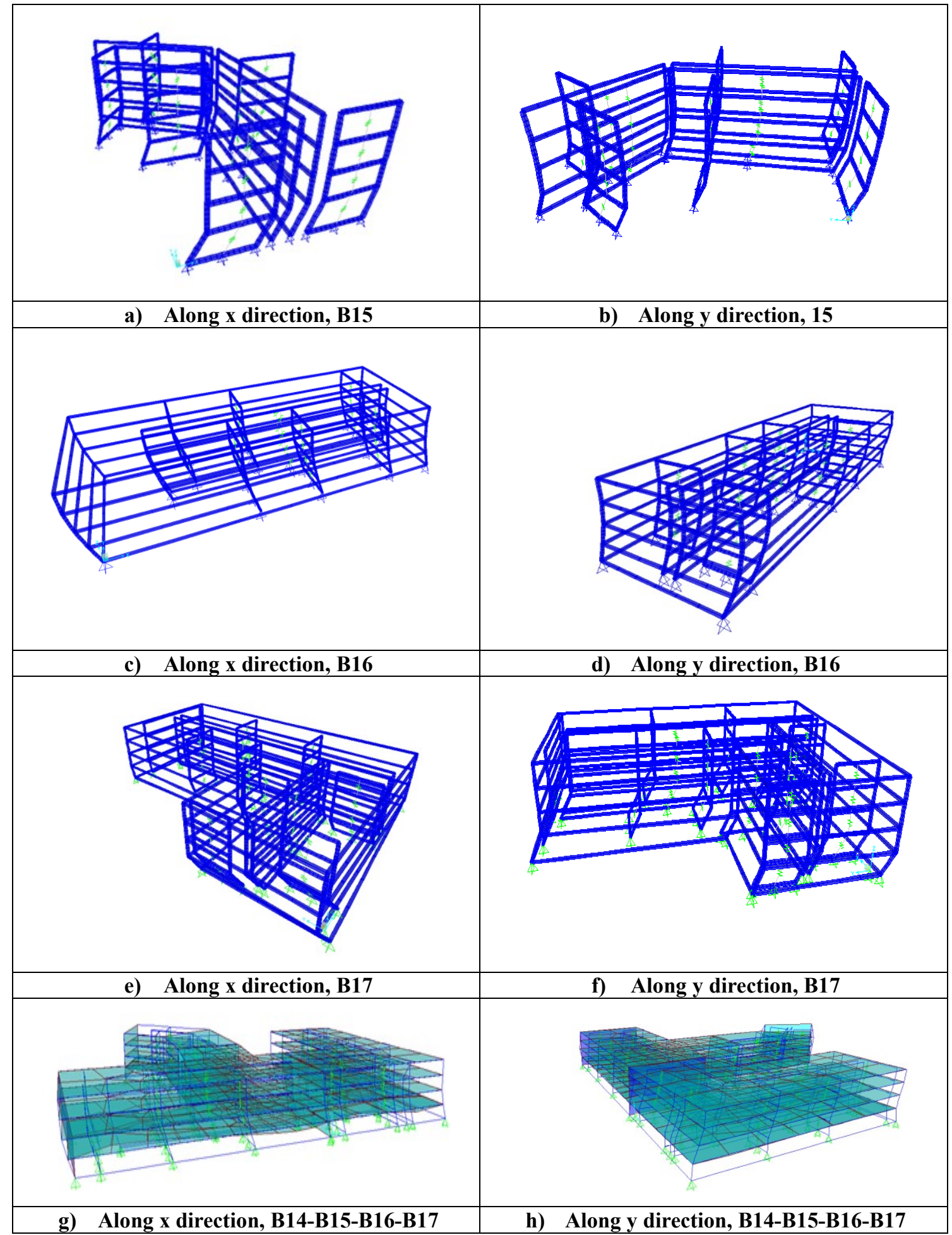

Figure D- 25 Mode shapes of the buildings measured in Test 2 


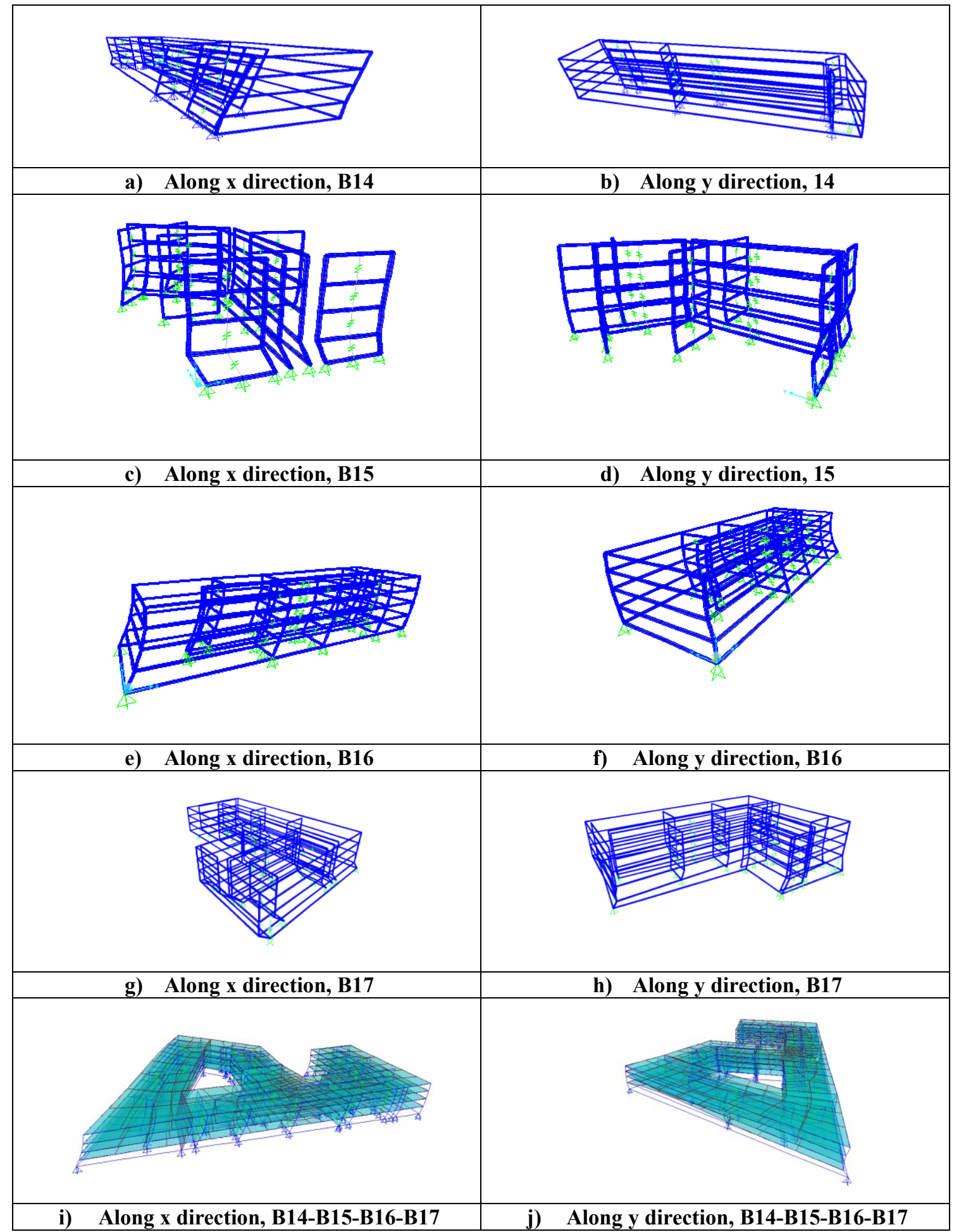

Figure D- 26 Mode shapes of the buildings measured in Test 3 


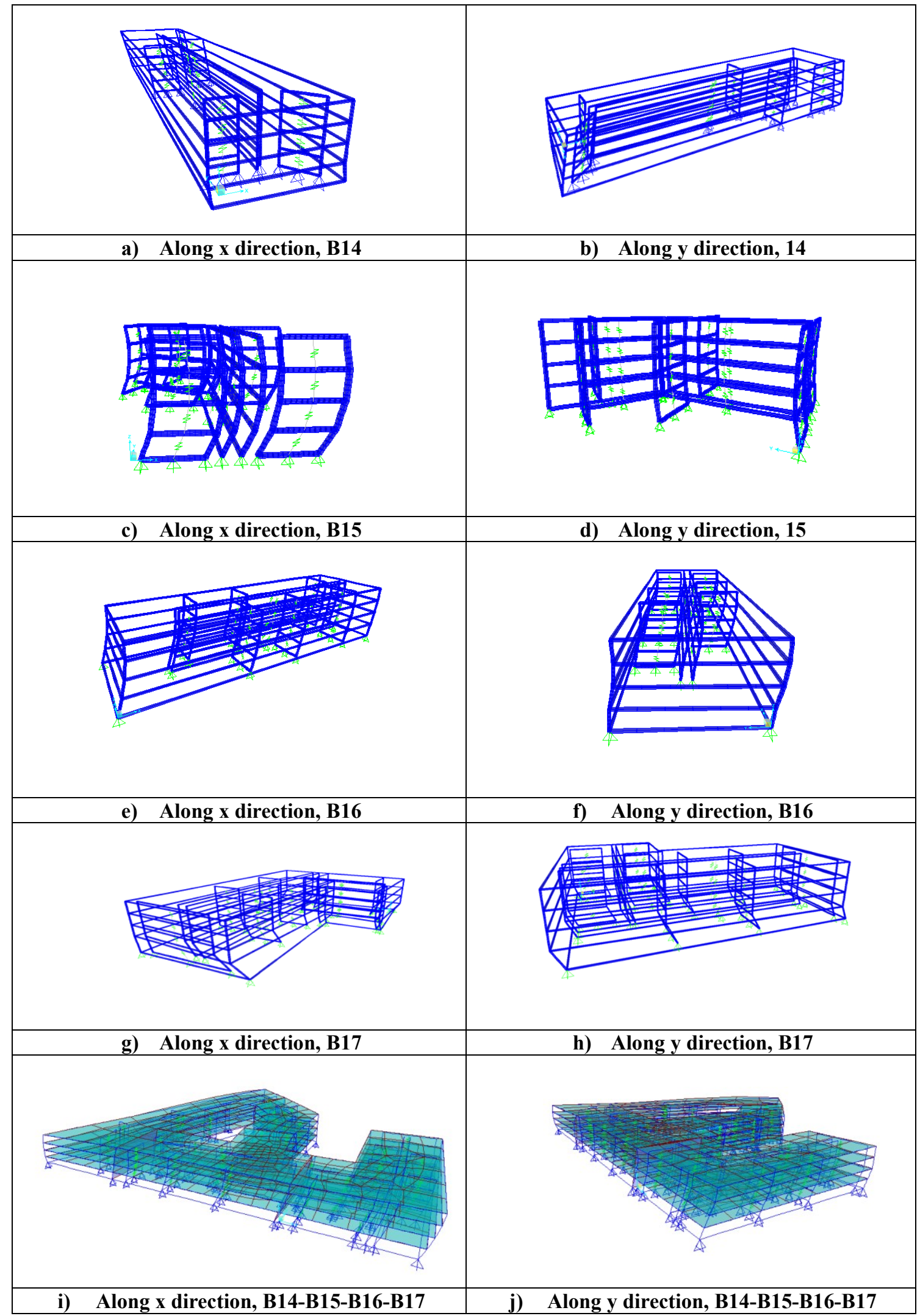

Figure D- 27 Mode shapes of the buildings measured in Test 4 


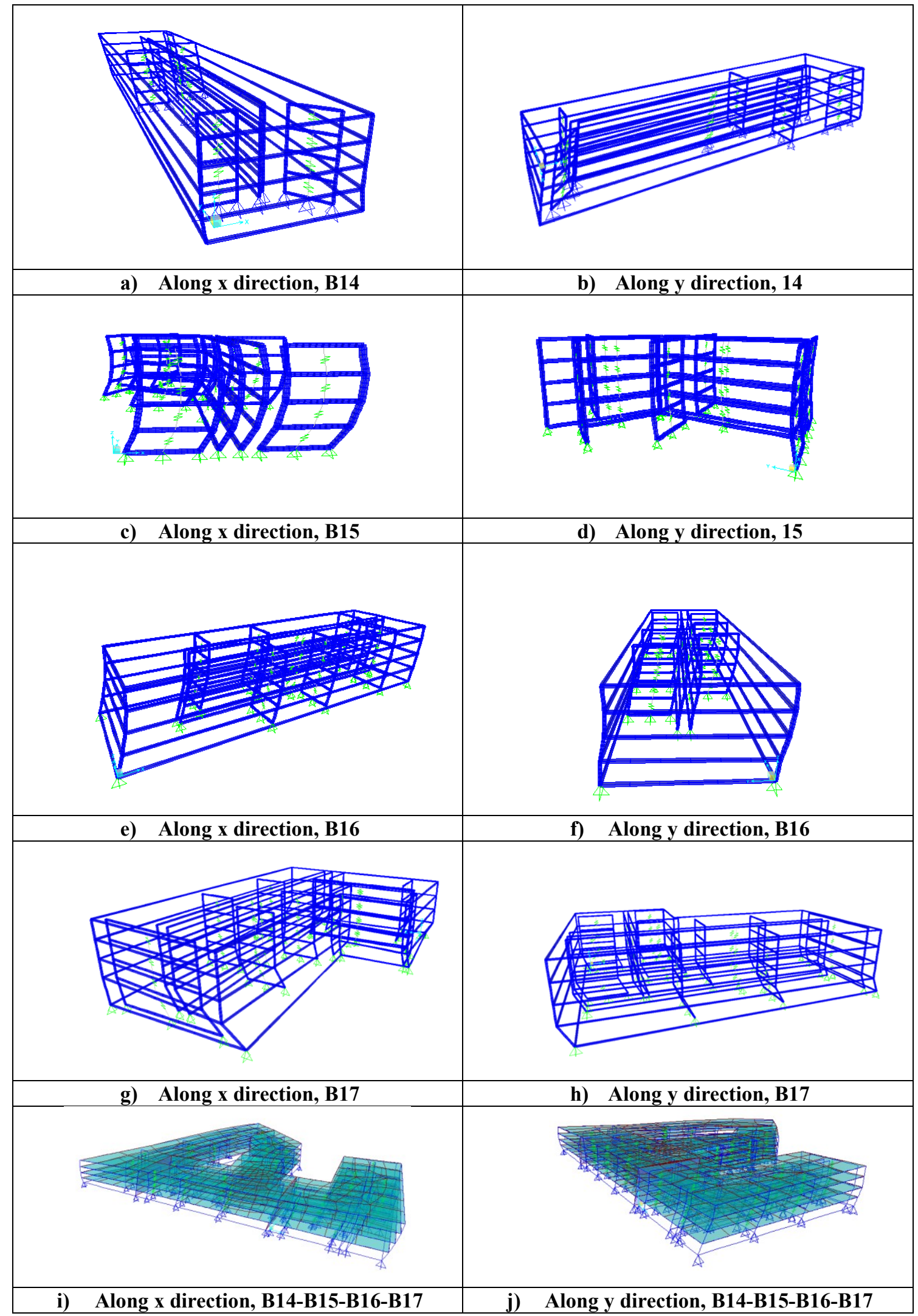

Figure D- 28 Mode shapes of the buildings measured in Test 5 


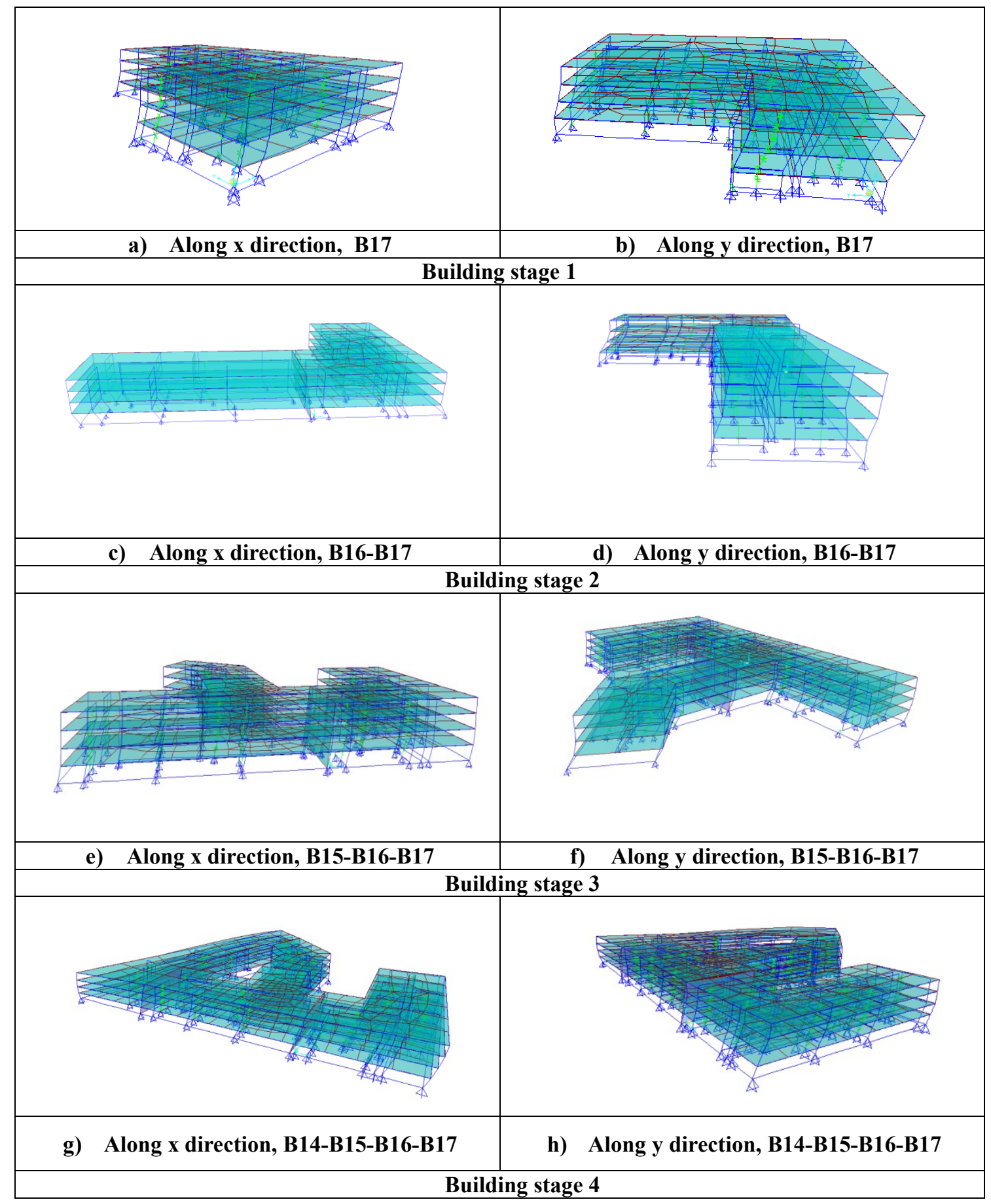

Figure D- 29 Mod shapes of different model stages 


\section{APPENDIX E}

Table E- 1 Natural periods of tested buildings vs. FE model results (Phase 1)

\begin{tabular}{|c|c|c|c|c|c|c|}
\hline \multirow{2}{*}{ Buildings } & \multicolumn{4}{|c|}{ T (sec) } & \multicolumn{2}{c|}{ Difference } \\
\cline { 2 - 7 } & \multicolumn{2}{|c|}{ Field Results } & \multicolumn{2}{c|}{ Model Results } & \multicolumn{2}{c|}{ (\%age) } \\
\cline { 2 - 7 } & Trans & Long & Trans & Long & Trans & Long \\
\hline B1 & 0.31 & - & 0.34 & 0.32 & 10 & - \\
\hline B5 & 0.37 & 0.25 & 0.42 & 0.37 & 14 & 48 \\
\hline B6 & 0.44 & 0.31 & 0.46 & 0.33 & 5 & 6 \\
\hline B7 & 0.34 & 0.37 & 0.37 & 0.38 & 9 & 3 \\
\hline B25 & 0.37 & 0.24 & 0.39 & 0.25 & 5 & 4 \\
\hline B31-B32 & 0.29 & 0.18 & 0.32 & 0.19 & 10 & 6 \\
\hline
\end{tabular}

Table E- 2 Natural periods of tested buildings vs. FE model results (Phase 2)

\begin{tabular}{|c|c|c|c|c|c|c|}
\hline \multirow{2}{*}{ Buildings } & \multicolumn{4}{|c|}{ T (sec) } & \multicolumn{2}{c|}{ Difference } \\
\cline { 2 - 7 } & \multicolumn{2}{|c|}{ Field Results } & \multicolumn{2}{c|}{ Model Results } & \multicolumn{2}{c|}{ (\%age) } \\
\cline { 2 - 7 } & Trans & Long & Trans & Long & Trans & Long \\
\hline B1 & 0.20 & 0.29 & 0.26 & 0.34 & 30 & 17 \\
\hline B5 & 0.28 & 0.35 & 0.30 & 0.40 & 7 & 14 \\
\hline B6 & 0.20 & 0.19 & 0.22 & 0.23 & 10 & 21 \\
\hline B7 & 0.25 & 0.23 & 0.32 & 0.28 & 28 & 22 \\
\hline B9 & 0.20 & 0.19 & 0.22 & 0.28 & 10 & 47 \\
\hline B22 & 0.18 & 0.14 & 0.19 & 0.17 & 6 & 21 \\
\hline B25 & 0.20 & 0.17 & 0.22 & 0.2 & 10 & 18 \\
\hline B18-B19 & 0.21 & 0.19 & 0.25 & 0.26 & 19 & 37 \\
\hline B20-B21 & 0.26 & 0.24 & 0.27 & 0.28 & 4 & 17 \\
\hline B26-B27 & 0.23 & 0.28 & 0.27 & 0.38 & 17 & 36 \\
\hline B31-B32 & 0.19 & 0.16 & 0.21 & 0.19 & 11 & 19 \\
\hline B14-B15- & 0.23 & 0.21 & 0.25 & 0.23 & 9 & 10 \\
B16-B17 & & & & & & \\
\hline
\end{tabular}


Table E- 3 Difference between measured and computed periods of buildings B31, B32 and B31B32

\begin{tabular}{|c|c|c|c|c|c|c|}
\hline \multirow{2}{*}{$\begin{array}{c}\text { Tests } \\
\#\end{array}$} & \multicolumn{6}{|c|}{ Difference b/w Measured and Computed Periods (\%) } \\
\cline { 2 - 7 } & \multicolumn{2}{|c|}{ B31 } & \multicolumn{2}{c|}{ B32 } & \multicolumn{2}{c|}{ B31-B32 } \\
\cline { 2 - 7 } & $\mathbf{X}$ & $\mathbf{Y}$ & $\mathbf{X}$ & $\mathbf{Y}$ & $\mathbf{X}$ & $\mathbf{Y}$ \\
\hline 1 & 12 & 10 & 11 & 9 & 12 & 7 \\
\hline 2 & 6 & 9 & 5 & 9 & 6 & 10 \\
\hline 3 & 12 & 11 & 43 & 22 & - & - \\
\hline 4 & 12 & 3 & 13 & 10 & - & 13 \\
\hline 5 & 13 & 13 & 21 & 14 & 0 & 0 \\
\hline 6 & 19 & 19 & 12 & 15 & 12 & 17 \\
\hline 7 & 19 & 20 & 25 & 19 & 19 & 16 \\
\hline
\end{tabular}

Table E- 4 Difference between measured and computed periods of buildings B14, B15, B16, B17 and B14-B15-B16-B17

\begin{tabular}{|c|c|c|c|c|c|c|c|c|c|c|}
\hline \multirow{3}{*}{$\begin{array}{c}\text { Test } \\
\#\end{array}$} & \multicolumn{10}{|c|}{ Difference b/w Measured and Computed Periods (\%) } \\
\hline & \multicolumn{2}{|c|}{ B14 } & \multicolumn{2}{|c|}{ B15 } & \multicolumn{2}{|c|}{ B16 } & \multicolumn{2}{|c|}{ B17 } & \multicolumn{2}{|c|}{$\begin{array}{l}\text { B14-B15- } \\
\text { B16-B17 }\end{array}$} \\
\hline & $\mathbf{X}$ & $\mathbf{Y}$ & $\mathbf{X}$ & $\mathbf{Y}$ & $\mathbf{X}$ & $\mathbf{Y}$ & $\mathbf{X}$ & $\mathbf{Y}$ & $\mathbf{X}$ & $\mathbf{Y}$ \\
\hline 1 & \multicolumn{2}{|c|}{ Not built } & \multicolumn{2}{|c|}{ Not built } & \multicolumn{2}{|c|}{ Not built } & 5 & 3 & 5 & 3 \\
\hline 2 & \multicolumn{2}{|c|}{ Not built } & 6 & 7 & 11 & 10 & 26 & 10 & 6 & 7 \\
\hline 3 & 14 & 26 & 16 & - & 11 & 6 & 21 & 4 & 7 & 8 \\
\hline 4 & 28 & 27 & - & 31 & 20 & 29 & 27 & 27 & 19 & 4 \\
\hline 5 & 24 & 22 & 25 & 31 & 11 & 24 & 22 & 27 & 9 & 10 \\
\hline
\end{tabular}

Table E- 5 Natural periods of tested buildings vs. $\left(\frac{h}{l} * A\right)$ parameter

\begin{tabular}{|c|c|c|c|c|}
\hline \multirow{2}{*}{ Building Id } & \multicolumn{2}{|c|}{$\frac{\boldsymbol{h}}{\boldsymbol{l}} * \boldsymbol{A}\left(\mathbf{m}^{\mathbf{2}}\right)$} & \multicolumn{2}{c|}{ Measured Periods (s) } \\
\cline { 2 - 5 } & Trans & Long & Trans & Long \\
\hline B5 & 434.4 & 868.8 & 0.28 & 0.35 \\
\hline B6 & 173.3 & 197.9 & 0.20 & 0.19 \\
\hline B9 & 170.0 & 184.5 & 0.20 & 0.19 \\
\hline B25 & 172.3 & 172.3 & 0.18 & 0.14 \\
\hline B22 & 127.0 & 61.7 & 0.20 & 0.17 \\
\hline B18-B19 & 296.2 & 237.9 & 0.21 & 0.19 \\
\hline B20-B21 & 479.9 & 468.2 & 0.26 & 0.24 \\
\hline B26-B27 & 203.3 & 398.5 & 0.23 & 0.28 \\
\hline B31-B32 & 145.0 & 218.0 & 0.19 & 0.16 \\
\hline
\end{tabular}




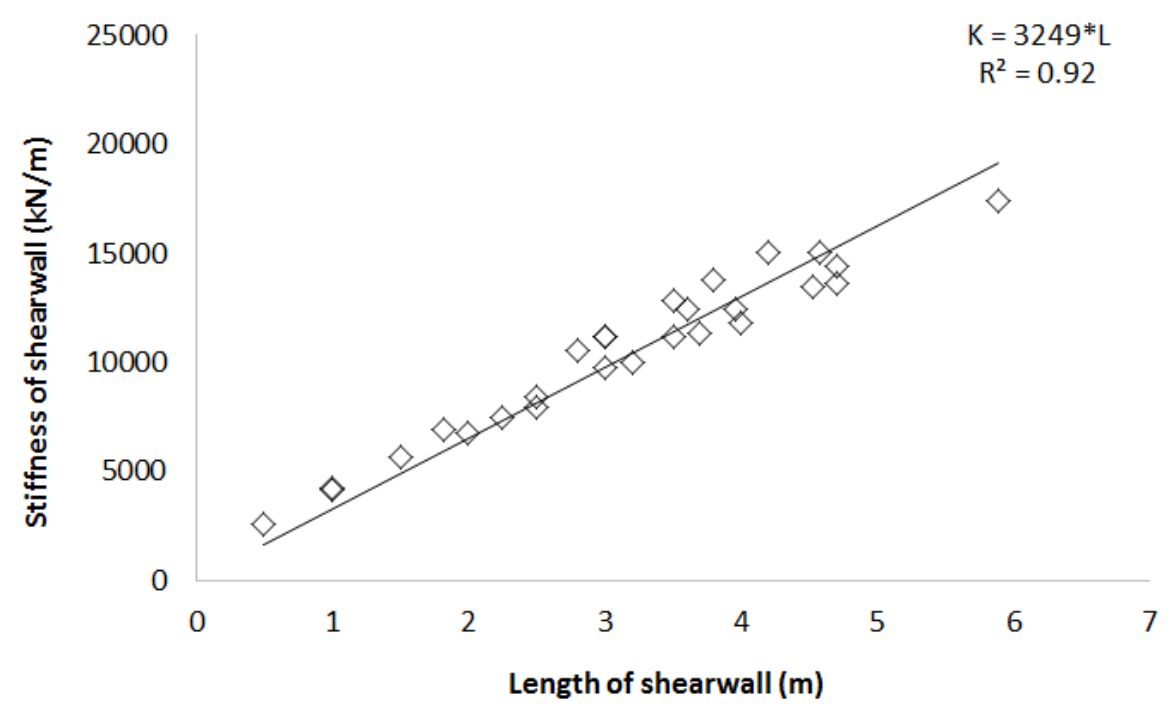

Figure E- 1 Stiffness of the measured buildings Vs. shear wall length 


\section{References}

ASTM D1761 (2012). "Standard test methods for mechanical fasteners in wood." American Society for Testing and Materials, West Conshohocken, PA, U.S.A.

ASTM. (2011). "Standard Test Methods for Cyclic (Reversed) Load Test for Shear Resistance of Vertical Elements of the Lateral Force Resisting Systems for Buildings". ASTM E2126-11, American Society for Testing and Materials, West Conshohocken, PA, U.S.A.

APEGBC (2009). "Structural, fire protection and building envelope professional engineering services for 5- and 6-storey wood frame residential building projects (mid-rise buildings)." APEGBC technical and practice bulletin, BC, Canada.

ASCE (2005). "Minimum design loads for buildings and other structures (ASCE/SEI 7-05)." Structural Engineering Institute, American Society of Civil Engineers, Reston, VA, U.S.A.

Applied Technology Council (ATC) (1978). "Tentative provisions for the development of seismic regulations for buildings". Report No. ATC 3-06, Applied Technology Council, Palo Alto, California, U.S.A.

Bendat, J., S., and Piersol, A., G. (2000). Random data: Analysis and measurement procedures, 3rd ed., John Wiley \& Sons, Inc., New York.

Brincker, R., Zhang, L., and Anderson, P. (2001b). "Modal identification of output only systems using frequency domain decomposition." Smart Materials and Structures 10, 441-445.

Beck, J., L., May, B., S., and Polidori, D., C. (1994a). "Determination of modal parameters from ambient vibration data for structural health monitoring". In Proceedings of First World Conference on Structural Control, International Association for Structural Control, Los Angeles, California, U.S.A.

Beck, J., L., Vanik, M., W., and Katafygiotis, L., S. (1994b). "Determination of stiffness changes from modal parameter changes for structural health monitoring". In Proceedings of First World Conference on Structural Control, International Association for Structural Control, Los Angeles, California, U.S.A.

BSSC. (2003). "NEHRP recommended provisions for seismic regulations for new buildings and other structures (FEMA 450)." Building Seismic Safety Council, National Institute of Building Standards, Washington, D.C. 
Computers and Structures, I.C., SAP 2000-advanced 16.0.0, 2014.

Casagrande, D., Rossi, S., Sartori, T., \& Tomasi, R. (2015). "Proposal of an analytical procedure and a simplified numerical model for elastic response of single-storey timber shear-walls". Construction and Building Materials, 102, 1102-1112.

CHMC, (2014). "Canadian wood frame house construction", $3^{\text {rd }} \mathrm{ed}$, Canada Mortgage and Housing Corporation, Canada.

Canadian Standards Association (CSA), (2014). "CAN/CSA O86-14 Engineering design in wood", Ontario, Canada.

Chopra, A., K. (2001). Dynamics of Structures: Theory and Applications to Earthquake Engineering. 2nd ed., Prentice Hall, Upper Saddle River, New Jersey, U.S.A.

Christovasilis, I., P., Filiatrault, A., and Wanitkorkul, A. (2008). "Seismic testing of full scale wood structures on two shake tables". World Conference on Earthquake Engineering, Beijing, China.

Collins, M., Kasal, B., Paevere, P., and Foliente, G., C. (2005). "Three-dimensional model of light frame wood buildings. I: Model description”. Journal of Structural Engineering, 131(4), 676-683.

Clough, R., W., and Penzien, J. (2003). Dynamics of structures, 2nd ed. (revised), Computers and Structures, Inc., Berkeley, California, U.S.A.

Collins, M., Kasal, B., Paevere, P., and Foliente, G., C. (2005). "Three-dimensional model of light frame wood buildings. II: Experimental investigation and validation of analytical model". Journal of Structural Engineering, 131(4), 684-692.

Camelo, V., S. (2003). "Dynamic characteristics of wood frame buildings". Doctoral dissertation, California Institute of Technology, Pasadena, California, U.S.A.

Carydis, P., G., and Mouzakis, C., P., (1982). "Ambient vibration measurements of undamaged and seismically damaged buildings". In Proceeding of. $7^{\text {th }}$ European Conference on Earthquake Engineering, Athens, Greece.

Carydis, P., and Mouzakis, H., P., (1986). "Small amplitude vibration measurements of buildings undamaged, damaged, and repaired after earthquakes". Earthquake Spectra, 2(3), 515-535.

CSMIP (1989). "Strong motion records from the Northridge, California earthquake of 1994", California Department of Conservative Division of Mines and Geology Office of Strong Motion Studies, Report No. OSMS 89-06, California, U.S.A. 
Crawford, R., and Ward, H., S. (1964). "Determination of the natural periods of buildings." Bulletin of the Seismological Society of America, 54(6), 1743- 1756.

Carder, D., S. (1936). "Vibration observations, Chapter 5 in Earthquake investigations in California 1934-1935." U.S. Dept. of Commerce, Coast and Geologic Survey, Special Publication No. 201, Washington, D.C, U.S.A.

Doudak, G., McClure, G., Smith, I., Hu, L., \& Stathopoulos, T. (2005). "Monitoring structural response of a wooden light-frame industrial shed building to environmental loads". Journal of structural engineering, 131(5), 794-805.

Eurocode 1 (2010). Actions on Structures - Part 1-4: General Actions - Wind Actions. BS EN 1991-1-4:2005+A1:2010. BSI, April 2010.

Ewin, D., J. (2000). Modal; testing: Theory, practice and application, $2^{\text {nd }}$ ed., Research Studies Press, Baldock, England.

Ellis, B., R., and Bougard, A., J. (2001). "Dynamic testing and stiffness evaluation of a six-storey timber framed building during construction”. Engineering Structures, 23(10), 1232-1242.

Enjily, V., Palmer, S. (1998) “TF2000-Background and progress of fullscale testing”. In 3rd Cardington Conference,, UK

Feldmann, A, S. (2015). "Dynamic properties of tall timber structures under wind induced vibration”. Master thesis, Technische Universität München, Germany.

Filiatrault, A., Christovasilis, I., P., Wanitkorkul, A., and van de Lindt, J., W. (2009). Experimental seismic response of a full-scale light-frame wood building. Journal of structural engineering, 136(3), 246-254

Farsi, M., N., and Bard, P., Y. (2004). “ Estimation des périodes propres de bâtiments et vulnérabilité du bâti existant dans l'agglomération de grenoble ". Revue Française de Génie Civil, 8(2-3), 149-179.

Folz, B., and Filiatrault, A. (2004). "Simplified seismic analysis of woodframe structures". World Conference on Earthquake Engineering, Vancouver, Canada.

Filiatrault, A., Fischer, D., Folz, B., and Uang, C., M. (2002). "Seismic testing of twostory woodframe house: Influence of wall finish materials". Journal of Structural Engineering, 128(10), 1337-1345.

Fischer, D. (2001). "Shake table tests of a two-Story woodframe house". CUREE Caltech Woodframe Project Task 1.1.1, Report, Richmond, CA. 
Gilles, D. (2011). "In situ dynamic characteristics of reinforced concrete shear wall buildings". Ph.D. dissertation, Department of Civil Engineering and Applied Mechanics, McGill University, Montréal, Quebec.

Gates, J., H. (1993). "Dynamic field response studies and earthauqke instrumentation of the meloland road overcrossing”. In Structural Engineering in Natural Hazards Mitigation, ASCE, 343-348.

Goel, R., K., and Chopra, A., K. (1998). "Period formulas for concrete shear wall buildings". Journal of Structural Engineering, 124(4), 426-433

Gupta, A., K., and Kuo, G., P. (1987). "Modeling of a Wood-framed House." Journal of Structural Engineering, 113(2), 260-278.

Gupta, A., K., and Kuo, G., P. (1985). "Behavior of wood-framed shear walls". Journal of Structural Engineering, 111(8), 1722-1733.

He, M., Lam, F., and Foschi, R., O. (2001). "Modeling three-dimensional timber light-frame buildings". Journal of Structural Engineering, 127(8), 901-913.

Hart, G., C., Lew, M., and Stillman, G. (1972). "Ambient, aftershock and mainshock response of two high-rise buildings". Proceedings of International Conference on Microzonation for Safer Construction Research and Application, Seattle, U.S.A.

Hart, G., C., DiJulio, M., and Lew, M., (1975). "Torsional response of high-rise buildings". Journal of the Structural Division, ASCE, 101, 397-416.

Hudson D., E. (1970). Dynamic tests of full-scale structures, in earthquake engineering, (ed. by R.W. Wiegel) Englewood Cliffs, Prentice Hall, New Jersey, U.S.A.

Ivanovic, S., S., Trifunac, M., D. and Todorovska, M., D. (2001). "On identification of damage in structures via wave travel times". In Strong Motion Instrumentation for Civil Engineering Structures, Springer, Netherlands, 447-467.

Källsner, B., and Girhammar, U., A. (2009). "Analysis of fully anchored light-frame timber shear walls-elastic model". Materials and Structures, 42(3), 301-320.

Kharrazi, M., H., K. (2001). "Vibration characteristics of single-family woodframe building”, Master Thesis, University of British Columbia, Vancouver, Canada.

Kharrazi, M. H., \& Ventura, C. E. (2006). "Vibration frequencies of woodframe residential construction". Earthquake spectra, 22(4), 1015-1034. 
Kircher, C., A., Reitherman, R., K., Whitman, R., V., and Arnold, C. (1997). "Estimation of earthquake losses to buildings". Earthquake spectra, 13(4), 703-720.

Kasal, B., Leichti, R., J., and Itani, R., Y. (1994). "Nonlinear finite-element model of complete light-frame wood structures". Journal of Structural Engineering, 120(1), 100-119.

Kamiya, F. (1988). "Nonlinear earthquake response analysis of sheathed wood walls by a computer-actuator on-line system." The 1988 International Conference on Timber Engineering, Forest Product Society, Seattle, Washington, U.S.A

Lafontaine, A., (2015). "Investigating the capacity and stiffness of joints used in gypsum wallboard sheathed light-frame wood shearwalls". Master thesis, University of Ottawa, Ottawa, Canada.

Lee, L., H., Chang, K., K., and Chun, Y., S. (2000). "Experimental formula for the fundamental period of RC buildings with shear-wall dominant systems". The Structural Design of Tall Buildings, 9(4), 295-307.

Mosalam, K., Hashemi, A., Elkhoraibi, T., and Takhirov, S. (2008) "Seismic evaluation of wood house over garage", $14^{\text {th }}$ World Conference on Earthquake Engineering, Beijing China.

Morales, D., M. (2000). "Fundamental period of vibration for reinforced concrete buildings". Master thesis, University of Ottawa, Ottawa, Canada.

Marshall, R., D., Phan, L., T., and Celebi, M. (1994). "Full scale measurement of building response to ambient vibration and the Loma Prieta earthquake". In Proceedings of 5th US National Conference on Earthquake Engineering, Chicago, Illinois, U.S.A.

Mendoza, L., Reyes, A., and Luco, J., E. (1991). “Ambient vibration tests of mexicali general hospital”. Earthquake Spectra, 7(2), 281-300.

Mulhern M., R., Maley R., P. (1973). "Building period measurements before, during and after the San Fernando, California, earthquake of February 9, 1971", vol. I. Washington DC: US Dept. of Commerce, National Oceanic and Atmospheric Administration, (Part B, 725-33).

NRC/IRC. (2015). "National Building Code of Canada 2015", National Research Council of Canada, Institute for Research in Construction, Ottawa, Ontario.

Ontario's 2012 Building Code Mid-Rise Combustible Building Amendments; Ontario Regulation 332/12 Amended by O. Reg. 191/14, effective 01/01/2015 
Oliveira, C., S., Carvalho, E., C., and Pereira, J., J. (1982). "Dynamic characterization of existing buildings based on experimental measurements". In Proceeding of 7th European Conference on Earthquake Engineering, Athens, Greece.

Pei, S., van de Lindt, J. (2009). "Shake table test results for the NEES Wood Capstone building”. Wood Design Focus, 19(4): 19-24.

Reynolds, T., Bolmsvik, A., Vessby, J., Chang, W., S., Harris, R., Bawcombe, J., \& Bregulla, J. (2014). "Ambient vibration testing and modal analysis of multi storey cross-laminated timber buildings". In World Conference on Timber Engineering, University of Bath.

Rainer, J., H., \& Karacabeyli, E. (2000). "Performance of woodframe construction in earthquakes". In Proceedings of the 12th World Conference on Earthquake Engineering, Auckland, New Zealand, 30, 1-8.

Steiger, R., Feltrin, G., Weber, F., Nerbano, S., \& Motavalli, M. (2015). Experimental modal analysis of a multi-storey light-frame timber building". Bulletin of Earthquake Engineering, 1-27.

Structural Vibration Solutions A/S. 2011, ARTeMIS Extractor Handy (Version 5.3) [Software], Available from http://www.svibs.com

S.P.A., M., Manuale tromino ENG TR-ENGY PLUS October 2008, M. S.P.A., Editor 2008.

Schott, J., R. (2005). Matrix analysis for Statistics, Willey \&Sons, Hoboken, New Jersey, U.S.A.

Saatcioglu, M., and Humar, J. (2003). "Dynamic analysis of buildings for earthquakeresistant design”. Canadian Journal of Civil Engineering, 30(2), 338-359.

Salenikovich, A., J. (2000). "The racking performance of light-frame shear walls". Ph.D Dissertation, Department of Wood Science and Forest Products, Virginia Polytechnic Institute and State University, Blacksburg, VA, USA.

Schuster, N., D., Ventura, C., E., Felber, A., and Pao, J. (1994). "Dynamic characteristics of a 32-story high-rise building during construction". In 5th US National Conference on Earthquake Engineering, Chicago, Illinois, US.A.

Skrinar, M., and Strukelj, A. (1996). "Eigenfrequency monitoring during bridge erection”. Structural Engineering International, 6(3), 191-194. 
SEAOC. (1999). "Recommended lateral force requirements and commentary (SEAOC Blue Book)." Seismology Committee, Structural Engineers Association of California, Sacramento, CA

Soltis, L., A. (1984). "Low-rise timber buildings subjected to seismic, wind, and snow loads". Journal of Structural Engineering, 110(4), 744-753.

Trifunac, M., D. (1970a). "Wind and microtremor induced vibrations of a twenty-two story steel frame building”. Earthquake Engineering Research Laboratory, Report No. EERL 70-011, California Institute of Tech. Pasadena, California, U.S.A.

Trifunac M., D. (1970b). "Ambient vibration test of a 39 story steel frame building". Earthquake Engineering Research Laboratory, Report No. EERL 70-02, Calif. Institute of Tech. Pasadena, California, U.S.A.

Trifunac, M. D. (1972). "Comparisons between ambient and forced vibration experiments." Earthquake Engineering and Structural Dynamics, 1, 133-150.

Tuomi, R., L., and McCutcheon, W., J. (1974). "Testing of a full-scale house under simulated snowloads and windloads". Forest Products Laboratory, Madison, Wise, Report No. FSRP-FPL-234.

Tarabia, A., M., and Itani, R., Y. (1997). "Seismic response of light-frame wood buildings". Journal of Structural Engineering, 123(11), 1470-1477.

Uang, C., M., and Gatto, K. (2003). "Effects of finish materials and dynamic loading on the cyclic response of woodframe shear walls". Journal of Structural Engineering, 129(10), 1394-1402.

Udwadia, F., E., and Trifunac, M., D. (1973). "Ambient vibration tests of full scale structures". In Proceeding of the 5th World Conference on Earthquake Engineering, Rome, Italy.

Udwadia, F., E., and Trifunac, M., D. (1974). "Time and amplitude dependent response of structures". Earthquake Engineering and Structural Dynamics, 2(4), 359378.

Van de Lindt, J., W., Pei, S., Pryor, S., E., Shimizu, H., and Isoda, H. (2010). "Experimental seismic response of a full-scale six-story light-frame wood building". Journal of Structural Engineering, 136(10), 1262-1272.

Ventura, C., E., and Schuster, N., D. (1996). "Structural dynamic properties of a reinforced concrete high-rise building during construction". Canadian Journal of Civil Engineering, 23(4), 950-972. 
Wirsching, P., H., Paez, T., L., and Ortiz, K. (2006). "Random vibrations: theory and practice". Dover Publications, INC, Mineola, New York, U.S.A.

Ward, H., S., and Crawford, R. (1966). "Wind-induced vibrations and building modes". Bulletin of the Seismological Society of America, 56(4), 793-813. 